\title{
THE DEVELOPMENT OF A DESIGN-FOR- ASSEMBLY METHOD FOR CONSTRUCTION AND INFRASTRUCTURE PROJECTS
}

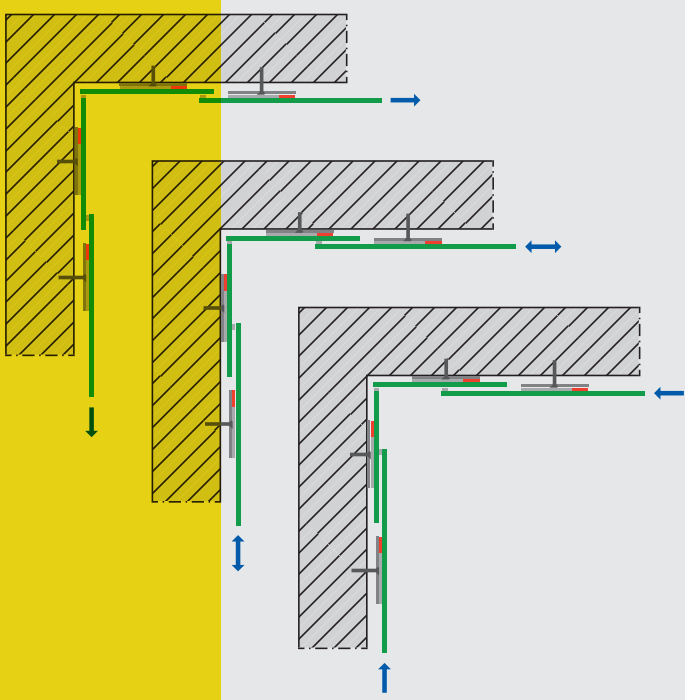




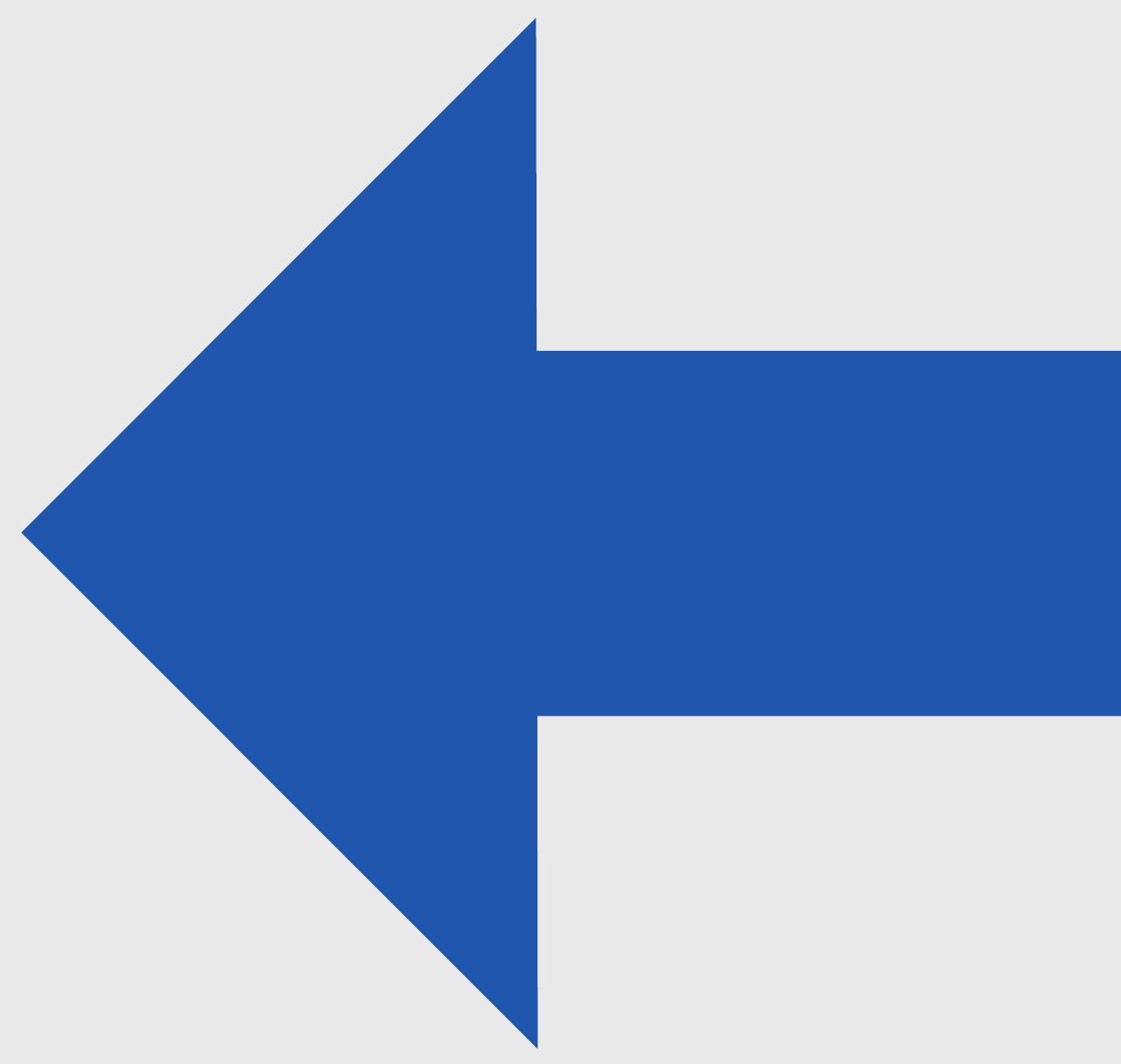




\section{THE DEVELOPMENT \\ OF A DESIGN-FOR- \\ ASSEMBLY METHOD \\ FOR CONSTRUCTION \\ AND INFRASTRUCTURE PROJECTS}

Wim Verburg 



\title{
THE DEVELOPMENT OF A DESIGN-FOR-ASSEMBLY METHOD FOR CONSTRUCTION AND INFRASTRUCTURE PROJECTS
}

\section{DISSERTATION}

\author{
to obtain \\ the degree of doctor at the University of Twente, \\ on the authority of the rector magnificus, \\ prof. dr.ir A. Veldkamp, \\ on account of the decision of the Doctorate Board, \\ to be publicly defended \\ Wednesday $30^{\text {th }}$ of June 2021 at 14.45 hours
}

by

Willem Hendrik Verburg

born on the 1st of May 1957

in Benschop, the Netherlands 
This dissertation has been approved by:

Prof.dr.ir. J.I.M. Halman

Dr. J.T. Voordijk

Cover design: Grafisch lokaal, Martin Leclercq \& Rob de Bree

Printed by: Ipskamp Printing

Design \& layout: Grafisch lokaal, Martin Leclercq \& Rob de Bree

ISBN: 978-90-365-5171-7

DOI: $10.3990 / 1.9789036551717$

(c) 2021 Wim Verburg, The Netherlands. If one refers to the author, title and year of publication, every part of this thesis may be used for non-commercial purposes, free of charge and free of copyrights without the written permission from the author. For commercial purposes written permission from the author is required. 


\title{
GRADUATION COMMITTEE
}

\author{
Chairman/Secretary Prof.dr.ir. H.F.J.M. Koopman \\ University of Twente, Engineering Technology \\ Promotor \\ Prof.dr.ir. J.I.M. Halman \\ University of Twente, Engineering Technology \\ Promotor \\ Dr. J.T. Voordijk \\ University of Twente, Engineering Technology \\ Members \\ Prof.dr.ir. A.M. Adriaanse \\ University of Twente, Engineering Technology \\ Prof.ir. M.F. Asselbergs \\ Delft University of Technology, Architecture and the Built Environment \\ Prof.dr.ir. L.A.M. van Dongen \\ University of Twente, Engineering Technology \\ Prof.dr.ir. J.J. Krabbendam \\ University of Twente, Behavioural, Management and Social Sciences \\ Prof.dr.ir. J.J.N. Lichtenberg \\ Eindhoven University of Technology, Built Environment
}





\section{SUMMARY}

Our built environment is no longer realised by processing materials at construction sites, but mostly by putting together elements on site that are produced elsewhere. When designing an object whose realisation is based on the use of construction parts that are produced off site, it is important to also consider the design for the assembly of the construction parts at the building location. The design of this assembly and its connections with other construction parts that are to be realised have a major impact on the efficiency with which it can be realised.

Unfortunately, insufficient attention has been paid so far to the design of assemblies. This gap between construction designs and their realisation inhibits the full potential of using assembly processes. It manifests itself through issues such as deviations in dimensions between the original design and the assembled system, disappointing aesthetic results and construction times that are far longer than necessary. As a consequence, the potential increase in efficiency is not fully realised. The inability to fully achieve an increased efficiency also means that the use of construction parts produced off site continues to have to compete with onsite production in the construction sector.

The above made considerations have led to the general conclusion that the design and realisation phases of construction processes are insufficiently aligned. The main goal of this $\mathrm{PhD}$ thesis therefore has been to contribute to the closing of the gap between the design and realisation phase of objects in the built environment which are realised through an assembly process. This has been realised by developing a design-for-assembly method for construction and infrastructure projects. To realise this development, this dissertation provides an answer to the following main research question:

How can construction and infrastructure objects be assembled by using an evidence based design-for-assembly method?

To answer this main research question, five sub-research questions were addressed in this dissertation:

1 What can be learnt from the design of mechanical assemblies and which design rules, design methods and techniques can be derived that are also applicable in the construction and infrastructure sector?

Chapter 2 of this dissertation includes an in-depth literature review about the design of mechanical assemblies. This review reveals that designers of all types of assemblies are confronted with geometric variations as a result of production and assembly processes. The likely geometric variations due to assembly processes and due to production processes can be considered as the two fundamentals for designing assemblies. In order to make reliable 
predictions about the expected geometric variations, an assessment is needed of the possible assembly and manufacturing related geometric variations after which one may deduce the possible impact of these geometric variations in the assembled state. The assembly of mechanical parts normally occurs at a specific location in a protected environment that can be specifically designed for the assembly of an artefact of which usually more than one is to be realised. In contrast, the assembly of an object in the built environment is generally realised outdoors and such an assembly is only realised once at that specific location. These differences affect the method that can be used to design the assembly. This means that a specific design-for-assembly method for the construction sector is required. However, the method used in designing a mechanical assembly can serve as a source of inspiration for the development of such a design method.

\section{To what extent are the current design process and design techniques, as applied in the construction and infrastructure sector, geared towards the design of assemblies?}

This question is addressed in Chapter 3. A study of the widely applied Dutch NEN 2574 standard for construction design processes revealed, that with respect to assembly and manufacturing, no explicit attention is given to geometric variations. As a consequence no desirable design activities are initiated that would accommodate relevant geometric variations. This analysis confirms and reinforces an earlier made recommendation made by the Advisory Council for Technology Policy in the Construction Sector. In their advisory report, the Advisory Council wrote that, the increased level of prefabrication in the construction sector, requires a feasibility assessment of the realisation of a building design in an early state of the design process.

With respect to design techniques that are currently applied in the construction and infrastructure sector, Systems Engineering, Design for Buildability and Design for Manufacturing and Assembly, the conclusion is drawn in Chapter 3, that these design techniques are unfortunately insufficiently geared to the design of assemblies in the construction and infrastructure sector. However, Building Information Modelling (BIM) as a design technique, could potentially be used as an aid in an assembly design process.

\section{What adaptations are necessary to the commonly used method for the design of objects in the built environment to make it suitable for objects that are constructed through an assembly process?}

In chapter 4 a first version is provided of the proposed design-for-assembly method. Important design aspects of this design-for assembly method are: the functional specification of the object to be realised; the specification of the geometric quality of the object; the expected geometric variations of the realised assembly; and the alignment of the specifications and the expected geometric variations. The first version of this design-for-assembly method consists of eight steps, which have been worked out in detail in Chapter 4. 
4 To what extent can the assembly process of dwelling transformations, utility buildings or infrastructure projects be improved by applying the proposed design-for-assembly method and how can the proposed designfor-assembly method be improved?

To answer these sub-research questions, several in-depth case studies were conducted in three domains of the construction and infrastructure sector: Four renovation projects in the residential sector; one office building project in the utility sector; and one bridge project in the civil engineering sector. The case studies clearly showed the added value of applying the proposed design-for-assembly method.

Chapter 5 provides a detailed description and analysis of the case study of four renovation projects. This case study shows that the use of the design-for-assembly method leads to the systematisation of artisanal construction activities, which allows them to be realised as assemblies. The case study of the four renovation projects also shows that the design-forassembly method can help in recognising gaps between the parties involved in the design phase and the execution of the assembly. A consistent application of the design-for-assembly method therefor avoids gaps between the parties involved. The case study also has made clear that the application of the design-for-assembly method can facilitate the development of an assembly process for the system-to-system connections of add-on façades.

Chapter 6 gives a detailed description and analysis of the case study of an office building project. This case study reveals that the proposed design-for-assembly method helps to achieve a structured transformation of the demand specification for the office building project into the execution of the assembly. The use of the proposed design-for-assembly method, makes flow-downs generally available for the assembly processes. This prevents the need for improvisation, which increases the safety of the employees. Applying of the proposed design-for-assembly method helps to optimise the assembly order. The assembly of the entire object is broken down into the assembly of various systems. The assembly order can then be optimised while interfaces ensure successful interactions between the systems. The specification of the interfaces is based on the geometric variations that have to be accommodated as a result of variations in the production and assembly of systems.

Chapter 7 reports a case study of a pedestrian bridge project. This Chapter shows the added value of adopting a product family concept for this bridge project. Like in the case studies, described in Chapters 5 and 6 respectively, the application of the proposed design-for-assembly method results in efficiency improvement and an increased safety of employees.

The conducted case studies, as described in Chapter 5-7, were also used to evaluate the first version of the design-for-assembly method for possible improvements. A complete overview of the required improvements of the first version of the design-for-assembly method is provided in Chapter 8 . 
5 What adjustments are needed to the first version of the design-forassembly method for construction and infrastructure projects to accommodate the findings from the series of case studies?

Based on the results of the case studies, the identified options to improve the first version of the proposed design-for-assembly method are explained in detail in Chapter 8. Based on the identified options to improve the first version of the proposed design-for-assembly method have led to the development of a final version of a design-for-assembly method, consisting of eight phases:

1 Design of the typology.

2 Determining Framework conditions.

3 Selection of the product architecture.

4 Design of the system-of-systems assembly.

5 Nominal design of the assembly.

6 Assessment of the feasibility of the assembly.

7 Preparation and execution of the assembly.

8 Completion of the assembly.

A detailed description of each of the distinguished phases is included in Chapter 8.

Besides presenting the main findings of this $\mathrm{PhD}$ study, Chapter 9 also includes an overview of the main scientific and managerial implications of the conducted study and it provides several recommendations that merit further study and action. 


\section{SAMENVATTING}

Onze gebouwde omgeving wordt niet meer gerealiseerd door het verwerken van materialen op bouwplaatsen, maar veelal door het assembleren van geproduceerde bouwdelen. Bij het ontwerpen van een object waarvan de realisatie is gebaseerd op het gebruik van constructiedelen die off-site worden geproduceerd, is het van belang om hierbij ook rekening te houden met het ontwerp van het assembleren van deze constructiedelen op de bouwlocatie. Het ontwerp van deze assemblage en de verbindingen met andere te realiseren constructiedelen heeft grote invloed op de efficiëntie waarmee deze kan worden gerealiseerd.

Helaas is er tot nu toe onvoldoende aandacht besteed aan het ontwerp van assemblages. Hierdoor is er een kloof tussen het ontwerp van constructies en de realisatie hiervan. Deze belemmert het volledige potentieel van het gebruik van assemblageprocessen. Deze uit zich door zaken als maatafwijkingen tussen het oorspronkelijke ontwerp en het geassembleerde systeem, tegenvallende esthetische resultaten en bouwtijden die veel langer zijn dan nodig. Als gevolg hiervan wordt de mogelijke efficiëntieverhoging niet volledig gerealiseerd. Het onvermogen om een volledig verhoogde efficiëntie te bereiken, betekent ook dat het gebruik van off-site geproduceerde constructiedelen blijft concurreren met onsite-productie in de bouwsector.

Bovenstaande overwegingen hebben geleid tot de algemene conclusie dat de ontwerp- en realisatiefase van bouwprocessen onvoldoende op elkaar zijn afgestemd. Het belangrijkste doel van dit proefschrift was dan ook bij te dragen aan het dichten van de kloof tussen de ontwerp- en realisatiefase van objecten in de gebouwde omgeving die gerealiseerd worden door middel van een assemblageproces. Dit is gerealiseerd door het ontwikkelen van een design-for-assembly methode voor bouw- en infrastructuurprojecten. Om deze ontwikkeling te realiseren geeft dit proefschrift een antwoord op de volgende onderzoeksvraag:

Hoe kunnen constructie- en infrastructuurobjecten worden geassembleerd op basis van een evidence-based design-for-assembly methode?

Om deze onderzoeksvraag te beantwoorden, zijn in dit proefschrift vijf deelonderzoeksvragen beantwoord:

1 Wat valt er te leren van het ontwerp van mechanisch samengestelde producten en welke ontwerpregels, ontwerpmethoden en technieken kunnen worden afgeleid die ook toepasbaar zijn in de bouw- en infrasector?

Hoofdstuk 2 van dit proefschrift beschrijft een diepgaande literatuurstudie over het ontwerp van mechanische producten. Hieruit blijkt dat ontwerpers van alle soorten assemblages te maken krijgen met geometrische variaties als gevolg van productie- en 
assemblageprocessen. De verwachtte geometrische variaties als gevolg van deze processen kunnen worden beschouwd als de twee basis uitgangspunten voor het ontwerpen van assemblages. Om betrouwbare voorspellingen te doen over de verwachte geometrische variaties, is een inschatting nodig van de mogelijke assemblage en fabricage gerelateerde geometrische variaties, waarna men de mogelijke impact van deze geometrische variaties in de geassembleerde toestand kan afleiden. De assemblage van mechanische onderdelen vindt normaliter plaats op een specifieke locatie in een beschermde omgeving die specifiek kan worden ontworpen voor de assemblage van een artefact waarvan er doorgaans meer dan één te realiseren is. Daarentegen wordt de assemblage van een object in de gebouwde omgeving doorgaans buiten gerealiseerd en wordt een assemblage cyclus maar één keer op die specifieke locatie gerealiseerd. Deze verschillen zijn van invloed op de methode die kan worden gebruikt om de assemblage te ontwerpen. Dit betekent dat er voor de bouwsector een specifieke design-for-assembly methode nodig is. De methode die wordt gebruikt bij het ontwerpen van een mechanisch samengestelde producten kan echter als inspiratiebron dienen voor de ontwikkeling van een dergelijke ontwerpmethode.

\section{In hoeverre zijn het huidige ontwerpproces en ontwerptechnieken, zoals toegepast in de bouw- en infrasector, gericht op het ontwerpen van assemblages?}

Deze vraag komt in hoofdstuk 3 aan de orde. Op basis van een analyse van de veel toegepaste Nederlandse norm NEN 2574 voor bouwontwerpprocessen is gebleken dat er bij het ontwerp van de assemblage en de fabricage geen expliciete aandacht is voor geometrische variaties. Als gevolg hiervan worden geen wenselijke ontwerpactiviteiten geïnitieerd die geschikt zijn voor optredende geometrische variaties. Deze analyse bevestigt en versterkt een eerder gedaan advies van de Adviesraad Technologiebeleid Bouw. In het adviesrapport schrijft de Adviesraad dat de toegenomen prefabricage in de bouwsector vraagt om een haalbaarheidsbeoordeling van de realisatie van een gebouwontwerp in een vroeg stadium van het ontwerpproces. Ten aanzien van ontwerptechnieken die momenteel in de bouwen infrasector toegepast worden, Systems Engineering, Design for Buildability en Design for Manufacturing and Assembly, wordt in hoofdstuk 3 de conclusie getrokken dat deze ontwerptechnieken helaas onvoldoende zijn afgestemd op het ontwerp van assemblages zoals toegepast in de bouw- en infrastructuursector. Building Information Modelling (BIM) als ontwerptechniek kan echter mogelijk worden gebruikt als hulpmiddel bij een assemblageontwerpproces.

3 Welke aanpassingen zijn nodig aan de gangbare methode voor het ontwerpen van objecten in de gebouwde omgeving om deze geschikt te maken voor objecten die door middel van een assemblageproces gerealiseerd worden? 
In hoofdstuk 4 wordt een eerste versie gegeven van de voorgestelde design-for-assembly methode. Belangrijke ontwerpaspecten van deze design-for-assembly methode zijn: de functionele specificatie van het te realiseren object; de specificatie van de geometrische kwaliteit van het object; de verwachte geometrische variaties van de gerealiseerde assemblage; en de afstemming van de specificaties en de verwachte geometrische variaties. De eerste versie van deze design-for-assembly methode bestaat uit acht stappen, die in hoofdstuk 4 in detail zijn uitgewerkt.

4 In hoeverre kan het assemblage proces van woningtransformaties, utiliteitsgebouwen en infrastructuurprojecten worden verbeterd door het toepassen van de voorgestelde design-for-assembly methode en hoe kan de voorgestelde design-for-assembly methode worden verbeterd?

Om deze sub-onderzoekvragen te beantwoorden, zijn diepgaande casestudies uitgevoerd in drie sectoren van de bouw- en infrastructuursector: vier renovatieprojecten in de woningbouwsector; een kantoorgebouwproject in de utiliteitbouwsector; en een brugproject in de infrastructuursector. De casestudies lieten duidelijk de meerwaarde zien van het toepassen van de voorgestelde design-for-assembly methode.

Hoofdstuk 5 geeft een gedetailleerde beschrijving en analyse van de case study van vier renovatieprojecten. Deze case study laat zien dat het gebruik van de design-for-assembly methode leidt tot systematisering van artisanale bouwactiviteiten, waardoor ze als assemblages kunnen worden gerealiseerd. Uit de casestudy van de vier renovatieprojecten blijkt ook dat de design-for-assembly methode kan helpen om hiaten tussen de betrokken partijen in de ontwerpfase en de uitvoering van de montage te herkennen. Een consistente toepassing van de design-for-assembly methode vermijdt daardoor hiaten tussen de betrokken partijen. De casestudy heeft ook duidelijk gemaakt dat de toepassing van de design-forassembly methode de ontwikkeling van een assemblageproces voor de system-to-system verbindingen van voorhanggevels kan ondersteunen.

Hoofdstuk 6 geeft een gedetailleerde beschrijving en analyse van de case study van een kantoorgebouwproject. Deze case study laat zien dat de voorgestelde design-for-assembly methode helpt om de vraagspecificatie voor het kantoorgebouw gestructureerd om te zetten in de realisatie van de assemblage. Door het gebruik van de voorgestelde design-forassembly methode zijn flow-downs algemeen beschikbaar voor de assemblageprocessen. Dit voorkomt de noodzaak van improvisatie, wat de veiligheid van de medewerkers vergroot. Het toepassen van de voorgestelde design-for-assembly methode helpt om de assemblagevolgorde te optimaliseren. De assemblage van het gehele object wordt opgesplitst in assemblages van verschillende systemen. De assemblage volgorde kan vervolgens worden geoptimaliseerd, terwijl interfaces zorgen voor succesvolle interacties tussen de systemen. De specificatie van de interfaces is gebaseerd op de geometrische variaties die moeten worden opgevangen als gevolg van variaties in de productie en montage van systemen. 
Hoofdstuk 7 beschrijft een case study van een project van voetgangersbruggen. Dit hoofdstuk toont de meerwaarde van het toepassen van een productfamilieconcept voor dit brugproject. Net als in de casestudies, beschreven in respectievelijk hoofdstuk 5 en 6, leidt de toepassing van de voorgestelde design-for-assembly methode tot efficiencyverbetering en een verhoogde veiligheid van medewerkers.

De uitgevoerde casestudies, zoals beschreven in hoofdstuk 5-7, werden ook gebruikt om de eerste versie van de ontwerp-voor-assemblage-methode te evalueren op mogelijke verbeteringen. Een compleet overzicht van de vereiste verbeteringen van de eerste versie van de design-for-assembly methode wordt gegeven in hoofdstuk 8.

5 Welke aanpassingen zijn nodig aan de eerste versie van de designfor-assembly methode voor bouw- en infrastructuurprojecten om de bevindingen uit de reeks casestudies te accommoderen?

Op basis van de resultaten van de casestudies worden de geïdentificeerde opties om de eerste versie van de voorgestelde ontwerp-voor-assemblage-methode te verbeteren in detail uitgelegd in hoofdstuk 8. Deze opties hebben geleid tot de ontwikkeling van een definitieve versie van een design-for-assembly methode. Deze bestaat uit acht fasen:

1 Ontwerp van de typologie.

2 Bepalen van de randvoorwaarden.

3 Selectie van de productarchitectuur.

4 Ontwerp van de system-of-systems design van de assemblage.

5 Nominaal ontwerp van de assemblage.

6 Beoordeling van de haalbaarheid van de assemblage.

7 Voorbereiding en uitvoering van de assemblage.

8 Afronding van de assemblage.

Een gedetailleerde beschrijving van elk van de onderscheiden fasen is opgenomen in hoofdstuk 8.

Naast de presentatie van de belangrijkste bevindingen van dit uitgevoerde $\mathrm{PhD}$ onderzoek, bevat hoofdstuk 9 ook een overzicht van de belangrijkste wetenschappelijke en bestuurlijke implicaties van het uitgevoerde onderzoek en bevat het verschillende aanbevelingen die verdere studie en actie verdienen. 




\section{TABLE OF CONTENT}

$\begin{array}{ll}\text { Summary } & 7\end{array}$

Samenvatting 11

Table of content 17

List of figures $\quad 23$

$\begin{array}{ll}\text { List of tables } & 27\end{array}$

$\begin{array}{lll}\text { Chapter } 1 \quad \text { General Introduction } & 29\end{array}$

1.1 Background of this research 30

$\begin{array}{lll}1.2 & \text { The conceptual design of this research } & 37\end{array}$

1.3 The technical design of this research 39

1.4 Outline of this thesis $\quad 44$

Chapter 2 The design of Mechanical Assemblies 45

2.1 Introduction 46

$\begin{array}{lll}2.2 & \text { Design of assemblies } & 47\end{array}$

2.3 Control of the geometrical quality $\quad 51$

2.4 Modelling assemblies $\quad 55$

2.5 Classification of assemblies $\quad 57$

2.6 The design process of assemblies 60

2.7 Designing the assemblies of structures 62

2.8 Evaluating and improving the design of assemblies 72

2.9 Designing assembly methods $\quad 75$

2.10 Communicating about the assembly of a product $\quad 77$

2.11 Field problem, design methods and design rules for $\quad 78$ designing assemblies

2.12 Conclusions $\quad 81$

Chapter 3 The design process and design techniques as applied 83 in construction and infrastructure projects

3.1 Introduction 84

3.2 The realization process and design issues in the construction industry

3.2.1 The construction realisation process according to the Dutch standard NEN 2074

3.2.2 Points of attention with regard to the design of assemblies 89

3.2.3 Conclusion regarding addressing the design issues 90 relevant for assembly

3.3 Design techniques applied in the construction 91 and infrastructure sector 
$\begin{array}{ll}\text { 3.3.1 Systems Engineering } & 91\end{array}$

3.3.2 Building Information Modelling 95

3.3.3 Accommodation of geometric variations 97

$\begin{array}{ll}\text { 3.3.4 Design for buildability } & 100\end{array}$

3.3.5 Design for manufacturing and assembly in construction 103

3.3.6 Concluding remarks with respect to the 105 five design techniques

$\begin{array}{lll}3.4 & \text { Conclusions } & 107\end{array}$

$\begin{array}{lll}\text { Chapter } 4 & \text { A first draft of a design-for-assembly method } & 109\end{array}$ for construction and infrastructure projects

4.1 Introduction 110

4.2 The design aspects and the general structure of the design-for-assembly method

4.3 The first draft of the design for assembly method 114

$\begin{array}{lll}4.4 & \text { Demand specification } & 118\end{array}$

4.5 Spatial and functional design

$\begin{array}{lll}4.6 & \text { System design } & 121\end{array}$

4.7 Nominal design $\quad 126$

4.8 Variation design 138

4.9 Preparing the execution of the assembly process 143

4.10 Execution of the assembly 145

4.11 The organisation of the design- and execution process 146

4.12 The first draft of the construction assembly design method 155 and its parameters

Chapter 5 A case study of four dwelling transformation projects $\quad 157$

$\begin{array}{ll}5.1 \text { Introduction } & 159\end{array}$

5.2 The transformation project to be realised 160

5.3 Characterisation of the dwelling transformation case study 163

$\begin{array}{lll}5.4 & \text { Goals of the case study } & 164\end{array}$

5.5 Method applied in the dwelling transformation case study

$\begin{array}{lll}5.6 & \text { Case } 1.1 & 167\end{array}$

5.6.1 Introduction to case 1.1

5.6.3 The design of the assembly

5.6.4 The design of the systems to be assembled 170

5.6.5 Findings concerning the realisation of the assembly 171

5.6.6 Findings concerning the proposed design-for-assembly method 
5.7.1 Introduction to case 1.2

5.7.2 Description of the systems to be assembled 174

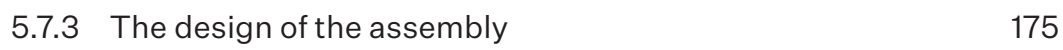

5.7.4 The design of the systems to be assembled 176

5.7.5 Findings concerning the realisation of the assembly 177

5.7.6 Findings concerning the proposed design-for-assembly 179 method

5.8 Case 1.3

5.8.1 Introduction to case 1.3

5.8.2 Description of the systems to be assembled 182

5.8.3 The design of the assembly

5.8.4 The design of the systems to be assembled 184

5.8.5 Findings concerning the realisation of the assembly 186

5.8.6 Findings concerning the proposed design-for-assembly 190 method

$\begin{array}{lll}5.9 & \text { Case } 1.4 & 191\end{array}$

5.9.1 Introduction to case 1.4

5.9.2 Description of the services 192

5.9.3 Preparing of the execution 193

5.9.5 Findings concerning the proposed design-for-assembly method

5.10 Overall findings regarding the proposed design-forassembly design method

5.11 Findings regarding the organisation of the assembly 194 design and the assembly process

$\begin{array}{ll}5.12 \text { The results of the case study } & 196\end{array}$

5.12.1 Improving the assembly process of dwelling transformation projects when applying the proposed design-for-assembly method

5.12.2 The improvement of the proposed design-for-assembly method

Chapter $6 \quad$ A case study of an utility building project 201

$\begin{array}{ll}\text { 6.1. Introduction } & 202\end{array}$

6.2. The utility building project to be realised

6.3 The characterisation of the utility project 203

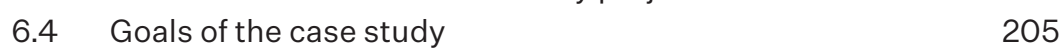

6.5 Methods used in the case study 206 
6.6 Description of the construction organisation 207

6.7 The design of the assembly 208

6.8 Findings concerning the realisation of the assembly 212

6.9 Feasibility of the assembly process for the supporting 230 structures

6.10 Findings regarding the organisation of the design and 233 realisation process

6.11 The results of the case study 235

6.11.1 Improving the assembly process of utility buildings by applying the proposed design-for-assembly method

6.11.2 The improvement of the proposed design-for-assembly 236 method

\begin{tabular}{|c|c|}
\hline Chapter 7 & A case study of an infrastructure project \\
\hline 7.1 & Introduction \\
\hline 7.2 & The infrastructure project to be realised \\
\hline 7.3 & Characteristics of the infrastructure project \\
\hline 7.4 & Goals of the case study \\
\hline 7.5 & Case study methodology \\
\hline 7.6 & Case study pedestrian bridges \\
\hline 7.7 & $\begin{array}{l}\text { Findings pertaining to the organisation of the design } \\
\text { and realisation process }\end{array}$ \\
\hline 7.8 & The results of the case study \\
\hline 7.8.1 & $\begin{array}{l}\text { Improving the assembly process of infrastructure projects } \\
\text { by applying the proposed design-for-assembly method }\end{array}$ \\
\hline 7.8 .2 & $\begin{array}{l}\text { The improvement of the proposed design-for-assembly } \\
\text { method }\end{array}$ \\
\hline
\end{tabular}

Chapter 8 The final version of the design-for-assembly method

8.1 Introduction

8.2 The results from the series of case studies

8.2.1. The desired modifications

8.2.2. The organisation of the design and realisation of assemblies in the built environment

8.2.3 Specification of the design method

8.3 The principles of the design method with regard to assembly as a production method

8.4 Principles of the design-for-assembly method

8.5 The final version of the design-for-assembly method

8.5.1 Phase 1: Design of the typology

8.5.2 Phase 2: Framework conditions 
8.5.3 Phase 3: Selection of the product architecture 265

8.5.4 Phase 4: Design of the system-of-systems assembly 267

8.5.5 Phase 5: Nominal design of the assembly 276

8.5.6 Phase 6: Assessment of the feasibility 278

8.5.7 Phase 7: Preparation and execution of the assembly 283

8.5.8 Phase 8: Completion of the assembly 286

8.6 The design-for-assembly method and the potential applications

8.7 A validation of the developed design-for-assembly method 287

8.7.1 From building to assembling in residential construction 288

8.7.2 From building to assembling in non-residential construction 289

8.7.3 From building to assembling for infrastructural projects 290

8.7.4 The overall results of the validation exercise for the 292 design-for-assembly method

8.8 Conclusion regarding the final version of the design- 293 for-assembly method

$\begin{array}{lll}\text { Chapter } 9 & \text { Discussion of findings } & 295\end{array}$

9.1 Introduction 296

9.2 Scientific contributions 299

9.3 Managerial implications 300

9.4 Recommendations for further research 301

$\begin{array}{ll}\text { References } & 305\end{array}$

$\begin{array}{ll}\text { Appendix } & 311\end{array}$

$\begin{array}{ll}\text { Acknowledgements } & 313\end{array}$

$\begin{array}{ll}\text { About the author } & 315\end{array}$ 



\section{LIST OF FIGURES}

Figure 1.1 Representation of the research process.

2.1 Design decisions on three levels.

2.2 The relationship between product architecture, "DFX in the Large" and "DFX in the Small".

2.3 Incorrect: Double dimensioning.

2.4 The effects of chain dimensioning.

2.5 A proper way of dimensioning: Parallel dimensioning.

2.6 The relationship between the process feasibility $\mathrm{C}_{\mathrm{pk}}$ and the likelihood of a qualitative issue.

2.7 World Coordinate Frame.

2.8 Connective models.

2.9 A classification of assemblies.

2.10 Key characteristics (KCs) of a car body.

2.11 Mapping functional elements to physical components.

2.12 Typology of interfaces.

2.13 Examples of types of product architecture.

2.14 Representation of the product architecture using a design structure matrix (a) and in the form of a digraph (b).

2.15 A Liaison Diagram and a Datum Flow Chain.

2.16 A liaison diagram of part of the assembly of a car body and the key characteristics of a car body that are to be realised.

2.17 Key Characteristics (KCs) flow-down.

2.18 The design of an assembly method.

2.19 Assembly model for a cabinet.

2.20 Context of realisation, the design rule to be designed and design issues.

3.1 Cross-section of a façade (prefab concrete \& masonry.

3.2 The System Engineering Process.

3.3 System and system context of the Dutch transport system.

3.4 The decomposition of a building.

3.5 Pieterskerk, capital in the nave, Leiden, circa 1410-1430.

4.1 The general structure of the construction assembly design method.

4.2 The process steps of the first draft of the design-for-assembly method.

4.3 An object as a representation of a functional and a technical system.

4.4 Integration of systems in the façade zone.

4.5 Flow-down construction of systems in the façade zone.

4.6 Single and multiple system-to-system joinings.

4.7 Assembly base key characteristic. 
Figure 4.8 Determining the assembly base's key characteristics for a two-dimensional construction part.

4.9 Tolerance interface.

4.10 Positioning a curtain wall to be assembled in the work in relation to a horizontal line.

4.11 Flow-down of the realisation of the system key characteristics.

4.12 Variation flow-down of a building assembly.

4.13 Flow-down for a subassembly.

4.14 The principles of dimensioning.

4.15 Dimensioning for plating.

4.16 Possible contributions of supplier chains.

5.1 The assembly to be designed for dwelling transformations.

5.2 Goals of the dwelling transformation case study.

5.3 The 'doorzon' dwellings before transformation.

5.4 Cladding the bathroom walls using the "mill system".

5.5 Hoisting a roof element into the desired position.

5.6 Cladding the bathroom walls using the "assembly corner elements system".

5.7 The position of the window frame in the add-on façade in relation to the existing window frame.

5.8 The assembly base for the sandwich panels at the location of a front façade and a side façade.

6.1 Results of the utility building case study.

6.2 Sources of geometric variation in the design of the assembly of a utility building.

6.3 Measured dimensional deviations in anchor points and the degree of process feasibility.

6.4 The sewer pipelines with metal supports and raising points.

6.5 Schematic representation of the position of the assembled columns that are vertically positioned in relation to the assembly base using a spirit level.

6.6 Schematic representation of the assembled columns that are positioned in relation to the grid dimensions based on acceptable dimensional deviations.

6.7 Variation flow-down of a supporting structure that consists of façade frames and hollow-core slabs.

6.8 Finding the information required for positioning the anchors.

6.9 Positioning the curtain wall prior to the attachment of the interfaces.

6.10 Dimensioning for the purposes of positioning: chain dimensioning on the left, parallel dimensioning on the right.

7.1 Goals of the pedestrian bridge case study. 
Figure 7.2 Transporting the Parks-Nature park bridge.

7.3 Positioning a Parks-Nature park bridge.

8.1 The process steps of the first draft of the design-for-assembly method.

8.2 The final version of the design-for-assembly method.

8.3 Design of the typology.

8.4 Framework conditions.

8.5 The selection of the product architecture.

8.6 The most promising product architecture options.

8.7 The system-of-systems design of the assembly.

8.8 Example of a construction system template.

8.9 Optimising the assembly order using the design structure matrix.

8.10 An excess of system-to-system connections.

8.11 The nominal design of the assembly.

8.12 Assessment of the feasibility of the nominal design of the assembly. 



\section{LIST OF TABLES}

Table 1.1 Main concepts used in this research.

2.1 Design for assembly rules and stakeholders involved.

2.2 The design methods and techniques that may be relevant for the assembly design in the field of the construction and the infrastructure industry.

3.1 The Dutch standard NEN 2574 with regard to the phasing of the construction realisation process.

3.2 The applicability of the identified design techniques in addressing design issues related to designing assemblies.

4.1 Completed design phases and types of procurement.

4.2 The parameters pertaining to the evaluation of a realised design of an assembly.

5.1 Findings regarding the evaluation of the proposed design-forassembly method.

6.1 Points for attention in the proposed construction assembly design method being evaluated.

7.1 Points of attention pertaining to the proposed construction assembly design method.

8.1 The results of the case studies.

8.2 Backgrounds and numbers of the experts of the workshop on residential construction.

8.3 Evaluation scores for the two overarching statements during the workshop on residential construction.

8.4 Backgrounds and numbers of the experts of the workshop on non-residential construction.

8.5 Evaluation scores for the two statements during the workshop on non-residential construction.

8.6 Backgrounds and numbers of the experts of the workshop on infrastructure projects.

8.7 Evaluation scores for the two statements during the workshop on infrastructural projects.

8.8 The overall evaluation scores from the three workshops on the applicability of the construction assembly design method in practice. 



\section{General introduction}

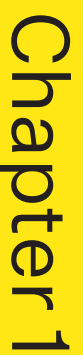

\section{Contents}

1.1 Background of this research

1.2 The conceptual design of this research

1.3 The technical design of this research

1.4 Outline of this thesis 
This opening chapter serves as an introduction to the research presented in this thesis. Section 1.1 provides general background information about the problems that arise if the design of offsite produced building parts is insufficiently aligned with the later onsite assembly process. Based on the problems outlined in section 1.1, the next section 1.2, presents the problem definition, the research objectives, the central research question and subresearch questions of this thesis. The chapter concludes with an outline of the overall thesis structure.

\subsection{Background of this research}

It is hard to imagine that the first iterations of modern-day mechanical devices such as aeroplanes and cars were once built in an artisanal manner. The early artisanal production explains why the first car bodies were referred to as coachwork. The development from the artisanal method of producing a 'coachwork' to the current automated assembly of a car body, also known as the "body in white", is the result of many advances in production technology, the focus on the assembly process and the manner in which production and assembly are coordinated. Boothroyd and Dewhurst [1983] were the first to conduct systematic research into the relationship between the design of the components of a product and the realisation of their assembly. This so-called design for assembly (DFA) research was primarily focused on modifying an existing design in order to optimise the efficiency of the assembly processes. The optimum result would be achieved by eliminating the assembly of a part altogether. Using the DFA method therefore led to a more integral design of artefacts. A subsequent development of the design process was "design for production" [Kals et al., 2009]. This involves giving unbroken attention during the design process to both manufacturing and assembly aspects. This ensures that the product design, the manufacture of the components and the realisation of the assembly are optimally coordinated.

At the time of the first production of the coachwork bodies, the attention given to assembly in the construction sector was comparable to that in the rising manufacturing sector. After all, both sectors still made extensive use of artisan-produced wooden constructions. The components of these wooden constructions, e.g. roof cowls, were produced and put together on site. Given that components were produced for a specific position in a construction, so-called system of assembly marks ${ }^{1}$ were added to the components for the connections to be realised [Janse, 2012]. These marks indicated which ends of certain components had to be put together to form a connection. Given the focus on both the production of the components and their assembly, this process can be classified as design for construction.

1 In Dutch, these are called "telmerken". 
"Design for construction" (DFC) was also used in the then-common masonry constructions by basing construction dimensions on the sizes of the bricks used in them. Design for construction was clearly being used for both wooden and masonry constructions. Since the people who manufactured and assembled the constructions were also involved in their design, the design for construction method was used implicitly. The substantive knowledge belonged to the people associated with the respective guild.

\section{Offsite production in the construction industry}

The architect Rem Koolhaas developed the "Elements of Architecture" exhibition for the architecture biennale that was held in 2014 in Venice. With this exhibition, Koolhaas highlighted that architecture consists of elements such as walls, windows, staircases, toilets and elevators. Earlier contributions in the Netherlands on the concept of elements in architecture, were made by Habraken and Van Randen. One of the most articulate and in $\square$ uential examples in this regard was the 'Theory of Supports' developed by Habraken [1972; 1999; 2003] within the SAR group. This theory makes a distinction between 'support' and 'infill'. From a social perspective it seeks to respond to user's preferences by offering flexibility needed for adaptation of individual units over time. And from a technical perspective it seeks a way of 'Open Building' where sub-systems can be installed or changed or removed with a minimum of interface problems. To realize this way of 'Open Building', Van Randen [1990] propagated the view that a building should be treated as an industry product composed of separate subsystems or elements which can be used in new construction projects as well in renovation projects. Design for adaptability and disassembly of building objects are key tasks in the process to realize circularity in the built environment. Building on the work of Habraken and Van Randen, Brand [1994] proposed a division of building objects into "layers of change" and made a distinction between respectively the layers Site, Structure, Skin, Services, Space plan and Stuff. When these layers are designed as separate elements, all other layers can be preserved when one of the layers needs to be adapted or replaced. This allows to maximize the life cycle of a building.

Alongside the 2014 exhibition in Venice, Koolhaas also published about the 'Elements' in a series of fifteen volumes [Koolhaas, 2014]. This series provides an overview of the evolution of the distinguished elements over time, as a result of various influences. Koolhaas's exhibition implicitly demonstrates that our built environment is no longer realised by processing materials at construction sites, but mostly by putting together elements on site that were produced elsewhere. These elements can be realised as one-of-a-kind products, as part of a series or as mass-produced objects. The elements can be created in a craftsman's workshop or by a machine or robot in a factory. In all these scenarios, they are often produced off site. 
The description given by Gibb [2001] can be used to define what these offsite possibilities entail:

Component manufacture and sub-assembly, examples include staircases and window frames.

- Volumetric pre-assembly, examples include sanitary facilities and modular elevator shafts.

- Non-volumetric pre-assembly, examples include façade elements and components of supporting structures.

- Modular building, examples include offices and residential blocks.

\section{Labour productivity in the construction sector}

Given that objects in the built environment are often realised through the onsite assembly of construction parts that are produced off site, one might think that the development of labour productivity in the construction sector has matched that in manufacturing industry. However, the "Reinventing Construction" study shows that it has developed very differently [McKinsey Global Institute, 2017]. On a global scale, the labour productivity in the construction sector has increased by an annual rate of one percent over the past twenty years. The development in labour productivity in the construction sector is also slower than in the economy as a whole, which saw an annual increase of 2.8 percent over the same period. In the long run, this will negatively impact investments in the construction sector, its total size and its appeal to employees. In social terms, this development is also undesirable given its effects on inflation and export opportunities [Botter, 1993].

In order to develop an understanding of the basic causes of the hardly increasing productivity in the Dutch construction sector and their consequences, an exploratory study was conducted. The results were then used to formulate the problem definition for this $\mathrm{PhD}$ research. With regard to the situation in the Netherlands, the following questions were investigated:

1 Why is labour productivity hardly increasing despite the growing popularity of using offsite-produced construction parts?

2 Is it possible to reduce the lead times of construction projects?

3 Why is so much construction waste being produced, despite more and better methods for accurate dimensioning?

The first of these questions stems from the findings of the McKinsey Global Institute [2017] with regard to labour productivity trends. The second question is relevant because of the link between the lead times of construction projects and interest charges, and the desire to reduce the current shortages in the existing Dutch housing stock. This sector would greatly benefit from much shorter lead times for construction projects. The third question is based on the understanding that the construction sector produces a large volume 
of construction waste. This concerns construction products that are transported to the construction site but then not, or incorrectly, processed and therefore disposed of as waste. Unfortunately, the National Waste Management Plan in the Netherlands does not offer any concrete information about the scope of this issue. In order to answer these three questions, they were discussed with several experts who work either directly or indirectly in the construction sector and a study of the application of the principles of mass customisation for infrastructural objects was also consulted [Stout, 2016].

The consulted experts in this preliminary investigation were involved in innovation in the construction sector such as the introduction of new production technologies and their application in both the initiation and realisation of buildings or infrastructure objects. Among these experts were a real-estate developer ${ }^{1}$, a senior staff member of an architectural firm ${ }^{2}$, a supplier of construction parts that are produced off site, an expert of SBRCURnet ${ }^{3}$, an expert of the Dutch Association for Building Supplies ${ }^{4}$ and members of Booosting ${ }^{5}$, Slim Bouwen $^{6}$ and Conceptueel Bouwen ${ }^{7}$. These experts were asked about the possible effects on labour productivity, lead times and reduction of construction waste with new or renovated objects if the parties involved were given the opportunity to apply new technologies such as building information modelling, production technologies and measurement technologies. These experts were also asked what possible restrictions stand in the way of applying these new technologies.

The consulted experts provided fairly similar answers to the questions on the effects of innovation on possible labour productivity, shorter lead times and reduction of construction waste. They all believed that significant improvements could be realised with regard to these aspects and that, in order to do so, it is particularly desirable to prevent or close the gap between the construction design and the realisation of objects. The effects of this gap are evident from the following practical issues that occur:

Dimensions in the assembled systems deviate from the design.

The design is not based on the dimensions of the components used in the assembly.

The aesthetic result intended by the designers appears infeasible in practice.

The specification of the systems to be realised is incomplete.

Construction times are far longer than necessary.

1 This developer has residential buildings and offices realised by building organisations.

2 This architectural firm has residential and utility buildings realised by building organisations.

3 A former knowledge organisation for the Dutch construction sector.

4 Industry organisation for building materials and elements.

5 Platform of innovators of building innovations.

6 Platform of suppliers of innovative building elements.

7 Network promoting the greater use of repeatable design. 
In practice, the effects of the gap between design and realisation may be resolved by the architectural firm providing detailed information about the construction parts to be used and ensuring their realisation by "nailing down" the specifications. This makes it then possible to reject suggested alternative solutions. Some parties resolve this gap by collaborating with regular partners, so-called co-creators. Working with co-creators is stimulated by various parties including Conceptueel Bouwen. The supporters of Slimbouwen want to avoid the aforementioned gap by splitting the design issue into four parts, i.e. supporting structure, shell, installation and finishing. These are referred to as "separated offices". In terms of organising the design, Slimbouwen advocates the introduction of a construction director. The goal is to appoint a Slimbouwen "officer" for each part. The four officers are supervised by the construction director. They are also responsible for the interfaces between the construction parts. The construction director is part of the design team. The officers are brought in by the construction director for the final design. The construction company then becomes a "coordinator" of the realisation of the object.

The Dutch Association for Building Materials believes that the separation between the structural design and its realization impedes the pursuit of higher labour productivity, shorter lead times and reduction of waste. This organisation expects significant improvements from different tendering methods, the standardisation of the geometry of construction parts and such initiatives as conceptual construction. The developer who had been interviewed, avoids the aforementioned gap by collaborating with supplying companies in the construction design of houses and offices. Furthermore, it gives these suppliers the opportunity to realise this design without the involvement of a construction company. In practice, the developer is then able to reduce the usual construction time by half and customers are still satisfied with the quality delivered by their suppliers. With this approach, the developer can realise detached houses in 100 days, whereas construction companies that use traditional methods need on average 245 days to do the same. In order to generalise these effects, this organisation advocates the use of Building Information Modelling (BIM) by the construction company's work preparation department.

This exploratory study showed that parties carry out certain activities in order to bridge the gap between an object's design and its realisation. However, these are not based on the use of any specific design method, but rather on practical experience.

\section{Design for production in the construction sector}

The gap between construction designs and their realisation that was detected during the exploratory study inhibits the full realisation of the potential of buildings using construction parts that are produced off site. When designing an object in the built environment that will be constructed using onsite assembly, there is apparently insufficient attention given to the possibility of using assembly processes. In her study on the application of the principles of mass customisation for an infrastructural object, Stout [2016] concluded that 
the principles of standardisation and modularisation could be applied but that this would require a different way of thinking from the actors involved.

Looking at the bigger picture, it seems that the construction sector's former focus on design for construction has been lost during the transition from onsite construction to assembly. Although there are design and realisation processes, these do not tie together that well. The design and the realisation are not approached in an integrated manner, which means that the full potential of using construction parts that are produced off site is not realised. During the design phase, their use is often not seen as the realisation of a production system, and so the potential increase in efficiency associated with the assembly method is not fully realised. The inability to fully achieve this increased efficiency also means that the use of construction parts produced off site continues to have to compete with onsite production in the Dutch construction sector.

When designing an object whose realisation is based on the use of construction parts that are produced off site, three design aspects are important $t^{1}$ :

- the functional design of the construction parts;

- the design for the manufacture and assembly of the construction parts;

- the design for the assembly of the construction parts at their final location in relation to the context of the object to be realised.

The functional design of the construction parts concerns the functions they must perform. This design is often based on an existing concept. The realisation of a functional design is one of the competences required of the designer of the object in question. Similarly, an existing concept can be used when designing the manufacture and assembly of the construction parts. Both aspects should be covered by the competences of the producer in question. The design of the assembly of the construction parts at the eventual location in relation to the context of the object to be realised is generally also a task for the designer of the project. The design of this assembly and its connections with other construction parts that are to be realised have a major impact on the efficiency with which it can be realised.

The effect that producing construction parts off site has on the efficiency of the construction process largely depends on the design of the assembly. If the design is not based on the assembly of offsite production, the potential gain in efficiency will not be achieved. Both the use of construction parts that are produced off site and the efficiency achieved therefore requires a design process that does away with the traditional divide between design and execution. This finding matches that of the Advisory Council for Technology Policy in the

1 These points are based on my 36 years of work experience in construction practice 
Construction Sector (ARTB). In its advisory report from 1998, the Advisory Council wrote that the feasibility of a design would have to be taken into account at an early stage due to an increase in prefabrication [ARTB, 1998]. This method, which the ARTB called "designto-build", also involves the systematic incorporation of experiences gained from execution.

In developing the design-to-build method, it is questionable to what extent the design-for-assembly methods that are applied for the design of mechanical items can be fully adopted and applied in the construction sector. In general, the assembly of mechanical units occurs at a specific location in a protected environment that can be specifically designed for the assembly of an artefact of which usually more than one is to be realised. In contrast, the assembly of an object in the built environment is generally realised outdoors and such an assembly is only realised once at that specific location. These differences affect the method that can be used to design the assembly. This means that a specific design-for-assembly method for the construction sector is required. However, the method used in designing a mechanical assembly can serve as a source of inspiration for the development of such a design method.

The method to be developed for the design of the assembly of objects in the built environment will be utilised in an engineering environment. This makes a solution-oriented approach preferable and, consequently, developing a so-called "technological rule" would be an appropriate solution [Bunge, 1967; Van Aken, 2005]. A technological rule can be defined as "an instruction to perform a finite number of acts in a given order and with a given aim” [Bunge, 1967]. A technological rule entails a general prescription for a specific class of problems. Its use is therefore limited to a specific field of application. A technological rule follows the logic of "if you want to achieve $\mathrm{Y}$ in situation $\mathrm{Z}$, then perform action $X$ ”. In design science research, technological rules are grounded on scientific knowledge and systematically tested within the context of their intended use.

Given the environment in which it will be developed and applied, a technological rule can be characterised as the development and systematic testing of a design rule [Baldwin et al., 2000]. In other words, the development and systematic testing of a general prescription for the assembly of construction parts, based on grounded scientific knowledge. By developing a design rule for the assembly of construction parts that are produced off site, the gap between design and realisation should be eliminated. This will contribute to both quality and production improvements in the construction and infrastructure sector and will also help to prevent construction waste. 


\subsection{The conceptual design of this research}

Based on the findings outlined in the previous section, the problem definition of this research can be stated as follows:

In the construction sector, the design and realisation phases are insufficiently aligned when using construction parts that are produced off site.

In line with Verschuren and Doorewaard [2015], a distinction is made between the objective of the research and the objective in the research.

The objective of this research is stated as follows:

Contributing to the closing of the gap between the design of offside produced building parts and their assembly on the construction site.

The objective in this research is formulated as follows:

To develop a design-for-assembly method for the assembly of objects in the built environment that is optimally tailored to the realisation of value creation for the end-user, the desired functionality and the assembly processes to be utilised on site.

In addressing this objective, a construction technologist is assumed to be the user of the developed design-for-assembly method. Construction technologists play an important role in designing the assembly of an object. In practice, construction technologists are responsible for the technical coordination and integration of supporting structures, building constructions and climate-control facilities at the building level ${ }^{1}$.

The central question of this research is as follows:

How can construction and infrastructure objects be assembled using an evidence-based design-for-assembly method?

1 Derived from the profile description of Delft University of Technology's "Architectural Engineering and Technology" Department, which is part of the Faculty of Architecture and the Built Environment. 


\section{The research method}

For this research into the development of a construction assembly design method, a design science research strategy is used [van Aken, 2005]. The core objective of a design science research strategy is to develop knowledge that can be used by professionals in the field in question to design solutions to their problems. The core research product of design science research is a generic design. This generic design should be a well-understood and well-documented innovative design that has been field-tested to establish its pragmatic validity. The generic design is supported by a design proposition that provides insight into where and how the generic design is to be used in the field [van Aken et al., 2016].

In this $\mathrm{PhD}$ research project, the generic design will be of a construction assembly design method. The first draft of this design rule will be created based on a comparison of the design rules, design methods and techniques that are used in the design of mechanical assemblies and those used for the design of objects in the built environment. The basis of this comparison will be the similarities and differences in the respective fields of application. It is important to note here that mechanical objects have been realised through assembly for decades. The first draft of the design rule will then be tested in the relevant field (i.e. construction). In this testing, multiple case studies will be conducted. The multiple case study approach operates as a kind of learning system: step-by-step one learns how to produce the desired outcomes in various contexts. After the initial series of cases, the design rule is further developed by reflection and induction, and subsequently tested and refined by adding more cases [Van Aken, 2005]. It is possible to choose either a developing or an extracting multiple case study approach. Both address a series of problems of a particular type. With the developing approach, these problems are resolved through collaboration between researchers and people who are part of the domain of the research while, in an extracting multiple case study, best practices in solving problems of a particular type are analysed. For this study, the extracting multiple case study approach was selected.

The development of the construction assembly design method will take the following steps: first analysis of the problem, next design of a solution and then further developing this solution in cycles of testing and redesign. The problem analysis is intended to provide insight into the problem to be resolved. Based on this insight, the first draft of the construction assembly design method will be developed. This draft version will next be tested using various case studies. The acquired insights are then used as input for the redesign of the assembly design method. The redesigned method will then be validated in terms of its relevance and applicability during three expert workshops. Given that the desired design rule is intended to be used for assemblies in residential and non-residential construction and infrastructural projects, the testing will cover all three domains. 


\section{Definitions}

The main concepts used in this research are defined in table 1.1.

Table 1.1: Main concepts used in this research.

\begin{tabular}{|c|c|}
\hline Oncept & Definition \\
\hline Assembly & $\begin{array}{l}\text { - Using a construction part without having to process it at the } \\
\text { location of the realisation. }\end{array}$ \\
\hline $\begin{array}{l}\text { Assembly process } \\
\text { Building technologist }\end{array}$ & $\begin{array}{l}\text { - The actions necessary for the realisation of an assembly. } \\
\text { - A professional active in the integral design of objects in the built } \\
\text { environment. }\end{array}$ \\
\hline & $\begin{array}{l}\text { - All objects which are not realised in an organic manner. } \\
\text { - Deviations from the design. }\end{array}$ \\
\hline Disrupted as & $\begin{array}{l}\text { - An assembly process with an unexpected distribution of cycle } \\
\text { times or one where the expected level of quality was not realised } \\
\text { with the assembly process. logistic analysis }\end{array}$ \\
\hline Technological rule & $\begin{array}{l}\text { - An instruction to perform a finite number of acts in a given order } \\
\text { and with a given aim [Bunge, 1967]. }\end{array}$ \\
\hline Value creation & $\begin{array}{l}\text { - All activities that contribute to a product or service that is valued } \\
\text { by an end user. }\end{array}$ \\
\hline
\end{tabular}

\subsection{The technical design of this research}

In the development and testing of the assembly design method, the reflective design cycle as described by Van Aken [1994; 2005] and Heusinkveld and Reijers [2009] will be applied. Five distinct phases are distinguished, namely:

Problem analysis.

Development of the first draft of the construction assembly design method.

Testing the first draft of the construction assembly design method.

4. Evaluation and redesign of the first draft of the design method and its relevance and applicability.

5 Reflection on the scientific and societal contributions of this research.

These phases are described below. The process steps in the research based on these phases are shown in Figure 1.1. 
Sub-research questions

What can be learnt from the design of mechanical assemblies and which technological rules, design methods and techniques can be derived that are also applicable in the construction and infrastructure sector?

To what extent are the current design process and design techniques, as applied in the construction and infrastructure sector, geared towards the design of assemblies?

\section{What adaptations are necessary} to the commonly method for the design of objects in the built environment to make it suitable for objects that are constructed through an assembly process?

To what extent can the assembly processes of dwelling transformation, utility building or infrastructure projects be improved by applying the proposed design-for-assembly method and how can the proposed design method be improved?
What adjustments are needed to the first version of the design-for-assembly method for construction and infrastructure projects to accommodate the findings from the series of case studies?

Is the goal of the research has been realised, what is the scientific contribution of the research, the societal relevance and the limitations of the developed design method?
Research process model

Chapter
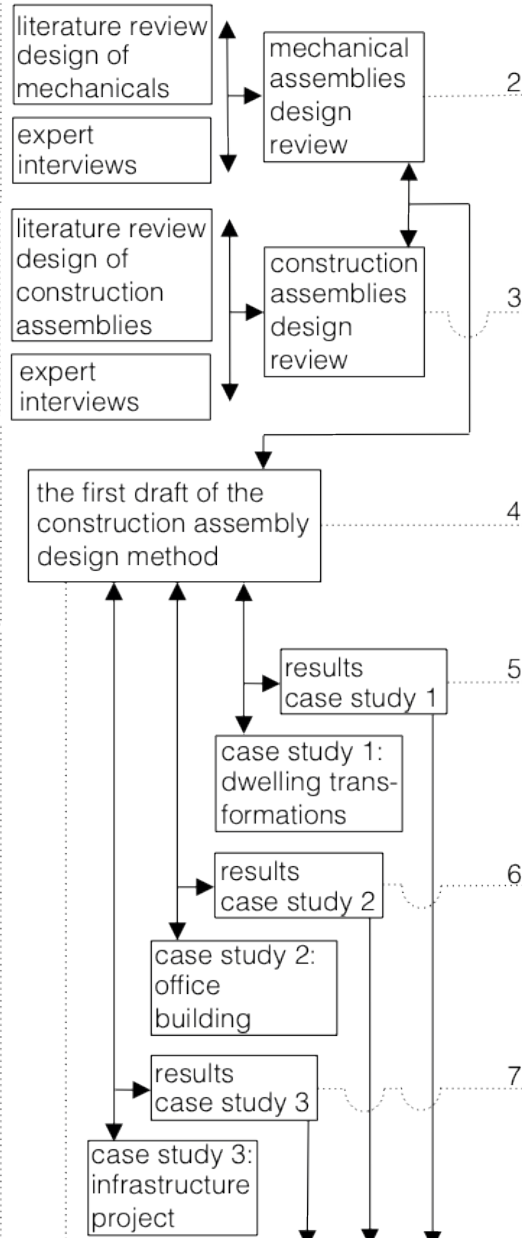

the first draft of the construction assembly design method case study 2: office building dwelling transformations

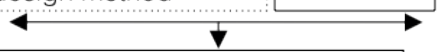

the final version of the construction assembly design method

conclusions

discussions and

Figure 1.1: Representation of the research process. 


\section{Phase 1: Problem analysis}

As explained in Section 1.1, it is not possible to directly transfer and apply the design-forassembly methods and techniques that are used for the design of mechanical assemblies to the construction and infrastructure sector. However, those methods can serve as inspiration for the development of an assembly design method for the construction sector. To this end, the design rules, design methods and techniques that are used for the design and realisation of mechanical assemblies and which might be useful for the construction design rule to be developed are identified. The sub-question to be answered in this manner is the following:

\section{What can be learnt from the design of mechanical assemblies and which technological rules, design methods and techniques can be derived that are also applicable in the construction and infrastructure sector?}

To answer this question, an extensive literature study on the design-for-assembly of mechanical assemblies has been conducted. In addition, interviews have been held with experts in the field of the design of mechanical assemblies. These experts include scientific experts as well as professionals in the field of equipment manufacturing.

To develop the design rule, the existing design process and design techniques that are used in the construction sector will be described and evaluated. To clarify the context in which objects in the built environment are assembled, a number of practical issues concerning the design and realization of these objects will be identified and discussed. In addition, earlier initiatives to improve the assembly of construction parts will be described. The sub-question to be answered in this manner is the following:

To what extent are the current design process and design techniques, as applied in the construction and infrastructure sector, geared towards the design of assemblies?

\section{Phase 2: Development of the draft construction assembly design method}

During this phase, an initial draft of the construction assembly design method will be developed. To do so, a design specification will be drawn up. This specification is based on aspects that are relevant for the design of assemblies in general and those which are specifically required for the design of assembled objects in the built environment. The sub-question to be answered in this second development phase is the following:

What adaptations are necessary to the commonly used method for the design of objects in the built environment to make it suitable for objects that are constructed through an assembly process? 


\section{Phase 3: Testing the first draft of the design rule}

During the third phase, the first draft of the design rule that was developed during Phase 2 is tested. To this end, an extracting multiple case study [Aken, 2005] will be undertaken. A characteristic of this approach is that the best practices or problem solving with regard to the design of the assembly of objects for the built environment and the actual reality when it comes to assembly are analysed. The sub-question to be answered in this testing phase is the following:

To what extent can the assembly process of dwelling transformations, utility buildings or infrastructure projects be improved by applying the proposed design-for-assembly method and how can the proposed design method be improved?

Appropriate cases could be selected based on any of the following classifications:
the functions of the objects;
2 the assemblies to be realised;
3 a classification of assemblies.

The first two classifications are not entirely straightforward. After all, an object can perform a number of functions and certain assemblies can be included in objects with various functions. The third classification concerns functionality: the number of assemblies to be carried out in the series, the dimensions, the mass and the type of construction part. On this basis, cases will be selected using the third classification method as the most appropriate.

Based on the chosen classification method, case studies will be conducted in three domains of the construction sector:

four extensive renovation projects in the residential sector;

one office building project in the utility building sector;

one bridge project in the civil infrastructure sector.

These building objects differ in terms of the desired functionality, the size of the series and the applied systems of construction parts produced off site. Together, the case studies are considered representative of assemblies of systems that can be applied for the development of objects in the built environment. The primary condition in the selection of the objects for the case studies is that the product architecture must be based on the use of construction parts that are produced off site. Furthermore, the selection will partially depend on the possibilities that arise during the execution of the study. Given that the case studies represent typical but distinct objects in the built environment, they will be conducted in parallel. As shown in Figure 1.1, the findings are described on a case by case basis and then for the three domains taken together. 
In order to be able to test the first draft of the design-for-assembly method, the case studies, the applied design-for-assembly method and, if possible, progress with the actual assembly are described. The choice was purposefully made to describe the actual realisation process of the assemblies whenever possible since, in the design phase, assembly processes always proceed exactly according to plan. Here, the goal was to describe the actual progress with an assembly process. In other words: the proof of the pudding is in the eating. Based on the actual assembly process, its progress can be assessed. Based on this assessment, a substantiated opinion can be formed about the accuracy of the applied design method and the assembly design method being tested.

The assessment of the actual progress of an assembly process will be based on the following criteria:

The extent to which the assembly of a system is carried out in accordance with the design.

- The extent to which the construction part was processed on site for the purposes of the assembly.

The extent to which the cycle times of the assembly of similar construction parts differ.

The extent to which the intended quality was realised.

Based on the observations, each case study will result in findings and insights with regard to the applied assembly design method against the first draft of the design rule. The findings and insights acquired will be used to evaluate the first draft of the design-for-assembly method. In addition, the contribution that the first draft of the design-for-assembly method could have made to the realisation of similar types of assemblies is explored.

\section{Phase 4: Redesign and evaluation of the first draft of the design-for-assembly method and its relevance and applicability}

During Phase 4, the first draft of the design-for-assembly method will be redesigned based on the test results from Phase 3. The sub-question to be answered here is as follows:

\section{What adjustments are needed to the first version of the design-for-assembly method for construction and infrastructure projects to accommodate the findings from the series of case studies?}

The insights into desired changes are derived from the multiple case study. To this end, these insights are combined and clarified. The previously formulated specification of the design-for-assembly method will then be redesigned to reflect these insights. The result of this redesign is the final version of the construction assembly design method.

Following this, this construction assembly design method will be validated. This will be done to assess its practical relevance and applicability. For this purpose, three workshops 
with experts in the field of construction and infrastructure site management will be organized on the following themes:

From building to assembly in residential construction.

From building to assembly in non-residential construction.

- From building to assembly for infrastructural projects.

To gather feedback, the experts in the workshops will be asked to complete surveys and to elaborate on the following two statements:

The assembly of the objects in question can be designed.

- The proposed construction assembly design method can be used for the design of these objects.

Furthermore, the experts in the workshops will be asked if the proposed construction assembly design method requires some modification or further clarification. The evaluation findings will be described and commented upon.

\section{Phase 5: Reflection on the scientific and societal contributions of this research}

In this last phase, the following aspects will be considered and discussed:

- The extent to which the goal of the research has been achieved.

- The scientific contribution of the developed construction assembly design method.

- The societal relevance of the developed construction assembly design method.

- The limitations of the developed construction assembly design method.

To conclude this work, recommendations for follow-up research will also be described.

\subsection{Outline of this thesis}

The manner in which the results of the five phases of the research are described in this thesis is shown in Figure 1.1. 


\section{The design of mechanical assemblies}

\section{Contents}

2.1 Introduction

2.2 Design of assemblies

2.3 Control of the geometrical quality

2.4 Modelling assemblies

2.5 Classification of assemblies

2.6 The design process of assemblies

2.7 Designing the assemblies of structures

2.8 Evaluating and improving the design of assemblies

2.9 Designing assembly methods

2.10 Communicating about the assembly of a product

2.11 Field problem, design methods and design rules for designing assemblies

2.12 Conclusions 


\subsection{Introduction}

This chapter seeks to gain insight into how mechanical assemblies are designed. Since mechanically produced artefacts, such as engines, devices, appliances and tools, almost always come about through an assembly process, an in-depth literature study on the design of mechanical assemblies has been conducted. Based on this literature review, an inventory has been made of the design rules, design methods and techniques that are used in the design and realisation of mechanical assemblies that might also prove useful in designing assemblies in the construction and infrastructure sector.

The questions that will be answered in this chapter are the following:

\section{What can be learnt from the design of mechanical assemblies and which technological rules, design methods and techniques can be derived that are also applicable in the construction and infrastructure sector?}

To answer both questions, this chapter first focuses on the general principles of design-for-assembly as described in the literature. In Section 2.1, 'Design of assemblies', definitions that are used in the literature related to assembly are discussed. Since assemblies consist of multiple parts, both the manufacture of the parts and their assembly are relevant. To this end, the product architecture and the relationships between manufacturing, assembly and logistics need to be considered. Section 2.2 explains why it is important for the assembly process to work with parts that have a predefined acceptable dimensional deviation. Section 2.3 describes three possible approaches to model the parts of an assembly and the relationships that have to be realised between them. In Section 2.4, three basic types of assemblies: distributive systems, mechanisms and structures are explained. Section 2.5 describes eight successive phases in the design process for assemblies as distinguished by Ulrich and Eppinger [2008] and three phases distinguished by Whitney [2004]. Based on inputs from Sections 2.4 and 2.5, Section 2.6 divides the process of designing assemblies of structures into seven successive phases. Given their relevance, four of these are described in more detail: the product architecture design phase, the system concept design phase, the nominal design phase and the variation design phase.

Although the assembly design is complete at the end of the variation design phase, it is customary to then evaluate the assembly design with regard to its efficiency. The thinking behind this is that any modification of an assembly in progress should in principle be prevented, and that the efficiency of a design can often be improved. Important parameters influencing efficiency include the number of parts to be assembled and the permitted dimensional deviations. A number of methods have been developed to carry out such evaluations. These are described in Section 2.7. Having evaluated the design of the product to be assembled, the assembly method is designed and finalised. This relates to the actual 
realisation of the assembly. Important aspects to be considered are the number of identical products that need to be assembled and the assembly operations to be performed. Section 2.8 describes the design of assembly methods. After the design of the assembly method has been completed, its implementation must be communicated to third parties. The relevant aspects and the manner of representing the assembly method to be used are described in Section 2.9.

Based on the literature review as described in Sections 2.1- 2.9, a number of design methods and techniques, and two design rules, are derived in Section 2.10 that seem likely to also be applicable when designing assemblies in the construction and infrastructure industry. This chapter ends with conclusions in Section 2.11 where answers are provided to the two initial research questions.

\subsection{Design of assemblies}

The definitions provided for assembly, as an activity involving joining parts together, generally depend on the context in which they are used. For example, Willemse [1997] in his $\mathrm{PhD}$ research used the following definition:

Assembly is the joining and fastening of single, manufactured parts in a specified sequence into a complete product or unit that is part of a product.

This definition applies specifically to the assembly of parts without the use of interfaces, which may be desirable for certain machines such as wafer steppers.

Zha et al. [2001], in "Knowledge-based approach and system for assembly oriented design, Part I: the approach", provide the following definition of assembly:

\section{Assembly is a model from general to detail that reflects certain relationships} on different levels.

This has to be understood as the sum of the relationships between two or more product components, i.e. an assembly is a product made up of more than one component.

In their article, "Designing Assemblies", Whitney et al. [1999] define assembly, as an activity, as follows:

Assembly is the activity in which all the upstream processes of design, engineering, manufacturing and logistics are brought together. 
In this, assembly is considered as the activity that is the result of a design process, and this is generically applicable to all conceivable assemblies. Given that the objective of my research is to derive technological rules for a design process, this review will adopt this general definition of assembly provided by Whitney et al. [1999].

Some products such as spoons, bottles and baseball bats, consist of a single part: the part and the product are one and the same. When designing such products, the only requirement is that the part can be manufactured. The associated process is known as design for manufacturing (DFM). Conversely, washing machines, trams, ships and airplanes are examples of products that consist of multiple parts. Such products require both the manufacture of the parts and their assembly. This requires a combination of design for manufacturing (DFM) and design for assembly (DFA). In combining both aspects, design for production (DFP) relates to that aspect of the design process that is intended to optimally tailor the design to the manufacturing and assembly possibilities. Kals et al. [2009] differentiate between the following design aspects within design for production (DFP):

\section{Design for manufacturing (DFM). \\ Design for assembly (DFA). \\ Design for logistics (DFL).}

These authors also state that - to achieve optimisation - the outcome of the design for production process should be evaluated several times and from multiple angles. Important evaluation aspects include:
the function performance;
the manufacturability;
the maintainability;
the environmental impact.

Next, they explain how these aspects can be evaluated. This is structured on three levels:

\footnotetext{
The product level.

- The subassembly level.

- The part level.
}

The relationships between these three levels are illustrated in Figure 2.1.

In general, the performance of a product is influenced by the production method applied. This also applies to products that are realised through an assembly process. It is therefore desirable to determine the possible influence of a production method on the performance of the end product. Whitney [2004], in what can be considered as the handbook for designing 


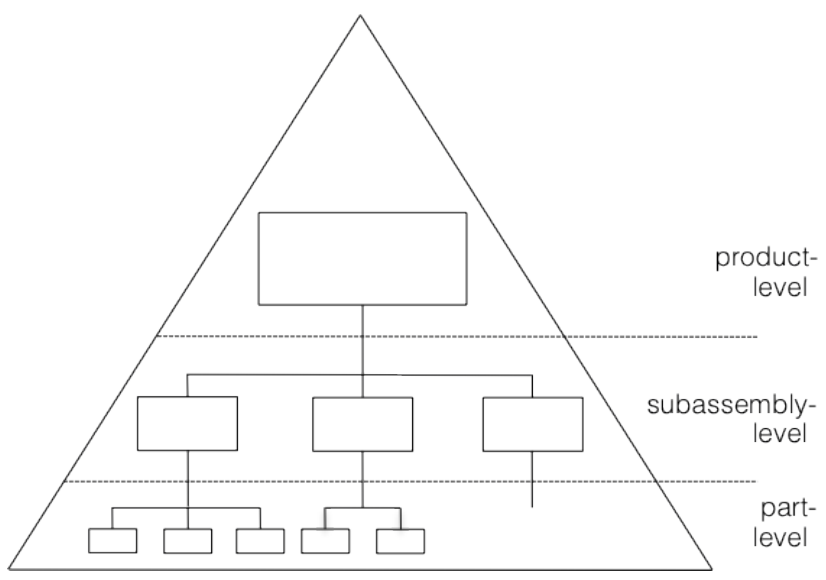

Figure 2.1: Design decisions on three levels [from Kals et al., 2009].

mechanical assemblies, states that, for this process, the structure of the product must be defined, including all the interrelationships between the parts. Then, each of the parts has to be defined including the materials to be used, dimensions, tolerances and surface finishes. He also indicates that the assembly design may open up business opportunities such as product customisation, outsourcing of product parts, a ramp-up in the event of increased demand and the mixing and matching of parts or subassemblies because:

- An appropriate assembly sequence can enable a company to customise a product by changing the final few parts.

- Properly defined subassemblies permit a company to design them independently, to outsource some or all of them as well as to switch between suppliers.

- A well-defined and executed product development process focused on assemblies can make the ramp-up to full production faster because problems can be diagnosed more quickly.

- Properly defined assembly interfaces can allow a company to mix and match parts or subassemblies to create custom products with little or no switching costs.

Whitney's description makes it clear that the design of an assembly not only affects the design of the parts themselves, but also other aspects such as the product structure and the materials that are used. In addition to the manufacturing method, the design must also consider the possible degree of disassembly and the recyclability, maintainability and assemblability. This justifies design for assembly as one of the possible "design for "X" (DFX)". In addition to recognising different foci $(\mathrm{X})$ in the various DFXs, it is also possible to differentiate between topics that are relevant throughout the entire design process and those that only relate to a certain phase of this process. To illustrate this, we will consider the classical design for assembly approach as described by Boothroyd et al. [1983]. The entire 
design process of assemblies is shown in Figure 2.2. Whitney considered the aspects of the product architecture, the first group, as "DFX in the large" and the second group "DFX in the small". The focus in "DFX in the large" is on the functioning of the entire product and on creating value for the end-user. Here, failure mode and effect analysis (FMEA) and Value Analysis (VA) can be used. In "DFX in the small", the focus is on the efficient realisation of the designed product - naturally while retaining its functionality. The concept of design for manufacturing and assembly (DfMA) can be put to good use here. It can be applied to the existing manufacturing and assembly process with the goal of reducing costs. This is achieved by going through one or more design for manufacturing and assembly cycles. However, both approaches are only possible once the initial product architecture has been defined.

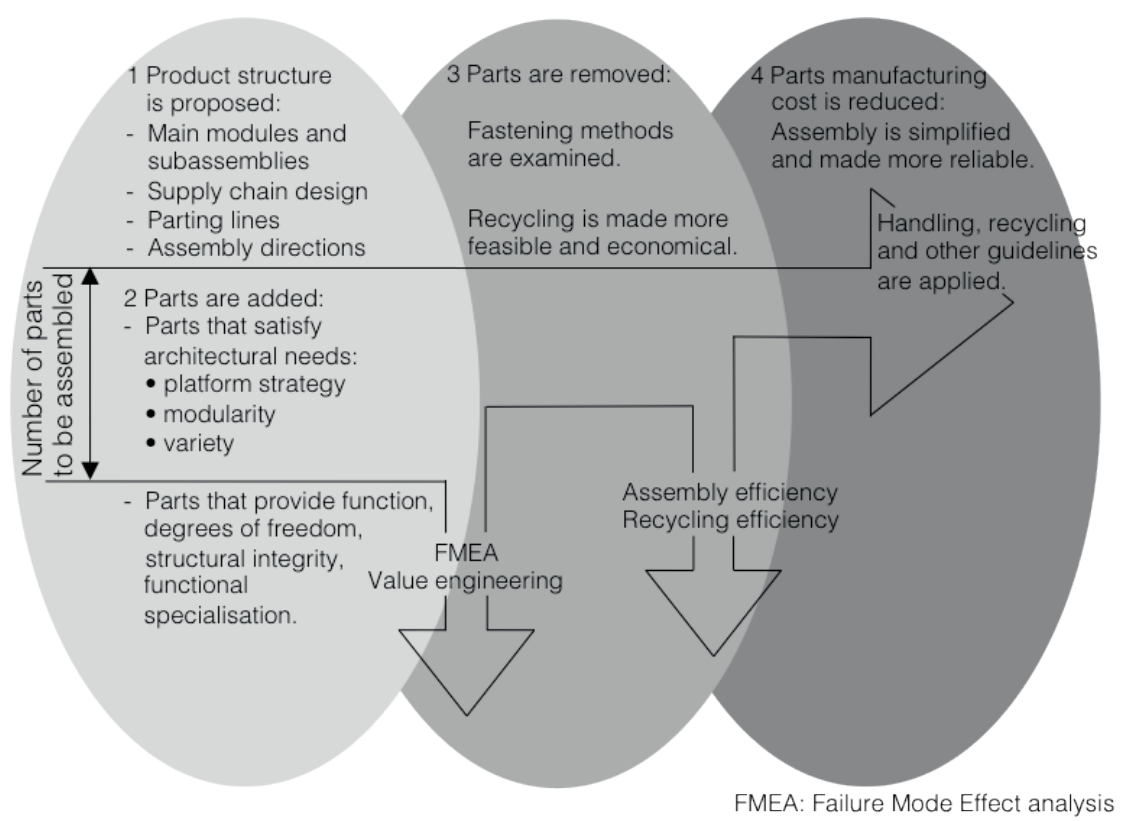

Figure 2.2: The relationship between product architecture, "DFX in the Large" and "DFX in the Small” [based on Whitney, 2004].

Once the product architecture is defined, a structure for the product is proposed and parts are added through a range of mechanisms and for a variety of reasons. Value engineering and "DFX in the large" tend to reduce the number of parts, while "DFX in the small" seeks to lower their cost and make their assembly and eventual disassembly more economic as illustrated in Figure 2.2. 


\subsection{Control of the geometrical quality}

An important characteristic of the components that form a product after going through an assembly process is their dimensional quality, i.e. the degree to which the actual dimensions of a part match those specified in the design. Dimension quality is also an important feature of an assembly in progress. If the dimensions are not properly managed, the assembly process is likely to be disrupted. If parts are only being produced for a single (i.e. one-off) product, these parts have a series size of one. Such parts are referred to as "unique". In order to be able to assemble these parts, the dimensional deviations have to fall within the range specified in the design. If more than one unit of a product is to be assembled, the component parts are not unique; there will be a series of each part. When it comes to assembling series of parts, which may have been produced at different locations, the term dimensional quality refers to the distribution of the dimensional deviations of all notionally identical parts in a series. The spread in the distribution of these dimensional deviations has a significant impact on the assemblability of these parts. If it is too great, a number of the parts of each product will have to be positioned individually. This means that, rather than assembling a series of products, it becomes a process of producing multiple one-off items by manipulating parts that are unique [Womack et al., 2007]. Assembling such parts requires time and expertise and such a production method does not contribute to the desired increase in labour productivity. To safeguard the assemblability of parts, it is therefore important that these parts can be produced with dimensional deviations that fall within a predetermined range.

To Henry Ford, it was clear that it does not benefit a mass production process if parts have to be further processed to facilitate the assembly process. He stated that, in mass production, there are no fitters. Achieving the desired production required serially produced parts that met certain requirements related to their dimensional quality. If a serially produced part was to be produced in multiple locations, this should not compromise the efficiency of the assembly process. In other words, the assembly had to be independent of the producer of the parts. Parts that meet this requirement are labelled "interchangeable".

The expertise necessary for the production of interchangeable parts was developed during the production of weapons [Whitney, 2004]. In 1765, the French army discovered the benefits of producing rifles with interchangeable parts since this made it possible to conduct on-the-fly repairs during combat. By around 1820, it became possible to produce interchangeable parts provided that they were all manufactured at a single location. Ten years later, this became possible for parts made in different locations. By 1850, the interchangeability of parts and mechanisation had advanced sufficiently to be used for the production of commercial products. In order to deliver products that meet a given quality standard, the parts are often required to be interchangeable to facilitate the assembly process. Around 1910, this development made the serial production of Ford automobiles possible. 
During any assembly process, a relationship between different parts is established. This may take the form of a connection or a fitting. In a "fitting" two parts are joined directly together whereas in a "connection" a third intermediate item links the two parts. A fitting can be seen as involving multiple connections. With a connection, there are certain requirements placed on both the part being connected and the object to which it is being connected. In the case of a fitting, there are requirements on the available space for the fitting and the parts to be assembled. On this basis, it is possible to formulate acceptable dimensional deviations for the successful realisation of an assembly. These are known as tolerances and indicate the maximum dimensional deviations that may occur in parts without compromising the assembly process. Determining the acceptable, and estimating the expected, dimensional deviations is part of any assembly process.

The ability to realise a certain dimension within its acceptable dimensional tolerances during manufacturing determines which method of industrial production is appropriate [Kals et al., 2009]. To meet the specified quality requirements in an economically acceptable manner, the manufacturing process of the part in question must be demonstrably managable. The geometrical quality realised through a manufacturing process can be demonstrated by:

Testing the geometry with gauges.

Measuring the geometry.

Setting a minimum value for the reliability of the manufacturing process.

\section{Testing the geometry with gauges}

To test a geometry with gauges requires examples of the part to be evaluated: one example with the minimum dimensions and one with the maximum dimensions. Conducting a trial assembly is also part of this method of testing geometric quality.

\section{Measuring the geometry}

When measuring the geometry of a part, a measurement protocol is used to determine whether it meets the set requirements. The basic assumption is that dimensional deviations will occur during a production process and, before determining whether a part meets the requirements, tolerances have to be defined. In order to communicate about the measuring and evaluating of parts, procedures for the dimensioning and measurement of parts will have to be developed. The dimensioning of a part to be produced is also referred to as "geometric dimensioning and tolerancing" (GD\&T).

In order to apply geometric dimensioning and tolerancing, the dimensions of a part must be determined in relation to a reference coordinate system so that reproducible measurements can be made. Furthermore, it is important that the measurements can be compared to the desired dimensions of the part in a standardised manner [Breedveld, 2011]. 
In order to evaluate the dimensions of parts, rules for dimensioning are necessary. There are two basic principles that should both be met [Breedveld, 2011]:

Every dimension of a product must be derivable from the design drawing ${ }^{1}$.

Every dimension of a product should only be derivable from the design drawing in one way.

If a dimension cannot be derived, the product cannot be produced. Double dimensioning, in the sense that a distance can be determined in more than one way should be avoided for industrially produced parts. This has to do with ensuring tolerances are clear and met, as shown in Figures 2.3 and 2.4. Given that dimensional deviations will always occur, the dimensioning as shown in Figure 2.3 is incorrect because it implies the absence of dimensional deviations and; because these will always occur, the indicated dimensioning cannot be applied in a production process.

This problem is resolved by adding tolerances to the listed dimensions. The first approach (chain dimensioning), shown on the left of Figure 2.4, is inconsistent since the sum of the maximum subdimensions is greater than the maximum total dimension (as shown in Figure 2.4 right). A useable and realisable form of dimensioning (parallel dimensioning) is shown in Figure 2.5.

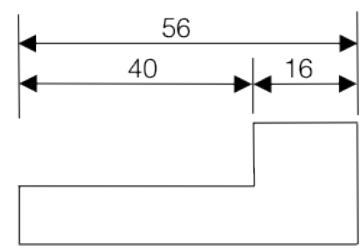

Figure 2.3: Incorrect: Double dimensioning [from Breedveld, 2011].

Chain dimensioning, as shown in figure 2.4 is unsuitable because it implies that the tolerance of the overall product consists of the sum of the sub-tolerances which is rarely the case. Instead, parallel dimensioning is usually applied in which the position of every point is dimensioned based on a defined reference frame, which makes it independent from any other dimensional deviations.

1 Meaning that it can be determined from dimensions provided on the drawing. Measuring distances off the design drawing is not allowed. 


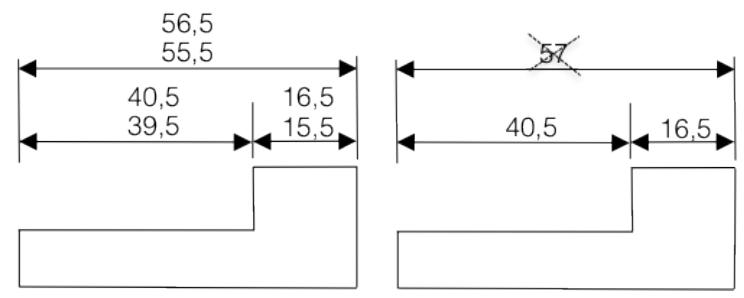

Figure 2.4: The effects of chain dimensioning [from Breedveld, 2011].

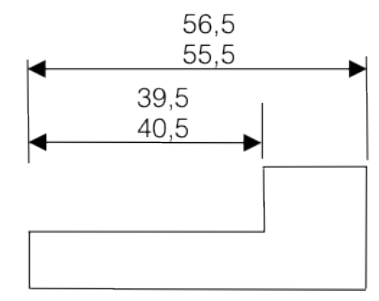

Figure 2.5: A proper way of dimensioning: Parallel dimensioning [from Breedveld, 2011].

The principles of geometric dimensioning and tolerancing apply not only when dimensioning the individual parts but also when dimensioning assemblies. The position of a part of an assembly should be clear. This is only possible if its position follows from the position of an already assembled part with its own tolerances or if it is indicated with a unique position dimensioned in relation to a defined reference frame.

\section{Using a minimum value for the reliability of the production process}

Evaluating the geometry in terms of a minimum value for the reliability of the production process uses the concept known as process feasibility. Process feasibility is used to express the suitability of a process for the realisation of a product [Kals et al., 2009]. It defines the acceptable geometric deviation as a stochastic variable, indicated using the so-called $\mathrm{C}_{\mathrm{p}}$ value. This value represents the ratio between the width of the tolerance field, the total acceptable dimensional deviation, and six times the standard deviation. With a $\mathrm{C}_{\mathrm{p}}$ value of 1 , the probability that a product, manufactured using a given process, meets the set requirements is $99.73 \%$.

The process feasibility value, $\mathrm{C}_{\mathrm{p}}$, can be used to estimate the reliability of a so-called clean centring. If this does not apply, the $\mathrm{C}_{\mathrm{p}}$ value is determined for the left and right tolerance fields and the smallest dimension is used. The resulting process feasibility is indicated by the $\mathrm{C}_{\mathrm{pk}}$ value. Indications of the relationship between this $\mathrm{C}_{\mathrm{pk}}$ value and the likelihood of a qualitative issue are shown in Figure 2.6. The qualitative assessment, based on the $\mathrm{C}_{\mathrm{pk}}$ value, provides an indication of quality in the sense of likely dimensional problems arising. 
Qualitative assessment of probability of a qualitative issue

\begin{tabular}{llr}
\hline $\begin{array}{l}\text { Qualitative } \\
\text { assessment }\end{array}$ & Criteria & $C_{p k}$ \\
\hline 1 & Low probability; almost never happens & $C_{p k}>1,33$ \\
4 & Rare, but a risk & $1<C_{p k}<1,33$ \\
7 & Likely to happen & $0,5<C_{p k}<1,0$ \\
10 & Almost certain to happen & $C_{p k}<0,5$
\end{tabular}

Figure 2.6: The relationship between the process feasibility $C_{p k}$ and the likelihood of a qualitative issue [from Thornton, 2004].

Given that reducing the acceptable dimensional deviations of a process always leads to an increase in costs, the acceptable process feasibility is based on a balancing of costs and benefits, which can be described using the so-called quality loss function [Yang, 2003]. The quality loss function describes the relationship between the costs and benefits associated with an increase or decrease in quality. One possible benefit is a reduction in the loss of value experienced by the end-user. This can be expressed as the costs associated with replacing the devices of disappointed end-users, but also as the devaluation of the brand. Improving the management of an assembly process may increase its costs, but it can also lead to savings on the costs of interfaces, making it the preferable option.

Determining tolerances is one of the most important aspects when designing an assembly. The way in which this can be done is described in more detail in Section 2.6. In mechanical engineering, a system of fittings and tolerances has been developed to evaluate the interchangeability of the parts in an assembly: the so-called International Organization for Standardization (ISO) fittings system. Based on the desired functionality of two interacting parts, a type of fitting is chosen. This is the combination of a certain fit, the dimensional difference between the "hole" and the "shaft" and the tolerances in the dimensions of the "aperture" and the "axis" [Kals et al., 2009]. By utilising the ISO fittings system and defining requirements for the process feasibility during product design, fitting problems during the design of machines can be controlled.

\subsection{Modelling assemblies}

When designing the assembly of products, modelling the parts of the assembly and the relationships that have to be realised between them is necessary to evaluate and/or simulate the design. This model should include the effects of variations in the geometric qualities of the parts and variations in their locations that may occur during assembly. One method of representation is a mathematical model of the assembly. A number of these have been described by Whitney [2004]. 
Whitney suggests three modelling methods:

Positioning objects in the world coordinate frame.

Describing the relationships between contact surfaces (surface-constrained model).

Describing the objects and their connections (connective models).

Whitney describes these methods with the goal of being able to describe an assembly as a chain of frames. For this purpose, it is assumed that the parts will not be deformed during the assembly process - they are seen as rigid bodies. The positions of these bodies are derived from the interfaces that exist between them.

\section{The world coordinate frame}

In this approach, the parts are positioned in a local coordinate system, which can be chosen in such a way that all the coordinates of the parts have positive values. Figure 2.7 shows two situations ( $\mathrm{a}$ and $\mathrm{b}$ ) for three objects (A, B and C). Situation 'a' concerns the design situation, while situation 'b' represents a situation that may occur during assembly. In situation ' $\mathrm{b}$ ', object $\mathrm{B}$ is located in a position that differs from the design. As a result, objects $\mathrm{A}$ and $B$ interfere with each other, while objects $B$ and $C$ are no longer connected. As such, this modelling method is unsuited to representing the assembly as a chain of frames.

(a)

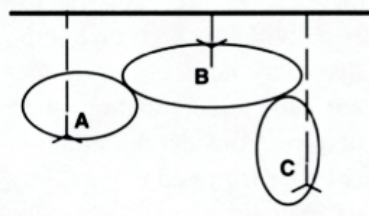

(b)

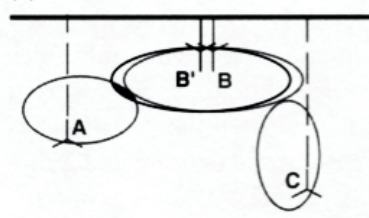

An Assembly of Three Parts in a World Coordinate Frame:

(a) The parts are in their nominal locations.

(b) Part B is in the wrong location. It interferes with part $A$ and no longer touches part $C$.

Figure 2.7: World Coordinate Frame [Whitney, 2004].

\section{The surface-constrained model}

This model type describes the relationships between the contact surfaces of the parts. For example: two sides of two parts could be parallel or perpendicular to each other. This makes it possible to a certain extent to accommodate geometric deviations in parts. This method of representation can be used for those assemblies that involve part-to-part relationships that are realised without interfaces, as described by Net [1998]. 


\section{Connective models}

This form of representation is based on an assembly of parts and of so-called "features". Each object has a "feature" at the location of a connection to another objects". The connection between the objects is realised by connecting the "features". These features could represent the mechanical behaviour of this connection with its six degrees of freedom. Figure 2.8 shows an assembly that consists of parts and features. With such a representation, with parts and "features", an assembly can be described as a chain of frames. This is also known as a connective model.

(a)

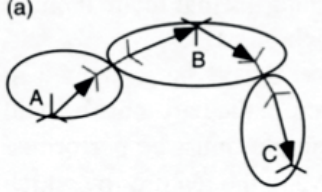

(b)

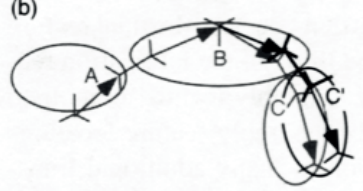

Three Parts joined by a Connective Assembly Model:

(a) The nominal situation.

(b) A feature on part B is misoriented and mispositioned, causing part $\mathrm{C}$ to be in the wrong position

Figure 2.8: Connective models [Whitney, 2004].

Since the connective model representation corresponds to the actual behaviour of an mechanical assembly, Whitney defines the resulting assembly design as follows:

An assembly is a chain of coordinate frames on parts designed to achieve certain dimensional relationships, called key characteristics between some of the parts or between features on those parts.

\subsection{Classification of assemblies}

Assemblies come in all shapes and sizes. For example, staplers, phones, bicycles, cars, wind turbines and ships are all assembled. The design process shown in Figure 2.2 can be used for all these products. When it comes to designing assemblies, the products will differ based on the design intent of the assembly. This may concern, for example, the acceptable variation in properties, the lead time of the assembly, the available space, the required degree of disassembly or the recyclability of the parts. These properties are quantified using characteristic properties, or key characteristics, which are defined as follows: 
A key characteristic is a quantifiable feature of a product or its assemblies, parts, or process whose expected variation from target has an unacceptable impact on the cost, performance, or safety of the product [Thornton, 2004].

In order to successfully design an assembly, it is important to identify as early in the process as possible the key characteristics related to the design intent and describe them in both qualitative and quantitative manners. The set of key characteristics must match the assembly's design intent [Whitney, 2004].

Based on differences in design intent, Whitney describes three types of assemblies:

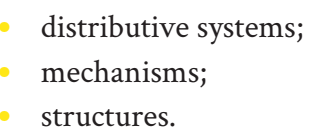

These types of assemblies are shown in Figure 2.9. Each type has specific key characteristics and the assembly models used are tailored accordingly. Each of the assemblies listed in the figure belong to a specific production system.

\section{Distributive systems}

The design intent of distributive systems is to create connections along which distribution can take place. Examples include ventilation systems and sewers. The key characteristics of a distributive system are its reliability, maximum flow resistance and capacity. For these systems, standard components such as pipes, elbow joints, connectors, wiring, clamps and pumps are often used. The assembly model of a distributive system may consist of an overview of the system and the standard components to be used.

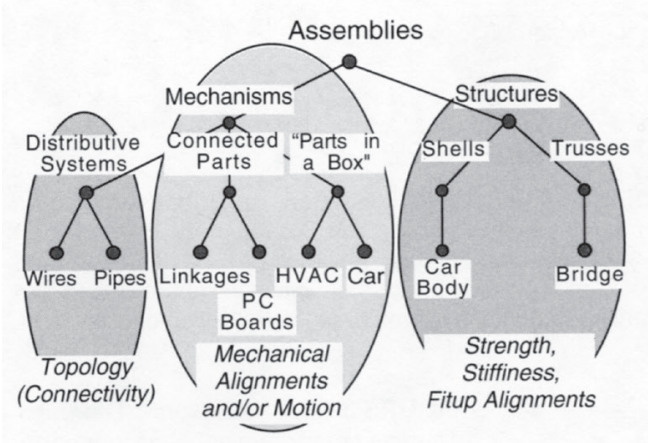

Figure 2.9: A classification of assemblies [Whitney, 2004]. 


\section{Mechanisms}

The "mechanisms" group subdivides into "connected parts" and "parts in a box" that both have to meet certain functional requirements. Examples include wind turbines and wafer steppers. These are assembled from parts designed specifically for a specific assembly. To realise the design intent, it is important that the geometry of the parts meets certain strict conditions. The risk of parts being switched during assembly is small, because they differ significantly from each other. With "parts in a box", the design intent is to provide a certain functionality in a limited space. To save space, interfaces are avoided and, as a result, the acceptable dimensional deviations of the parts are often minute.

\section{Structures}

The "structures" type covers products whose key characteristics can be expressed as a geometric quality. Examples include car bodies, ships and bridges. Examples of key characteristics include the smoothness of the ship's hull, the dimensions of a part of a bridge and the bridge as a whole, and the consistent dimensions of the seams in the doors and hoods of cars. An example of the key characteristics of a car body product is shown in Figure 2.10. The key characteristic $(\mathrm{KC})$ of interest to be achieved is equal hood spacing between the outer fenders. In the figure, heavy lines link the main parts, the subassemblies and the necessary assembly features. Also shown are some of the parts that make up the subassemblies. These parts must also be made and assembled correctly in order that the key characteristics are met. The dashed lines show organisational boundaries between the producer and its suppliers of the parts, subassemblies, and important assembly and checking fixtures.

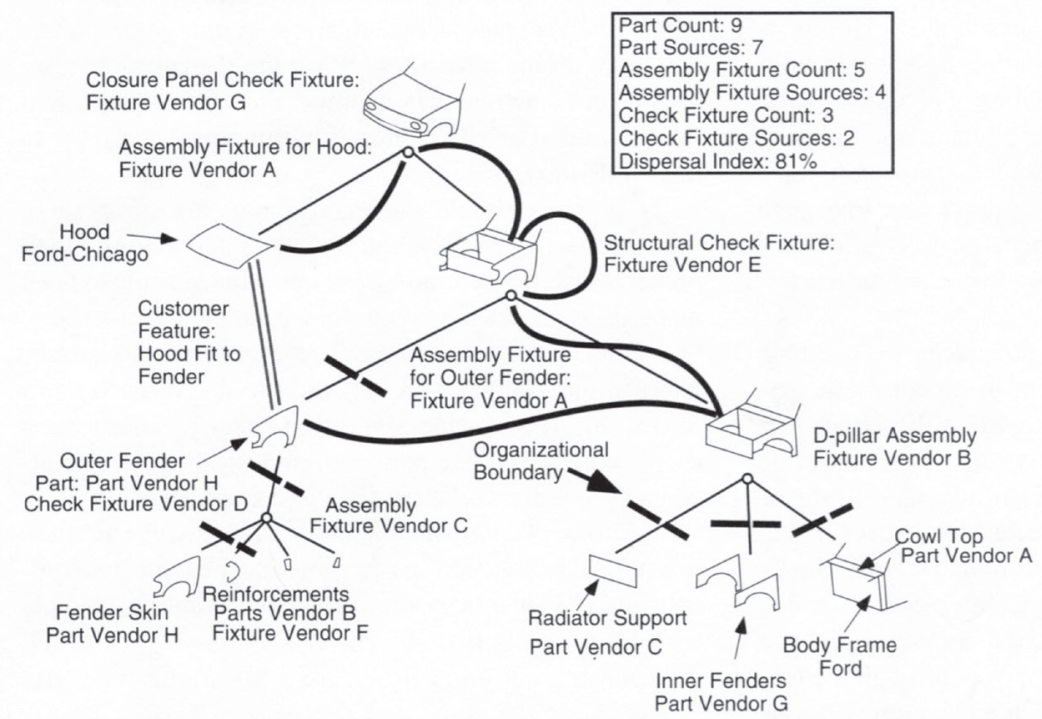

Figure 2.10: Key characteristics (KCs) of a car body [Whitney, 2004]. 
This $\mathrm{PhD}$ thesis addresses the assembly of objects in the built environment. The key characteristics of such objects are somewhat similar to those of car bodies and bridges. For example, the seams in an assembled building façade are comparable to those in a car body, and bridges also feature in the built environment. Given this commonality, the main focus in the following sections will be on the design of assemblies that fall within the "structures" category. Thus, no consideration has been given to the design of assemblies belonging to the distributive systems ${ }^{1}$ and mechanisms classes.

\subsection{The design process of assemblies}

The process of designing assemblies can be characterised as "top-down design". This process must result in a product that meets the wishes of the end-user and any "design for $\mathrm{X}$ " items. In addition, it must also result in acceptable costs. In terms of the latter point, it is primarily important to manage the costs associated with dealing with the variations that affect the key characteristics of the assembled product. This is addressed in the literature under the heading "variation risk management" [Thornton, 2004].

Thornton describes the application of "variation risk management" based on the design process as outlined by Ulrich and Eppinger [2008]. This process is divided into the following phases:

\section{Requirements development}

The voice of the customer is understood and translated into requirements.

\section{Concept development}

Technical solutions are developed and evaluated to determine the best concept.

\section{Product architecture design}

The basic architecture of the product is developed, including how it is to be subdivided into major systems and the interfaces between systems.

\section{Systems concept design}

The concepts and approaches for the design of the major systems are developed.

\section{Detail design}

Detailed design drawings are made, and manufacturing processes are selected or developed for the systems and the overall product. Dimensions and tolerances for all

1 This includes mechanical and electrical installations as used in objects in the built environment. 
parts and manufacturing processes are finalised.

\section{Product testing and refinement}

The individual systems are reintegrated into a prototype (usually a physical prototype) to evaluate the product performance as a whole.

\section{Transition to production}

The product is manufactured in small quantities on production equipment.

\section{Production}

During full-scale production, teams should work to continually reduce cost and improve quality. Although a basic principle is that a developed product can be tested prior to production, this will often not be the case when designing structures. This will often be because constructions are often a one-off product and so extensive that an entire test assembly would be a very expensive investment. In effect, this would mean that the construction in question would have to be assembled twice, once to validate the design of the assembly, and again to realise the construction. The decision is therefore often made to only perform an assembly test for some critical parts of the construction.

Whitney [2004] also described the design of assemblies and identified the following phases:

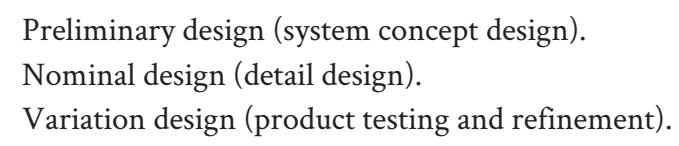

Of these three phases, preliminary design is similar to the systems concept design (phase 4 in Thornton's process above). During the nominal design phase, the dimensioning of the parts is addressed. Thornton's [2004] phasing structure does not mention the dimensioning of the systems to be used. Given that this is an important activity during the design of an assembled structure, the nominal design phase will be considered as a distinct process step in this $\mathrm{PhD}$ research. During the variation design phase, the effects of geometric deviations are evaluated, which is also very relevant in the design of structures.

Thornton [2004] advocates the use of concurrent engineering to conduct "variation risk management" during the design process,. Whether third parties are brought in during the design of an assembly should therefore depend on the contribution they can make to managing the costs of geometric variations. If the expected contribution is significant, the party in question could take full part in the design process since this is needed to manage the costs resulting from variations in the parts or the assembly. 


\subsection{Designing the assemblies of structures}

Based on the considerations explained in Section 2.5, the design process of assembled structures can be seen in terms of the following phases:

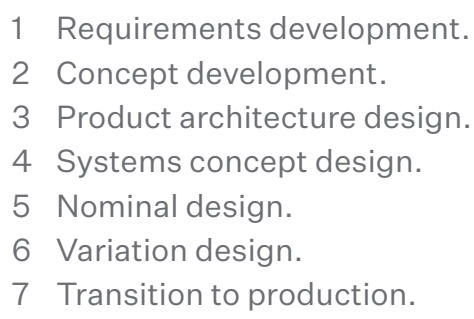

Phases 3 to 6, i.e. product architecture design, systems concept design, nominal design and variation design, are relevant to the actual design of the assembly and are thus described in more detail below.

\section{Phase 3: Product architecture design}

Product architecture is about the relationships between the overall product, its parts and its subassemblies: how those items are arranged in space and how they work together to provide the product's functions [Whitney, 2004].

Ulrich [1992] defines the architecture of a product as covering the:

Arrangement of functional elements.

Mapping of functional elements to physical components.

Specifications of the interfaces between interacting physical components.

To illustrate this, Ulrich uses the example of two variants of trailer as shown in Figure 2.11.

The upper half of Figure 2.11 shows a direct one-to-one connection between the functional elements of the product and its components. This is termed a "modular" product architecture and the product consists of an assembly of components that make up the product through their interfaces. The lower half of Figure 2.11 shows a product architecture in which multiple components are involved in the realisation of a single function. This is known as an "integral" product architecture. The upper and lower halves of the trailer have slots cut in them and the strip of material remaining between the two slots acts as a leaf spring. The cargo is hung by straps from the two springs in the upper half. The axle is attached to the spring in the lower half. Covers (shown shaded) are attached over the slots. The nose piece component contains the trailer hitch. 


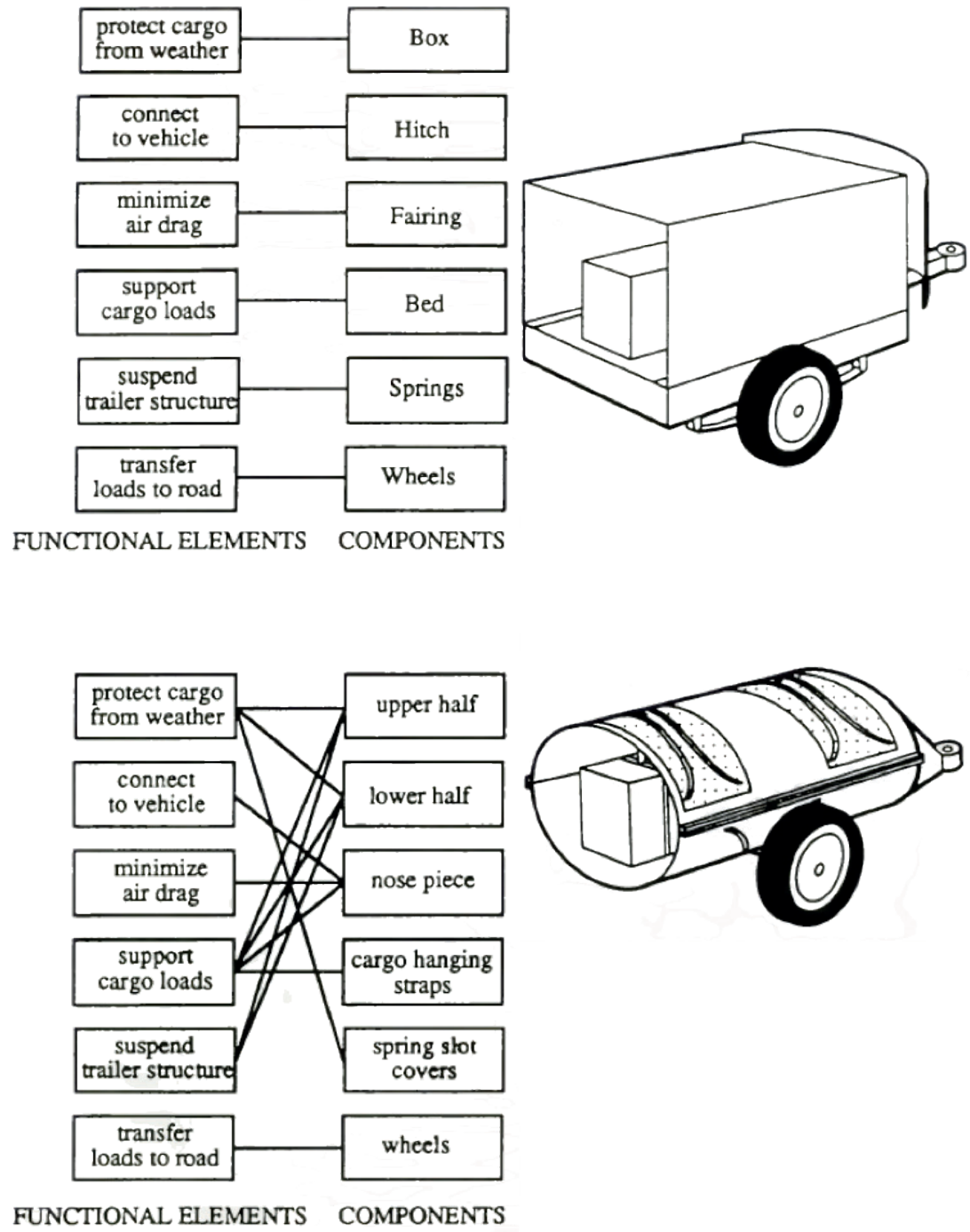

Figure 2.11: Mapping functional elements to physical components [Ulrich, 1992].

Turning to the interfaces that realise the decoupling, Ulrich differentiates between the following types of interfaces:

decoupled interfaces;

coupled interfaces. 
With a "de-coupled interface", a change made to one of the connected components does not affect the interface. For a "coupled" interface, a change to a component requires a change in the interface. This distinction is relevant when it comes to designing assemblies. Figure 2.12 shows examples of both types of interfaces. The coupled interface requires an ability to change the box whenever a change in the thickness of the bed is made to accommodate the increased structural loading.
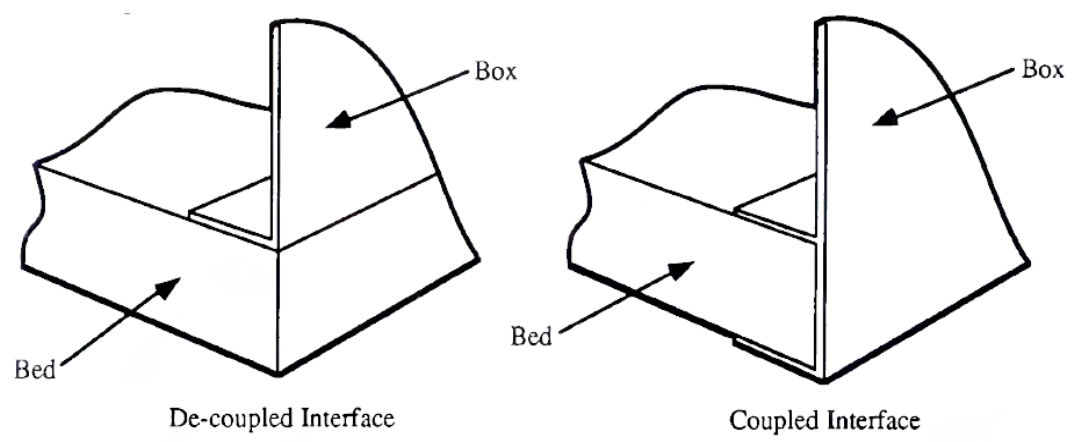

Figure 2.12: Typology of interfaces [Ulrich, 1992].

Ulrich explains his architecture concept with the help of different types of product architectures. Further detailing the modular approach results in the following types:

Type

Characteristics

Slot

All interfaces are different. A specific interface is required for every connection between components.

Bus All components are connected to a single component. This connection is realised with a single interface type.

Sectional

The connection between all components is realised with a single interface type.

These three types are modular, and the component interfaces are de-coupled. These types differ from each other in terms of how the interactions between the components are organised. Figure 2.13 shows Ulrich's classification, including integral, being applied to a number of different products. 

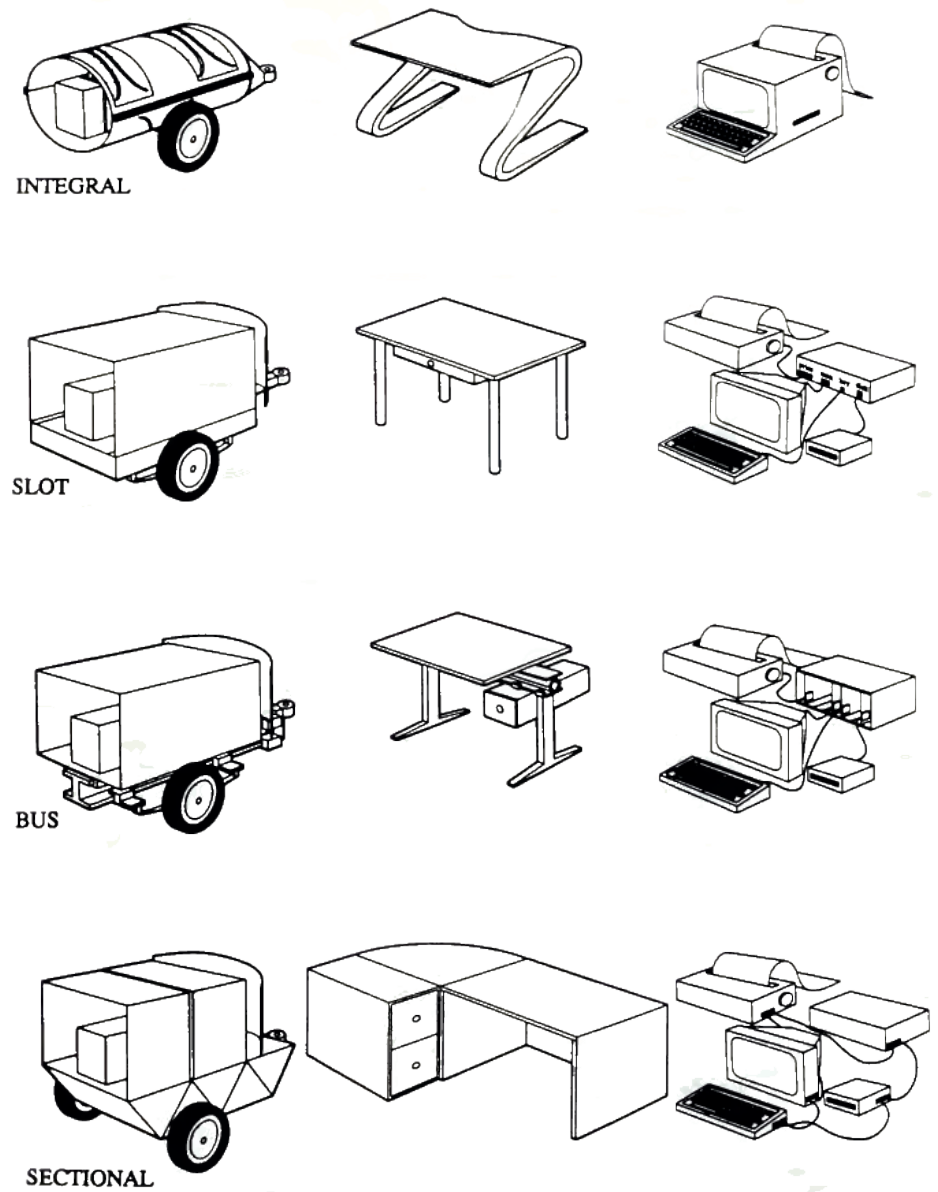

Figure 2.13: Examples of types of product architecture [Ulrich, 1992].

As described in Section 2.1, the design of the assembly, and therefore the product architecture, has a large impact on the producer's business operations. When developing a product for a market, the question is which product architecture is best suited for this purpose. Ulrich states that no standardised approach can be formulated to answer this question: it depends, among other things, on the market, the technology and the organisational structure of the firm. However, Baldwin and Clark [2000], and later Eppinger et al. [2012] and AlGeddawy et al. [2017] and others, have succeeded in describing the development of a product architecture.

Eppinger et al. [2012] describe the development of a product architecture through the application of a design structure matrix (DSM). The principle of a design structure matrix 
is shown in Figure 2.14 and this matrix is used to represent the relationships between the parts of an assembly. Using an "X", the matrix shown here indicates whether the parts listed in the columns affect the parts listed in the rows. Given that this influence can only have one of two values, this is known as a binary representation. With the help of such a design structure matrix, the effects of combining parts in an assembly can be evaluated. Such combinations of modular parts result in integral components that can have a positive impact on the realisation.

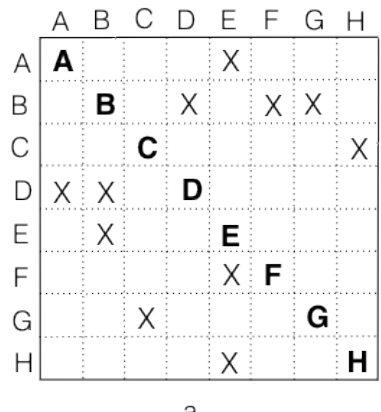

a

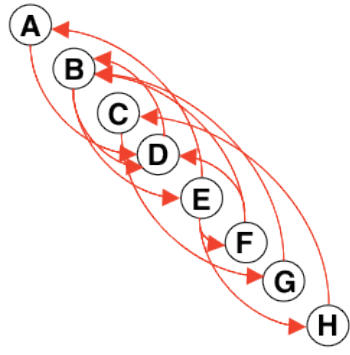

b

Figure 2.14: Representation of the product architecture using a design structure matrix (a) and in the form of a digraph (b) [from Eppinger, 2012].

AlGeddawy et al. [2017] developed a method to optimise the design of an assembly of modular products by introducing a variable that represents the complexity of an assembly of parts. This makes it possible to calculate the so-called product assembly complexity index for each assembly route. This index represents the complexity of a given assembly order.

If a certain market can be served with products in which a number of components have been used to realise certain functions, these products form a so-called product family. It is also possible to develop an integrated product to perform a number of subfunctions of products. Such a product is known as a platform. By developing platforms, the number of parts to be assembled can be reduced.

Fine $[1998,2000]$ outlined a product architecture concept in order to classify and design supply chains. Fine views the availability of a modular product architecture as the foundation for ongoing development within the industry in question. A lack of such an architecture affects the design of the supply chain in terms of the geographic, organisational, cultural and digital proximity of possible suppliers. Digital proximity relates to the use of software for various activities including communication and design. Fine supports this with examples from the bicycle, PC, automotive and aviation industries. 


\section{Phase 4: System concept design}

Whitney [2004] explains that the information needed for the design and evaluation of an assembly is collected during the system concept design phase. This involves an overview of the parts, the general dimensions, the degrees of freedom, the assembly order and the key characteristics to be realised with the assembly. In the case of structures, Whitney views this information as concerning the dimensional relationships that are important to the value of the final product.

Whitney uses a so-called "datum flow chain" (DFC) to describe the positioning and degrees of freedom of the parts of an assembly. The various parts are represented by a dot. A connection between parts is represented with a line. The collection of "dots" and "lines" is known as a "liaison diagram". If a part is involved in realising a key characteristic, this line becomes an arrow. To clarify the connections between the parts, the degrees of freedom that are constrained are shown by said arrows. A "datum flow chain" is then produced based on the "liaison diagram". Figure 2.15 shows a liaison diagram (left) and the associated datum flow chain (right). The arrows in a datum flow chain also represent the order of assembling the parts. As a result, datum flow chains can be used to determine the dimensional deviations that may occur during an assembly. The liaison diagram shows which parts are connected to which. The datum flow chain shows how they are connected and constrained. Each line ( $\operatorname{arc}$ ) is labelled with the degrees of freedom it constrains or the names of those degrees of freedom in any convenient coordinate system. This datum flow chain is intended to deliver a key characteristic $(\mathrm{KC})$ between part $\mathrm{A}$ and part $\mathrm{D}$. The $\mathrm{KC}$ is indicated by the double line next to the arrow. No information is given regarding which degrees of freedom are important in this KC.

A

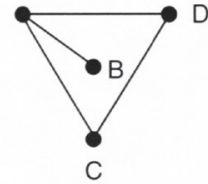

A

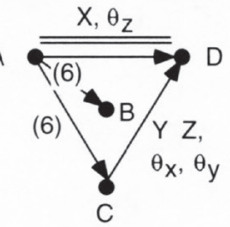

Figure 2.15: A Liaison Diagram and a Datum Flow Chain [Whitney, 2004].

In the datum flow chain shown (Figure 2.15 right), it is clear that part A forms the foundation of the assembly by the fact that arrows only point away from part A. Further, the positions of $\mathrm{B}$ and $\mathrm{C}$ are derived from $\mathrm{A}$, and the position of $\mathrm{D}$ from $\mathrm{A}$ and $\mathrm{C}$. The datum flow chain also indicates the degrees of freedom that are constrained by a "part-part relationship”. The A-B relationship constrains six (6) degrees of freedom. In other words, part $B$ is constrained such that it is in a stable (fixed) position. 
Provided a datum flow chain has been produced for an assembly, the following information is available:

The expected performances of the assembly.

Measurable quantities giving the expected performances.

- The position of the parts to be assembled, derived from the parts or fixtures that have already been assembled.

Figure 2.10 shows the key characteristics of a part of a car body. Figure 2.16 shows the corresponding liaison diagram based on this design.

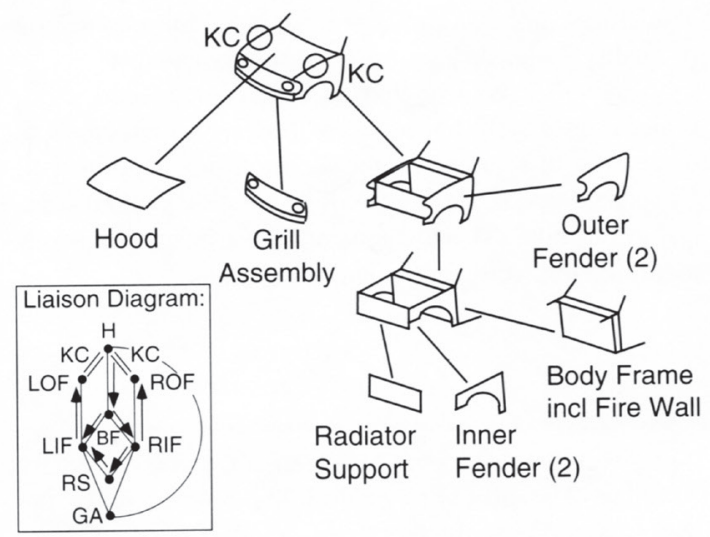

Figure 2.16: A liaison diagram of part of the assembly of a car body and the key characteristics of a car body that are to be realised [Whitney, 2004].

The diagram at the top shows the assembled parts of the front end of a car. The key characteristics (marked by circles) require equal size gaps between the car hood $(\mathrm{H})$ and the left and right outer fenders (LOF and ROF). Note that these parts are not assembled directly to each other. The liaison diagram depicts the chain of parts leading from one side of the gap to the other. Each part is represented in the liaison diagram (bottom left) by a dot and each part-to-part relationship by a line. The two key characteristics are represented by parallel lines. The arrows leading from the hood to the two outer fenders pass through the intermediate parts in the chain. At the ends of the chain are the key characteristics. The flow chain shows that the body frame (BF) forms the foundation of this assembly. It also shows that a key characteristic has to be realised between the hood and the grill assembly (GA), and that these parts are not directly connected.

The presentation of an assembly using liaison diagrams and datum flow chains is based on Whitney's definition of an assembly and the principle that the assembly is not affected by any deformation of the parts (ridgid bodies). Although Whitney does not state it explicitly, 
his definition of an assembly, and the representation method based upon it, particularly apply to mechanical assemblies that consist of parts created in of a single production system.

Table 2.1: Design for assembly rules and stakeholders involved [from Demoly et al. 2009].

\begin{tabular}{|c|c|c|c|c|c|c|}
\hline no. & $\begin{array}{l}\text { design for assembly } \\
\text { rules }\end{array}$ & $\begin{array}{l}\text { product } \\
\text { manager }\end{array}$ & designer & $\begin{array}{l}\text { process } \\
\text { engineer }\end{array}$ & $\begin{array}{l}\text { assembly } \\
\text { planner }\end{array}$ & $\begin{array}{l}\text { ergono- } \\
\text { mist }\end{array}$ \\
\hline \multicolumn{7}{|c|}{ minimize product complexity } \\
\hline 1 & $\begin{array}{l}\text { reduce part count with } \\
\text { multifunctional parts }\end{array}$ & & action & & & \\
\hline 2 & eliminate fasteners & & action & action & & \\
\hline \multicolumn{7}{|c|}{ structure the product } \\
\hline 3 & $\begin{array}{l}\text { integral versus modular } \\
\text { architecture }\end{array}$ & action & & & action & \\
\hline 4 & $\begin{array}{l}\text { allow functional subassemblies to } \\
\text { be tested independently }\end{array}$ & action & & & action & \\
\hline 5 & $\begin{array}{l}\text { minimize part/subassembly } \\
\text { weight }\end{array}$ & action & action & & action & action \\
\hline 6 & use stable subassemblies & action & action & & action & action \\
\hline 7 & $\begin{array}{l}\text { ensure that the product has a } \\
\text { suitable base part on which the } \\
\text { assembly is built }\end{array}$ & action & action & & action & \\
\hline \multicolumn{7}{|c|}{ simplify assembly operations } \\
\hline 8 & facilitate handling & & action & & & action \\
\hline 9 & $\begin{array}{l}\text { facilitate insertion (self-aligning } \\
\text { and self-location) }\end{array}$ & & action & & & action \\
\hline 10 & minimize assembly directions & action & & & action & action \\
\hline 11 & use symmetric parts & & action & & & action \\
\hline 12 & provide orientation features & & action & & & action \\
\hline 13 & insert pats from above & & action & & & action \\
\hline 14 & $\begin{array}{l}\text { ensure accessibility/vision for } \\
\text { insertion and fixturing tools or } \\
\text { fingers }\end{array}$ & & action & action & & action \\
\hline 15 & $\begin{array}{l}\text { minimize use of flexible, small } \\
\text { and sharp parts }\end{array}$ & & action & & & action \\
\hline 16 & check materials compatibility & & action & action & & \\
\hline 17 & $\begin{array}{l}\text { eliminate adjustments } \\
\text { (through tolerancing) }\end{array}$ & & action & action & action & \\
\hline 18 & use kinematics design principles & action & action & & & \\
\hline 19 & $\begin{array}{l}\text { choose the correct joining } \\
\text { method }\end{array}$ & action & action & action & action & \\
\hline \multicolumn{7}{|c|}{ standard design } \\
\hline 20 & $\begin{array}{l}\text { standardize parts (to reduce } \\
\text { part type) }\end{array}$ & & action & & & \\
\hline 21 & use standard materials & & action & action & & \\
\hline 22 & use standard joining processes & & action & action & & \\
\hline
\end{tabular}


When it comes to designing assemblies, Baxter et al. [2007], Sundin et al. [2016] and Demoly et al. [2009] advocate the reuse of design information from previously realised products. Baxter et al. describe a method based on making information about the previous design available on both the process and the product. This can be done using a parameterised product model. Sundin et al. describe the development of a design for manufacturing and assembly methodology for a new material application in the aviation sector. To this end, methods and tools were developed in the form of checklists, manuals and training materials to facilitate design for manufacturing and assembly. Demoly et al. [2009] call for the use of "assembly-oriented design" in the early stages of the design process. Assembly-oriented design can be seen as a proactive tool to be used when designing assemblies. It has been operationalised by developing design-for-assembly rules for certain aspects of the design, indicating which rules are relevant for which stakeholder. An example is shown in Table 2.1. This can help avoid the need for redesigns during later stages of the process.

\section{Phase 5: Nominal design}

The basic principle in this stage is that there are no dimensional deviations in the parts of the assembly, and that all parts can be positioned in exactly the right place. In other words, this is a theoretical situation. Using these principles, the designer can draw up a plan for the realisation of the key characteristics. This involves determining the nominal location of the parts in space in such a way that the relevant key characteristics are realised. The designer has to do the following:

- Systematically relate the identified key characteristics to important datums on subassemblies, parts and fixtures on the various assembly levels - from parts to subassemblies to the final assembly.

- Design consistent dimension and tolerance relationships or locating schemes among elements of the assembly so as to deliver these key characteristics.

- Identify those assembly procedures that best deliver the key characteristics repeatedly without driving the cost too high.

The realisation of these criteria results in the following information:

Location responsibility: Which parts or fixtures determine the location of which other parts.

Constraints: Which degrees of freedom of a part are constrained by which surfaces on which features of which other parts or fixtures, including checking for inappropriate over- or under-constraints. 
Upon completion of the nominal design, the following will have been incorporated:

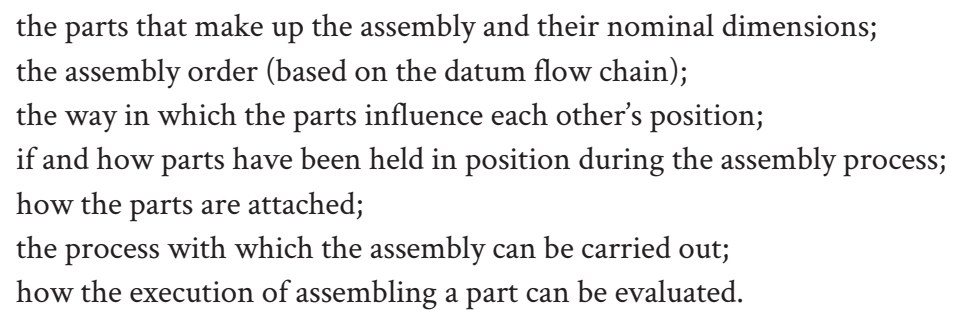

\section{Phase 6: Variation Design}

The nominal design in phase 5 is based on zero variation in the dimensions of parts and the assembly. Furthermore, a certain assembly process is assumed. Given that an assembly process has to be manageable, the realisability of the nominal design must be tested. Whitney describes the following steps:

- Allocate tolerances from each key characteristic (KC) to the mating parts in its datum flow chain.

- Study each arc in each datum flow chain to determine the effects of variations in the dimensions and location of a feature, and variations in the positioning point or the connection. Modify the design if necessary.

- Analyse the realisability of the key characteristics using a three-dimensional variation analysis. Variations may occur in the datum flow chain, feature set, attachments/auxiliary constructions and assembly order. Modify the design if necessary.

The variation analysis provides assurance on realising the assembly's design intent in a controlled manner.

Evaluating the variations that occur in assemblies is also addresed in Variation Risk Management [Thornton, 2004]. Variation Risk Management describes how the realisability of key characteristics can be tested using a so-called "variation flowdown". In this, all possible sources of variation are included and defined using key characteristics. A distinction is made between the following types of key characteristics:

Product key characteristics.

System key characteristics.

Assembly key characteristics.

Part key characteristics.

Process key characteristics. 
With the exception of the process key characteristics, all the abovementioned key characteristics pertain to a geometric characteristic. Thornton links the process key characteristics to the manufacturing process. Process key characteristics are described as process capabilities - the previously discussed Cp values. Process capabilities can also be linked to assembly processes. These may concern, for example, cycle times and the variation that can be expected during an assembly process, which may or may not include the use of fixtures and the execution of control measurements. The process capabilities can be determined using a so-called variation flow-down. When using this flow-down method, the assembly process, the tools used in it and the competences of the assemblers must all be described in detail.

A variation flow-down represents the relationship between the sources of variation and a geometric key characteristic of the product. Figure 2.17 shows an example of such a flowdown. The example here is drawn from the automotive industry and shows how key characteristics describing the customer's perception of a cab door cab be flowed down through subassemblies, to features on parts, and finally to manufacturing processes.

The advantage of the flow-down method is that the assembly process itself is also included as a possible source of variation. This makes it possible to also consider the effects of, for example, using different tools or training the assemblers.

Based on the flow-down, the probability that a geometric key characteristic of the product is realisable can be estimated. Nowadays, it is also possible to gather the data needed to describe the processes using process mining [Wang, 2007]. If this reveals that the key characteristic in question cannot be realised in a controlled manner, mitigation measures will have to be taken. A potentially valuable measure is to modify the testing and inspection procedures to make it possible to incorporate the learning effects that occur during the conducting in the evaluation.

\subsection{Evaluating and improvingthe design of assemblies}

The assembly design process generally results in controlled assembly. That is not to say that the design is efficient, often further optimisation is possible. Important parameters for further optimisation are the number of parts to be assembled and the acceptable dimensional deviations. The focus on improving assembly processes with the help of a structured analysis began to appear around 1970. As indicated in Figure 2.2, this approach to optimising the assembly design is known as "DFX in the small". The goal of conducting this type of design-for-assembly assessment is to objectively evaluate an assembly process and improve it based on the findings [Boothroyd et al.,1983]. 


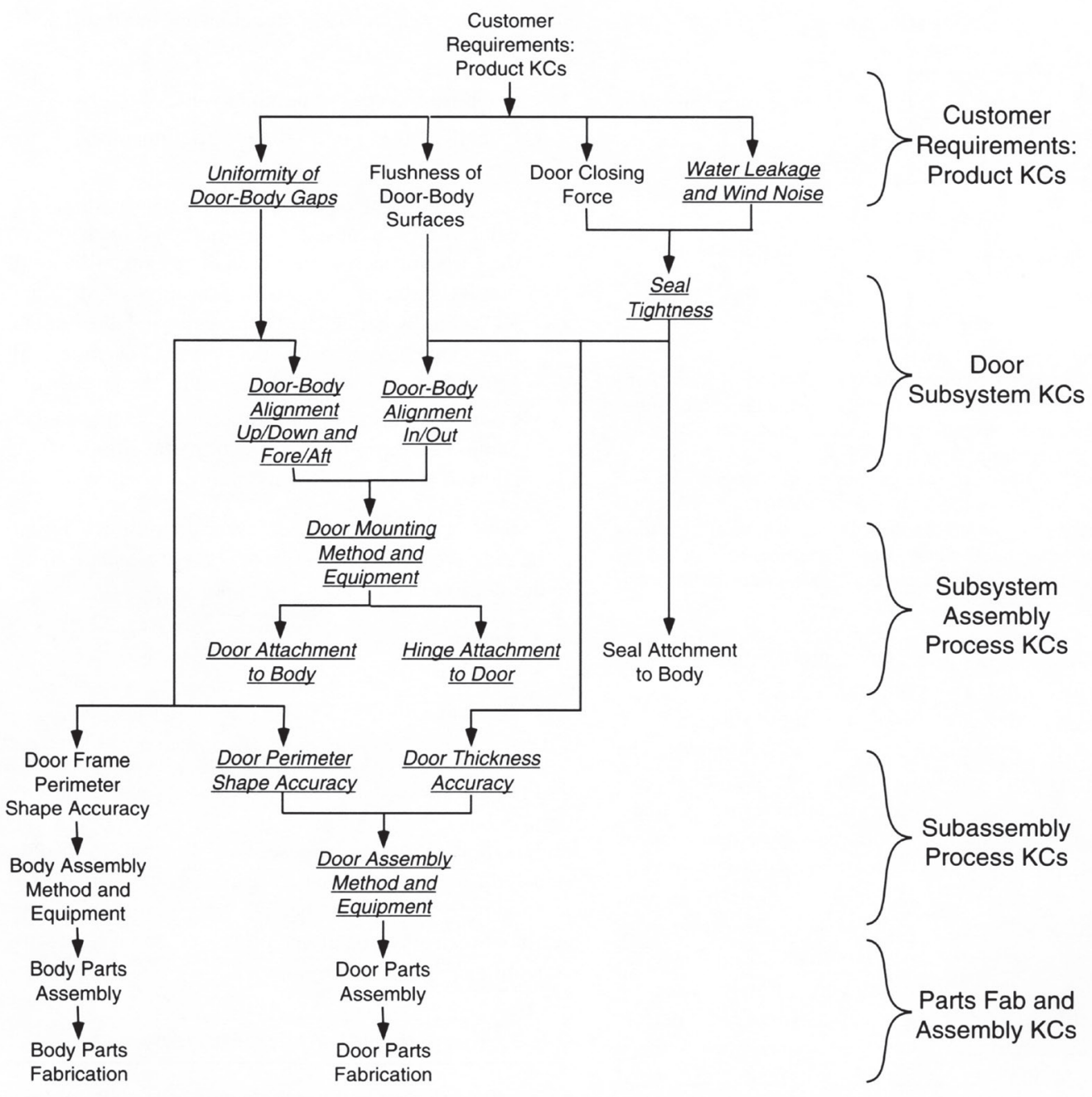

Figure 2.17: Key Characteristics (KCs) flow-down [Whitney, 2004].

The basis of the execution of a design for assembly in the small optimisation is a detailed description of the assembly and the associated time studies. By conducting such studies, it becomes possible to classify assembly steps and assign a timeframe to them. By modifying assembly steps, it becomes possible to optimise the assembly process. Well-known design for assembly in the small methods are:

The Boothroyd-Dewhurst Method [Boothroyd et al., 1983].

The Hitachi Assemblability/Assembly Reliability Method [Miyakawa and Ohashi, 1986].

The Toyota Ergonomic Evaluation Method [Niimi and Matsudaira, 1997]. 
All design for assembly in the small methods describe a way to define an assembly as a collection of sequential standard steps. These steps are assigned a classification. These common steps include:

- Picking up and manipulating a part with one hand.

Picking up a part with one hand and then manipulating it with two hands.

- Placing a part with specific characteristics.

This classification makes it possible to estimate the assembly time and determine the average overall assembly time. Next, modifications to the design can be proposed and evaluated. Redford [1994] views Design for Assembly as part of Design for Manufacturing with the main goal of striving to simplify the product structure. The number of parts can be used as an indication of the quality of an assembly. Based on representations of the knowledge of and the method for evaluating assemblies, Redford distinguishes four types of assemblies.

1 Those that have design principles and design rules.

2 Those that employ quantitative evaluation procedures.

3 Those that use a knowledge-based approach.

4 Those that use computer-aided methods.

An example set of design principles and design rules is provided by Boothroyd et al. [2010] as follows:

1 Reduce numbers of parts and part types.

2 Strive to eliminate adjustments.

3 Design parts to be self-aligning and self-locating.

4 Ensure adequate access and unrestricted vision.

5 Ensure the ease of handling of parts.

6 Minimise the need for reorientations during assembly.

7 Design parts that cannot be installed incorrectly.

8 Maximise part symmetry or make parts clearly asymmetric.

The other by Redford [1994] distinguishes types of assemblies are only available in certain industrial sectors where they are part of product lifecycle management programmes. Using design for assembly as a way to improve the design of an assembly of structures will often be impossible in practice due to a lack of results from time studies. During the realisation of an assembly, the design for assembly approach is always possible since it can make use of the flow-down of an assembly process and the associated process capabilities. 


\subsection{Designing assembly methods}

Important aspects when designing an assembly method are:

The number of products to be assembled.

The assembly operations to be performed.

These aspects are described in more detail below. Subsequently, the design of an assembly method will be discussed.

\section{The number of products to be assembled}

Kals et al. [2009] describe a classification of assembly methods based on the number of products to be assembled. These can be divided into:

The large-scale serial assembly of cars on an assembly line.

- The serial assembly of airplanes, using large-scale subassemblies.

- The mostly manual assembly method used for the single-unit and small-scale serial manufacture of machines and machine tools.

- The assembly of ships, buildings and industrial installations.

Of these four assembly methods, those used for cars and airplanes take place on an assembly line in a building. The assembly of the other objects on the list may take place in buildings or on site. This process often consists of assembling subassemblies.

\section{The assembly operations to be performed}

The assembly operations to be performed are divided into primary and secondary steps.

Primary assembly steps are:

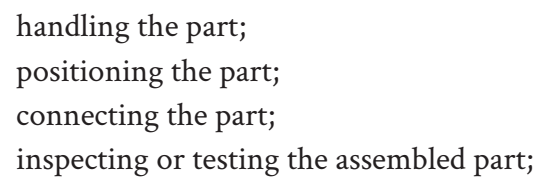

Secondary assembly steps are:

storage of the assembly;

transporting the assembly;

cleaning the assembly;

packaging of the assembly. 
When discussing the design of assembly processes, Witney [2004] pays separate attention to the use of robots. Here, the motions required for the assembly process and the forces to be exerted during the assembly are important. The motions are divided into so-called gross and fine motions. The forces depend on the type of interface and are particularly influenced by the fine motions. The gross motions during an assembly process relate to the transport of a part to within the vicinity of the assembly location. From this location, the part must be slowed down and given the correct orientation required for the assembly. The actual placement can be viewed as a controlled collision. After this collision, the part must be in the correct position without having been damaged. Without going into any further detail, it is clear that the design of such a collision is highly dependent on the dimensions and mass of the part and the context. For the assemblies considered here, the mass ranges from a tenth to many thousands of kilogrammes. The context may take the form of an assembly line, an assembly hall or free space.

\section{The design of an assembly method}

Designing an assembly method requires information about the separate steps and the cycle time. The design of an assembly method is represented schematically in Figure 2.18. Both the system and the product requirements of the assembly to be realised provide constraints on the design of the assembly method. Some modifications to the requirements may be desirable or even necessary.

Figure 2.18: The design of an assembly method [from Whitney, 2004].

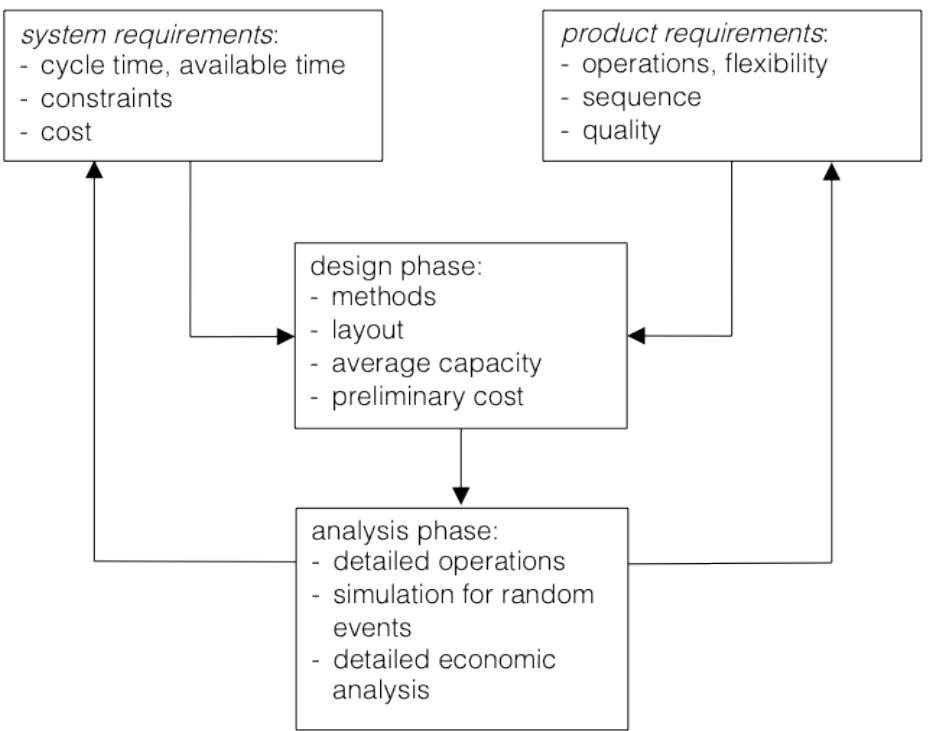

When choosing an assembly method, the flow-down technique introduced in Section 2.6 can be used to represent the entire assembly process and each step can then be optimised based on the assumed process capabilities. 


\subsection{Communicating about the assembly of a product}

The most concise definition of an assembly model is that it captures the design intent [Whitney, 2004]. Whitney states that the design intent may include the planning of the assembly process, the interfaces, the assembly cycles, the variation analysis, the contribution of subcontractors and advice linked to repair and recycling. Whitney uses the key characteristics explained earlier to capture these aspects. In Whitney's method, the design of an assembly will represent the key characteristics during each phase. This is because it is desirable to describe these key characteristics during each phase of the design process to ensure consistency. A more formal description of an assembly model was provided by Sudarsan et al. [2006]. This reads as follows:

The assembly model represents the function, form, and the behaviour of the assembly and defines both a system level conceptual model and associated hierarchical relationships. The model provides a way for tolerance representation and propagation, kinematics representation, and engineering analysis at the system level. The assembly model is open so as to enable plug and play with various applications, such as analysis (FEM, tolerance, assembly), process planning, and virtual assembly (using VR techniques).

Assembly models for assemblies range from a parts list, a structured bill of materials, a wiring schematic, an isometric view with a description of the parts or the assembly steps to be carried out and a description of the test protocol to be conducted in order to safeguard quality. Perhaps the most well-known type of assembly model is that used by IKEA, a Swedish manufacturer. An example is shown in Figure 2.19. It is remarkable that this type of assembly model is seemingly understood around the world.

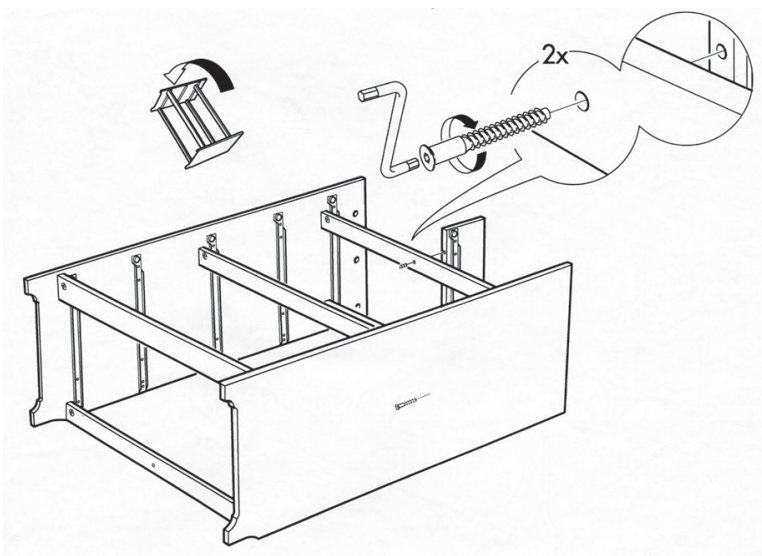

Figure 2.19: Assembly model for a cabinet [IKEA]. 
To facilitate communicating about, and during, the design and assembly of a product, a so-called open assembly model has been developed. This can be used to clearly communicate all the information that is relevant to an assembly [Xu et al., 2014]. The relevant items are:

\footnotetext{
Constituent parts.

Topology relations.

Constraint relations.

Assembly relations.

Assembly plan.
}

\subsection{Field problem, design methods and design rules for designing assemblies}

\section{Field problem of assembly designs}

Designers of all types of assemblies are confronted with geometric variations as a result of production and assembly processes. Examples of these geometric variations are the dimensional deviations in a car body shell, due to the manufacturing process, and the deviation in the height of an aircraft wing due to inaccurate positioning during assembly. The presence of geometric variations due to production processes and due to assembly processes can be considered as the two fundamentals for designing assemblies. The presence of geometric variations confronts designers of assemblies with the question of how to determine how they influence the value of the end product. The designers must determine how this influence can be defined and determined in terms of the functionality to be realised. Moreover, it must be determined whether the specified functionality can be realised at an acceptable cost.

In order to answer the question about realization at an acceptable cost, it is necessary to quantify the effects of geometric variations on the defined functionality in the assembled condition. Variation management as described by Tornton [2004] can be used for this quantifying purpose. If it appears that these variations fail to meet the functional specification, it will be necessary to consider whether the specification can be aligned with the geometric variations that can be achieved with the intended manufacturing and assembly processes. This can be done by adjusting the specification. If this is not possible, then the design or the manufacturing and assembly processes will have to change.

Anticipating the likely geometric variations due to production and assembly processes when designing an assembly can be considered as the field problem which needs to be solved by applying technological rules. This field problem is represented by the following 
four design issues:

1. The functional specification of the product to be realised.

2. The specification of the geometric quality of the product.

3. The expected geometric variations in the assembled condition.

4. The alignment of the specified geometric quality and the expected geometric variations.

\section{Design methods of assembly designs}

In the previous sections, a number of design methods and applied techniques were described to solve the four design issues within the field problem of assembly design. A selection of these design methods that could possibly be applied in the construction and infrastructure industry is presented in Table 2.2. Each design issue is further explained below the table.

Table 2.2: The design methods and techniques that may be relevant for the assembly design in the field of the construction and the infrastructure industry.

\begin{tabular}{|c|c|c|}
\hline $\begin{array}{l}\text { design issues of the field } \\
\text { problem }\end{array}$ & design methods & techniques to be applied \\
\hline $\begin{array}{l}1 \text { functional specification of the } \\
\text { object to realize }\end{array}$ & $\begin{array}{l}\text { - a design field related } \\
\text { design method } \\
\text { - decomposition principle }\end{array}$ & $\begin{array}{l}\text { - value engineering } \\
\text { - systems engineering }\end{array}$ \\
\hline $\begin{array}{l}2 \text { specification of the geometric } \\
\text { variations of the object }\end{array}$ & $\begin{array}{l}\text { - a design field related } \\
\text { design method } \\
\text { - decomposition principle }\end{array}$ & $\begin{array}{l}\text { - } \text { systems engineering } \\
\text { - design structure matrix } \\
\text { representations } \\
\text { - datum flow chain }\end{array}$ \\
\hline $\begin{array}{l}3 \text { expected geometric } \\
\text { variations in the assembled } \\
\text { condition }\end{array}$ & $\begin{array}{l}\text { - variation management } \\
\text { - geometric dimensioning } \\
\text { and tolerancing } \\
\text { - logistic analysis } \\
\text { - assembly analysis } \\
\text { - assembly process } \\
\text { communication protocol }\end{array}$ & $\begin{array}{l}\text { - modelling of assemblies } \\
\text { - flowdown techniques } \\
\text { - ISO-standards } \\
\text { - design of assembly } \\
\text { evaluation and improving } \\
\text { - assembly model } \\
\text { - flowdown techniques }\end{array}$ \\
\hline $\begin{array}{l}4 \text { alignment of the specification } \\
\text { of the geometric quality and } \\
\text { the expected geometric } \\
\text { variations }\end{array}$ & $\begin{array}{l}\text { - variation design } \\
\text { - quality loss function }\end{array}$ & $\begin{array}{l}\text { - product testing } \\
\text { - value engineering }\end{array}$ \\
\hline
\end{tabular}

\section{Design issue: Functional specification of the object to be realised}

By definition, an assembly to be realised consists of a number of parts. Systems engineering can be used as a tool to decompose the object into a number of parts. The assembly-related functionalities of assemblies are described by means of key characteristics. Value engineering can be used to estimate the benefits and costs of an assembly to be realised.

\section{Design issue: Specification of the geometric variations of the object}

The parts are further defined using systems engineering. The design structure matrix can be used to determine optimum assembly order. 
A method related to the design field is used to specify the key characteristics in relation to the functionality to be realised. The method selected therefore depends on the type of assembly. The geometric variations that influence a key characteristic can, for example, then be represented through a datum flow chain.

\section{Design issue: Expected geometric variations in the assembled condition}

In order to be able to make reliable statements about the expected geometric variations, it is desirable to have insight into the way these geometric variations manifest themselves in the assembled state. To this end, it is necessary to quantify all manufacturing and assembly related geometric variations and to interpret the influence of these geometric variations in the assembled state. However, this is only possible if these variations can be managed. Flow-down techniques and ISO standards such as ISO-14638: "Geometrical product specifications (GPS)" and ISO 1101: "Geometrical product specifications (GPS)-Geometrical tolerancing -Tolerance of form, orientation, location and run-out" can be used for this purpose.

\section{Design issue: The alignment of the specification of the geometric quality and the expected geometric variations}

The design of an assembly can be considered complete if the expected geometric variations correspond to the geometric quality and the realisation costs are acceptable. This can be achieved by minimising the costs associated with the realisation of the specification. Flowdown techniques can be used for this. The assembly of smaller assemblies, or of sub-assemblies, can also be tested using a mock-up. Another way to optimise the costs of realising an assembly is to apply a trade-off between a decrease in costs and ensuing reduction in quality. Value engineering can be applied here.

\section{Design rules for designing assemblies}

Distinct design rules, as instructions to perform a finite number of acts in a given order with the aim of designing assemblies, can be distinguished based on a classification of the sources of geometric variations that can be expected based on the context of the realisation. For example, mechanical assemblies are usually created at fixed locations in controlled circumstances where a certain assembly operation is also performed in one place. An example of a design rule for the design of a mechanical assembly has been described in section 2.6 'designing the assemblies of structures'. The design rules that are applied in the design of mechanical assemblies are based on the fact that their feasibility can be tested in advance. If sensible, this will be by realising a prototype, if not, maybe due to the dimensions of the assembly, the feasibility can be tested by means of a variation design.

In contrast to mechanical assemblies, the assembly of objects in the built environment is usually carried out outdoors. As a consequence, the assembly process is exposed to all sorts of weather conditions. Further, each product will be assembled at a different location. Therefore, in addition to the geometric variations in the parts, a design rule is required that also addresses variations in the contexts in which the assembly will be created. This 
is shown schematically in Figure 2.20. The design rule for the design of an assembly to be developed for the construction and infrastructure sector must therefore align with the context in which the objects in question are to be realised. This context relates to the availability of modular building products and the manufacturing and assembly processes. With mechanical systems, the availability of modular parts can be assumed, but this does not apply in the construction and infrastructure industry. Due to the small numbers of similar objects being realised in this industry, modular parts are not always available and, if they are available, the application will vary depending on the designers involved.

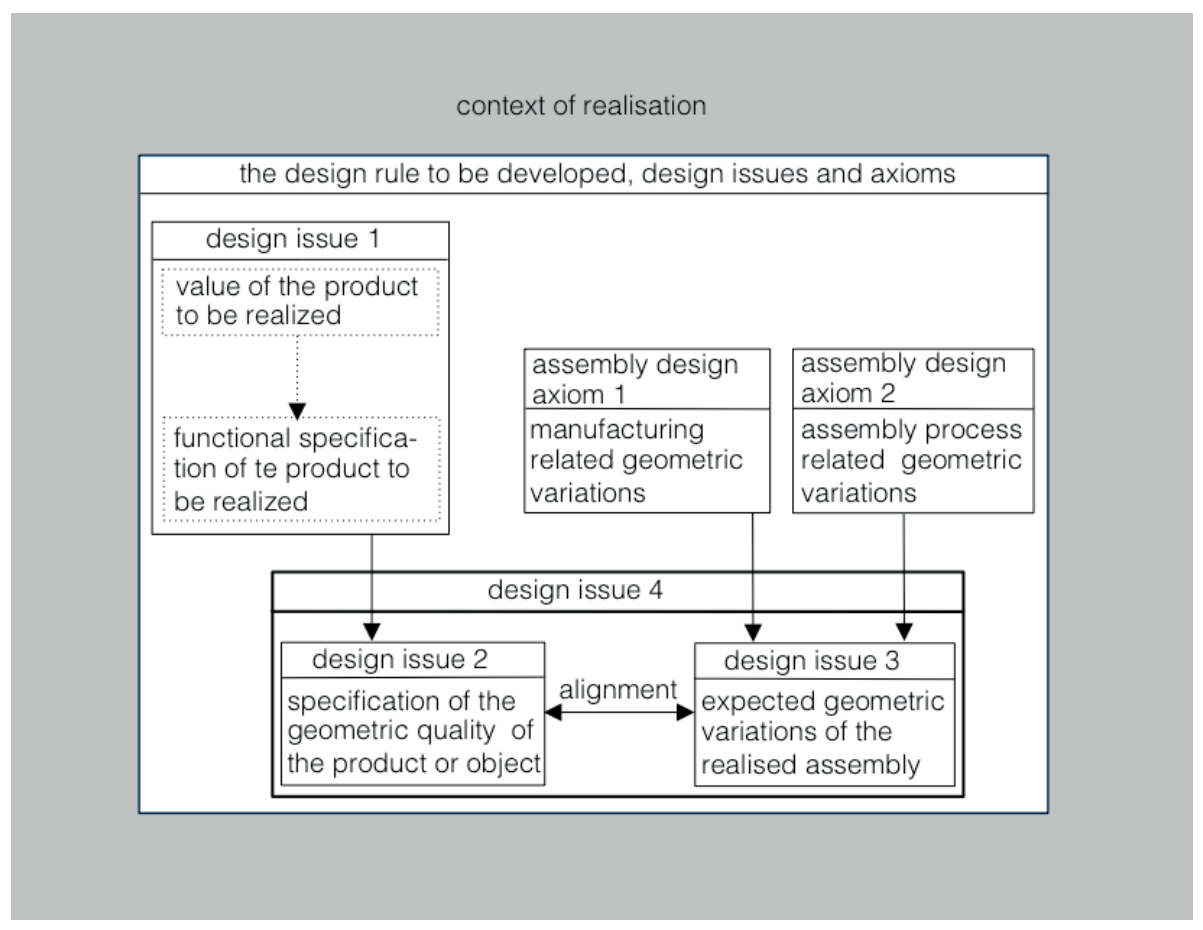

Figure 2.20: Context of realisation, the design rule to be designed and design issues.

\subsection{Conclusions}

The questions this chapter set out to answer are the following:

What can be learned from the design of mechanically produced artefacts and which design rules, design methods and techniques can be derived that are also applicable in the construction and infrastructure sector? 
On the basis of an in-depth literature study into the design of mechanical assemblies, the conclusion seems justified that it is possible to design mechanical assemblies in such a way that they are produced in a controlled manner with regard to quality and costs. This also makes it possible to optimise these assemblies with regard to value creation for the end-user and the costs of realisation.

The literature review of the design of mechanical assemblies has clarified the field problem of the design of mechanical assemblies and the applied design rules, design methods and techniques. It can also be concluded that the described field problem and design issues are relevant for the design of all types of assemblies, including assemblies in the construction and infrastructure sector. However, the design rule that is applied to the design of a certain type of assembly needs to be based on its specific context. In the construction and infrastructure sector, this context relates to the availability of modular building parts and their applied manufacturing and the outdoor assembly processes.

The design rules and a number of design methods and techniques that are applied when designing mechanical assemblies may also be applicable to the design of assembled building and infrastructure objects (as illustrated in Table 2.2). 


\section{The design process and design techniques as applied in construction and infrastructure projects}

Contents

3.1 Introduction

3.2 The realization process and design issues in the construction industry

3.2.1 The construction realisation process according to the Dutch standard NEN 2074

3.2.2 Points of attention with regard to the design of assemblies

3.2.3 Conclusion regarding addressing the design issues relevant for assembly

3.3 Design techniques applied in the construction and infrastructure sector

3.3.1 Systems Engineering

3.3.2 Building Information Modelling

3.3.3 Accommodation of geometric variations

3.3.4 Design for buildability

3.3.5 Design for manufacturing and assembly in construction

3.3.6 Concluding remarks with respect to the five design techniques

3.4 Conclusions 


\subsection{Introduction}

Chapter 2 has described the field problem of assembly design. This field problem is represented by the following four design issues:

1 The functional specification of the object to be realised.

2 The specification of the geometric quality of the assembly to be realised.

3 The expected geometric variations in the assembled condition of the assembly to be realised.

4 The alignment of the specification of the geometric quality and the expected geometric variations of the assembly to be realised.

In this chapter, we will elaborate on the extent to which attention is given to the abovementioned design issues during the design and realisation of building objects. The research sub-question that will be answered in this chapter is therefore the following:

To what extent are the current design process and design techniques, as applied in the construction and infrastructure sector, geared towards the design of assemblies?

In answering this question, Section 3.1 will describe and evaluate current construction design and realisation, as prescribed in the Dutch standard NEN 2574 [1993], as to the extent that attention is paid to problems in the field of assembly design. Next, in Section 3.2 , the prevailing design techniques that are applied in the construction and infrastructure sector are evaluated on the extent to which attention is paid to the described field problem of assembly design. Section 3.3 draws conclusions that answer the chapter's research sub-question.

\subsection{The realisation process and design issues in the construction industry}

\subsubsection{The construction realisation process according to the Dutch standard NEN 2574.}

The realisation process in the construction industry follows the process steps prescribed in Dutch standard "NEN 2574 Construction drawings - Arrangements of data on building drawings". The NEN 2574 standard distinguishes eleven successive realisation phases. These eleven phases can be clustered into four main process parts: Demand specification; Design; Elaboration of the design; and Construction (see Table 3.1). The 'Construction' part relates to the actual object realisation. 
Table 3.1: The Dutch standard NEN 2574 with regard to the phasing of the construction realisation process.

\begin{tabular}{|c|c|c|}
\hline & main process parts & realization phases \\
\hline \multirow{5}{*}{$\begin{array}{l}\frac{5}{\sqrt{0}} \\
\stackrel{2}{2} \\
\frac{5}{0} \\
\frac{0}{0} \\
\frac{1}{0}\end{array}$} & demand specification & - initiative \\
\hline & & - feasibility study \\
\hline & design & - structure design \\
\hline & & $\begin{array}{l}\text { - preliminary design } \\
\text { - final design }\end{array}$ \\
\hline & elaboration of the design & $\begin{array}{l}\text { - job description } \\
\text { (bill of materials) } \\
\text { - pricing }\end{array}$ \\
\hline 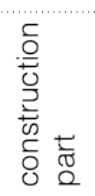 & construction & $\begin{array}{l}\text { - work preparation } \\
\text { - realization of the object } \\
\text { - delivery of the object }\end{array}$ \\
\hline
\end{tabular}

The NEN 2574 standard prescribes the drawings that should be produced in each of the phases of the realisation process. This provides insight into the work that the different parties such as the architect, engineering consultants, constructor, contractor and suppliers are expected to deliver in each phase. The eleven realisation phases are briefly summarised below.

\section{The initiative phase}

The first phase in the construction realisation process is intended to identify the required process inputs to develop the functional requirements, and to identify potential financial and design constraints. The design constraints define those factors that limit design flexibility, such as regulatory standards and environmental and customer conditions and limits.

\section{The feasibility study phase}

Here, to determine the feasibility of the construction project, an analysis is made of the functional, technical, financial and spatial aspects of the intended construction project.

\section{The project definition phase}

In this phase, the project principles, objectives and scope are defined, leading to a detailed specification of the functional, technical, financial and spatial requirements.

The functional requirements reflect a detailed specification of all user activities to be accommodated and their relationships (internal and external). This also includes an examination of future developments that may arise, and which should be taken into account during project design. 
The technical requirements specify the technical principles within which the project must be realised. These principles concern construction, construction technology, installations, building physics, regulations and norms and energy consumption.

The financial requirements determine the financial constraints within which a project must be realised. These concern the (maximum) investment costs, the (maximum) operating costs and the possible (minimum) operating income. Construction costs and operating costs are determined in terms of usage-related units ( $\mathrm{m} 2, \mathrm{~m} 3$, student, bed, etc.) on the basis of cost indicators. The task-based construction budget is determined from these calculations The spatial requirements specify the principles to be applied with regard to location; ( $\max$ - min.) volume; ( $\max$ - min.) surface area; ( $\max$ - min.) built-up surfaces; and (max.- min.) height, all including their mutual relationships.

\section{The structure design phase}

In this phase, the technical consequences of the functional requirements and the requirements set out by construction standards and guidelines are considered. This results in a structural design and corresponding design sketch drawings. In this, the location of construction boundaries, the possible location of space boundaries, supports, the locations of vertical and horizontal traffic are indicated.

With an accuracy of the order of $300 \mathrm{~mm}$, it is then possible to derive from the drawings, data on the terrain area, built-up area, gross floor area, facade area, roof area and building volume. Based on the available data, the investment costs, operating costs and operating income can be estimated with reasonable accuracy. The construction costs are compiled on the basis of cost indicators for element clusters. The costs that are determined in this way will serve as task-setting partial budgets during the further elaboration of the plan

\section{Preliminary design phase}

In the preliminary design phase, the net floor area per room for each selected functional unit is determined on the basis of the intended user activities and the required furnishing elements. To this end, a surface analysis and a relationship diagram are produced. These data serve as a first draft for the space book. The preliminary design also provides a plan for the construction, the installations and the building's physical assumptions. In the preliminary design, location drawings and assembly drawings are made in such a way that a sufficient representation of the project is given regarding its location, the main layout, the structural and the construction set-up and the architectural appearance.

On the basis of the available data and drawings, a global budget regarding investment costs, operating costs and possible revenues is made. In this global budget, the construction costs are compiled as far as possible on the basis of prices per unit element, and if not by means of costs.

If necessary, these unit element estimates must also provide advice for the adaptation and adjustment of the intended design. 


\section{Final design}

The final design phase generally consists of two steps. The first involves elaborating the preliminary design in accordance with the wishes of the client. This elaboration includes four deliverables: a space description, a technical description, the final design drawings and a final financial plan. The final design drawings consist of site and assembly drawings. These have the purpose that a full understanding of the project can be obtained. In addition, these drawings and the technical description of each element should also provide sufficient information to calculate the expected amount per element. The final financial plan is made to determine the construction costs. It is based on an element budgeting system and compiled on the basis of unit prices. If the combined budget of the elements exceeds the target construction budget, target adjustments need to be formulated. The second step considers possible adjustments to the final design. This can be necessary to fulfil regulations and/or comments from the competent authorities or third parties (such as the Municipal Works Department, Urban Planning Department, Land Company, Welfare Commission and future users).

\section{Job description (bill of materials) phase}

This phase includes the following deliverables:

An application for the building permit.

A space book as further specification of the space description.

Extensive descriptions of the finishes, layout and installations.

An accurate work description and specification of the project to obtain a complete and detailed picture of the project in terms of construction, materials, dimensions etc. This description also includes calculations related to the construction, installations and building physics.

- Administrative and technical provisions (regulations with regard to building materials and construction).

Specification drawings, including accurate site drawings, assembly drawings and component drawings. These drawings should be drafted in such a way that, together with the accompanying job specifications, the quantities of material and products to be processed, the required equipment and the processing standards can be determined and a final price formulated.

\section{Pricing phase}

The pricing phase includes:

The announcement of the tender or the invitation of candidate(s).

Provision of specifications, drawings and relevant appendices.

Provision of information and/or directions.

Preparation of the contractor budget. 
Receiving the tender(s) and giving advice to the client regarding awarding the work. The award and signing of the contractor contract.

\section{Work preparation phase}

In the work preparation phase decisions are made about how the object will be realised and how the realisation process will be documented. Important documents in this respect are:

The space book (which will be amended if necessary).

- Realisation provisions in which certain facets of the specification description are further developed.

- Location drawings, assembly drawings and component drawings, which are further elaborated versions of the pricing drawings produced in step 7.

A working budget for the realisation which is drawn up according to the order of the construction activities. In addition, a financing plan is produced in which the payment times are indicated in relation to the expected progress of the implementation.

\section{Realisation of the object}

The realisation phase covers the actual realisation of the intended object on the construction site or through building parts off-site. Various aspects of progress with the realisation are monitored and registered, such as:

- The registration of the work insofar as it is important for adjusting the space book.

- The registration of the status of the work with regard to completion of work parts or building parts, type and quantity of supplied building materials, supply and removal of equipment.

- The actual expenditures which are compared to the financing plan. If necessary, adjustments are made. Financial consequences with regard to more and less work, deductible quantities, settlement of wages and/or price changes and the accuracy of approximate estimates are monitored and registered. All financial data are ultimately processed in periodic financial reports.

\section{Delivery of the object}

During the project realisation process, weekly progress reports are produced. After project completion, a decision is made as to whether the delivered work can be approved and put into use. If a maintenance period is included in the contract in order to correct shortages and defects during that period, the related work carried out will be evaluated. After the project is finished, the final realised state is documented on location drawings (revision drawings).

Based on the description above, it can be concluded that the Dutch standard NEN 2574 does not relate to a specific construction production method. Further, although the NEN standard 2574 recognises the importance of assembly, points for attention when designing assemblies are not provided. 


\subsubsection{Points for attention with regard to the design of assemblies}

Component drawings are produced in the work preparation stage of NEN 2574. To create greater unity between component drawings, the "Stichting Research Rationalisatie Bouw" developed quality guidelines "Quality of design drawings in the construction sector" [Research Rationalisatie Bouw, 2007]. To facilitate a smooth construction execution process, the guidelines provide recommendations on how to further develop certain aspects of the design drawings into site drawings, assembly drawings and component drawings. To this end, the guidelines recommend documenting the following aspects on these drawings:

Location and dimensioning for the execution of:

- the building (component) and its structural elements;

- the construction;

- the installations;

- the permanent layout;

- the site layout.

- Combinations and connections to facilitate the execution of:

- the structural elements;

- the construction elements;

- the installation elements in relation to the building elements.

Design and confirmation of the permanent layout in relation to the building components to facilitate the execution.

Design and connection of the terrain elements to facilitate the execution.

An overview of components to be produced off-site.

The production of components used to create building parts.

The combination of components into building parts.

The last three items are particularly relevant for the assembly of an object. In addition to this list, the quality guidelines also provide examples of the aforementioned drawings. Figure 3.1 illustrates one of these examples.

Based on the principles of geometric quality specification, as described in Section 2.2, it can be concluded that Figure 3.1 relates to the dimensioning of a building part. As described in Section 2.2, the geometric tolerances and their influence on the indicated dimensions of the building part concerned should be indicated. By providing these tolerances, the geometric quality of the construction part is specified. Surprisingly, this information is missing from the example drawing shown. Given that geometric deviations are always present, this lack of information means that information required for positioning during assembly is missing. The assembly of this building part will therefore have to be improvised as sufficient information for its positioning is lacking. As a result, it is also unknown where the dimensional 
deviations will be accommodated. It can also be concluded that, in this particular example, the basic principles of geometric dimensioning and tolerances are not applied.

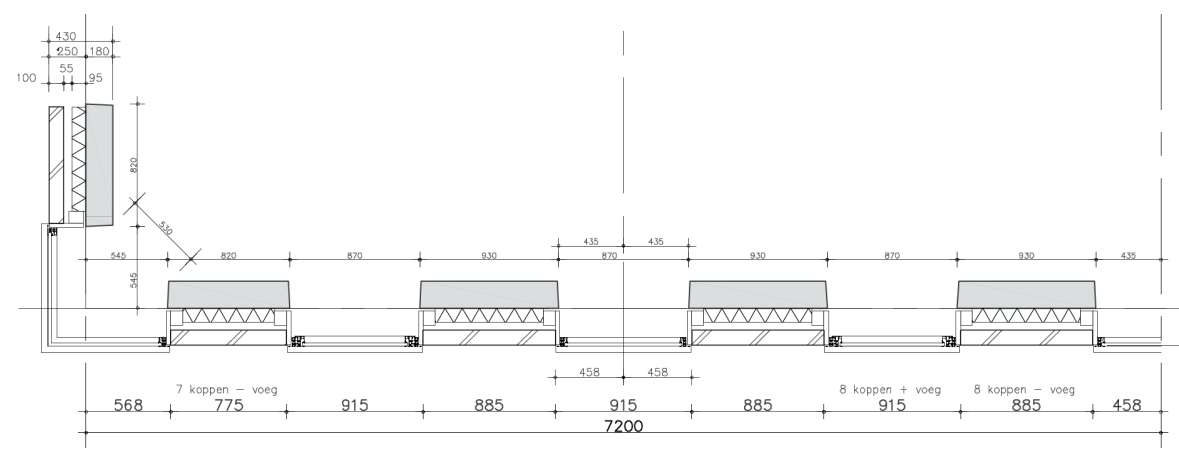

Figure 3.1: Cross-section of a façade (prefab concrete \& masonry) [Stichting Research Rationalisatie Bouw, 2007].

\subsubsection{Conclusion regarding addressing the design issues relevant for assembly}

The relevance of the Dutch standard 2574 and the "Quality of design drawings in the construction sector" guidelines in the assembly design process can be deduced by evaluating their relative contribution to resolving the four earlier discussed design issues:

\section{Design issue 1: The functional specification of the object to be realised}

According to NEN 2574, attention must be given in the project definition phase to the project principles, objectives and defined scope. On this basis, it should be possible to specify in detail the functional, technical, financial and spatial requirements. The conclusion can therefore be drawn that applying this Dutch standard can help solve this specific design issue.

Design issue 2: The specification of the geometric quality of the assembly to be realised NEN 2574 does not relate to a specific construction production method. The design process described in this standard does not consider the specification of the geometrical quality of an assembly to be realised and cannot therefore be used to resolve this design issue.

\section{Design issue 3: The expected geometric variations in the assembled condition of the assembly to be realised}

The design process described in NEN 2574 does not address the presence of geometric variations. Further, although the "Quality of design drawings in the construction sector" guidelines, based on this standard, provide instructions for making the drawings of building 
parts to be assembled, it assumes that no relevant production-related geometric variations are present. The runs contrary to one of the fundamentals of assembly design, that this should be based on being able to master and accommodate these variations. A minimal basis for this is recognising their presence, and this does not seem to exist. Standard NEN 2574 and the quality guidelines based on it cannot therefore be used to address this design aspect.

\section{Design issue 4: The alignment of the specification of the geometric quality and the expected geometric variations of the assembly to be realised}

Both NEN 2574 and the quality guidelines based on it fail to address the presence and the effects of geometric variations. So, again, they cannot be used as a tool to resolve this design issue.

\subsection{Design techniques applied in the construction and infrastructure sector}

This section describes a number of design techniques used in the construction and infrastructure sector that are expected to be relevant when designing assemblies. The section closes by drawing conclusions regarding the extent to which the issues identified in designing assemblies are addressed by the techniques described. These described design techniques are:

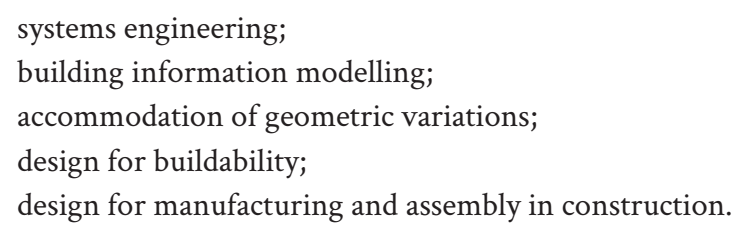

\subsubsection{Systems Engineering}

Systems Engineering (SE) can be defined as "an interdisciplinary approach and means to enable the realisation of successful systems. SE considers both the business and the technical needs of all customers with the goal of providing a quality product that meets the user needs" [INCOSE, 2020].

A characteristic of SE is the separation of functions and design solutions. This is shown in the SE process model depicted in Figure 3.2. 


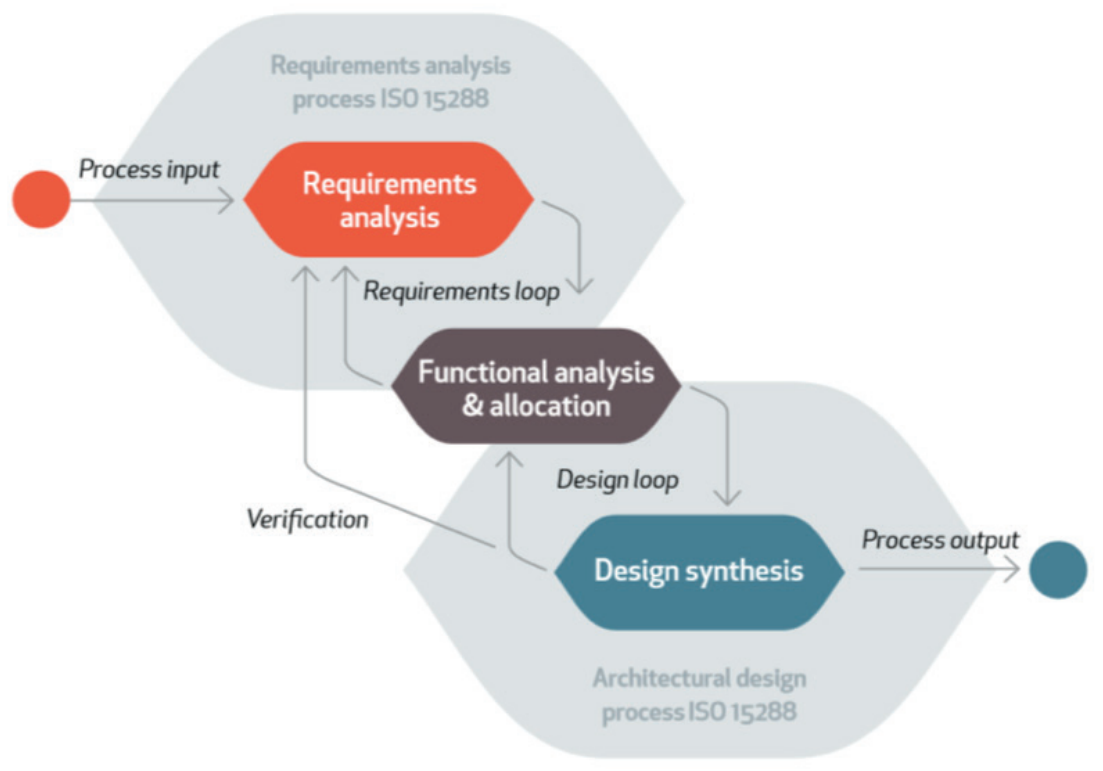

Figure 3.2: The System Engineering Process [Alsem et al., 2013].

The SE process involves three loops. The first loop, the requirements loop, focusses on functional analyses in combination with requirement analyses. The second, design, loop focusses on functional allocation and design. The third loop focusses on validation and verification. Validation amounts to checking whether the design meets customer expectations, verification is checking whether the design satisfies the requirements [Boonen, 2018].

Systems engineering is used to design successful systems for complex products. The idea is that every system can be broken down into subsystems, components, subcomponents and finally parts by using a hierarchical structure. The relationships between these elements are labelled interactions. The interactions are realised through interfaces [Kossiakoff et al., 2011]. A functional decomposition can be used to develop a product platform for a product or the product architecture of an object. Furthermore, systems engineering can be used to describe the product architecture and the interactions between systems [Eppinger et al., 2012]. Systems engineering can therefore be used for the functional specification of a design product and for describing the interactions between the (sub)systems to which this product can be broken down. The application possibilities of systems engineering are in line with the design issues of construction assemblies as described in Section 2.10.

In the Netherlands, SE was first introduced in infrastructure projects at the end of the 1990s by Rijkswaterstaat and Prorail. The first applications concerned large and complex infrastructure projects. 
Rijkswaterstaat stimulates its desired method of collaboration with the market by utilising systems engineering for the design of functional systems. To facilitate this, Rijkswaterstaat regularly releases revisions of its Guideline for Systems Engineering in the infrastructure sector [Werkgroep Leidraad Systems Engineering, 2013]. The application of systems engineering in this sector is mainly focused on developing a way to decompose systems into subsystems in a structured manner, both functionally and in relation to the selected components, which are also known as building blocks. Figure 3.3 shows how Rijkswaterstaat represents the Dutch transport system by applying a systems engineering approach.

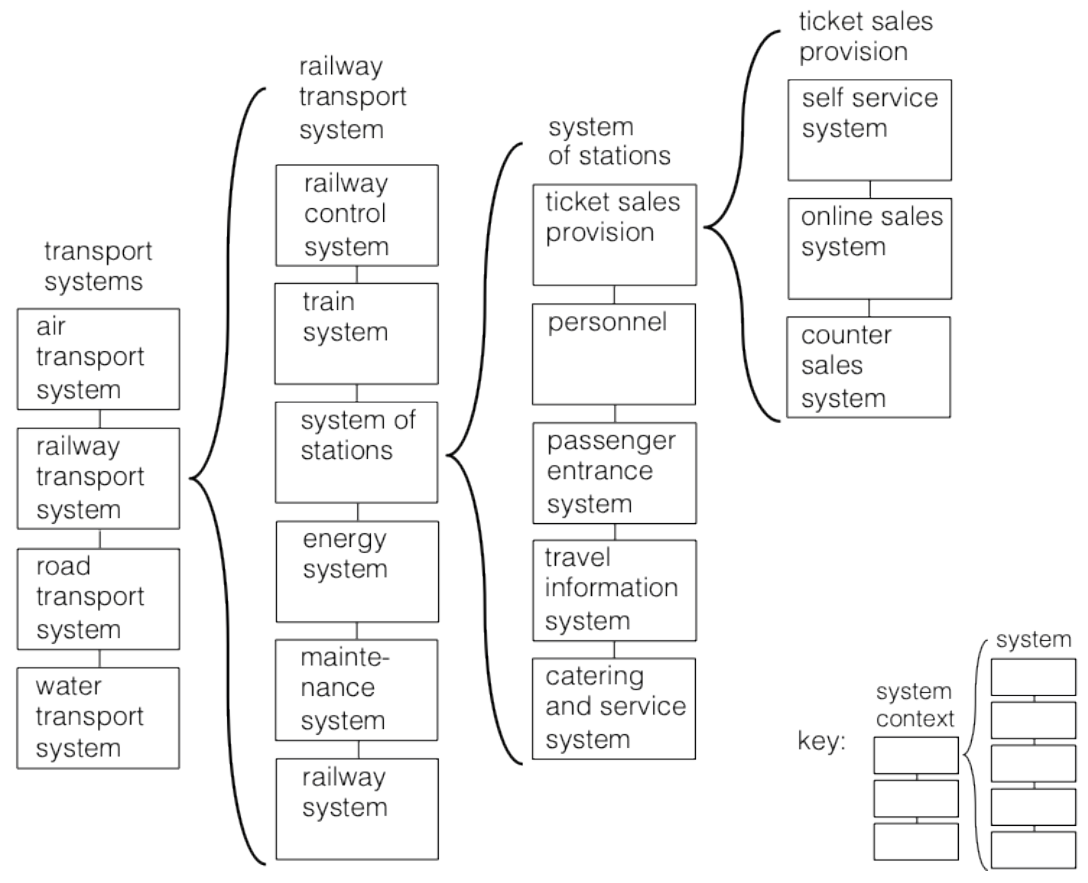

Figure 3.3: System and system context of the Dutch transport system [based on Werkgroep Leidraad Systems Engineering, [2013].

Figure 3.4. shows an example of decomposing a building into building elements, building components, and products and materials. One of the first initiatives to stimulate the use of systems engineering in the construction sector in the Netherlands was undertaken by "Stichting Bouw Research". This occurred in a preliminary study in which SE was applied for a housing project in the city of Almelo [Spekking, 2010]. On the basis of this pilot study, the conclusion was drawn that SE facilitated the structured identification of stakeholders' demands and their wishes. This first study, was followed by a large number of SE applications in the construction sector [Graaf, 2014]. 


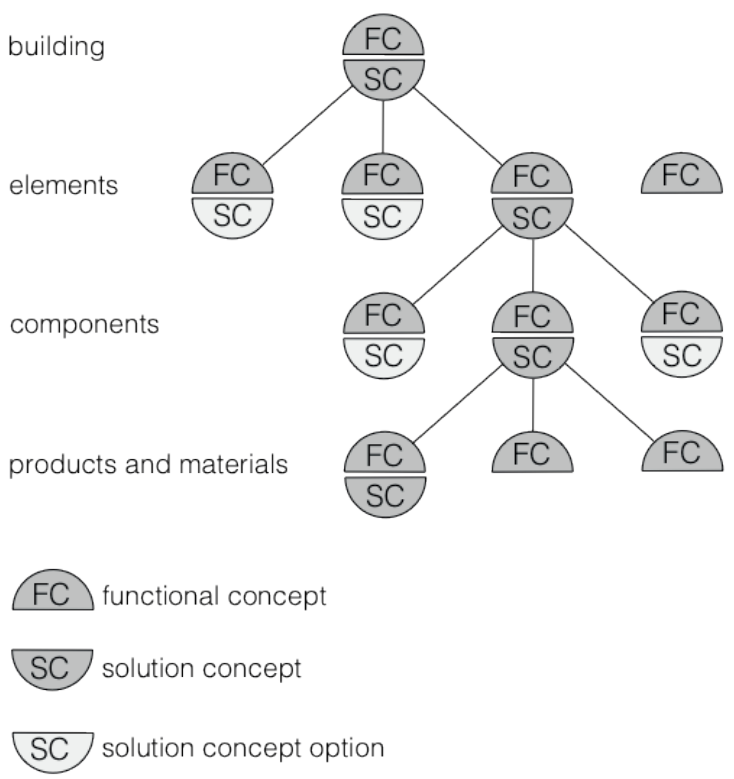

Figure 3.4: The decomposition of a building [from Spekking, 2010].

\section{The relevance of systems engineering in the design of assemblies}

The relevance of systems engineering in the construction and infrastructure sector for the assembly design process can be deduced by evaluating its contribution to resolving the four earlier discussed design issues:

\section{Design issue 1: The functional specification of the object to be realised}

Applying systems engineering facilitates the drawing up the program of requirements in a structured manner. Since this program also relates to the function of the object to be designed and the relevant market segment, this program of requirements can be regarded as a functional specification of the object to be realised. One can therefore conclude that systems engineering can be applied as a tool to resolve this specific design issue.

\section{Design issue 2: The specification of the geometric quality of the assembly to be realised} The functional analysis and the allocation part of the systems engineering process model includes a decomposition. Provided this decomposition relates to subassemblies of the assembly as described in Section 2.1, it can also be used to specify the geometrical quality of the assembly. As such, the decomposition principle applied in SE can be applied as a tool to resolve this design issue. 


\section{Design issue 3: The expected geometric variations in the assembled condition of the assembly to be realised}

Systems engineering is not concerned with determining the geometric quality of an assembly's design and therefore cannot be used to resolve this design issue.

\section{Design issue 4: The alignment of the specification of the geometric quality and the expected geometric variations of the assembly to be realised}

Systems engineering is not concerned with influencing the geometric quality of an assembly's design and therefore cannot be used to resolve this design issue.

\subsubsection{Building Information Modelling}

Building Information Modelling (BIM) has often been defined as a set of interacting policies, processes and technologies generating a methodology to manage the essential building design and project data in a digital format throughout a building's lifecycle (Eastman, 2011). The core of this is a digital representation of the object to be realised: the building information model. In recent years, a wide range of methods have been developed that apply such a model, for example, it is used in budgeting, the simulation of building processes and controlling for the double use of space by building components. This section addresses the application of BIM in the context of designing an assembly of objects realised by the construction and infrastructure sector.

The extent to which building information modelling can be applied when designing the assembly of objects depends on the quality of the geometric data that are used. If these incorporate the deformations that occur during the assembly and the assembly-related geometric variations, the building information model can be used in the design of assemblies. However, if the data in a building information model are just based on the design data, as is often the case in practice, this model cannot be considered as a reliable representation of reality since, in reality, as a result of the manufacturing and assembly processes, geometrical variations are present and deformations occur in the finished construction. Therefore, based on the usual definition of a building information model, such models cannot be considered as a realistic representation. The relevance of deformations that occur during the realisation of an object is described in Box 1. 
Box 1: Deformations during the execution of an object in the built environment.

An important characteristic of objects in the built environment is that they are subject to deformation, both during their realisation and after completion. The resulting deformations should avoid negatively affecting an object's performance. Determining the deformations during the operational phase is part of the everyday practice of constructors. They must demonstrate that the deformations of objects in the built environment during the operational phase fall within acceptable limits. The fact that the deformations that will occur during the realisation phase are not always accounted for in the design is clear from the article "Learning from deformations" [Arts et al., 2011].

In "Learning from deformations", the deformations that occur in a number of buildings during the construction phase are described. These deformations occur as a result of the construction's inherent weight and their severity also increases with the height of a structure. Depending on the properties of the foundation and the construction that rests on it, this may lead to vertical and/or horizontal deformations of the construction. These deformations should not negatively affect the usability of the object or its constructive, physical or aesthetic qualities. This means that an object under construction needs to be in the geometric position indicated in the design after the deformations that are anticipated during the realisation phase have occurred. Therefore, it needs to be possible to compensate for any deformations that occur during the object's realisation. To achieve this, it may be necessary to adjust the dimensions of the construction components (the so-called product dimensions) in such a way to compensate for any later deformations. Given the uncertainties in predicting deformations to constructions during their execution, it is advisable to monitor for deformations during the execution phase. If relevant, this process should be described as part of the design. An example of how this can be achieved is provided in "Measurement monitoring in building skyscrapers" [Lemmens, 2012].

To acquire insight into the developing deformations during the realisation phase, one can make predictions of likely deformations at certain key moments during the realisation phase using the constructor's schematics. To enable this monitoring, the constructor needs to make these calculations in a timely manner and include the findings in the information provided to the contractors. However, as the article "Learning from deformations" makes clear, this is not always the case [Arts et al., 2011]. In practice, it is generally the contractors' responsibility to make the calculations necessary for the realisation.

As previously explained, the applicability of building information modelling in the design of assemblies depends on the extent to which the data contained therein represents the reality of the as-built situation. Box 1 shows that the reality is influenced by distortions and on geometrical variations that result from manufacturing and assembly processes. As a result, the application of building information modelling in assembly design depends on the availability of assembly-related geometric information. This indicates that the application of building information modelling does not necessarily directly contribute to resolving the four design issues described in the introduction to this chapter. 


\section{The relevance of building information modelling to the design of assemblies}

The relevance of building information modelling to the assembly design process in the construction and infrastructure sector can be deduced by evaluating its relative contribution to resolving the four earlier discussed design issues:

\section{Design issue 1: The functional specification of the object to be realised}

Building information modelling is not intended or suitable for the functional specification of an object. The relevance of building information modelling to this issue is not obvious.

Design issue 2: The specification of the geometric quality of the assembly to be realised As indicated in the definition of a building information model, such a model can in principle be regarded as a representation of a building design. In the context of this design issue, building information can be applied to visualise the effects of a specific specification of the geometric quality.

\section{Design issue 3: The expected geometric variations in the assembled condition of the assembly to be realised}

If the data are available, a building information model of an object to be assembled can be used to represent and assess the expected geometric position of the construction parts. In the context of this design issue, building information modelling can be applied to visualise the effects of these expected geometric positions.

\section{Design issue 4: The alignment of the specification of the geometric quality and the expected geometric variations of the assembly to be realised.}

A building information model cannot be used to influence the geometric position of an assembled building part. It can, however, be used to represent the effects of certain measures on this position. In the context of this design issue, a building information model of an assembly to be realised can be supportive.

\subsubsection{Accommodation of geometric variations}

A very practical way to take account of possible geometrical variations in the design of assemblies is to assess in advance to what extent these can be anticipated. If applicable, the design should be adapted in such a way that these variations do not adversely affect the technical functionality of the end result. The designer should also try to mask possibly disturbing visual effects of geometric variations. As an example, Box 2 on the next page illustrates how, centuries ago, geometric variations were accommodated through the inclusion of a capital as an interface between columns and ceiling ribs. 
An interface can be defined as a coupling between two or more components. This principle of designing interfaces between construction parts in order to accommodate possible geometric variations is often applied in the construction and infrastructure sector. In the context of a building, an interface is a physical and functional coupling (a connection or joint) between building components. Ideally, interfaces should be standardised to facilitate modularity, exchangeability and transformability of building components to increase the adaptability of buildings.

An interface's specification defines the protocol for the primary interactions across the component interfaces, and the mating geometry where there is a geometric connection [Sanchez \& Mahoney, 2012]. Research by the OBOM group in the Netherlands focused on the importance of interfaces between building components, or "building nodes" (Dutch: bouwknopen). Research on the actual connections (or joints) between building components [Olie, 1996] created a so-called "typology of joints" that supports the sustainable development of buildings. A problem related to interfaces is that there are no clear design rules or guidelines about how interfaces can be developed. This is problematic when a company decides to develop a new product for the building industry because there is a risk that it will be incompatible with other products in the same industry. With greater understanding and agreement about interfaces, companies will be better placed to innovate independently, with a lower risk of developing a product that is incompatible with other products in the construction industry.

\section{The relevance of accommodating geometric variations as a design approach in the design of assemblies}

\section{Design issue 1: The functional specification of the object to be realised}

This design approach for accommodating geometric variations relates to the design of interfaces between building components. As such, this approach cannot be used for the functional specification of an object to be realised.

\section{Design issue 2: The specification of the geometric quality of the assembly to be realised} The design approach to accommodate geometric variations addresses the design of interfaces between building components and can therefore be used in the process of specifying the geometric quality of the assembly.

\section{Design issue 3: The expected geometric variations in the assembled condition of the assembly to be realised}

The design approach is intended to accommodate possible expected geometric variations. This design approach can therefore be applied in the context of this design issue. When designing assemblies, this design approach is valuable because it is based on masking the visible effects of geometric variations in building parts. 
Box 2: By designing capitals, anticipate possible geometric variations.

Around 1350, there was a wave of construction in the coastal regions of the then Netherlands that saw a preference for natural stone in many buildings including churches [Hurx, 2010]. This material largely came from quarries in or near Brussels. It was transported to the construction sites, either as unprocessed rough-hewn blocks of stone or as products produced off-site. The rough-hewn blocks were processed on-site in so-called construction warehouses and then assembled. The pre-processed products were produced at workshops near the quarries themselves. The choice for off-site production combined with assembly was made because of the time that could be saved with this approach.

When designing the pillars for the churches, the architect could choose between clustered columns or capitals. Clustered columns are characterised by a smooth transition from the columns to the ribs of the vaulted ceiling. To achieve this transition, the blocks have to fit perfectly together during the assembly process. Alternatively, when using capitals, these link the columns to the ceiling's ribs. Furthermore, a cover layer was placed on top of the capital. Separating the colonettes from the ceiling ribs afforded greater flexibility in the positioning of the ribbed vault. This meant that the construction could be built with blocks that did fit together perfectly by creating some flexibility in individually positioning the cover layer and the ceiling's ribs.

Separating the colonettes from the ceiling ribs with cover plates created the space necessary to accommodate unavoidable geometric variations. These cover plates served as an assembly base for what would be placed on top of them. The use of cover plates shortened the construction time by facilitating the use of elements produced off-site. When using clustered columns, the system of ribs and arches is basically set at the start, enabling the various elements to be produced in a construction warehouse. The use of components produced off-site, necessitated by a desire to keep the construction time as short as possible, did however require a modification of the architecture as a result of the assembly process.

Nevertheless, these cover plates, despite the available adjustment, could not always hide the dimensional deviations of the various components as is visible in the Pieterskerk in Leiden (Figure 3.5). It is apparent that the arches are too large at the point where they rest on the cover plate. As a result, part of the arch sticks out from the cover plate. A possible explanation is that the arches were constructed in the construction warehouse at the same time that the columns were being ordered and that the builders did not realise their dimensional mistake until the cover plate arrived from the quarry.

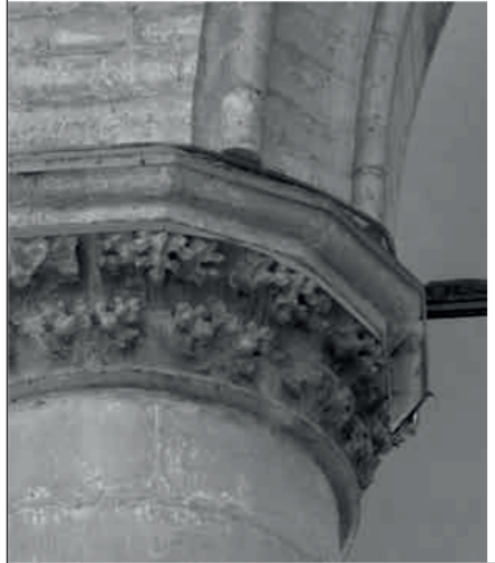

Figure 3.5: Pieterskerk, capital in the nave, Leiden, circa 1410 - 1430 [Hurx, 2010] 


\section{Design issue 4: The alignment of the specification of the geometric quality and the expected geometric variations of the assembly to be realised}

This design approach to accommodate geometric variations is intended to realise an acceptable solution for the expected geometric variations. This design approach can therefore be applied in the context of this design issue.

\subsubsection{Design for buildability}

Buildability involves a pre-construction exercise that assesses designs from the perspective of those that will manufacture and install components and carry out the construction work. Buildability can be considered as one of the decisive aspects of building design [Gray, 1984]. Buildability can be defined as the extent to which a design facilitates efficient use of construction resources and enhances ease and safety of on-site construction whilst meeting the client's requirements [Wong et al, 2005]. Buildability considerations amount to the designer's deliberations on how their designs affect site operations in terms of time, cost and safety performance and to agreed quality levels from its constituent materials, components and subassemblies.

Over the years, researchers and government agencies have highlighted principles and factors that affect buildability. The main recommendations were summarised by Simonsson [2011]:

Ferguson [1989] suggested that the assembly of parts is highly dependent on a number of factors such as tolerances, the variety of different parts, conversion of materials into subassemblies or finished structures, "handling" of parts on- and off-site, repetition of work and the co-ordination of dimensions.

The Government of Singapore has outlined a Code of Practice on Buildable Design [BCA, 2004], which states that a builder and/or contractor needs to achieve a minimum buildability score to be granted a building permit. The principles used for a buildable design are based on Standardisation, Simplicity and Single integrated elements. The buildability score approach is designed to increase the quality of buildings by increasing the relative ease of construction while not limiting architectural designs.

Pheng and Abeyegoonasekera [2001] recognised the importance of a stable flow of materials, components and subassemblies to aid progress with the construction work and achieve efficient, cost-effective on-site construction. Efficiency increases as a result of using standardised structural components that create repetitive work cycles on-site. CIRIA, cited in Francis and Sidwell [1996], recommended seven different steps for achieving good buildability: Carry out thorough investigation and design; Plan for essential site production requirements; Plan for a practical sequence of operations and early closure; Plan for simplicity of assembly and logical trade sequences; Detail for 
maximum repetition and standardisation; Detail for achievable tolerances; and Specify robust and suitable materials.

Adams [1989] further elaborated on the seven CIRIA steps and extended it to 16 steps: Investigate thoroughly; Consider access at the design stage; Consider storage at the design stage; Design for minimum time below ground; Design for early enclosure; Design for skills available; Design for simple assembly; Use suitable material; Plan for maximum standardisation/repetition; Maximise use of plant; Allow for sensible tolerances; Allow a practical sequence of operations; Avoid return visits by trades; Plan to avoid damage to work by subsequent operations; Design for safe construction; and Communicate clearly. Furthermore, it was noted that the designer is usually contracted by the client and therefore has no obligation or incentive to include buildability concepts that will benefit the contractor who is only supposed to follow the designer's plans. The lack of dialogue between design and construction was seen as hampering productivity increases in the construction industry.

It is important not only to know that a work task can be performed, but also how it should be performed [Ballard, 2000]. Decisions made early in the design phase are decisive in the specification, planning and execution of downstream activities [Jørgensen and Emmitt, 2009]. As such, they can impact on how a production process can be completed on site. Therefore, the designer should incorporate knowledge from the critical actors in the project to enable the design to incorporate buildability factors such as simple assembly, maximum repetition/standardisation and a practical sequence of operations. There is also a significant interdependence between subsystems where a decision regarding one subsystem can have a major influence on design and assembly processes of others.

The National Research Counsil (NCR) report 'Advancing the Competitiveness and Efficiency of the U.S. Construction Industry' [NCR, 2009], recommended five activities to make construction more productive, which they called "Opportunities for Breakthrough Improvements":

1 Widespread deployment of Building Information Modelling (BIM).

2 Improved job-site efficiency through more effective interfacing of people, processes, materials, equipment and information.

3 Greater use of prefabrication, preassembly, modularisation and off-site fabrication techniques and processes.

4 Innovative, widespread use of demonstration installations.

5 Effective performance measurement to drive efficiency and support innovation.

Applying the first three items in the NCR list relates to enhancing integration of the design and the production processes. The use of prefabrication, preassembly, modularisation and off-site production also requires feedback of information about production rules and design constraints to be passed upstream in the construction process [Malmgren et al., 2010]. 
Although buildability also relates to the use of assembly as a production method, it has so far not specifically paid attention to geometric variations and therefore not to the related design issues. Naturally, buildability-facilitating activities relate to the design of assemblies in the construction sector. The relevance of practically manageable tolerances has also been recognised. However, it is not indicated how all the aforementioned issues can be operationalised in a coherent manner. Directions are provided on how to improve buildability. However, the four design issues described in the introduction of this chapter relate to the specification and prediction of geometric variations associated with certain manufacturing and assembly processes and the buildability literature does not address this.

\section{The relevance of design for buildability in the design of assemblies}

\section{Design issue 1: The functional specification of the object to be realised}

The main aspects of design for buildability are not related to describing the functional specification of the object to be realised. Therefore, the buildability approach cannot be used to address this design issue.

Design issue 2: The specification of the geometric quality of the assembly to be realised The relevance of practically feasible tolerances has also been recognised as an element of buildability. However, what should be understood by this or how these can be determined has not been described. The application of buildability therefore does not contribute to resolving this design problem.

\section{Design issue 3: The expected geometric variations in the assembled condition of the assembly to be realised}

The key aspects of design for buildability point to the importance of recognising aspects affected by geometric variations such as manufacturing and assembly processes. However, it is not indicated how this can be addressed during a design process. In order to be able to apply design for buildability in relation to this design issue, it is desirable that this design approach be further developed.

\section{Design issue 4: The alignment of the specification of the geometric quality and the expected geometric variations of the assembly to be realised}

Design for buildability does not provide a method that can be used to address this design issue. 


\subsubsection{Design for manufacturing and assembly in construction}

The application of design for manufacturing and assembly (DfMA) in the design of mechanical assemblies was described in Section 2.1. Its application in the field of construction has been described by Gao et al. [2019] in an extensive literature review. The literature consulted for this was selected using an English language abstract and citation database. The search terms used were "design for manufacture and assemble", "design for manufacture", "design for assembly", "DfMA", "design for construction" and "construction". In addition to the typical benefits of implementing DfMA, this led to three emerging perspectives on DfMA in construction:

DfMA as a systematic process.

DfMA as an evaluation model.

DfMA as a means for prefabrication.

These perspectives and typical benefits of implementing DfMA are described below.

\section{DfMA as a systematic process}

DfMa is recognised as a systematic process that can add value to the construction/production process by standardising and limiting the number of design alternatives. The applicability of DfMA in the construction sector is comparable to that in manufacturing industry. Its application encourages designers to record experiences from previous projects and use them in designing new ones. In this, it is desirable to set up an iterative design process to enable continuous optimisation of a design. The requirements for this process are a team approach or simultaneous engineering. The application of DfMA turns the traditional sequential design process into a process in which design and manufacturing influence each other.

\section{DfMA as an evaluation model}

It has been found that in order to apply DfMA as an evaluation model it is desirable that the assemblability of a design can be determined on the basis of objective criteria. Both the Boothroyd-Dewhurst method and the Hitachi method are considered applicable evaluation methods, and these are described along with their application in Section 2.7. Gao et al. [2019] note that these evaluation methods have been developed for manufacturing industry. It has also been noted that assemblability in construction has many similarities with buildability and that the criteria necessary for determining an objective DfMA index can be developed on the basis of buildability aspects. Criteria developed in this way can be applied in simulation software. 


\section{DfMA as a means for prefabrication}

The application of DfMA in the construction industry is considered a way to stimulate off-site production. In order to classify off-site production, reference is made to the classification described by Gibb [2001] and shown in Section 1.1. In the context of stimulating the application of DfMA in construction, the classification used by the Singapore Building and Construction Authority [BCA, 2016] has been regarded as a driver of game-changing DfMA technology. This classification is based on a subdivision process based on the series: 'material', 'component', 'assembly' and 'module'.

\section{Typical benefits of implementing DfMA}

In general, there is a lack of empirical evidence regarding the value of using DfMA in construction. The benefits of applying DfMA are often described in a qualitative sense and relate to reducing material costs, and minimising assembly and transport costs. The Royal Institute of Britisch Architects (RIBA) [2013] found a reduction of 20-60\% in construction time, and a greater programme certainty.

\section{The relevance of design for manufacturing and assembly in the design of assemblies}

The relevance of design for manufacturing and assembly in the construction and infrastructure sector, as described by Gao et al. [2019], in the assembly design process can be deduced by evaluating its contributions to solving the four earlier discussed design issues:

\section{Design issue 1: The functional specification of the object to be realised}

Design for fabrication and assembly as described by Gao et al. [2019] aims to limit work on the construction site. On this basis, DfMA cannot be applied in functionally specifying an object.

Design issue 2: The specification of the geometric quality of the assembly to be realised With regard to the design of assemblies, design for manufacturing and assembly is particularly suitable for evaluating a design based on its buildability aspects. Buildability recognises the importance of tolerances, but it is not indicated how these can be specified. As such, design for manufacturing and assembly is not applicable in the context of this design issue.

\section{Design issue 3: The expected geometric variations in the assembled condition of the assembly to be realised}

The application of design for manufacturing and assembly is particularly suitable for evaluating a design based on buildability criteria and not for overcoming geometric variations. In order to be able to use DfMA to address this design problem, this design approach needs further development. 


\section{Design issue 4: The alignment of the specification of the geometric quality and the expected geometric variations of the assembly to be realised}

As described under the previous design issue, design for manufacturing and assembly is particularly suitable for evaluating a design based on buildability criteria and not for dealing with geometric variations. For DfMA to be useful in addressing this design problem, it requires further development.

\subsubsection{Concluding remarks with respect to the five design techniques}

Table 3.2 shows the applicability of the five described design techniques. Their applicability will now be further explained.

Table 3.2: The applicability of the identified design techniques in addressing design issues related to designing assemblies.

\begin{tabular}{|c|c|c|c|c|}
\hline \multirow[b]{2}{*}{$\begin{array}{l}\text { design techniques } \\
\text { applied in the } \\
\text { construction industry }\end{array}$} & \multicolumn{4}{|c|}{ design issues as a representation of the field problem } \\
\hline & $\begin{array}{l}\text { functional } \\
\text { specification } \\
\text { of the object } \\
\text { to realize }\end{array}$ & $\begin{array}{l}\text { specification of } \\
\text { the geometric } \\
\text { variations of } \\
\text { the object }\end{array}$ & $\begin{array}{l}\text { expected geo- } \\
\text { metric variations } \\
\text { in the realised } \\
\text { assembly }\end{array}$ & $\begin{array}{l}\text { alignment of the } \\
\text { specification } \\
\text { and the expected } \\
\text { geometric } \\
\text { variations }\end{array}$ \\
\hline $\begin{array}{l}1 \text { systems } \\
\text { engineering }\end{array}$ & is applicable & $\begin{array}{l}\text { the decompo- } \\
\text { sition principle } \\
\text { is applicable }\end{array}$ & $\begin{array}{l}\text { application is } \\
\text { not obvious }\end{array}$ & $\begin{array}{l}\text { application is not } \\
\text { obvious }\end{array}$ \\
\hline $\begin{array}{l}2 \text { building information } \\
\text { modelling }\end{array}$ & $\begin{array}{l}\text { application is } \\
\text { not obvious }\end{array}$ & $\begin{array}{l}\text { is applicable } \\
\text { for support }\end{array}$ & $\begin{array}{l}\text { is applicable } \\
\text { for support }\end{array}$ & $\begin{array}{l}\text { is applicable for } \\
\text { support }\end{array}$ \\
\hline $\begin{array}{c}3 \text { accommodation of } \\
\text { geometric variations }\end{array}$ & $\begin{array}{l}\text { not } \\
\text { applicable }\end{array}$ & is applicable & is applicable & is applicable \\
\hline $\begin{array}{l}4 \text { design for } \\
\text { buildability }\end{array}$ & $\begin{array}{l}\text { application is } \\
\text { not obvious }\end{array}$ & $\begin{array}{l}\text { application is } \\
\text { not obvious }\end{array}$ & $\begin{array}{l}\text { further devel- } \\
\text { opment is } \\
\text { required for its } \\
\text { application }\end{array}$ & $\begin{array}{l}\text { further devel- } \\
\text { opment is } \\
\text { required for its } \\
\text { application }\end{array}$ \\
\hline $\begin{array}{l}5 \text { design for manufac- } \\
\text { turing and } \\
\text { assembly }\end{array}$ & $\begin{array}{l}\text { application is } \\
\text { not obvious }\end{array}$ & $\begin{array}{l}\text { application is } \\
\text { not obvious }\end{array}$ & $\begin{array}{l}\text { further devel- } \\
\text { opment is } \\
\text { required for its } \\
\text { application }\end{array}$ & $\begin{array}{l}\text { further devel- } \\
\text { opment is } \\
\text { required for its } \\
\text { application }\end{array}$ \\
\hline
\end{tabular}

\section{Systems engineering}

Systems engineering can be used to formulate the functional specification of the object, and the decomposition principle applied in systems engineering can also be applied in the design of assemblies. Systems engineering is not concerned with determining the geometric quality of assembly processes and cannot therefore be applied in the design of aspects that specifically relate to this. 


\section{Building information modelling}

Building information modelling is especially suitable for displaying parts in a three-dimensional space. This is extremely valuable when designing assemblies. As such, it does not appear relevant when drawing up functional specifications. However, when specifying the geometric quality of an object to be realised, it can be used to represent the space available to accommodate geometric variations. It also offers possibilities to represent the consequences of assembly processes and dimensional deviations in building parts in the as-built situation. Building information modelling is therefore a potentially valuable technique when designing assemblies.

\section{Accommodation of geometric variations}

The accommodation of geometric variations design technique is applied in the design of objects that come about by means of assembly. The interfaces designed in this context anticipate the geometric variations to be accommodated. These variations are in principle derived from the manufacturing and assembly processes applied. The geometric variations that can be accommodated through a designed interface can be considered as a specification of this interphase. However, this specification could deviate from the functional specification of the object to be designed. As such, this design technique can particularly be applied in addressing design issues 2, 3 and 4 .

\section{Design for buildability}

This design technique is similarly applied when designing objects. This also makes it unsuitable for the specification of objects to be realised. Engineering for buildability refers to design goals when designing assemblies. Some of these goals were considered in Section 2.7 'evaluating and improving the design of assemblies'. Although such goals are stated in the design technique, there are no design rules with which they can be realised through design decisions. In order to be useful in the design of a construction assembly, a design rule needs to be developed for this.

\section{Design for manufacturing and assembly in construction}

The application of design for manufacturing and assembly in construction can be considered as a method for evaluating an already available design. As such, this method is not suitable for specifying objects to be realised. In applications of DfMA, the aim is to achieve goals related to the assembly rather than the goals of a project to be designed. To be usable in the design stage, a design rule needs to be developed to address this aspect. 


\subsection{Conclusions}

The sub-question that this chapter set out to answer was the following:

To what extent are the current design process and design techniques, as applied in the construction and infrastructure sector, geared towards the design of assemblies?

After an analysis of the design process that is generally used in the construction and infrastructure sector, it can be concluded that attention is not explicitly given to the occurrence of geometric variations. As a consequence no desirable design activities are initiated that would accommodate relevant geometric variations associated with off-site fabrication and assembly.

Of the design techniques described in Section 3.2, systems engineering, the accommodation of geometric variations, design for buildability and design for manufacturing and assembly appear to have the potential to be applicable in addressing the identified design issues related to geometric variations. However, these techniques all need to be further developed for this purpose. Here, building information modelling could be used as an aid.

The conclusion with regard to the sub-question to be answered in this chapter is that the design process applied and the design techniques are insufficiently geared to the design of assemblies as realised in the construction and infrastructure sector. This finding reflects an earlier recommendation by the Advisory Council for Technology Policy in the Construction Sector [ARTB, 1998] who, in view of the increased level of prefabrication in the construction sector, recommended to take, already at an early stage of the design process, into account the feasibility of a design during its execution. ARTB labelled this specific process activity as "Design-to-build". 



\section{A first draft of a design- for-assembly method for construction and infrastructure projects}

\section{Contents}

4.1 Introduction

4.2 The design aspects and the general structure of the designfor-assembly method

4.3 The first draft of the design for assembly method

4.4 Demand specification

4.5 Spatial and functional design

4.6 System design

4.7 Nominal design

4.8 Variation design

4.9 Preparing the execution of the assembly process

4.10 Execution of the assembly

4.11 The organisation of the design- and execution process

4.12 The first draft of the construction assembly design method and its parameters 


\subsection{Introduction}

This chapter covers Phase 2 of this research (see also Section 1.3). It concerns the development of the first draft of the construction assembly design method. This was addressed by answering the following sub-question:

What adaptations are necessary to the commonly used method for the design of objects in the built environment to make it suitable for objects that are constructed through an assembly process?

Given the question to be answered in this chapter, the specification for the design-for-assembly method is based on the objectives described in Section 2.2 for assemblies in general, namely: creating value for the end user through an efficient realisation of the designed product. From this, the specification is as follows:

When applied, the design-for-assembly method results in value for the end user and the efficient realisation of objects in the built environment. Given that the design of such an object cannot usually be tested by means of a test assembly, the design result must be realised in a transparent manner and must be usable when procuring assembly activities. The method must be applicable by construction technologists.

To answer the current question, the results from the first research phase were used. Based on these results, Section 4.2 describes the design aspects and the general structure of the design method that is to be developed. Section 4.3 then explores the design process of the method in more detail. Sections 4.4 to 4.10 further substantiate the method. Given the possibility that suppliers are involved in the design of the assemblies of objects, Section 4.11 describes how their involvement can be organised during the design process and how assemblies can be procured. Finally, the conclusions regarding the sub-question are answered and the design method parameters that will be used in the case studies are described in Section 4.12.

\subsection{The design aspects and the general structure of the design-for-assembly method}

This section covers the design aspects and the general outline of the design method.

\section{The design aspects of the method to be developed}

As described in Section 2.11, the design aspects of a design-for-assembly method must be derived from its relevant context. The relevant context has been described in Chapter 3 . 
The design aspects and context-related interpretation are described below. This is based on the four design aspects of the field problem identified in Section 2.10.

\section{Design aspect 1: Functional specification of the object to be realised}

It was noted in Section 2.5 that design for assembly can be used for structures, with shells and trusses given as examples. Such structures consist of parts that belong to a single production system and can therefore be seen as a single system. However, objects in the built environment often consist of components produced off-site as described by Gibbs [2001]. For example, a building consists of a supporting structure, climate separation and installations and a viaduct consists of a substructure and a superstructure. These construction parts often belong to different production systems. In order to design the assembly of an object, it needs to be seen as a collection of systems, a so-called system of systems. Through system-to-system interfaces, these then become a constructed whole. The meeting points between systems are called system-to-system joinings. A connection often concerns a geometric requirement for a joint between systems. According to Eekhout's hierarchical sequence [Eekhout, 2015], a system consists of a collection of building parts that, after assembly, realise a certain functionality. Connections in a system become system interfaces and joinings within them are called system joinings.

In the context of the operationalisation of design aspect 1 , the available design must be decomposed into systems. Parts that have been produced through a certain production system can be considered as one system.

\section{Design aspect 2: Specification of the geometric quality of the object}

As with structures, the design intent of the assembly that is to be designed must be describable. The design intent of an object to be assembled involves the realisation of the technical and aesthetic specifications, which are defined using measurable units [Henket, 2013]. These can be derived from the requirements specification. For each recognised system, geometric units must describe how the design intent can be realised.

\section{Design aspect 3: Expected geometric variations of the realised assembly}

With a few exceptions, the assembly of an artefact always requires an assembly base that can be seen as dimensionally stable. Built objects are connected to the ground through their foundations, which transfer the mass of the object and the loads in and on the systems to be assembled to the ground. The foundation can also be part of an assembly that has to be designed. When the assembly of an object is being designed, the foundation is considered to be dimensionally unstable given the prevailing situation in the Netherlands. The implication is that the foundation or assembly base of a system to be assembled may deform during assembly.

When designing artefacts such as mechanical systems, the deformations that occur can 
generally be ignored. Although deformations do occur, they are so minute that they do not affect the assembly processes or can be avoided with the use of fixtures. Assembling a system of objects in the built environment is also subject to deformation during assembly. This results in a deformed state of the system of systems, which often affects the assemblies to be designed. The deformations that occur over time can often be calculated. Calculating the deformation is not part of the design of the assembly; rather the information about the expected deformation is made available to facilitate the design of the assembly.

The specification of the design method states that the method to be developed must result in the efficient realisation of objects in the built environment. It is therefore assumed that the process feasibility (Cpk) of the assembly processes used in the construction is greater than one.

\section{Design aspect 4: The alignment of the specification and the expected geometric variations}

In ensuring this alignment it must be clear when it is desirable to utilise third-party knowledge, e.g. the expertise of suppliers. Furthermore, it must also be clear how these third parties can be involved in the design and realisation processes.

The result of the alignment, and the design method to be developed, amounts to a model, the so-called assembly model, based on which the assembly can be realised. In this model, the positions of the components of the assembly are generally indicated in relation to the world coordinate system. This position must be realised upon completion of the assembly.

Positioning the parts in relation to the world coordinate system is a deviation from the positioning method that is commonly used for mechanicals. These are often seen as a so-called chain of frames [Whitney, 2004]. However, this is only possible if deformations do not occur during the assembly process. Moreover, the position of building components is determined in relation to a world coordinate system and not in relation to other components.

\section{The general design of the design-for-assembly method}

The design-for-assembly method that will be developed is created by adapting the design method commonly used for constructions, as described in Section 3.1, in such a way that it produces the desired output as described in Section 4.1. Given that a construction is seen as a system of systems, this design method will consist of a component that pertains to the system-of-systems design and a component that pertains to the design of the individual systems. The representation of the design-for-assembly method shown in Figure 4.1 is based on this. 


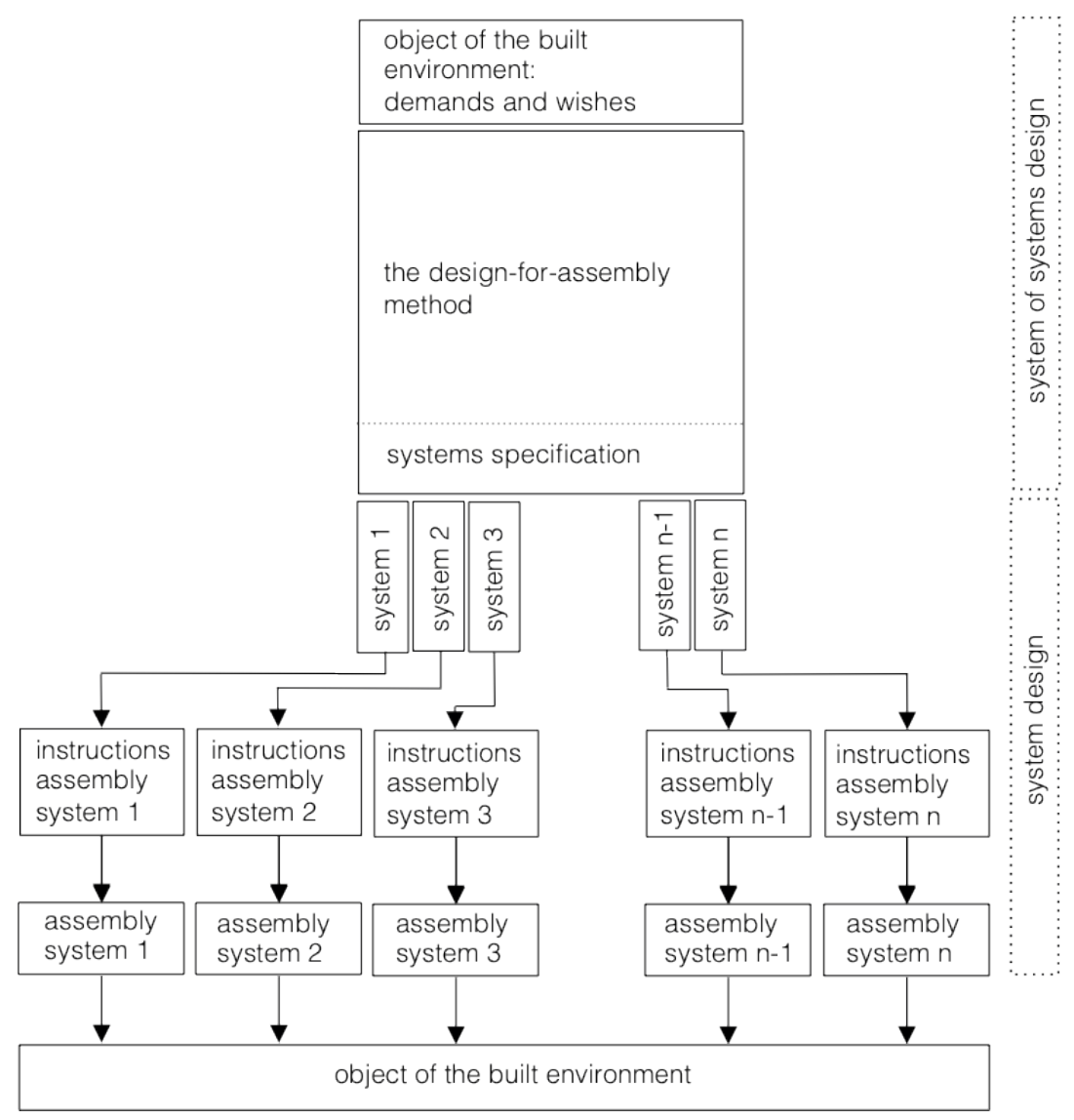

Figure 4.1: The general structure of the construction assembly design method.

As shown in Figure 4.1, the design for the assembly of an object in the built environment consists of the system-to-system design of the entire assembly and the system design of the assemblies of the individual systems. The number of systems to be designed depends on the number of distinguishable production systems given all the parts to be assembled. The parts whose geometric qualities are determined in a similar manner, whose dimensional deviations can be described using a tolerance field with a certain process feasibility and whose assembly can be realised using the same assembly process all belong to the same production system. Parts that belong to the same production system can be seen as interchangeable. The fact that various building parts are made from the same material does not necessarily mean that these parts belong to the same production system since they might have been produced using several vastly different production methods. The construction assembly design method to be developed must result in the integral design of the entire assembly. 


\subsection{The first draft of the design-for-assembly method}

Designing its assembly is an important aspect during the design process of a construction object. The extent to which this aspect is relevant varies depending on the construction. For example, sometimes the hoisting capacity or the accessibility will impose conditions on the building parts. There are also assemblies where the intended behaviour of the construction imposes conditions on the system interfaces between the building parts, as is the case with column splices. There are also assemblies that are realised without any such issues and without specifically focusing on this aspect at all. The latter occurs when the design can be realised based on the tacit knowledge of the parties.

The extent to which the assembly requires explicit attention during the design of an object is therefore a consequence of the design of the technical system. It depends on the requirements, the context and the selected technical solutions. Assembly needs to be considered at the same time as the design of an object. The phasing of the design process has to make it possible to identify the aspects that are relevant for assembly in each phase. For each phase, the design result can be described with an assembly model. Furthermore, it is desirable to be able to assess the executability and efficiency of a proposed assembly method before its actual implementation.

The process steps of the first draft of the construction assembly design method are outlined below and represented in Figure 4.2. These are a composition of design methods that are commonly used for the design of objects in the built environment, e.g. NEN 2574 Construction drawings - arrangements of data on building drawings standard (described in Section 3.1) and of assemblies as structures (described in Section 2.6). The first process step "demand specification" is the result of the phases "initiative, feasibility study and the project definition" as outlined in NEN 2574. The process step "spatial and functional design" is an addition to NEN 2574, it is in line with the phase "demand specification" and corresponds to the phase "product architecture design" as described in Section 2.6. Given that an object is viewed as an assembly of systems, a "system design" phase as described in Section 2.6 is added. This system design phase replaces the "structure and preliminary design" phase of NEN 2574. This ties in with the use of the term "systems engineering". The "nominal design" process step, as described in Section 2.6, replaces the final "design" phase of NEN 2574. The "variation design" process step concerns an extension of the design process as described in NEN 2574 and it replaces the "job description" phase of NEN 2574. The methods and techniques described in Section 2.11 can be applied during the "variation design" process step. The "preparations of the assembly" process step replaces the "pricing and work preparation" phases of NEN 2574 and the "execution of the assembly" process step, replaces the "realization of the project" phase of NEN 2574.

The method represented in Figure 4.2 realises the design of the assembly process by following 
the same steps that are used in the design of a structure (described in Section 2.6). These steps are:

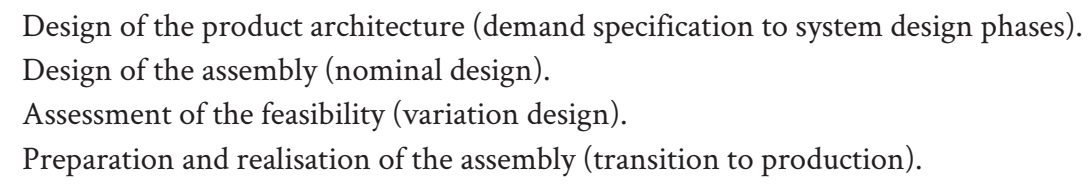

The design-for-assembly method that facilitates explicit attention to the design of the assembly process consists of the following phases:

\section{Demand specification}

During this phase, the design intent is described. Designing the assembly process is not relevant at this point. The demand specification will be covered in more detail in Section 4.4.

\section{Spatial and functional design}

This offers insight into the internal and external appearance and fitting into the environment. Upon completion of this phase, the functional spatial design of the object will be available. During this phase, the assumptions are established for the design of the assembly process. The spatial and functional design will be covered in more detail in Section 4.5.

\section{System design}

During this phase, the systems to be utilised, maybe including a supporting structure, climate separation system, climate control, bridge deck and finishing, are selected and the rough dimensions determined. Furthermore, the assembly order, the demarcation of the systems, the interfaces and the joinings between these systems are identified and qualitatively described. This is similar to identifying the parts and the key characteristics of an assembly design as described in Section 2.2. Systems can be demarcated with the help of a "geometric dimensioning and tolerancing" system. The system design will be covered in more detail in Section 4.6.

\section{Nominal design}

The nominal design of the assembly can be drawn up based on the assumption that all systems consist of construction parts that meet the preferred dimensions [Ferguson, 1989], that they are all in the correct position during assembly, that the joinings have been realised and that no deformation has occurred. This is considered the nominal situation. The nominal design will be covered in more detail in Section 4.7.

\section{Variation design}

The design of the assembly of a construction can generally not be tested by producing a prototype. When it comes to constructions, one must determine what dimensional deviations 
may occur in the assembly, in the dimensions and in the position of the construction parts in realising the key characteristics. If these deviations prove irresolvable, the design or the design intent must be modified. Furthermore, the assembly processes that are to be used must be described and it must be determined whether the supposed process capabilities are feasible. The realisation of the variation design is similar to that used for designing the assembly of mechanicals (described in Section 2.6).

In addition to functionally assessing the designed assembly process, it is also evaluated in terms of the duration and costs of its realisation. If the assessed assembly processes do not meet the requirements, an alternative must be developed, which must then also be assessed. If no suitable process can be found, the key characteristics would appear to be infeasible under the applied conditions. The design of the assembly process will be finished once a design is assessed as having feasible key characteristics and as meeting the requirements regarding costs and realisation time. The variation design will be covered in more detail in Section 4.8.

\section{Preparations for the assembly}

During this phase, the assembly of the individual systems can be optimised using the methods and techniques defined by Boothroyd, Dewhurst and Knight [2010]. Based on the evaluated and optimised design, the preparations for assembly are made. These consist of drawing up manuals for the assembly of the systems to be used and, in some cases, developing a plan for monitoring the deformations that might occur during assembly. Such manuals are also known as installation plans. These preparations for assembly will be covered in more detail in Section 4.9.

\section{Execution of the assembly}

This phase concerns the logistical preparations at the assembly area and the assembly of the construction parts. Depending on the degree of uncertainty regarding assembly capabilities, it may be desirable to conduct control measurements. These should relate to the defined key characteristics. The degree of control can be assessed based on the so-called process feasibility, as described in Section 2.3. The execution of the assembly will be covered in more detail in Section 4.10.

\section{Completion of the assembly}

By drawing up and issuing control documents, the object is handed over to the client. 


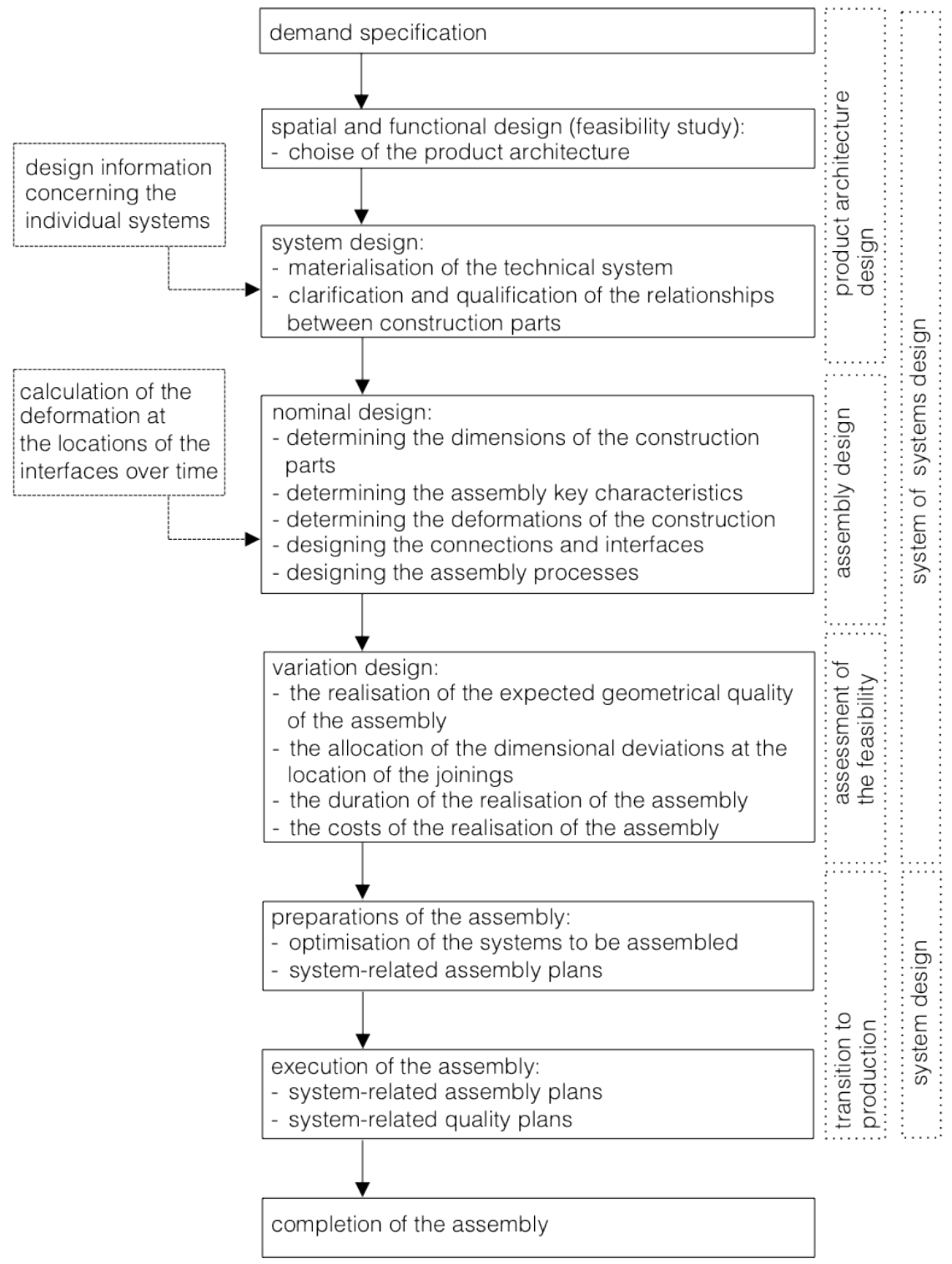

Figure 4.2: The process steps of the first draft of the design-for-assembly method. 


\subsection{Demand specification}

In Section 3.1, the "demand specification" was described as part of the design process. This means that, at this point, a functional, technical, financial, spatial and organisational framework has been defined for the demanded object. Hofman et al. [2006] describe the way in which trade-off decisions regarding standard solutions versus specific consumer preferences can be made using a so-called vignette method.

Henket [2013] describes the performance requirements for the construction of a new building. These pertain to the architectural value, the user requirements and ecological values. Henket argues that performance requirements should be open to discussion and verifiable, and he advocates the use of measurable units. If this is not possible, he suggests using alternative performance requirements that make use of concepts such as transparent, warm and soft. An example of a demand specification is the Ambition Document for a new courthouse in Amsterdam [Rijksvastgoedbedrijf, 2014].

The demand specifications for infrastructural projects often consist of a design brief and a visual quality plan. These documents do not provide any information regarding how the project will be realised. The manner in which the Dutch Central Government Agency Rijkswaterstaat procures its works is outlined in the Procurement Regulations Works 2012 [Rijkswaterstaat, 2012].

\section{Design result}

Using an assembly model for the purposes of supporting the assembly process does not require any additional design activities during the demand specification phase. This is because, during this phase, no decision has yet been made regarding the use of construction parts that are produced offsite. The performance requirements that are to be realised can be described using measurable units.

\subsection{Spatial and functional design}

During this phase, the spatial-functional design is created, which offers insight into the internal and external appearance and fitting into the environment. The spatial and functional design needs to be assessed in light of the demand specifications prior to designing the assembly process. The assessed spatial and functional design serves as the starting point for the process of designing the assembly.

Henket [2013] substantiates performance requirements, which are based on the demand specification, in the form of requirements for the functional and technical system as shown in Figure 4.3. The functional system consists of all the conditioned spaces within the 
building. The technical system is the materialisation of the construction. For a building, the spatial and functional design addresses the functional system. The design of the assembly process pertains to the technical system, the performance of which is also known as the "product key characteristics". These are generally derived from the design intent of the object to be realised. The product key characteristics related to the design of the assembly concern the degree to which the effects of geometric variations are still acceptable. Given that these are numerous, it is desirable to limit them to those effects that, possibly based on prior experience, are considered to be a given. Examples of product key characteristics are the maximum tilt of a number of columns, the acceptable variance in joint width between two construction parts produced offsite and the maximum leakage of a joint between two sewer pipeline sections that were produced offsite.

Henket's distinction between a functional and a technical system also applies to objects that are not intended to create conditioned spaces, examples of which are the objects that are realized by the infrastructure sector. Note that the realisation of a technical system is rarely a goal in itself unless the purpose of is to study its feasibility.

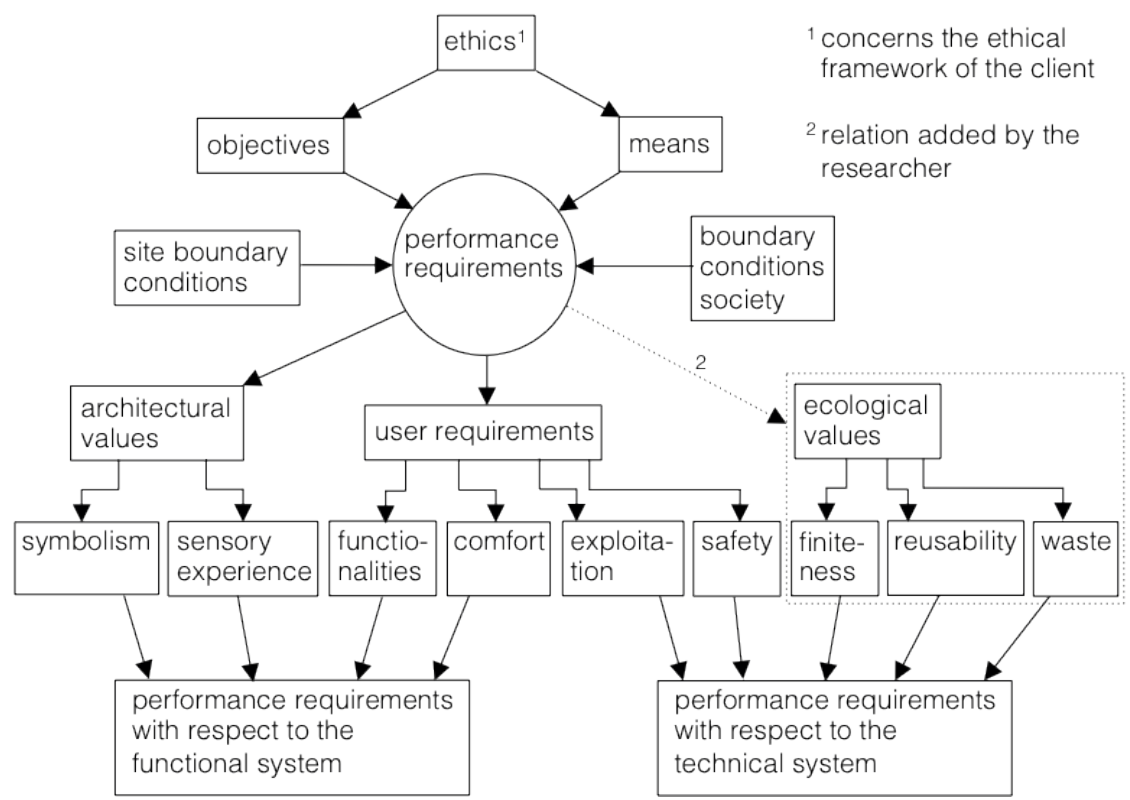

Figure 4.3: An object as a representation of a functional and a technical system [from Henket, 2013].

During the spatial and functional design phase, the product architecture is also chosen, i.e. the choice is made between a "modular" or an "integral" approach [Ulrich, 1992]. A modular approach may be based on the application of units of the functional system; with one unit 
consisting of components of a number of technical systems. The spatial and functional design is broken down into such units, which are also referred to as modules. Modules can be produced entirely offsite. In addition to connecting the systems, the realisation of the object involves the linking together of the modules at the assembly location. As part of the FutureHome project, a study was conducted on the robotised assembly of such modules [Martinez et al., 2008]. During the expansion of the Erasmus University Medical Center in Rotterdam, the application of the modular approach was considered [Crone, 2007]. This approach was utilised for a housing development project in Hengelo [Crone, 2007]. The differences between the modular and the integral approach are explained in more detail below.

\section{Modular approach}

Here, the functional system is broken down into modules, the proper functioning of which requires interfaces between the modules. When designing the individual modules, an integral approach will be used. In designing the functionality of the interfaces, it is possible to choose between monofunctional and multifunctional interfaces [Ulrich, 1992]. During this phase of the design, it is desirable to describe the functions in a qualitative manner.

\section{Integral approach}

The integral approach for the realisation of a technical system is seen as an assembly of systems. The completed assembly provides the desired technical system. The assembly of the systems takes place on a sequential basis, where the already assembled systems form the base for the next system in line. The design of the assembly process focuses on those components of the technical system whose properties are important for realising the design intent.

When designing the assembly using the integral approach, the functional and the technical systems must be fully described in measurable units upon completion of this phase. The technical system has been broken down into separate building segments ${ }^{1}$, indicated with a for building elements preferred classification method. Furthermore, the performance to be provided by each segment, or combination of segments, is also described. The performance requirements outline the value created, the costs and the desired realisation time.

\section{Design result}

The result of either the modular or the integral approach is the initial implementation of the design intent. This should include the measurable units with which it has been substantiated. The chosen product architecture can be described in the assembly model. When

1 A collection of construction parts that can perform a similar function. 
choosing the modular approach, the modules, interfaces and preconditions pertaining to the assembly location can be described. When choosing the integral approach, the technical systems and the preconditions pertaining to the assembly location must be described in a qualitative manner.

\subsection{System design}

Based on the approach developed by Henket [2013], the system design concerns the further concretisation of the technical system. During this phase of designing the object, the materials for the systems to be applied (e.g. the supporting structure, climate separation, climate control, guardrails and finishing) are selected and their rough dimensions and weights can be determined. Furthermore, the relationships to be realised between the various systems must be identified and qualified, and the assembly order determined. These can pertain to qualities which are deemed important, or which are relevant for the assembly. It is desirable to incorporate all this information in the assembly model. This aspect is covered in more detail at the end of this section.

\section{Materialisation of the technical system}

The material choices and the indicative dimensions of the subsystems, also known as construction parts, of the technical system can be determined through consideration of values and costs. The indicative dimensions of the construction parts should be partly determined based on the production technology, the transport options to and from the assembly location, the available hoisting facilities and the assembly process. For both architectural and civil works, these often determine the maximum dimensions and weights of construction parts. The manner in which the material choices are made is only important for the assembly process when variables that affect the design intent are a factor. A good example is construction time: a shorter construction time can be used to reduce interest payments or begin generating income earlier.

\section{Clarification and qualification of the relationships between construction parts}

In order to design the assembly process, it is essential to identify the relationships between the various construction parts during this phase of the design and to describe them in a qualitative manner. As Chapter 2 addressed regarding the design of mechanicals, for objects in the built environment these relationships must also be determined based on the key characteristics to be realised. For the relationships between construction parts, these are the system-to-system key characteristics which often pertain to joinings. Examples include:

The joining between a bollard and a quay wall.

The joining between the leaf of a bridge and the abutment. 
The joining between the moving parts of a floodgate and the construction.

The joining between a traffic gate and the foundations.

The joining between a climate separation and the supporting structure in a building.

The joining between a jetway and the gate in an airport.

For the sake of clarification, examples 4 and 5 are described in more detail below.

\section{The joining between a traffic gate and the foundation}

The system-to-system characteristics to be realised concern the location and the strength of the foundation, including the anchoring. The location concerns the position of the foundation on the correct side of the road, the orientation of the connecting line between both foundations and the distance between both anchors, measured horizontally parallel to the connecting line. The strength concerns the vertical and horizontal forces to be handled and a certain rotational rigidity perpendicular to the connection line between both foundations.

The joining between a climate separation and the supporting structure in a building In the publication "Integration in the façade zone", Gerritse [1986] described joinings between systems. He examined the interactions between commonly used construction parts in the façade zone. The following systems can be present:

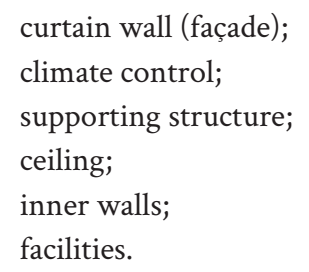

In the system design, its desired functionality is described in more detail. Furthermore, choices pertaining to the tectonics can be included. This mainly concerns information about the geometry, which is comparable to the design of the assembly of a car body, which is generally based on the product key characteristics to be realised.

The number of joining details that require further information depends on the extent to which the designer wishes to influence the geometry and tectonics. Figure 4.4 shows a design sketch where the important system-to-system joinings, also known as joining details, have been marked. Such joining details provide insight into the system-to-system key characteristics that must be provided by the construction parts in the as-built situation. This enables the required joinings between the construction parts to be identified and described. The figure shows that, in this specific example, the number of joinings that require further information is limited. 

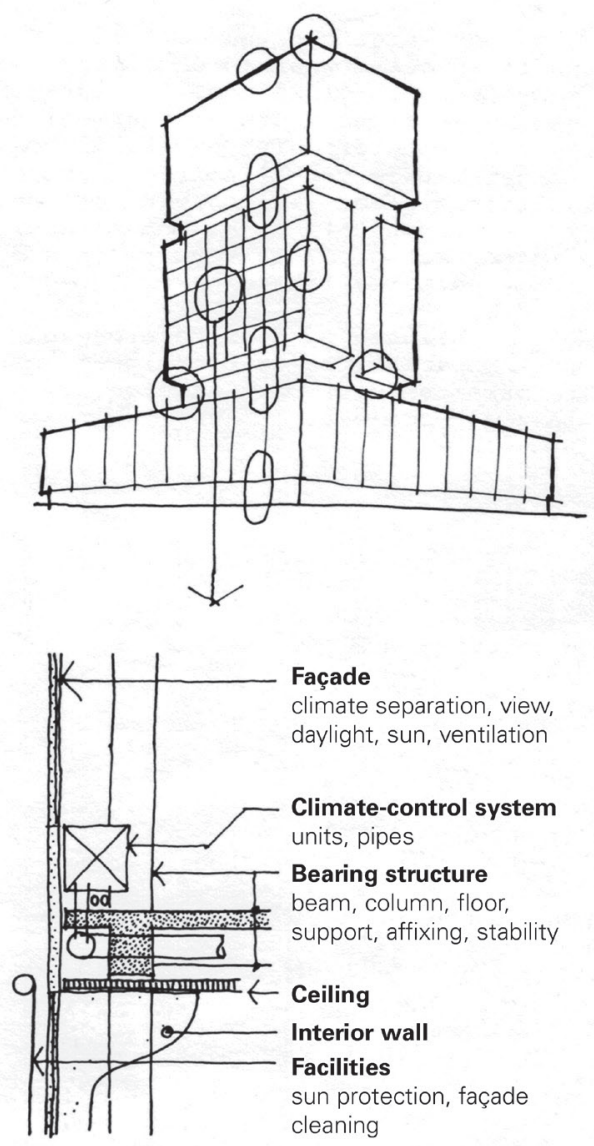

Figure 4.4: Integration of systems in the façade zone [Gerritse, 1986].

In addition to identifying and describing the joinings, the type of joining and the assembly order must also be determined during this phase. For assemblies of complex systems, the flow-down representation introduced in Chapter 2 can be utilised. In the example of the traffic gate, the assembly order cannot be altered, which means the joinings to be realised can be described straight away. Here is an example of such a description:

For the joining of a traffic gate to the foundation, the geometric quality of the foundation can be described using its dimensions, a certain elevation in relation to a reference point and the flatness of the horizontal axis at the location of the joining to be realised. In practice, it is not necessary to describe such a joining every time. When a certain joining is used more than once, it can be described with the help of certain parameters as a system element of an assembly. 
To illustrate the flow-down representation, the example provided above of the design of an office façade zone is used. This flow-down is shown in Figure 4.5. With the help of connecting lines, the flow-down "construction of systems in the façade zone" shows the relationships between the product and system key characteristics and illustrates the sequential order of assembly. Furthermore, the system-to-system relationships are also shown. The represented assembly begins with the "load-bearing construction", which forms the basis of the assembly.

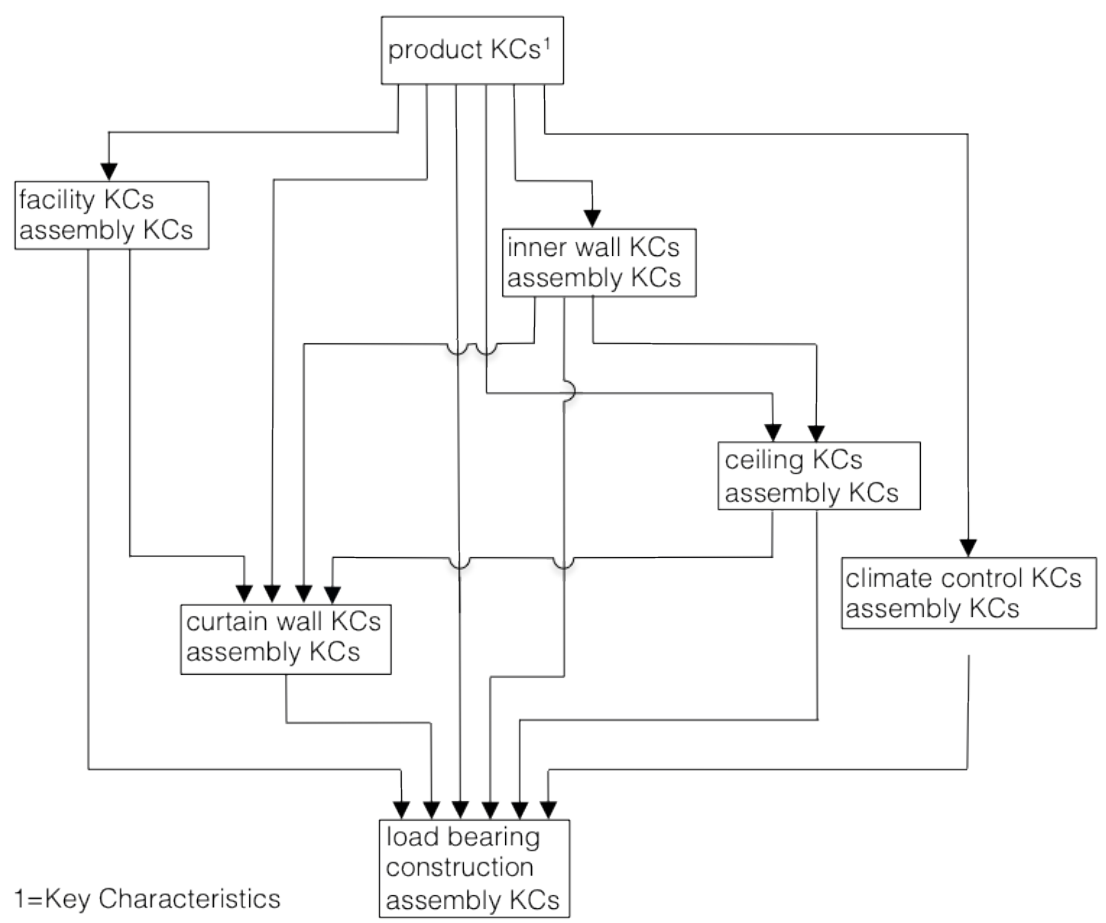

Figure 4.5: Flow-down construction of systems in the façade zone.

The system-to-system key characteristics relate to the quality of the joinings between the various construction parts. Based on the flow-down, the geometry at the location of these joinings between construction parts can be described in a more-detailed qualitative manner.

In describing the key characteristics of the systems that are to be realised with the assembly, as shown in Figure 4.5, it will become clear which systems have to contribute to this realisation. Examples of product key characteristics that are relevant for the façade zone are the visibility of variations in joint width and variations in the flatness of the façade relative to a plane defined in a world coordinate system. It is important to determine whether there are any problematic key characteristics. Problematic key characteristics can occur when a 
system-to-system characteristic depends on variations that are present in the dimensions of products or deviations in their position when there is no option to accommodate these. Their occurrence is not immediately apparent when looking at the flow-down, although they can be detected by analysing the flow-down.

The flow-down shows, for example, that the key characteristics of the curtain wall only depend on those of the supporting structure. This is therefore a one-on-one relationship, which means that any variations can generally be accommodated at the location of this joining. However, the realisation of the key characteristics of the inner walls depends on the realisation of the supporting structure, the curtain wall and the ceiling. They are also realised in that order. Next, Figure 4.4 shows that the position of the ceiling is related to the top of the glass line and that the inner walls are connected to the floor. This means that the inner walls have to realise their key characteristics, while also meeting the condition of having to connect properly at the top and bottom. As such, this is a so-called multiple joining. Its realisation using inner walls that are produced offsite is problematic given the variation in floor elevation and the position of the glass line. Such problematic key characteristics should be avoided whenever possible. In this case, the issue can be resolved by not linking the position of the ceiling to the top of the glass line, but to a certain distance above a key characteristic of the floor. This method is commonly used in practice. It is desirable that the acceptable dimensional deviations are properly indicated.

Problematic joinings can also be a result of the type of joining that is used. In terms of the joinings between the systems, a distinction is therefore made between regular and problematic joinings. A joining between systems is classified as problematic if it has to meet a key characteristic whose realisation in practice is uncertain. There are two types of problematic joinings, namely:

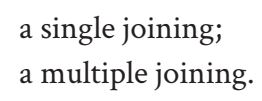

Both joining types are shown in Figure 4.6. In this situation, it is assumed that the part that is already in place and the part that has to be connected to it are not positioned on the same plane. If that is the case, the single joining becomes a multiple joining.

In order to realise the system-to-system joinings shown in Figure 4.6, both the part that is already in place and the part that has to be connected have to meet certain requirements regarding their straightness, flatness, dimensions and the supposed orientation of the planes involved in the joining. Due to the dimensional deviations that always occur, the realisation of these joinings is theoretically impossible and should therefore be avoided if possible. If that is not possible, adequate key characteristics must be described for the construction parts in question. 


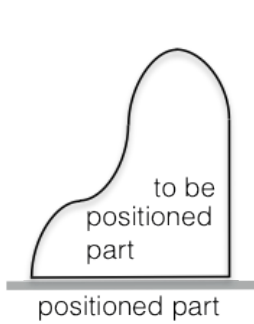

a

single joining

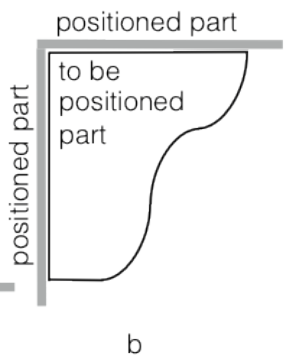

b

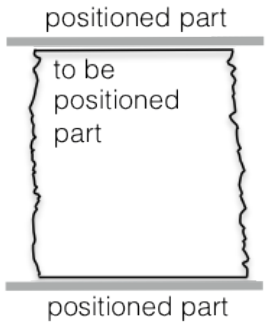

C

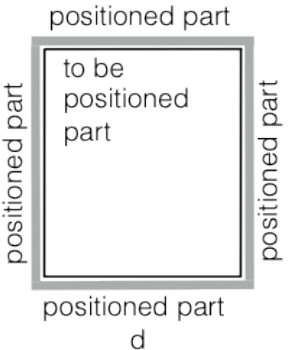

multiple joining

$$
\begin{array}{ll}
\text { examples: } & \text { a - a glass plate installed on a floor } \\
& \text { b - a kitchen sink placed in a corner } \\
& c \text { - bridge deck of a vertical lift bridge } \\
& \text { d - a door in a frame }
\end{array}
$$

Figure 4.6: Single and multiple system-to-system joinings.

\section{Design result}

Upon completion of the system design, the spatial-functional design can be described in more detail using the following items:

The product's product key characteristics to be realised.

The system key characteristics to be realised.

- The materials and construction parts to be used for the systems.

The rough dimensions and weights of the construction parts.

The qualitatively described system-to-system key characteristics to be realised.

- The assumed assembly order.

- The assumed assembly processes to be used.

- The identification of the problematic system-to-system joinings.

The design result can be described in the assembly model, in the form of a building information model with determined a level of detail. The information regarding the key characteristics to be realised, the assembly order and the assumptions made related to the assembly process can be described by linking these to the systems and representing them in a flow-down. If the realisation of key characteristics is problematic, this can also be described in the assembly model.

\subsection{Nominal design}

The goal of the nominal design of the assembly process is to ensure that the product key characteristics can be realised in the eventual as-built situation. The input consists of the result of the system design phase. The key system-to-system characteristics, which were 
qualitatively described during the previous phase, are quantified as part of the nominal design. The aforementioned key characteristics such as variations in joint widths and flatness must therefore be specified.

Whitney's [2004] method of representation is not used to represent the nominal design since it is based on a modelling of the assembly process based on the chain-of-frames approach. Instead, to represent the assembly process of the technical system of the object to be realised, a representation was chosen that is based on positioning using a world coordinate system. Here, the as-built situation can be used to determine the forces that occur in constructions and construction parts. This offers the following benefits:

The location of the local axis system of a component can be positioned in relation to that of other construction parts, and also in relation to the local world coordinate system. It allows any deformations that occur during the assembly and use of the object to be quantified.

- It ties in to the method commonly used by construction and structural engineers.

In this nominal design, it is assumed that the dimensional deviations in the construction parts are virtually non-existent and that no deformations occur. Nevertheless, in order to take deformations into account for the final design, these deviations are calculated. During the nominal design phase, the aspects shown in Figure 4.2 come into play. These are:

Determining the dimensions of the construction parts.

Determining the assembly key characteristics.

Determining the deformation of the construction.

Designing the joinings and interfaces.

Designing the assembly processes.

These aspects are described in turn below, followed by a description of the design result of this phase.

\section{Determining the dimensions of the construction parts}

To design the assembly, it is necessary to know the dimensions of the construction parts. These dimensions, the so-called nominal dimensions, are determined through calculations. The calculation method itself is not important for the design of the assembly. For the purposes of this study, preferred dimensions are seen as nominal dimensions. These dimensions are also used when designing the joinings.

\section{Determining the assembly key characteristics}

Any construction part that serves as the assembly base for another construction part has assembly key characteristics. The connection between the assembly base and this other 
construction part is realised with an interface. This is considered to be a component of the construction part that has to be connected. This makes it possible to demarcate the various construction parts. The key characteristic of an assembly base occurs at the location where the interface is connected to this base, as shown in Figure 4.7. In other words, the location of a point in relation to a reference frame.

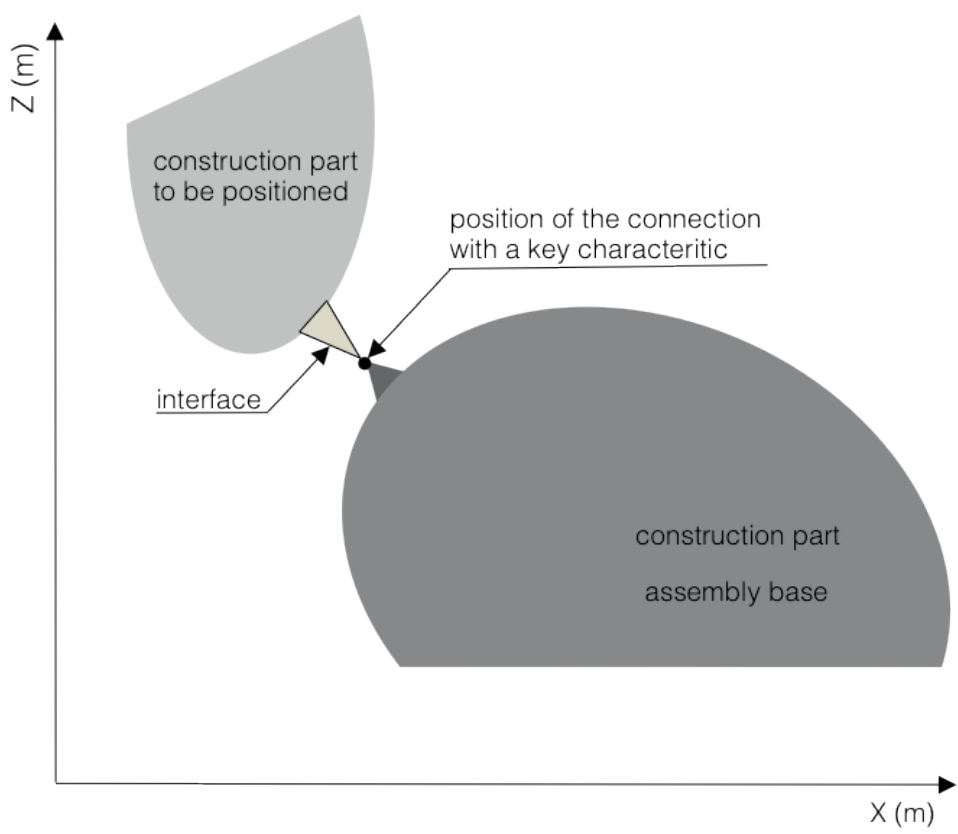

Figure 4.7: Assembly base key characteristic.

Identifying the assembly key characteristics of an assembly base starts with designing the positioning of the construction part for which the assembly base is used. It must be positioned in such a way that the key characteristics are realised. To this end, so-called critical points are defined on the construction part to be positioned, as shown in Figure 4.8. The assembly process must realise the positioning of these critical points in the desired as-built situation in order to allow the construction part in question to optimally perform its desired function. The position of a construction part can now be defined by the position of these points in relation to reference positions, which are generally defined in relation to a certain reference frame [Maas et al., 1996].

A construction part generally has three dimensions and therefore six degrees of freedom, i.e. three directions of translation and three directions of rotation. When positioning a construction part, it is put in the correct position and then fixed in such a way that prevents 
shifts in any of these directions. For a dimensionally stable object, this can be achieved by correctly positioning at least three points that are not all in a straight line. The number of attachment points for construction parts that are classified as dimensionally unstable depends on their rigidity.

After positioning and fixing, the interfaces of the construction part are connected to the assembly base. When adding a construction part, its degrees of freedom must be limited in such a way that the construction part as a whole cannot move in relation to the assembly base. Given the fact that the geometry of construction parts varies over time as a result of changes in temperature and relative humidity, the resulting geometric variations should not lead to damage to the construction. Such geometric variations are known as imposed deformations. The degrees of freedom must therefore be limited in such a way that the imposed deformations cannot result in any damage, while also ensuring that the key characteristics are still realised. The process of determining the assembly key characteristics of a two-dimensional construction part is represented in Figure 4.8. The realisation of its key characteristics $(\mathrm{KCs})$ requires it to be in a certain position relative to the world coordinate reference frame. This is indicated in relation to this frame using the position of the critical points on the construction part. The tolerances on the $\mathrm{X}$ - and $\mathrm{Z}$-axes are also shown. The construction part is connected to the assembly base with interfaces at points $\mathrm{A}$ and $\mathrm{B}$. The interfaces accommodate the dimensional deviations that occur in both the construction part and at the locations where the interfaces are connected to the assembly base.

The construction part represented in Figure 4.8 is connected with interfaces to an assembly base at points $\mathrm{A}$ and $\mathrm{B}$, the so-called attachment points. The interfaces determine the degrees of freedom of the construction part. These accommodate:

The dimensional deviations of the construction part segment.

- The dimensional deviations of the assembly base, the so-called assembly key characteristics.

Determining the relationship between the positions of the critical points, the dimensional deviations in the construction part and the desired location of the interface attachment points strongly depends on the object. For assemblies of objects of a civil nature like viaducts, these can be derived directly from the requirements for the technical system. For example, this is the case when determining the position of the rotation points of a floodgate or that of a column in a supporting structure. However, the climate separations within buildings are sometimes so complex in nature that it is common to first build a mock-up, from which the locations of the critical points and the attachment points of the interfaces in the as-built situation can be determined. 


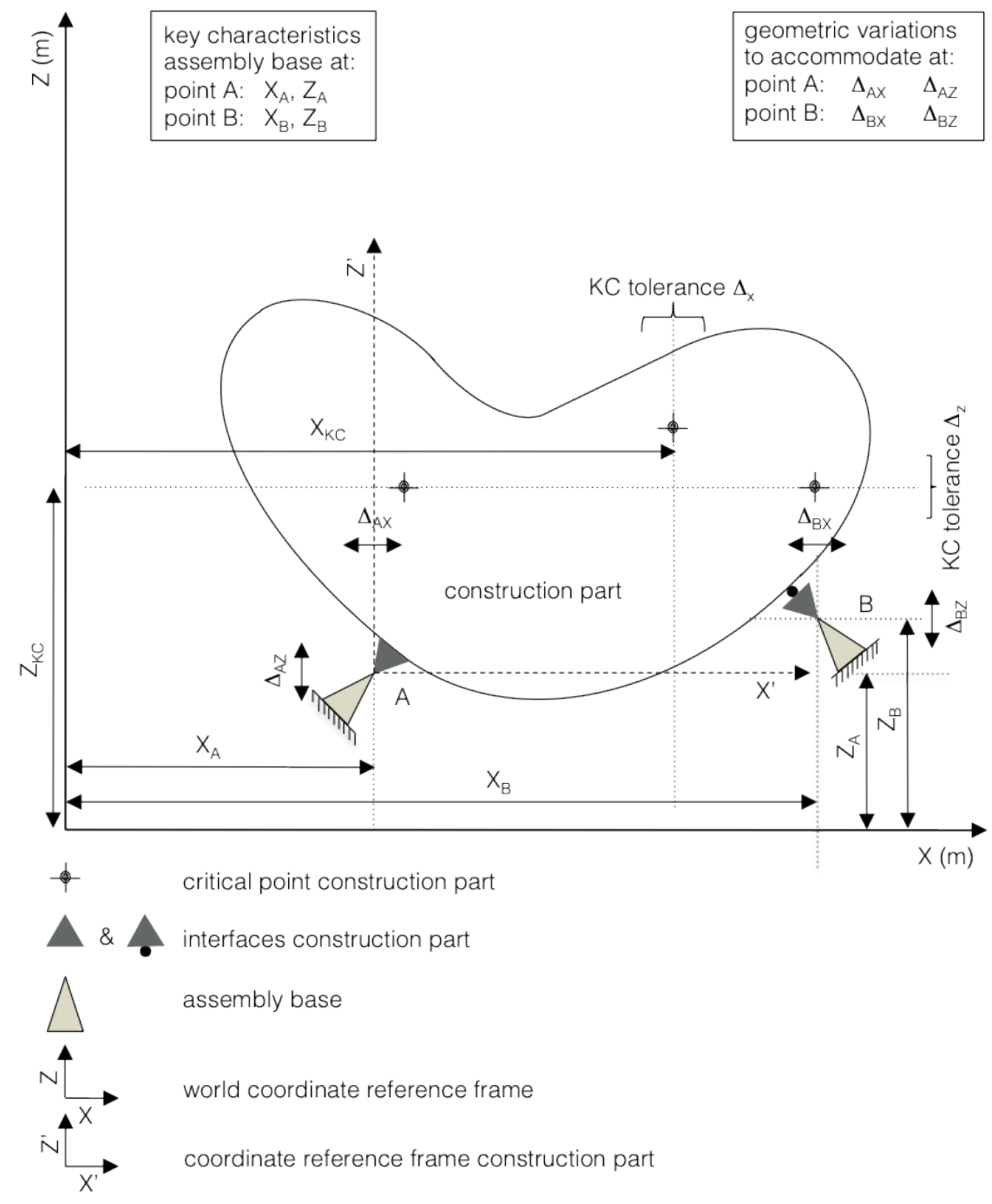

Figure 4.8: Determining the assembly base's key characteristics for a two-dimensional construction part.

The sum of the dimensional deviations (represented as vectors) in the assembly base and in the construction part segment at the location of the attachment points must be accommodated by the interfaces, see Figure 4.9. The assembly key characteristics therefore define the expected deviations in the locations where the interface of a different construction part segment will be attached. 


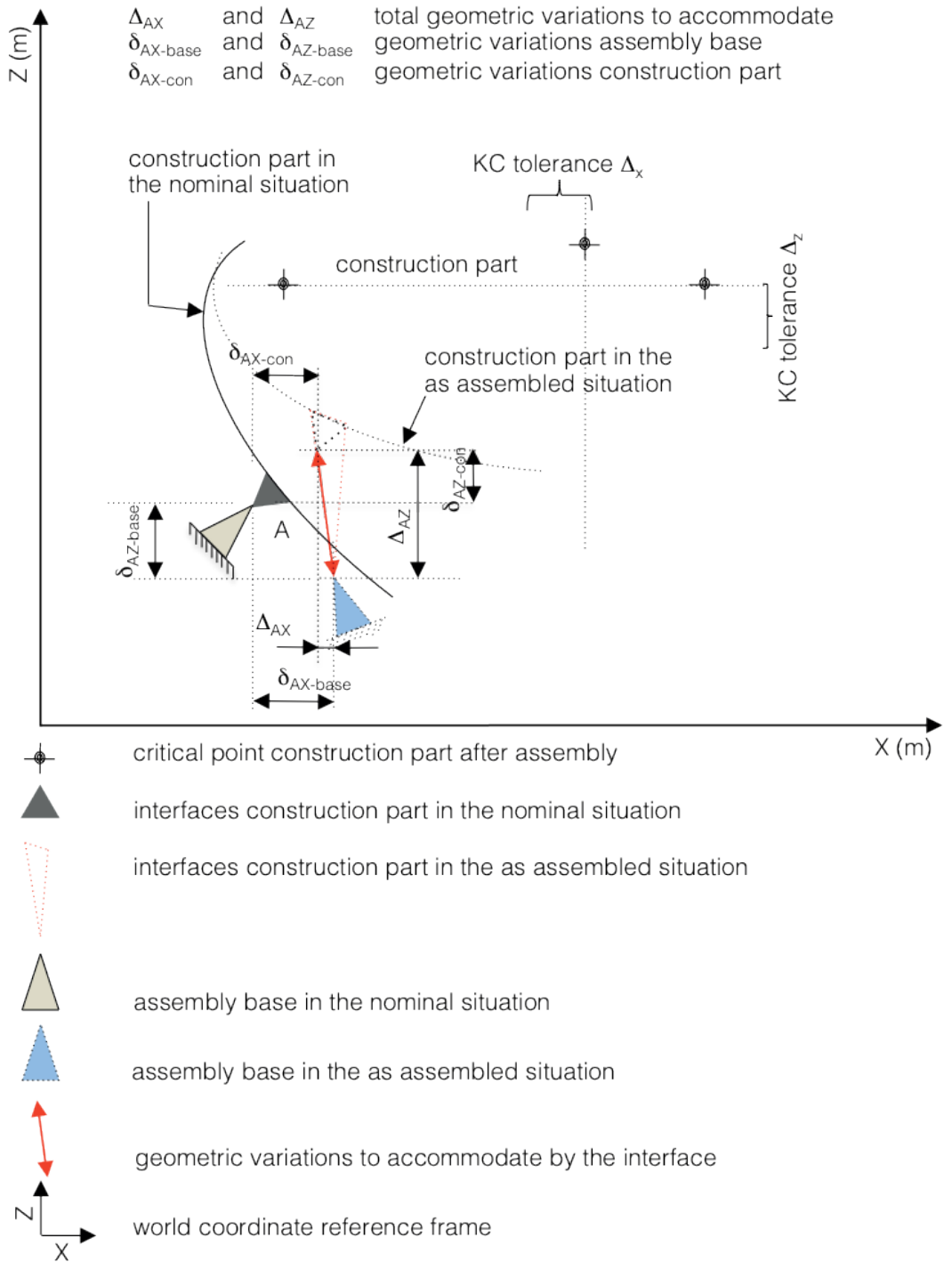

Figure 4.9: Tolerance interface.

In the absence of deformations and product and assembly dimensional deviations, a construction part can be connected to the assembly base without needing to include any tolerance. In this theoretical situation, the attachment points of the interfaces can be utilised as critical points. However, given current manufacturing and assembly processes, the interfaces must provide a certain tolerance. 
For the nominal design of the assembly process of the construction, the following questions must be answered for all construction parts:

What are the key characteristics of each construction part?

What are the positions of the critical points?

How large are the expected dimensional deviations of the construction part?

What are the expected deviations in terms of positioning?

How large are the assembly key characteristics that have to be realised?

How large is the tolerance of the interfaces?

The flow-down of the system design can be used to determine the assembly order.

Figure 4.10 shows the positioning of the jambs of a curtain wall in a vertical plane as they are commonly inserted in practice. A number of jambs are positioned at floor level on the horizontal plane in relation to the framework of the building. In Figure 4.10, this is the case for the jamb indicated by a black circle ${ }^{1}$. The other jambs are positioned relative to this first jamb using the red string as a guide. The dimensional deviations between the edge of the floor and the positioned jambs are accommodated by the available adjustment in the interfaces.

\section{Determining the deformation of the construction}

This action concerns the deformations in the foundation and in those parts of the construction that serve as assembly bases. The deformations that occur affect the forces and the behaviour of the entire object over time and the position of the interface attachment points. Although these deformations can occur over the entire lifespan of an object, the majority will occur during the assembly process [Arts et al., 2011]. When designing the assembly process, this fact must be anticipated in order to realise the design intent despite any deformations. This may require the following activities:

1 Identifying the attachment points that are relevant for the assembly.

2 Calculating the deformations that may occur over time at the location of these points.

3 Calculating the deformations of individual construction parts.

4 Designing measures to compensate for the deformation of the foundation.

5 Developing a plan to monitor the occurrence of deformations.

For the purposes of the nominal design, the first two actions must be carried out. The remaining steps may turn out to be necessary during the variation design phase.

1 In reality, this is an opening in the jamb. 


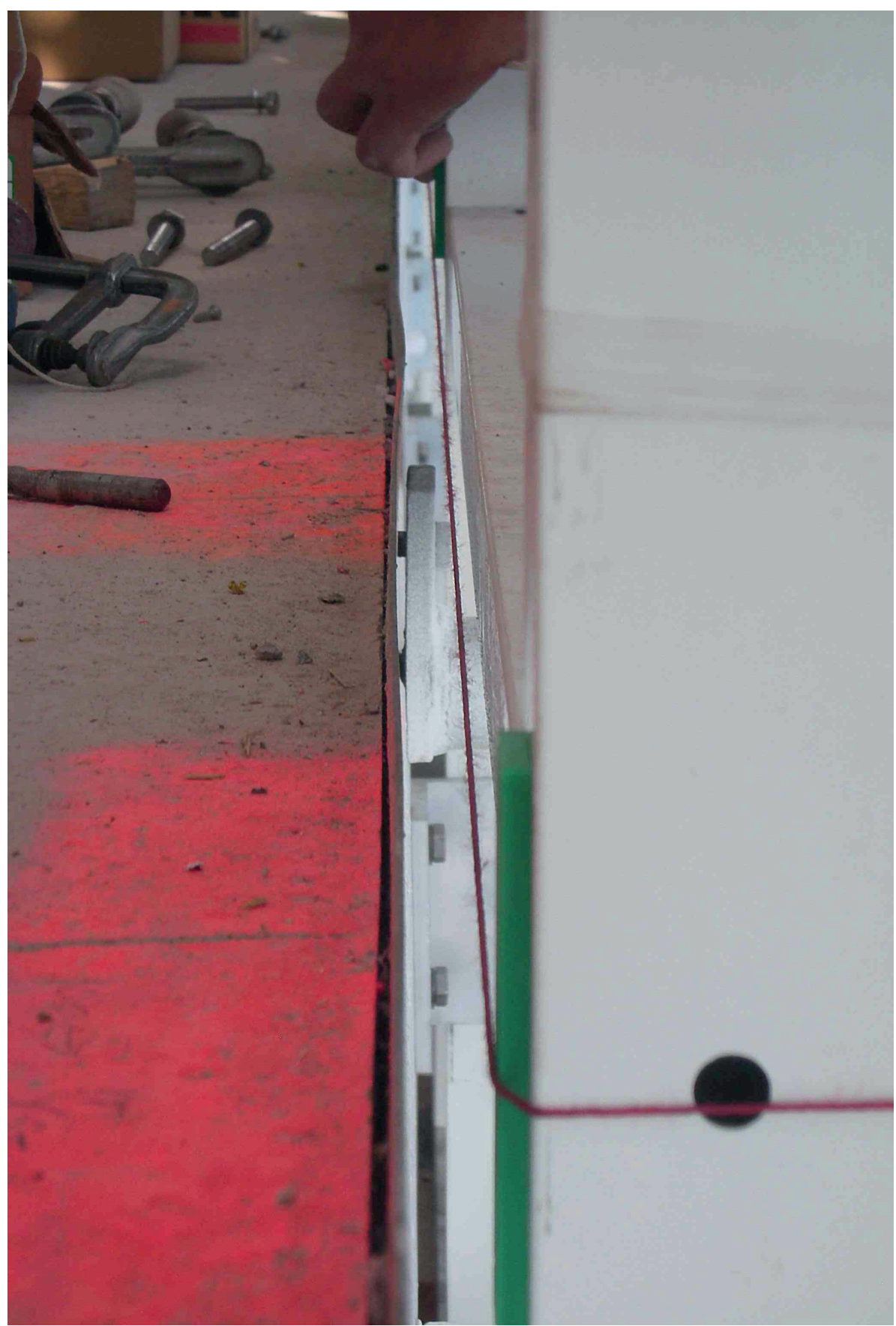

$T$
0
0
$\frac{1}{0}$
0
$\stackrel{1}{c}$
$\frac{1}{\lambda}$
+

Figure 4.10: Positioning a curtain wall to be assembled in the work in relation to a horizontal line. 


\section{Designing the joinings and interfaces}

For the system-to-system joinings, a distinction is made between regular and problematic joinings. A joining between systems is classified as problematic if it has to meet a key characteristic whose realisation is uncertain in practice. Attention needs only to be focused on this type of joining. Figure 4.6 shows several examples of problematic joinings.

When designing problematic joinings, a compromise has to be found between the visibility of dimensional deviations and the feasibility of the joinings. For example, dimensional deviations in joinings with a small gap are far easier to spot than those with a larger width. When determining the acceptable width of dimensional deviations based on their possible visibility, one can use the method described in Maatafwijkingen [Vastert, 1995]. The feasibility of achieving a joining with a certain width depends on the dimensional deviations in the parts and the degree of accuracy with which they can be positioned and fixed. The system-to-system joinings in civil engineering projects often have to meet certain functional requirements. A good example is the joining in a viaduct at the point where the bridge deck meets the substructure. In this situation, the key characteristics of this joining are related to the hindrance it creates for traffic.

The interfaces provide the connections between construction parts. Some interfaces only transfer forces while others can also be used for the positioning of construction parts. The performances to be delivered when it comes to accommodating deformations and dimensional deviations have already been described. Interfaces must also be easily accessible and adjustable. The latter aspect can be described and possibly improved using a classical design-for-assembly approach.

\section{Designing the assembly processes}

Once a system is assembled, it has to satisfy the system key characteristics. Their realisation depends on key characteristics of the parts and on the process, the quality of the assembly bases and the quality of the design itself. All of this is represented in the form of a flowdown in Figure 4.11.

The performances desired in an assembly process can be described using the process capabilities that were introduced in Chapter 2. Possible variables in an assembly process are:

1 The mass and dimensions of the construction parts.

2 The height of the assembly and the desired reach.

3 The geometric quality of the positioning.

4 The duration of an assembly cycle. 


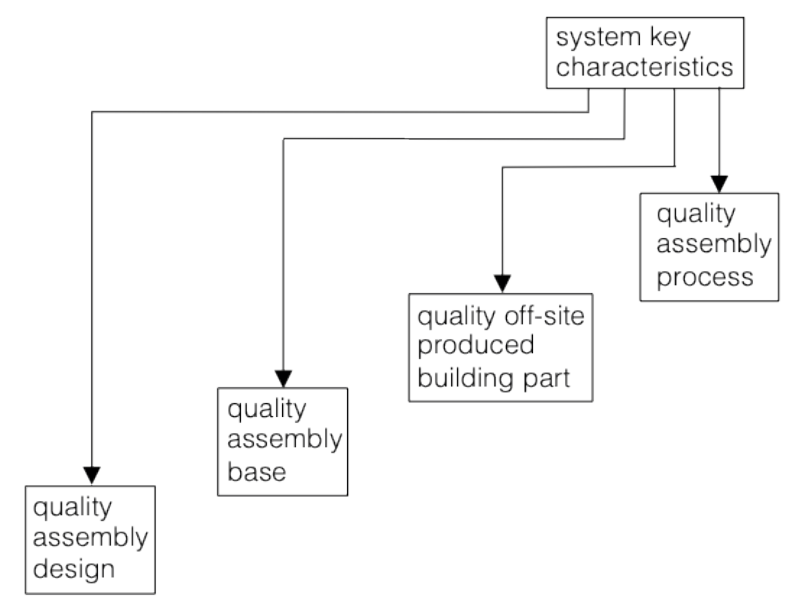

Figure 4.11: Flow-down of the realisation of the system key characteristics.

Aspects 1 and 2 were already addressed in the system design phase. Aspects 3 and 4 can be influenced during the nominal design phase. These aspects consist of the following components:

a Attaching the construction part to the hoisting facility.

b Transporting the construction part to the assembly position.

c Positioning the construction part.

d Fixing the construction part.

e Detaching the hoist.

$f$ Providing the requisite facilities for positioning.

g Attaching the construction part.

$\mathrm{h}$ Verifying the assembly against the quality plan.

Components a, b, c, d and e are dependent on the sector and material, and require the availability of certain tools. Anticipating their application is worth considering. Components $\mathrm{f}, \mathrm{g}$ and $\mathrm{h}$ which belong to the classical design-for-assembly domain can be influenced to a significant degree by the design. The possibilities to do so are explained below:

\section{Providing the requisite facilities for the positioning}

It has to be possible to position a construction part segment, in relation to certain references, in such a way that the design intent is realised in the as-built situation. To this end, critical points are identified on the construction part to be positioned. Van Hoof distinguishes between free and forced positioning [Maas et al., 1996]. In the case of free positioning, a measurement tool with which the correct locations of the critical points are identified is used to determine the right position. In the case of forced positioning, a stop is utilised. Either method can be chosen during the design of the assembly process. 
When using the free positioning approach, the distance of the critical points of the construction part in relation to the references is measured. Once the correct distance has been achieved, the construction part can be attached. When designing the assembly, a procedure must be developed for this based on the desired accuracy. The measurement tools that are used must also be described, as these affect the accuracy that can be achieved. A flow-down can be used for this purpose.

The accuracy that can be achieved with the free positioning method cannot be theoretically determined. Although the process and the measurement tools can be described, the realised accuracy cannot - although it can be determined with the help of experiments. Based on such experiments, the accuracy and the process feasibility of a certain free positioning method can be determined.

When using the forced positioning method, stoppers are available from which the position of a construction part can be derived directly. The assembly base can also serve as a stopper. In an optimally designed assembly process, there will be no need to use the free positioning method at all. The possible accuracy and the process feasibility of the forced positioning method can be determined with the help of experiments. It is possible to realise a higher degree of accuracy in terms of positioning with the forced positioning method than with the free positioning method.

The positioning method used in construction assemblies is often a combination of free and forced positioning. The assembly base almost always features a provision for positioning the interfaces, which makes it possible to determine the desired position through measurements and then fix the interface. The accuracy realised depends largely on the measurement technique that is used. Examples of measurement techniques are a plumb line, a long carpenter's spirit level, a theodolite, a laser and a chalk line.

In designing the assembly of a given construction part, it is primarily important that the geometric quality to be realised is defined including the maximum allowable deviation in combination with the cycle time to complete the task. The geometric quality can be determined with the principles that were used in designing the interface in question. The cycle time can be deduced from the planning for the entire assembly process of the construction. The maximum allowable deviations have to fall within the process capability of the assembly process to be utilised.

\section{Attaching the construction part}

The interfaces that are used for the connection have to meet the functional requirements. There are often multiple options. When choosing, design-for-assembly aspects have to be considered, such as: 
The accessibility of the connection.

Safety during making the connection.

The facilities to be used.

The requisite skills.

- The time needed to realise the interface.

The possible consequences for the manufacture of the construction parts.

The choice can be made by an overall consideration of safety, functionality, direct costs and the time required to realise the interface.

\section{Verifying the assembly in light of the quality plan}

Errors that may occur during the execution of an assembly are [Whitney, 2004]:

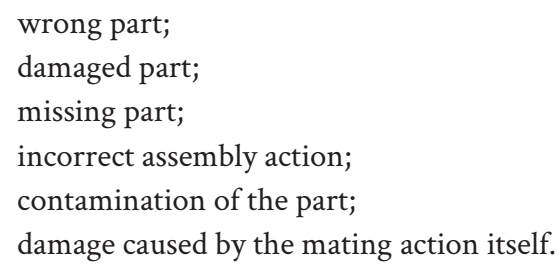

The assembly process should describe actions that enable such errors to be detected. The quality of each assembly process should be verifiable.

\section{Design result}

When it comes to designing the assembly process, the following information should be available for each construction part upon completion of the nominal design:

The assembly order.

The demarcation between the construction parts.

The nominal dimensions, mass and manufacturing tolerances.

- The deformations that will occur over time as a result of the known loads.

- The positions of the coordinate system in the world coordinate system in the non-deformed situation.

- The specification of the interfaces.

The positioning method.

The assembly key characteristics to be realised.

- The assembly process to be used.

The geometric quality of the assembly.

The cycle time of the assembly.

- The way in which the quality will be safeguarded. 
The nominal design can be represented using a three-dimensional representation of the building information model drawing. The information that is relevant for the assembly can be attached to the various construction parts as labels.

\subsection{Variation design}

During the variation design phase, an assessment is carried out to determine whether the product key characteristics are likely to be realised based on the nominal design. This probability depends on:

The realisation of the expected geometric quality of the assembly.

The allocation of the dimensional deviations at the location of the joinings.

The duration of the realisation of the assembly.

This section addresses these points. If the assessed nominal design of the assembly process does not meet the requirements, an alternative must then be developed, which must then also be assessed. If no suitable assembly process can be found, the product key characteristics are apparently infeasible under the applicable conditions. Finally, this section describes the information that is available for the assembly model upon completion of the assessment.

\section{The realisation of the expected geometric quality of the assembly}

The geometric quality depends on the deformations, the dimensional deviations in the parts and the dimensional deviations that are the result of the assembly itself. The geometric quality amounts to the sum of these deformations and dimensional deviations, which can both change and be predicted over time. The calculated sum depends on the statistical distribution of the individual deviations.

The changing deformations over time were calculated during the nominal design phase,. The dimensional deviations of the assembly process over time can now be determined with the help of a flow-down. Such a flow-down must be substantiated to the level at which there is certainty about the probability of the characteristic in question being realised or the availability of the desired competences. To illustrate this point, Figure 4.12 shows a flowdown of the assembly of a building. Note that the outfitting is not included.

In the flow-down, a distinction is made between the following key characteristics:

Those pertaining to a product or construction part.

Those pertaining to an assembly process.

Those pertaining to an assembly base. 


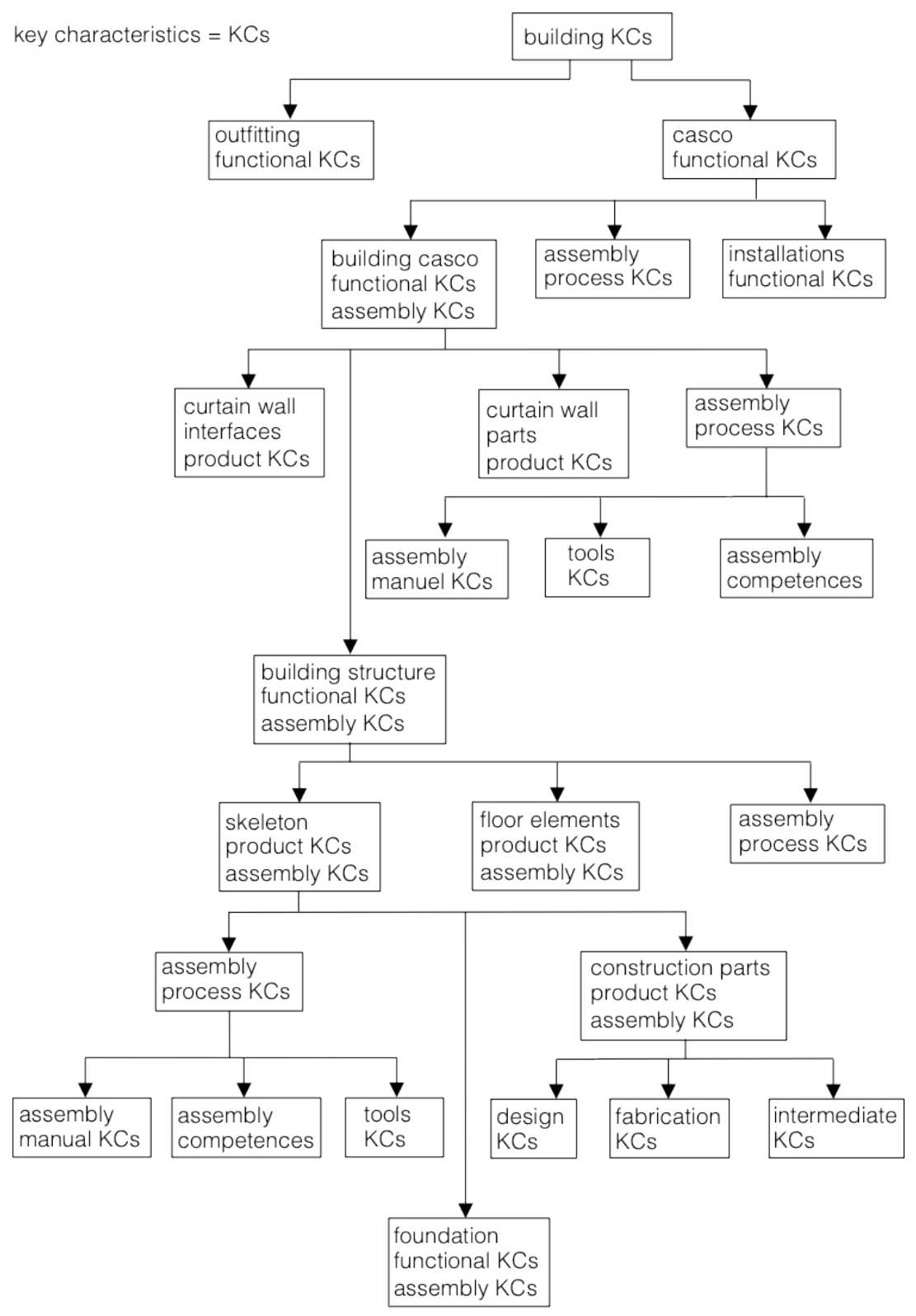

Figure 4.12: Variation flow-down of a building assembly. 
The key characteristics of products and construction parts are derived from the desired functionality of the technical system. With the realisation of the assembly process, it is desirable to determine whether the products to be used do indeed possess the required key characteristics. The key characteristics of the assembly process depend on the dimensional deviations in the parts, the tools and the relevant competences. The key characteristics of the assembly bases relate to their geometric quality.

In general, the key characteristics of an assembly process can be determined based on the flow-down and its description. However, it is desirable to validate key characteristics in practice through studies and, when it comes to actual realisation, optimise the process capabilities in terms of costs and benefits. This will also provide insight into the statistical distribution. Although they could be calculated, it is preferable to validate the geometric variations by measuring the deformations that occur.

By determining the changing sum of the deformations and the dimensional deviations over time, the geometric quality of the assembly can be determined. If it is found that the chosen interfaces offer sufficient tolerances to compensate for these deviations, the realisation of the assembly process based on the assessed nominal design is feasible.

Even when there is insufficient information with which to determine the process capabilities in relation to the desired quality of the assembly processes to be used, it is still advisable to construct a variation flow-down. Such a flow-down makes it possible to qualitatively assess the risks when using concurrent engineering and improve the assembly process in such a way that these risks become acceptable. For example, the quality of assembly processes could be improved by monitoring the quality of the dimensional control. Figure 4.13 shows a flow-down of the assembly process of a subassembly.

Using concurrent engineering, it is also possible to determine the key characteristics of an assembly process by constructing the flow-down in question from the bottom up. An important assessment criterion for the quality of an assembly process for an entire construction is that the control of its geometrics does not depend on the number of systems to be assembled. If there is an accumulation of deviations then such a dependency exists and, as a result, the quality of the assembly process as a whole cannot be controlled, which is clearly an undesirable situation.

If information is not available on the process feasibility of achieving the required quality of an assembly process, a monitoring system can be developed in order to determine the process feasibility during the realisation and further optimise the process [Lemmens, 2012]. If the expected geometric deviations of the entire assembly are too large, measures must be taken to reduce them. In addition to modifying the design itself, the following options exist: 


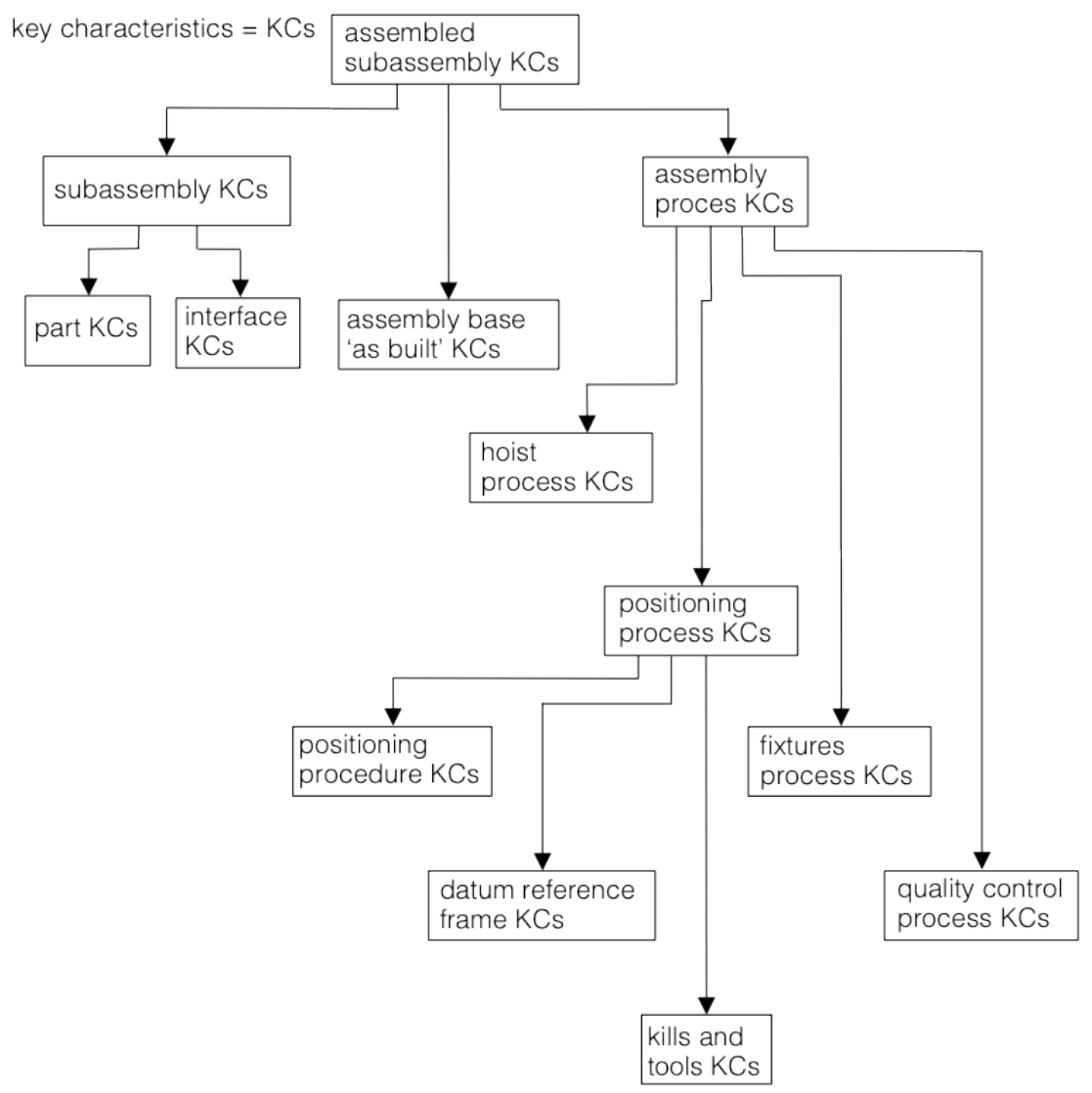

Figure 4.13: Flow-down for a subassembly.

- Modify the requirements for the key characteristics.

- Adjust the rigidity of the construction.

- Improve the quality of the assembly base, e.g. by jacking up columns.

- Compensate for the effects of deformations:

- modify the dimensions of the construction parts;

- apply deformations in advance, e.g. pre-cambered;

- preload the construction;

- apply provisions to overcome the difference between the actual and acceptable deformations by modifying the functionality of the interfaces.

Reduce the dimensional deviations of the construction parts.

Increase the accuracy with which the construction parts are positioned.

A combination of the above measures. 


\section{The allocation of the dimensional deviations in the joinings}

Given that the position of a construction part is determined using the desired position of the critical points, it is possible to allocate their dimensional deviations to the location of the system-to-system joinings. This requires space in the joinings to other construction parts. If this space is not available, this can result in direct damage to construction parts or their uncontrolled positioning. During an assembly process, both situations are undesirable. The possible allocation of the dimensional deviations in the construction parts is therefore also a verification aspect for the design of the assembly.

Verifying the allocation of the dimensional deviations in construction parts can be carried out by determining, for each construction part that is subject to dimensional deviations, what space it can take up in the assessed nominal design. Here it can be assumed that the assembly key characteristics of the joints have been realised. Deviations that are allowed in the realisation of the construction part key characteristics can be taken into account.

The effects of dimensional deviations in the assembly and in construction parts can be clarified using the building information model. For example, it is possible to enter the maximum deviations resulting from the assembly process and those found in the construction parts into the model and perform a so-called clash control, which reveals whether there is sufficient space to accommodate the dimensional deviations of the construction parts.

\section{The duration of the realisation of the assembly}

The flow-downs of all the assembly processes make it possible to reliably estimate the duration of the entire assembly process. If this deviates from the desired realisation time, certain corrective measures can be taken, such as adjusting the cycle times or increasing the capacity of the assembly processes to be used.

\section{Information for the assembly model}

In assessing the feasibility of the nominal design, an estimation is made of the possible risks that may occur during its realisation. If, based on this assessment, it is decided to begin the assembly process, then these risks are considered acceptable. Accepting the risks comes down to weighing the costs of reducing the risks against the probability of having to deal with rework and waste costs. There are always ways to reduce the risks such as. conducting trial assemblies.

The assessed nominal design, the expected deformations, the flow-downs that were used, the process feasibilities $\left(C_{p}\right)$ to be realised and other information can all be included in the building information model. In particular, it is desirable to include information that is relevant to the realisation of the assembly process such as the positioning method selected. 
With a feasible nominal design in hand, the design of the assembly process is complete. All the information that was developed during the design process, from the demand specification up to the assessed nominal design, combines to form the assembly plan for the construction. The applied level of detail will increase after the spatial and functional design. This plan therefore also contains information about the assembly processes to be used, the accuracies to be achieved and the verification activities to be performed.

\subsection{Preparing the execution of the assembly process}

To prepare for the realisation phase of a construction project, various plans including the following are drawn up [Maas et al., 1996]:

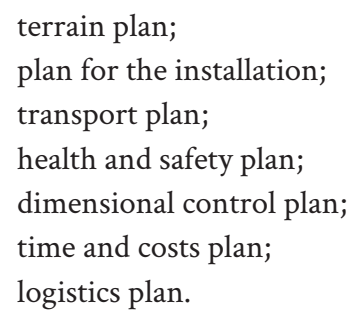

Although these plans all stand on their own, they are also connected in various ways. For example, the installation speed affects the required supply of the construction parts: if the two do not align, it may be necessary to provide a temporary storage solution. The latter, in turn, will affect the terrain plan. During assembly, such plans are drawn up for each assembly process. What plans are drawn up in practice depends largely on the complexity of the project and the construction method. For a construction that is mostly assembled on site, the installation plan will be more important than for a project based around the pouring of concrete. Given that an installation plan is especially important for the realisation of an assembly, this will be covered in more detail below.

Prior to the development of the installation plan for a system to be assembled, it may be possible to optimise it. To this end, the general methods and techniques for optimising assemblies can be utilised (see Section 2.7).

For the assembly of a construction, an installation plan relates to a single system, e.g. the supporting structure or the floodgates. In general, the basic principles of the assembly have already been chosen during the nominal design phase and their feasibility has already been assessed with a flow-down and found to be sufficiently reliable. The following information is available for each system and can be used to develop a plan for its assembly: 


\section{Location of the assembly.}

\section{Flow-down.}

- Position of the local 3D coordinate system in the local coordinate system (the fixed point).

- Position of the critical points of the construction parts.

- Reference to be used for the positioning.

- Method and accuracy of the positioning.

- Interfaces to be utilised.

- Location of the connections of the interfaces.

- Mass and dimensions.

- Hoisting tools.

- Hoisting path.

- Fixtures to be used.

- Attachment method.

- Tools to be used.

- Measurement technique to be used.

- Control measurements to be conducted.

- Desired cycle time.

- Desired competences.

Most of these points are also included in the respective flow-down. Drawing up the installation plan also requires information regarding:

Location where the construction parts will be delivered.

- Order in which they are delivered.

- Delivery of the hoisting facilities.

- Placement of the hoisting equipment.

- Who carries out which activities.

Once all this information is available, the installation plan for a system can be drawn up. The following points are important to note:

- An incorrect installation when utilising the assembly concept, is always due to errors made during preparation.

- The assembly plan protects the safety of its executors.

- Study the interaction between the use of the hoisting path and the execution of other activities.

- Working directly underneath a hoisted load must be avoided at all times.

- Assess the quality of the assembly base in a timely manner.

- Only include essential information on installation plans.

- The information should be clear and unambiguous. 


\section{Provide the references to be used for the positioning.}

Ensure the positioning does not depend on the dimensional deviations in the construction part.

Draw up a hoisting plan for complex hoisting operations.

The executors of the installation must be able to consult the plan.

Focus on the assessment of the executed assembly action.

Paper installation plans are not waterproof.

Record the realised quality based on a protocol.

In order to systematically improve the installation of a construction part, feedback about the implementation process is desirable. The assembly process can be systematically optimised based on this feedback. This is relevant for the entire supplier chain.

\subsection{Execution of the assembly}

During this phase, it is still possible to drawn up specific assembly plans and the quality of the assembly needs to be reported. To this end, several aspects that are important for the assembly are described below.

\section{Assembly plans}

In practice, one often uses drawings in which architectural dimensioning principles have been applied for assembling constructions. Chain dimensioning is used, where the listed dimensions are derived from the nominal design. Chain dimensioning is only workable if there are no dimensional deviations; it should therefore not be used for constructions. The information used for the assembly should be based on parallel dimensioning. The principles of dimensioning are shown in Figure 4.14.

The references used for parallel dimensioning can be derived from the key characteristics [Breedveld, 2011]. This is applicable for the assembly of linear construction parts and for plating. In the plans, the position of the construction part's coordinate system, or the critical points, must be listed in relation to the data reference frame. In its realisation, the key characteristics must be achieved.

Furthermore, when using a reliable dimensioning method, it will be clear where any dimensional deviations of the building parts end up. Its application is shown in Figure 4.15. In this image, the position of each construction part is shown, which also reveals where the dimensional deviations arise. The assembly of a construction part is finished with a quality assessment based on a protocol. 

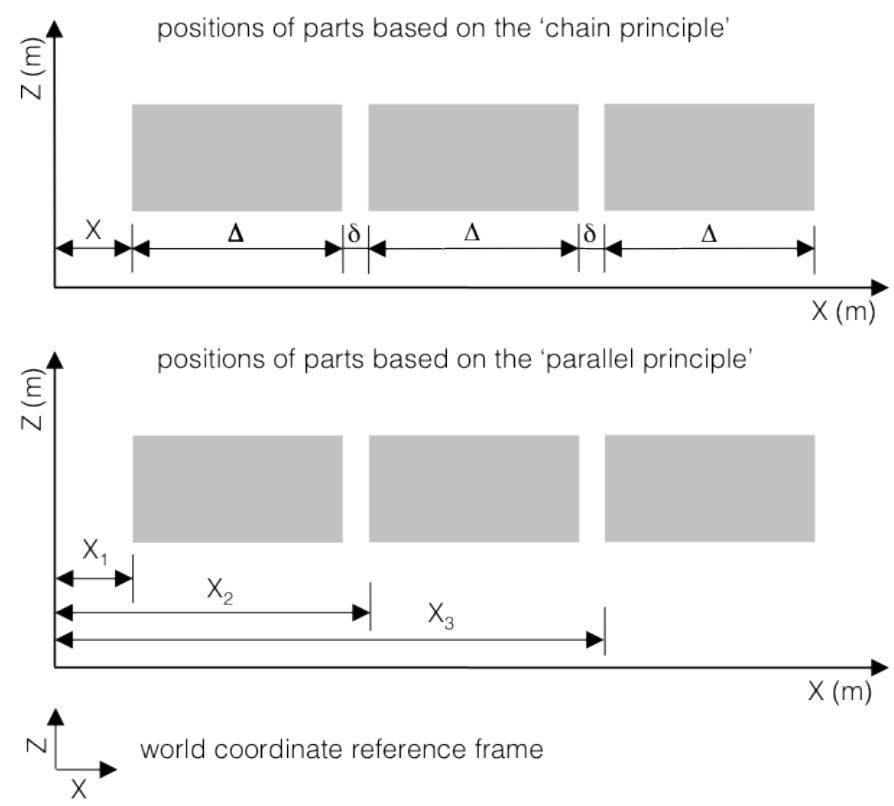

Figure 4.14: The principles of dimensioning.

\section{Quality plan}

This plan describes the manner in which the assemblers substantiate the quality plan that was drawn up together with the client. The contractors and the client will have coordinated the contents of this plan [Chao-Duivis et al., 2004]. The realisation of the quality plan is part of the acceptance of the construction by the client. With the execution of the acceptance procedure that was detailed in the demand specification, the assembly is completed.

\subsection{The organisation of the design and realisation process}

This section covers the organisation of the design and realisation process for objects that are largely realised through assembly on site. It was emphasised earlier that the complexity of realising an object in the built environment is largely determined by its design ${ }^{1}$. There are also projects where the demanded requirements determine the complexity ${ }^{2}$. As the com-

1 One example of this was the new Arnhem Central railway station that was opened in 2015. The chosen architectural design was so complex that the project was completed years behind schedule.

2 As was the case for the recently realised North/South line of the Amsterdam metro. Its complexity is a direct result of the functional requirements to be realised. 


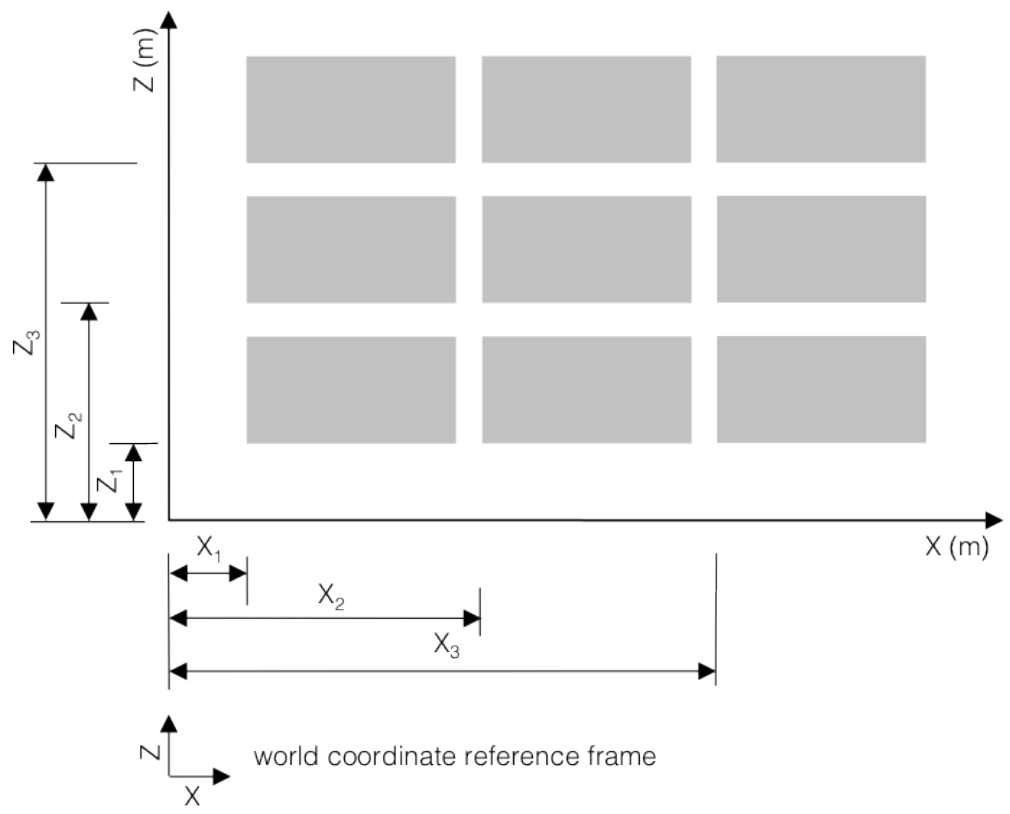

Figure 4.15: Dimensioning for plating.

plexity of realising a construction increases, so do the risks associated with using controlled assembly processes. These can be managed by involving experts in the design process, bringing in expertise which is often available in supplier chains. These possess knowledge pertaining to the manufacture and assembly methods of their products. It is assumed that this knowledge can be brought in during one or more phases of the design process. In all cases, it is related to a system of the assembly that is to be realised, e.g. a foundation, a supporting structure or a façade of which the design or assembly might require specific expertise. A system that requires such expertise is known as a critical system. If there are any critical systems, it is desirable to involve a supplier chain in the design of an object. This may relate to the realisation of the system key characteristics and/or the assembly key characteristics and the associated risks [Thornton, 2004].

The input from a supply chain described in this section is similar to what Vrijhoef describes as the "integration of site and supply chain" [Vrijhoef, 2011]. A supplier chain can be involved from the design up to the realisation of an assembly. This makes it possible to view certain activities at the construction site as separate activities, in this case the assembly of systems to be conducted by a supply chain partner.

When considering involving a supplier chain in the design of an assembly of objects, it is important to know when it makes sense to do so. This aspect is covered below. Following this, it is described how the procurement of the assembly based on the contributions of sup- 
plier chains can be handled without compromising the integral approach of the design and its realisation. These contributions should be described in the respective assembly model. The section ends by drawing conclusions.

\section{Involving a supplier chain}

Tailoring the design of an assembly to the capabilities of one or more supplier chains creates conditions for its controlled realisation. This not only benefits the manageability of the process, but also has a positive effect on the costs. However, the client has to decide the extent to which supplier chains are involved. They must be able to control the design process in such a way that they have the desired insight into the quality for the end user, the costs and the associated risks.

When developing a form of collaboration between the designers and a supplier chain, it is essential that it benefits both parties. Hofman describes the considerations that are important for the realisation of contractor-supplier relationships when it comes to the development and industrial production of modular houses [Hofman et al., 2009]. These are:

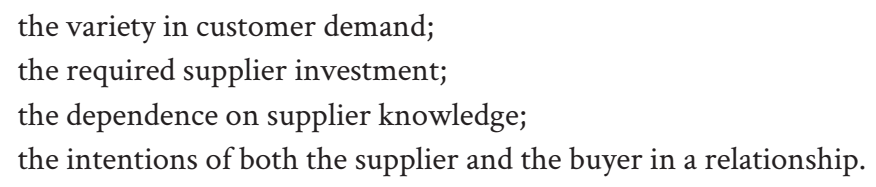

These issues also appear to be relevant for the involvement of a supplier chain in the design of an assembly.

As to whether a supplier chain should be involved in the design, the following issues are considered important:

1 When is a system a critical system?

2 What does a construction supplier chain consist of?

3 What are the possible contributions of a supplier chain?

These three issues are explored in turn below.

\section{When is a system a critical system?}

When designing the assembly of an object its value for the end user is represented by the product key characteristics. These are expressed in measurable units and describe the functionality to be realised [Henket, 2013]. When it comes to involving a supplier chain in the design of an assembly, both the functionality to be realised and the quality of the assembly process are important. Sections 4.7 and 4.8 described how these aspects are incorporated in the design method. The extent to which the realisation of the desired functionality or 
another quality aspect is critical is deduced from the expected process feasibility, which is determined based on a flow-down. Section 2.3 described how this should be greater than unity for a controlled assembly. If it is found during a design process that this degree of control cannot be met given the available knowledge of the design team, the system becomes a critical system.

\section{What does a construction supplier chain consist of?}

The hierarchical sequence of construction products was described by Eekhout [2015]. In the construction sector, there are very few businesses that focus on this entire sequence. The foundation of a supplier chain in the construction sector generally consists of one or more multinational businesses which produce semi-finished products (commercial material) or elements. Using these semi-finished products or elements, other businesses develop and produce the construction products that come next in the hierarchical sequence. Depending on the sector in question, these businesses may also handle the assembly of their own products at the construction site - although that is not always the case. For example, a producer of construction products with a large geographical sales region is unlikely to handle the assembly of their products themselves. It is common for such organisations to train local businesses to carry out the assembly as desired. A construction-related supplier chain therefore consists of at least two links; one that is responsible for the (often-industrial) production of semi-finished products or elements and one that focuses on their assembly. In practice, it will be necessary to map out the supplier chain in question when searching for information for the design of the assembly. By doing so, it will become clear which links or suppliers can provide the relevant knowledge and information.

\section{What are the possible contributions of a supplier chain?}

The possible contributions of a supplier chain are described in the literature regarding the development of new products that involve one or more critical elements [Petersen et al., 2005; Thornton, 2004]. These authors adopt similar approaches to describe the contributions of supplier chains, as shown in Figure 4.16. The supplier chains in the construction sector can be grouped in a similar manner.

\begin{tabular}{|c|c|c|c|}
\hline None & 'White Box' & 'Grey Box' & 'Black Box' \\
\hline $\begin{array}{l}\text { No supplier } \\
\text { involvement. } \\
\text { Supplier 'makes } \\
\text { to print'. }\end{array}$ & $\begin{array}{l}\text { Informal supplier } \\
\text { integration. } \\
\text { Buyer 'consults' } \\
\text { with supplier on } \\
\text { buyer's design. }\end{array}$ & $\begin{array}{l}\text { Formalized sup- } \\
\text { plier integration. } \\
\text { Joint development } \\
\text { activity between } \\
\text { buyer and } \\
\text { supplier. }\end{array}$ & $\begin{array}{l}\text { Design is primarily } \\
\text { supplier-driven, } \\
\text { based on buyer's } \\
\text { performance } \\
\text { specifications }\end{array}$ \\
\hline
\end{tabular}

increasing supplier responsibility

Figure 4.16: Possible contributions of supplier chains [from Petersen et al., 2005]. 
Section 2.3 described why the expected feasibility of the assembly process must be greater than 1 for a controlled assembly. If, during the design process it appears that this level of control with regard to certain key characteristics cannot be met, the system becomes a critical system. These key characteristics may pertain to systems that consist of standard products, system products or specialised products [Eekhout, 2015,]. The competences of a supplier may be related to design, production and/or assembly skills. Based on the distinction between the aforementioned product types and competences, suppliers in the construction sector can be grouped together as follows:

\section{Black-box suppliers: Suppliers of a system that consists of system or specialised products.}

These suppliers design, deliver and assemble a system based on specified key characteristics drawn up by a designer. The supplier has knowledge of the relevant assembly processes and the degree to which these are controlled.

\section{Grey-box suppliers: Suppliers of a system that consists of system products.}

These suppliers design, supply and assemble a system based on a combination of elements that have already been used in the past. This system is realised based on a specification drawn up by its designers, referring to quality, realisation time and costs. The quality links to the desired functionality. The realisation of the assembly is controlled, and the process feasibility is known to the suppliers.

\section{White-box suppliers: Producers of a system that consists of standard products.}

These suppliers produce a system based on a design drawn up by a third party. They can also offer advice regarding the production method. The assembly is handled by a third party.

\section{None: Assembly companies.}

These suppliers assemble systems based on a design drawn up by designers. They can also offer advice regarding the assembly method. The systems are produced by third parties. The degree to which the assembly can be controlled depends largely on the design.

By involving a supplier, the critical aspects can be identified more accurately, the possible consequences can be determined, and any necessary measures can be taken. For example, it may be desirable to bring in both a white-box supplier and an assembly company for the design and realisation of a specific assembly. The possible contributions of a supplier chain to the realisation process are described below for each type of supplier. 


\section{Black box: Suppliers of a system that consists of system or specialised products}

To enrich the built environment, one may want to utilise a system with which one has no prior experience. This introduces uncertainties regarding the possibilities for achieving the system key characteristics and the specification of the interactions. Here, suppliers can be brought in to make these uncertainties controllable, develop flow-downs and produce mock-ups. They can be brought in during or after completion of the spatial and functional design and can contribute to the system design and its substantiation. This type of supplier can participate in the design process. In these situations, it is important to clearly delineate the contribution of the supplier and describe the key characteristics to be realised using quantitative units. With regards to procurement, it is possible to split this into the provision of consultancy services, the construction system and the realisation of the assembly.

\section{Grey box: Suppliers of a system that consists of system products}

The use of system products does not inherently offer guarantees regarding the realisation of assembly key characteristics, the realisation of the desired process feasibility or the realisation time. Bringing in suppliers can provide the necessary guarantees. If there is any uncertainty regarding the realisation of the assembly key characteristics, trial assemblies may offer a solution. Based on these trial assemblies, realistic flow-downs can be developed. These can then be used to assess the process feasibility.

These suppliers can be brought in to assist in determining the risks associated with the realisation of a nominal design. If these risks are too large, the suppliers can also be involved in searching for suitable control measures. The involvement of a supplier of system products could be limited to the assessment of the nominal design. In terms of procurement, it is possible to split this into the provision of consultancy services and the realisation of the assembly.

\section{White box: Producers of a system that consists of standard products}

When using a system that consists of standard products, whether the product key characteristics will be achieved may also be uncertain. This could relate to the scope, the interfaces, the tolerances and their manageability, or special properties of the parts. These issues can be addressed by bringing in a producer.

These suppliers can be brought in to assist in the study of the risks associated with the application of a construction system that consists of standard products. If these risks are too large, the producers can also be involved in the search for suitable control measures. These suppliers can participate in the design process. In these situations, it is important to clearly delineate the contribution of the supplier and describe and agree upon the key characteristics to be realised using quantitative units. With regards to procurement, it is possible to split this into the provision of consultancy services and the delivery of the systems in question. 


\section{None: Assembly companies}

A flow-down may reveal uncertainties concerning feasible dimensional deviations, the use of hoisting facilities or the cycle times to be employed for an assembly. Here, bringing in an assembly company to develop and quantify the flow-down can offer the necessary certainties.

Assembly companies can be brought in to assess the feasibility of an assembly as proposed in a nominal design. If necessary, they can implement changes to improve the manageability of the realisation process. An assembly company can only assess the nominal design. It is possible to split procurement into the provision of consultancy services and the realisation of the assembly.

\section{Procuring the realisation of the assembly}

The phasing of the design and realisation process as described in this study offers three points at which one could procure an assembly-based construction assignment. These are shown in Table 4.1 with the corresponding completed design phase.

\begin{tabular}{ll}
\hline $\begin{array}{l}\text { completed assembly } \\
\text { design phase }\end{array}$ & type of procurement \\
\hline - demand specification & \\
- spatial and functional design & - design and build \\
- system design & - engineering and build \\
- nominal design & \\
- variation design & - assembly to order \\
- preparation of the assembly &
\end{tabular}

Table 4.1: Completed design phases and types of procurement.

The procurement method based on the demand specification that is often used in practice is not seen as a method that fits within this framework. After all, it is unclear at that stage whether a product architecture that is realised through the assembly of systems that are produced offsite will be utilised. Procuring the realisation of an object that has been developed up to the nominal design is also not considered desirable. In this situation, it is uncertain whether the assembly can be realised in a controlled manner. Procuring an object at this stage will be plagued by too many uncertainties pertaining to the realisation of the key characteristics under the stated conditions. Procurement based on documentation in which the entire assembly has already been prepared is not considered realistic because the preparation for the execution of the on-site assembly work would then have to be carried out by third parties.

The types of procurement that are suitable when the proposed assembly approach is used are:

Design and build: $\quad$ procurement based on a spatial and functional design.

Engineering and build: procurement based on a system design. 
Assembly to order: $\quad$ procurement based on an assessed nominal design.

When procuring a construction, there is always a transfer of responsibilities. The procuring party is responsible for the relevant documentation. The contractor is responsible for the activities that are conducted based on these documents. It is up to the contractor to convince the procuring party that the work has been realised in accordance with the documentation. Given that the assembly of a construction can only rarely be realised by a single party, the contractor will also bring in other parties to assist with its realisation. Depending on the type of procurement, the contractor will therefore also become responsible for the further design of the assembly process. Such a role has been defined as a "system integrator" [Vrijhoef, 2011]. In his study of the application of supply chain management in the construction sector, he describes this role as having "to integrate the whole supply system". Vrijhoef's definition does not incorporate the use of so-called subcontracting. If the client involved a supplier in the design, they can serve as a subcontractor.

When using supply chain management in sectors where the final products are realised through the procurement of a design developed by the client, as is common in the construction industry, Vrijhoef identifies two system integrators: a "demand system integrator" and a "supply system integrator". For the procurement types discussed here, the "demand system integrator" is involved up to the procurement phase, whereas the "supply system integrator" is involved during the procurement and subsequent phases. When procuring a construction that is to be realised through an assembly process, the assembly model will be part of the documentation used for the procurement. The degree to which the realisation of the assembly is described in this documentation will depend on the level to which it has been developed. This will also be covered in the following description of the procurement types and their respective substantiation of the assembly mode

\section{Ad 1 Design and build - procurement based on a spatial and functional design}

For the spatial and functional design, either a modular or an integral product architecture is chosen. When it comes to procurement, the assembly concept is only relevant if a modular product architecture was chosen since it is then highly likely that building components produced offsite will be used. For procurement based on a spatial and functional design, subcontracting is only possible if a supplier was involved in the development of the spatial and functional design.

\section{Assembly model}

If a supplier was brought in to assist in the development of the spatial and functional design, and they are also involved in the design and realisation of the assembly, their contribution must be clearly delineated and the key characteristics to be realised must be described using quantitative units. Furthermore, how the communication between the supplier in question and the client has been organised must be described. 


\section{Ad 2 Engineering and build - procurement based on a system design}

Once a system design has been established, it is known which systems are to be assembled and the relationships between them are described in qualitative terms. This applies to both the modular and the integral product architectures. Subcontracting will only be possible if a supplier was already involved. In all other instances, the contractor will serve as the supply system integrator and will be responsible for the further development of the system design.

\section{Assembly model}

The assembly model must describe the key characteristics of the systems to be utilised and the qualitative relationships between these systems. If one or more suppliers were involved in the system design, and they are also involved in the design of the assembly, their contribution must be clearly delineated and the key characteristics to be realised must be described using quantitative units. Furthermore, how the communication between the supplier(s) in question and the client has been organised must be described. In the further development of the assembly, the suppliers will collaborate with the supply system integrator.

\section{Ad 3 Assembly to order - procurement based on an assessed nominal design}

For a procurement during the variation design phase, subcontracting is possible. All the construction parts to be used and the interfaces have been specified, and the assembly key characteristics are known. Furthermore, the feasibility of these key characteristics has been assessed; a process that suppliers may have been involved in.

\section{Assembly model}

The assembly model must describe the key characteristics of the construction parts that have been realised and the quantitative relationships to be realised between these construction parts. If one or more suppliers were involved in the assessment of the nominal design, and they are also involved in the design of the assembly, their contribution must be clearly delineated and the key characteristics to be realised must be described using quantitative units. Furthermore, how communication between the supplier(s) in question and the supply system integrator has been organised must be described.

\section{Conclusion}

Designing the assembly of objects in the built environment can be combined with a number of organisational forms, with regards to both the design and the realisation. As described in this chapter, it is possible to procure the realisation phase without compromising the integral approach to design and realisation. During phase three of the study - the case studies - the manner in which the assembly of the objects in question is organised will be explored in more detail. 


\subsection{The first draft of the construction assembly design method and its parameters}

\section{The first draft of the construction assembly design method}

This Chapter has described the first draft of the design-for-assembly method which satisfies the specification stipulated in Section 4.2.

\section{The first draft of the method and its parameters}

The first draft of the construction assembly design method has been evaluated with the help of a series of case studies. These are described in Chapters 5, 6 and 7. It was necessary to relate the findings derived from these case studies to this draft of the method [Stuart et al., 2002]. The design method is therefore represented using parameters as shown in Table 4.2. For mapping purposes, the design method is divided into three parts. For each part, the respective phases and parameters are listed. A parameter can be defined as the design goal to be realised within the phase in question.

\begin{tabular}{|c|c|c|}
\hline $\begin{array}{l}\text { product architecture } \\
\text { design }\end{array}$ & $\begin{array}{l}\text { assembly design and } \\
\text { assessment of the feasibility }\end{array}$ & transition to production \\
\hline $\begin{array}{l}\text { a demand specification: } \\
\text { qualitative formulation of } \\
\text { the requirements for the } \\
\text { assembly }\end{array}$ & $\begin{array}{l}\text { d nominal design: } \\
\text { determine construction } \\
\text { part dimensions and quan- } \\
\text { titatively describe system- } \\
\text { to-systems relations }\end{array}$ & $\begin{array}{l}\text { f preparation of the assembly: } \\
\text { plans available concerning } \\
\text { dimensional control of the } \\
\text { assembly }\end{array}$ \\
\hline $\begin{array}{l}\text { b spatial and functional } \\
\text { design: } \\
\text { selecting the product } \\
\text { architecture based on } \\
\text { off-site production }\end{array}$ & $\begin{array}{l}\text { e variation design: } \\
\text { design assembly } \\
\text { processes and assess the } \\
\text { effects of geometric } \\
\text { variations on the design }\end{array}$ & $\begin{array}{l}\text { g execution of the assembly: } \\
\text { availability of assembly } \\
\text { instructions }\end{array}$ \\
\hline $\begin{array}{l}\text { c system design: } \\
\text { qualitative description of } \\
\text { the system-to-systems } \\
\text { relations }\end{array}$ & & $\begin{array}{l}\text { h completion of the assembly: } \\
\text { protocols pertaining to } \\
\text { quality-assurance are } \\
\text { available }\end{array}$ \\
\hline
\end{tabular}

Table 4.2: The parameters pertaining to the evaluation of a realised design of an assembly.

One of the outputs of each the case studies described in respectively Chapters 5, 6 and 7, is a table with the same structure as Table 4.2 that shows the parameter-related case study findings. For evaluation purposes, these tables are then combined in one single table in Chapter 8 . 



\section{Case study: four building transformation projects}

\section{Contents}

5.1 Introduction

5.2 The four transformation projects to be realised

5.3 Characterisation of the dwelling transformation case study

5.4 Goals of the case study

5.5 Method applied in the dwelling transformation case study

5.6 Case 1.1

5.6.1 Introduction to case 1.1

5.6.2 Description of the systems to be assembled

5.6.3 The design of the assembly

5.6.4 The design of the systems to be assembled

5.6.5 Findings concerning the realisation of the assembly

5.6.6 Findings concerning the proposed design-for-assembly method

$5.7 \quad$ Case 1.2

5.7.1 Introduction to case 1.2

5.7.2 Description of the systems to be assembled

5.7.3 The design of the assembly

5.7.4 The design of the systems to be assembled

5.7.5 Findings concerning the realisation of the assembly

5.7.6 Findings concerning the proposed design-for-assembly method

$5.8 \quad$ Case 1.3 


\section{Contents}

5.8.1 Introduction to case 1.3

5.8.2 Description of the systems to be assembled

5.8.3 The design of the assembly

5.8.4 The design of the systems to be assembled

5.8.5 Findings concerning the realisation of the assembly

5.8.6 Findings concerning the proposed design-for-assembly method

$5.9 \quad$ Case 1.4

5.9.1 Introduction to case 1.4

5.9.2 Description of the services

5.9.3 Preparing of the execution

5.9.4 The execution

5.9.5 Findings concerning the proposed design-for-assembly method

5.10 Overall findings regarding the proposed design-for-assembly design method

5.11 Findings regarding the organisation of the assembly design and the assembly process

5.12 The results of the case study

5.12.1 Improving the assembly process of dwelling transformation projects when applying the proposed design-for-assembly method

5.12.2 The improvement of the proposed design-for-assembly method 


\subsection{Introduction}

The dwelling transformation case study was conducted to evaluate the first draft of the design-for-assembly method for construction and infrastructure projects ${ }^{1}$. The research question that will be answered in this chapter is:

\section{To what extent can the assembly process of dwelling transformation projects be improved by applying the proposed design method and how can the proposed design method be improved?}

In the Netherlands, the "Energiesprong" programme (also known as the "Stroomversnelling" project [Stroomversnelling] was carried out between 2010 and 2016. The goal of this programme was to substantially reduce the energy consumption of existing dwellings since the natural gas consumption in dwellings represents a significant part of the Netherlands' annual $\mathrm{CO}_{2}$ production. To reduce energy consumption, especially those dwellings that were built prior to 1980 need to be adequately thermally insulated and the energy consumption based on natural resources ${ }^{2}$. To realise these objectives, these dwellings need to be upgraded.

In order to conduct this transformation in accordance with the applicable preconditions, the dwellings have to remain in use during the improvements ${ }^{3}$. To ensure this is tolerable for residents, the transformation has to be completed within a week and a half [Brugh, 2014]. Based on experiments, it was concluded that this timeframe was feasible provided an industrial approach is followed. This approach boils down to the use of construction parts that are produced offsite.

As part of the Energiesprong programme, six housing corporations and four construction companies signed the Stroomversnelling-Huur agreement. This agreement stipulates that the involved parties have committed themselves to renovate 11,000 dwellings by the year 2020 to such an extent that their total annual energy consumption, based on a number of given preconditions, is zero. The ambitions of the Stroomversnelling-Huur deal make this transformation project a relevant candidate for closer examination in the context of this $\mathrm{PhD}$ research. After all, the product architecture is based on the use of construction parts that are produced offsite, a quick realisation is desired, and four construction companies are involved. As a result of the latter, four case studies were conducted within the context of

1 Also referred to as 'the proposed design method'

2 Energy resources that produce no or very little $\mathrm{CO}_{2}$.

3 Between 1970 and 1990, thousands of dwellings in the Netherlands were renovated. During the renovation process, residents were relocated to temporary housing. It is now known that the temporary relocation of residents is expensive relative to the costs of the renovation activities themselves. 
this study. These are identified as case studies 1.1 to 1.4 and described in Sections 5.6 to 5.9. Sections 5.2 to 5.5 cover the transformation projects to be realised, the characterisation of this case study, the goals and the methods used. Sections 5.10 and 5.11 describe the findings related to the proposed design method and the organisation of the design and realisation process. The results of the case study are summarised in Section 5.12.

\subsection{The four transformation projects to be realised}

In the period from 1945 to 1980 , housing corporations in the Netherlands built more than one million houses. As with all objects in the built environment, these houses are products of their time. Seen from today's perspective, the thermal insulation of many of these houses ${ }^{1}$ is inadequate. As a result, considerable $\mathrm{CO}_{2}$ is produced during the burning of natural gas to heat these houses. Given the importance of reducing emission levels, it is desirable to be able to climatise these houses using sustainable energy. According to current insights, this requires a major reduction in the heat loss of these houses. Based on total cost of ownership, a so-called "zero-energy" approach is considered optimal [Tol et al., 2012]. In this context, "zero energy" means that the annual net total energy use registered by the energy meter, based on a number of preconditions, is negative or zero.

The houses, often built on the order of housing corporations, were constructed in a serial manner such that multiple houses were built to a single design. In most cases, dozens of houses share the same design, where eight to twelve houses form a so-called block. The front of such a block faces the street, while the rear leads on to gardens. Such blocks of identical dwellings form a so-called template. Dwellings built during a certain period often share many similarities, such as the so-called "doorzonwoning" of which many were built during the 1960s and 1970s. The serial nature of the houses is an important factor in the transformation to zero-energy dwellings, as this creates opportunities for a serial approach. However, although these houses may look the same to the naked eye, precise measurements often indicate otherwise. Many dimensions show variations in the order of around ten millimetres. Furthermore, the interior design and the window frames have often been renovated over time, making these houses even more unique. Nevertheless, their serial

1 Since 1964, the thermal insulation of buildings has to meet NEN 1068: Thermal insulation of buildings standard. This means that buildings built before 1964 can today be classified as uninsulated. The insulation of dwellings built between 1964 and 1980 gradually improved to a level that is acceptable by today's standards.

2 A 'doorzonwoning' is the name for a type of house that was often built in the Netherlands in the twentieth century. The name is derived from the fact that the living room extends over the entire depth of the house. This room has windows at the front and back, so the sun can shine through the whole room. 
realisation does create opportunities for the development of a concept for dwellings with certain characteristics. Such a concept relates to the product architecture, the construction parts that were used and the techniques to be utilised. The concept-based approach allows the large-scale application of construction parts produced offsite, thereby requiring less labour at the construction site and reducing costs. This approach can be seen as industrial.

Volume is a precondition for facilitating an industrial approach to transforming existing dwellings into zero-energy dwellings,. In the last century, it was seen that both producers and assembly and construction companies were only willing to invest in innovation and production technology if there was sufficient demand. In addition to creating preconditions to realise this volume, it is also desirable that the housing corporations present the project in such a way that producers and businesses are enabled to submit their tenders based on the total cost of transformation. This method of tendering for construction projects is known as "integrated" where a single party is responsible for both the design and the realisation. Agentschap NL [Tol et al., 2012] and Salcedo Rahola [2015] investigated which integrated tendering method fitted best in the Netherlands. The study by Agentschap NL found that the design-build approach is most suitable, whereas Salcedo Rahola concluded that the design-build-maintain approach is preferable. The latter tends to be used in practice in the Netherlands. This means that the providers of the housing transformations are responsible, for a predetermined period, for the design, realisation and maintenance of the zero-energy dwellings they contracted. To create the conditions in which a sufficient volume can be realised, six housing corporations and four construction companies signed the "Stroomversnelling-Huur" deal. In this deal, the corporations are the "buyers" and the construction companies the "providers." The providers produce zero-energy dwellings based on design-build-maintain contracts and the buyers guarantee the purchase of the products on the condition that they are offered with an energy-performance guarantee.

The Stroomversnelling-Huur deal covered 11,000 dwellings with each provider responsible for 2,775 dwellings. In principle, these had to all be renovated by 2020 . To allow both buyers and providers to gain from a learning curve, the realisation of the project was phased. The prototype phase for each construction company covered 700 houses built in a serial manner. The buyers provided templates of dwellings that are suitable for a zero-energy approach to the providers. Only one house was renovated at first, which served as the prototype for the template in question. Such a prototype also showed the residents of the dwellings what they could expect from the transformation process. Once the first houses were completed, the project was upscaled to larger numbers of dwellings. To be able to scale up the transformation project, $70 \%$ of the residents of the neighbourhood in question had to agree to the "zero-energy" approach [Stroomversnelling].

A complicating factor in realising the zero-energy dwellings is that the projects are located all over the country. As a consequence, a single project, even if it consists of a dozen dwellings, 
is insufficient to allow a nationally operating provider to go through a learning curve. Perhaps as many as four projects are required to allow a nationally operating provider to acquire organisation-wide experience with the zero-energy approach. This is also true for suppliers.

In addition to reducing energy requirements, the transformation can also be used to modernise the interior of the dwelling by, for example, refinishing the walls, floors and ceilings and installing new kitchen cabinets and sanitary facilities. These enhancements can be used to bring residents on board with the zero-energy approach. However, the costs involved have to come within the available budget. This was put equal to the value that is created by the transformation, which is realised through energy savings, an extended operational period and the expected increase of the dwelling's value when its operational period ends. The available budget was outlined in the Collaboration Agreement of the Stroomversnelling deal [Stroomversnelling]. The price that the buyers pay for a zero-energy transformation depends on the phase in which it is realised. The costs are highest during the prototype phase and decrease during subsequent phases. The usability of an existing prototype naturally also depends on dwellings meeting the same template. Important characteristics include the available heating source, the heating output system, the roof construction, the structure of the walls and the amount of daylight.

As part of the Stroomversnelling project, the buyers and providers made agreements about performance levels that are to be met. These so-called performance guarantees pertain to the entire dwelling and are enforced for a longer period than usual. At the start of a project, the parties involved sign a purchasing agreement. It outlines the performances that have to be delivered, which concern:

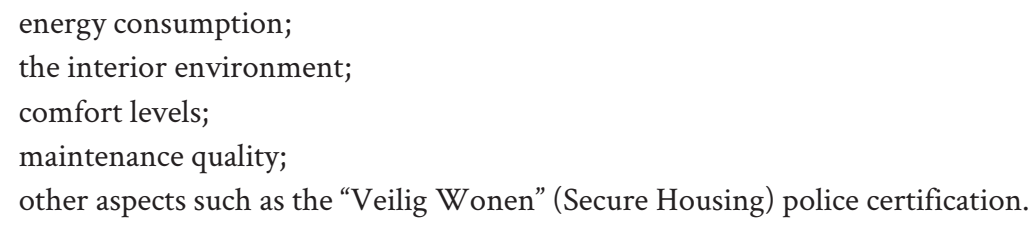

Furthermore, agreements were made about the price and the schedule. The purchasing agreement does not say anything about the aesthetic quality of the dwellings, although a project does have to receive standard approval from the building aesthetics committee.

An industrial approach is needed in order to renovate a considerable proportion of the dwellings in the Netherlands to become zero-energy houses. This makes the application of design for assembly in the context of the Stroomversnelling-Huur deal a relevant case study. 


\subsection{Characterisation of the dwelling transformation case study}

The case study addresses the transformation of dwellings. It concerns the floors, walls, roofs, sanitary facilities, technical installations and kitchen furniture. The project is executed by removing construction parts and then assembling new systems, or processing semi-finished products, at the construction site. For the assembly process, the existing dwelling serves as the assembly base. The dimensions of the dwellings and the construction parts to be assembled are such that any deformations that occur during assembly are negligible. A complicating factor during the transformation is in realising the connections of the systems to be assembled to the existing dwellings since accurate information about the as-built geometry is not available. As a result of the construction processes originally employed, all the dwellings differ to some extent despite the serial production method that was employed. The design method to be used for the assembly must therefore account for this uncertainty.

In terms of the classification characteristics described in Section 2.8, this project can be seen as small-scale manufacture, since each project consists of no more than dozens of dwellings. It can therefore be expected that investments have been made in both the manufacture and the assembly aspects. The dimensions and mass of the construction parts to be assembled are such that no special transport or heavy hoisting is required. The function of the construction parts is a key characteristic of this project. When designing the assembly, it is important to take the following geometric variations into account:

those permitted in the as-built situation;

those present in the assembly base;

those present in the construction parts;

those resulting from the assembly processes.

These variations create the field problem that was introduced in Section 2.10. In Section 3.3 , it was explained that the construction sector does not have a design rule to resolve this issue in a structured manner. The design principles outlined in Section 4.2 apply here. This case can be seen as representative of a small-series assembly project in the construction sector where the impact of any deformations that occur during the realisation is negligible. The assembly to be designed is shown in Figure 5.1. 


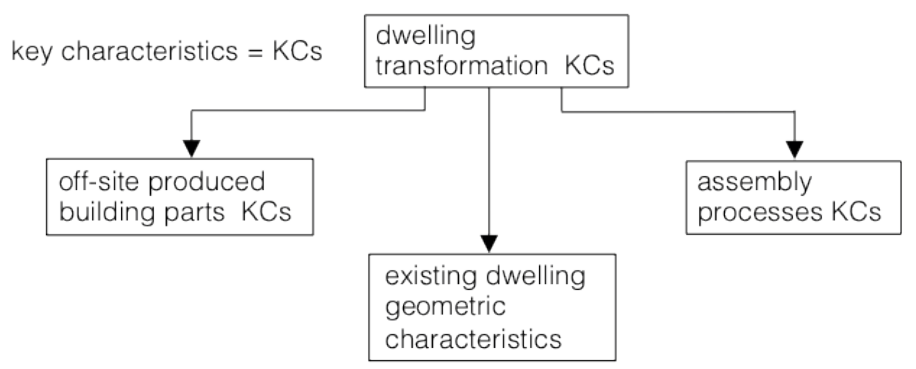

Figure 5.1: The assembly to be designed for dwelling transformations.

\subsection{Goals of the case study}

The goals of the proposed design-for- assembly method which will be evaluated pertain to both the system-of-systems design of the entire assembly and to the design of the assembly of the individual systems. Furthermore, as a result of this case study, options were to be presented to the providers on how their assembly design could be improved. These so-called contractor notes were submitted directly to the providers and are not included in this thesis. The goals are shown in Figure 5.2.

\subsection{Method applied in the dwelling transformation case study}

Ideally, the case studies would address the entire design and realisation process. Unfortunately, this was not possible since, in all four cases, the design of the respective transformation projects had already been completed. Given that these case studies do not include a spatial and functional design, the evaluation will only concern the subsequent design phases (see Figure 4.2). To evaluate the proposed design-for- assembly method, information was gathered on the assembly design method that was used and about the realisation of the assembly. This was achieved through semi-structured interviews with members of the providers' organisations who were involved in the projects. Furthermore, the realisation of the assembly was monitored on site and the findings were described. The proposed designfor- assembly method was evaluated based on this information. Below, each of the following research components is covered in more detail:

interviews;

monitoring;

findings. 


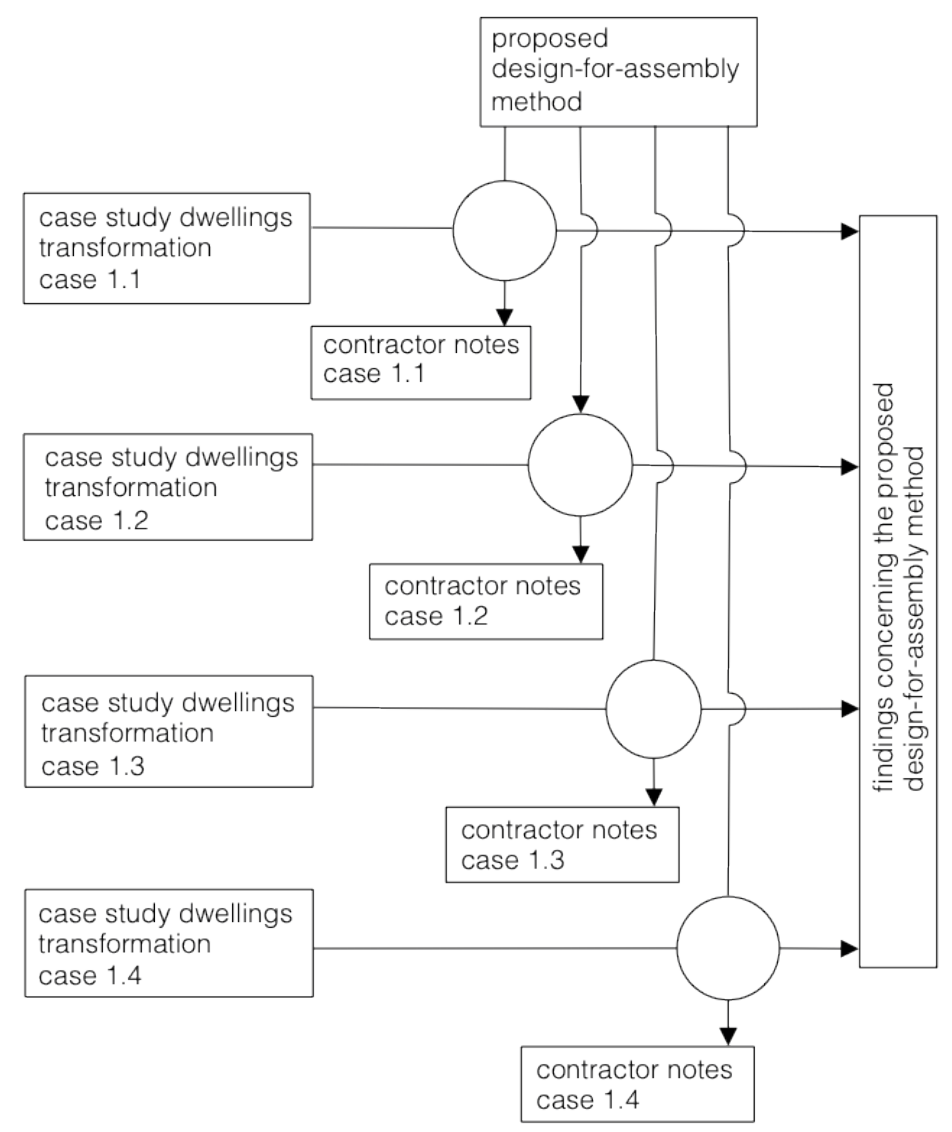

Figure 5.2: Goals of the dwelling transformation case study.

\section{The interviews}

In all four cases, interviews were held with the providers, and service providers, co-creators and/or suppliers. The interviews with the provider specifically addressed the system-of-systems design of the assembly. The following topics were discussed:

- the vision with regard to the assembly of constructions;

- the project organisation;

- the phasing and substantiation of each design phase.

The vision with regard to assembly was discussed because this provides an indication of the extent to which the providers were focused on a system-of-systems design. The questions about the project organisation were used to gather information about the responsibilities and activities of the buyers, the service providers, the co-creators and the suppliers. The 
questions about the phasing and the substantiation of each phase sought to acquire more detailed information about the design method that was used. During the interviews with the co-creators and the suppliers, the focus was primarily on the manner in which the design was tailored to the individual assembly processes.

\section{Monitoring}

The goal of the monitoring was to keep a close eye on the assembly processes of the individual systems. The structure of a single assembly cycle, as described in Section 4.6, was used. This includes the following aspects:

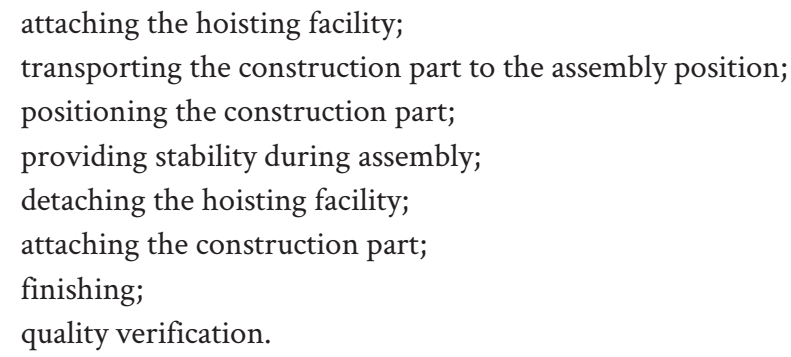

By monitoring a number of assembly cycles of a system being assembled, it is possible to rate it based on the aspects described in Section 1.5. If the assembly design is good, the assembly will be carried out in accordance with the design, the construction parts will not need to be modified, the assembly proceeds in a controlled manner with a virtually constant cycle duration and the quality of the assembly is verified upon completion. If there are large deviations between assembly cycles, attempts are made to uncover the cause. This may be the result of a sub-optimal design of the assembly. In both events, attempts are made to explain the experienced situation based on the design of the assembly.

\section{Findings}

Based on the interviews and the monitoring, findings are described with regard to the evaluated proposed design-for-assembly method. For each case, the following items are covered:

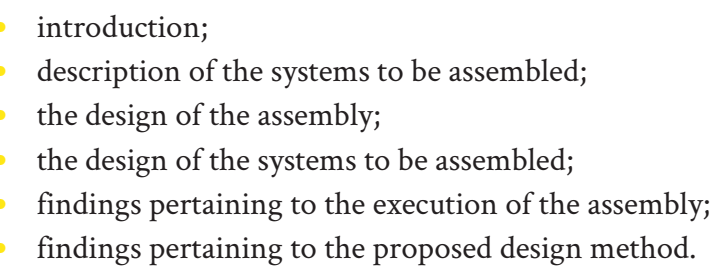

Given the aim of evaluating the proposed design-for-assembly method, the findings with regard to the execution of the assembly are especially relevant. As described in Section 1.3, 
the evaluation is based on the extent to which the execution is in accordance with its design and whether or not it is seen as disrupted. This evaluation, and the design method that was used, have been mapped to the proposed design-for-assembly method [Stuart et al., 2002]. To this end, the method was represented using parameters shown in Table 4.2. An assembly is not seen as disturbed if it was executed in accordance with the design and if the design matches the proposed design method being evaluated. Following this approach, each monitored assembly process provides information that can be used in the evaluation. The evaluations are described in Section 5.10 for cases 1.1 to 1.4.

In these cases, the buyers of the renovated dwellings have opted for a design-and-build approach. The design method to be evaluated describes how suppliers can be involved in this approach. Based on the findings, the design method has been evaluated concerning the manner in which the providers involve parties in the design and execution. The findings are described in Section 5.11.

\subsection{Case 1.1}

\subsubsection{Introduction to case 1.1}

Case 1.1. concerns a nationwide housing provider in The Netherlands who collaborates with three partners in the development of zero-energy dwellings: an architectural firm, an installation company and a supplier of façades that are produced offsite. The provider developed the concept together with these partners and carries out the assembly activities at the construction site. These assembly activities are carried out by various branches of the provider's organisation that are located all over the country. The company fills the role of system integrator and oversees the supply chain. The product, i.e. the renovated dwelling, is marketed using a brand name. Four interviews were conducted (between 29 October and 23 December 2015): two with employees of the provider's organisation - one who is mainly responsible for the development of the transformation concept and one whose main responsibility is the execution - and two with employees of partner organisations. The interviewees were identified based on a recommendation from the provider.

Both the provider and the partners prefer onsite assembly because it reduces costs, improves quality and has a shorter realisation time. This method is also necessary because of a shortage of qualified staff. When developing zero-energy dwellings, it is important to avoid hindering residents as much as possible since the dwelling will remain in use during the transformation, and satisfied residents are helpful in acquiring new projects. In addition to onsite assembly, the industrial production of construction parts is also necessary. Today, many construction parts are produced in factories with many of the steps carried out by machines. Nevertheless, the provider claims that the composition and structure of the construction parts that are produced offsite are often based on existing concepts that 
involve manual production. Therefore, this should not be seen as true industrial production of construction parts. However, significant savings can be realised in the civilian and non-residential construction sector by adopting industrial processes (as with the development of the Model T Ford between 1910 and 1924). The provider commented that strange things happened in the construction sector. One example was that the details differ for each project - why is it not possible to choose from a series of standard details? The civilian and non-residential construction sector does not seem to be striving for standardisation and re-use solutions. It seems to be in the interest of many parties to come up with something new every time. Developers want to develop something new, architects want to leave their mark on every project, and construction companies operate based on cost price plus a margin. As a result, there is no drive to standardise. In this setting, cheaper constructions result in smaller profits!

Some construction companies are still focused on delivering capacity, even after the economic crisis. Standardisation is desirable, but yet not essential. With the help of computer-aided design and computer-aided manufacturing, it is possible to produce small series of products although larger series do offer more opportunities for optimisation. A lot is expected of chain integration. For the provider, this is a way to control the costs of failure. However, it is not a means to innovate and develop smarter products. The employee of the provider who is primarily responsible for the assembly believes that a zero-energy project is best executed in the form of a single transparent process that runs from the moment of project acquisition to the handover of the zero-energy dwelling to the residents and the buyer. At the front end of this process, the zero-energy product can be developed. Such a process can be based on the possibilities and the expectations that were communicated to residents. Within the context of such a process, the use of construction parts that are produced offsite, i.e. the assembly process, can be optimised in collaboration with the partners.

The architectural firm is responsible for the design. The same firm is involved in every zero-energy project and, for each one, they create a design based on the concept and the façade finishes permitted by the provider. The knowledge developed during the project is stored in a library that contains all their knowledge about the characteristics of the zero-energy dwelling projects and the improvements to the concept that were employed.

During the first quarter of 2016, the provider decided to cease executing zero-energy dwelling transformation projects due to financial problems. At the time of the interviews, there were no ongoing projects and no new projects were later accepted. As a result, no ongoing projects could be visited. Based on the interviews, only findings related to the system-of-systems design are described. 


\subsubsection{Description of the systems to be assembled}

The concept consists of three components: the shell of the dwelling, the interior, and the installations. The shell consists of the façade, the floor and the roof. The façade has a number of possible finishes, which are described in the library. Solar panels are installed on the roof to provide power and the dwellings are fully electric. The interior component consists of renovating the kitchen, the bathroom and the toilet. On an earlier prototype, the existing façade was removed but this proved to be a poor solution. Based on this experience, it was decided to install an additional add-on façade instead. This solution consists of two add-on façade components on the front of the dwelling and two on the rear (installed one above each other). These add-on façades feature windows and doors. In upgrading the side façades of the dwellings, additional battens, insulation and finishing are handled on site. Sandwich panels with standard dimensions are used for the roof. Using Lichtenberg's terminology [2002], the add-on façades can be classified as special system products, while the sandwich panels are standardised system products. The façade elements also contain pipes and ducts for warm-air heating, Warm air is blown through these ducts into the dwelling near the reveals of the window frames. To install the sandwich panels, the roof tiles and battens are removed but the trusses are left in place. The solar panels are attached to the sandwich panels.

No construction parts except for the kitchen furniture are used in renovating the interior. Instead, a semi-finished product is used that consists of sheeting with glued-on tiles. These elements are processed on site. As a result, the interior activities do not involve any assembly and this aspect was not examined further. Why the choice was made to process semi-finished products rather than using the assembly method was not clarified.

The heating installation consists of a heat pump, a ventilation unit with heat recovery, a boiler and an inverter. All these were mounted on to a steel frame offsite and then installed in the attic. Pipes run from this frame for connection to the air heating and warm water outlets. The installation company is responsible for connecting the installation and installing a drain for the condensate.

\subsubsection{The design of the assembly}

According to the agreements made as part of the Stroomversnelling project, the design of the assembly can be established based on:

purchasing agreement;

wishes of the residents;

wishes of the building aesthetics committee. 
There are qualitative principles based on these factors that apply to the design of the façade in the as-built situation. For example, the façade has to look good from the outside and from within. Residents also want to retain their balconies. The appeal of the exterior design has been operationalised by criteria such as the joints between the various elements not being noticeable. The design of the add-on façades utilise elements that must each connect physically to the existing façade. This means that the add-on façades consist of separate components. The physical quality of the connection to the existing façade has not been specified. This is created by means of a strip of foam. This strip is placed on the edges of the front facade. The joinings between the panels should only be nice. The sandwich panels on the roof run from the ridge to the wall plate where they connect to the upper edge of the add-on façade. This connection has to meet certain physical requirements.

\subsubsection{The design of the systems to be assembled}

For the purposes of the design and the realisation, a 3D scan was made of all the dwellings that are to be transformed. Using these scans, drawings for the components of the shell are made to millimetre accuracy. Typologically speaking, the add-on façades are classified as timber-frame inner cavity walls. They consist of a wooden frame with insulation, pipelines, air ducts, window frames, plating and stone strips on the exterior. The add-on façades are industrially produced with dimensional variations of the order of a few millimetres. The dimensioning of each element is tailored to the dwelling in question. No calculations were made for the expected dimensional deviations in the as-built situation.

During transport, the elements are placed on blocks and delivered on a just-in-time basis. To attach the add-on façade to the existing façade, specially developed attachments are used: J-anchors. These are attached to the existing façade in positions determined by a calculation. The J-anchors position the add-on façade in the vertical plane and in the direction perpendicular to the existing façade. In the direction parallel to the existing façade, the $\mathrm{J}$-anchors allow the element to be moved. Acceptable dimensional deviations for the J-anchors have not been specified.

The individual add-on façades and the façade as a whole have to meet certain aesthetic requirements. The brickwork represented by the stone strips has to be appear unbroken horizontally at the locations of the seams, and the horizontal joints cannot be visible. The location where the dimensional deviations occur has been carefully considered. Professionals speak of the accommodation of dimensional deviations. Where possible, the vertical joints are located behind the drainpipe that runs down the boundary between individual dwellings. In the 'masonry', bands have been applied with vertically placed stone strips to mask the horizontal seams between the add-on façade elements. The positioning of the add-on façades in the direction parallel to the existing façade is determined on site. The 
connections of the sandwich panels on the roof to the upper add-on façade have been prepared in advance. No information was provided on the positioning of the sandwich panels.

Designs were created for the add-on façades and guidelines are available for their assembly. These are based on assembly manuals from a Swedish furniture supplier. A project is evaluated after its realisation. Based on this evaluation, modifications can be suggested. The parties involved believed that prototypes were still being developed. When a project's execution is about to begin, there is a so-called "warm assessment" whose purpose is to coordinate the possibilities with residents and assess the characteristics of the dwelling. It focuses on the location of incoming pipelines, drainage pipes, exterior light fixtures and other features that may impede a rapid realisation.

\subsubsection{Findings during the realisation of the assembly}

The provider indicated that the process at the construction site was not yet entirely under control. When façade elements are delivered to the construction site by the supplier as per the agreements made, the workers on the construction site would sometimes ask the delivery person what they were doing there. In these cases, it appeared that the construction work had fallen behind. The costs of the activities on the building site were now of the order of $50 \%$ of the total costs. Local newspapers ${ }^{1}$ had reported on the zero-energy dwellings realised by this provider and stated that residents were promised a project lead time of ten days, but it was actually three months. Furthermore, the residents did not believe the promised comfort was being realised. Given that it was not possible for us to monitor the execution of an assembly, there are no findings pertaining to the realisation.

\subsubsection{Findings concerning the proposed design-for-assembly method}

Given that it was not possible to monitor the actual assembly process, there is no information about whether this proceeded according to plan or not. For this case, the findings relate to the organisation and the following phases of the proposed design method. These are the:

system design;

nominal design;

variation design.

1 This source is unnamed due to the unattributable nature of the case study. 
It was recognised that the design of the assembly would affect the end result of the project. The key characteristics to be realised were recognised, although these had not been concretised. By describing a number of connection problems between building parts in a qualitative sense, it has been recognized that the assembly relates to a system-of-systems design issue. This is a key principle in the method to be evaluated. In the proposed design method, this is substantiated by formulating performance requirements for the system design. The method to be evaluated is based around the use of construction parts that are produced offsite. When designing an assembly procedure there is a risk that this may turn out to be impracticable for reasons such as the expected variations in product dimensions. The decision to use semi-finished products for the interior work in this project appears to have been made in advance. It is likely that creating work for local businesses was a consideration here. Although the realisation of the assembly was not monitored, it is strongly suspected that there was no integral approach to the design and the assembly, as is intended in the development of both nominal and a variation designs. For example, the correct position of the façade panels was not determined and no thought was given to the consequences of the unavoidable variations in product dimensions and dimensional deviations when attaching the anchors and positioning the construction parts to be assembled. The method used in this case therefore differs from the method being evaluated.

Generally speaking, the findings pertaining to the design of the assembly reveal that, in this case, the systems approach was used to a lesser extent than the method being evaluated presumes. Further, no desirable changes to the proposed design method came to light. In this case, the provider had involved a supplier of façade elements and an installation company in the system design. Given that it was not possible to monitor the assembly, it is also not possible to confront findings with the organisational aspects of the design method.

\subsection{Case 1.2}

\subsubsection{Introduction to case 1.2}

This case again addresses a nationwide provider in The Netherlands who collaborates with a number of co-creators on zero-energy dwelling projects. This collaboration is focused on the realisation of mutual benefits and therefore meets an important condition of an outsourcer-co-creator relationship [Gelderman et al., 2007]. The provider serves as the product's designer and system integrator. In the role of system integrator, they also oversee the assembly of the offered zero-energy dwellings. The approach employed by this provider has been discussed with seven individuals between 4 September and 4 December 2015. The interviewees were approached on the recommendation of the provider. Furthermore, an ongoing zero-energy dwelling project was visited where the assembly of the façade and roof elements was currently underway. 
According to the provider, the Dutch stock of social dwellings consists of a number of types. These can be divided into two main types: "apertures in the façade" and "doorzon". This case concerns the "doorzon" type, see Figure 5.3. The provider expects to possibly carry out 2,500 zero-energy dwelling transformations every year. For the project that was visited, the buyer and the provider worked together to draw up an information booklet for residents that, among other things, explains the possible measures that can be taken as part of the transformation. The lead time of the transformation of the entire dwelling is listed as ten working days; if residents have their bathroom renovated, that has a lead time of five working days.

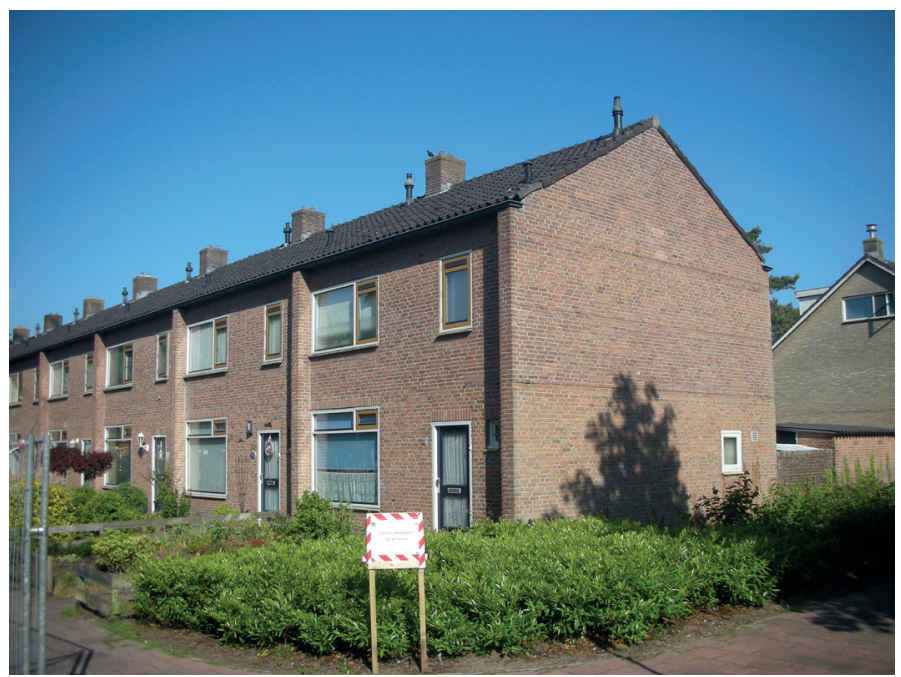

Figure 5.3: The 'doorzon' dwellings before transformation.

The provider and its co-creators are convinced of the necessity of using an assembly method for zero-energy dwelling transformations, both for the architectural measures and the technical installations. This allows fragmentation in the execution to be avoided and addresses the shortage of skilled professionals. The fragmentation that plagues current housing development projects is a result of the industrial methods that are used, for which an organisation based on workflows directed using network schedules is most appropriate. For zero-energy transformation projects, network schedules are not suitable because they offer insufficient flexibility. Up to twelve parties are involved in the zero-energy projects and it is not feasible to have each party carrying out their respective activities individually. This would require waiting around for each other to finish, and this is unrealistic given the deviating circumstances that always occur to some degree. Although the provider does not deliver any execution capacity; it still has a person fulfilling the classical foreman role. The provider believes that the traditional contractor role requires a different site superintendent to a project involving assembly by co-creators. 
For executing the interior activities in the dwellings, the parties involved switched to autonomous teams. Such teams perform all the interior activities. Given that the time required of each discipline differs, the team members are expected to be multidisciplinary so they can take over each other's tasks if necessary. For example, the plumber is expected to be able to paint as well.

To gain inspiration with regard to the assembly method, the provider had visited assembly lines for personal vehicles. If any faults are detected there, the person who identified the issue stops the assembly line. The provider also strove to improve the available methods for safeguarding quality during assembly. The provider considers the further development of the assembly process with regard to specifying performance ${ }^{1}$ and safeguarding the quality of the work to be the responsibility of the co-creators.

A traditional construction process includes "work preparation" and "purchasing" phases among others. The provider does not use these phases in the zero-energy projects. Instead of the classical work preparation and purchasing phases, the preparation for the assembly shifts forward in the design process. This method is appropriate, and the provider's work supervisors were willing to employ smaller tolerances between the façade elements when using this method.

\subsubsection{Description of the systems to be assembled}

The zero-energy approach consists of the design of four modules: the installations, the façade, the roof and the interior. Furthermore, the ground floor is insulated but, as this does not require any design skills, it is not included in the scope of this study. The interior work consists of the bathroom, the toilet, the kitchen and any associated pipe systems. The façade and roof modules consist of four elements per dwelling. This provider also uses façade modules for the front façades. The dwelling is powered by solar panels that are installed on the roof.

One co-creator is responsible for the design and production of the façade modules, while a different co-creator handles their installation. The latter also handles the finishing of the façade, meaning that they have a stake in their careful positioning. The façade modules can be seen as timber-frame elements. They are delivered to the construction site complete with window frames and glass. The width of the elements is equal to the width of a dwelling, and their height is roughly the same as that of a dwelling's storeys. In the façade module, elements are used that must each physically connect to the existing façade. To achieve the desired thermal insulation, each element must provide a virtually airtight connection to the

1 One example is defining the desired quality using key characteristics. 
existing façade. The joints between the various elements do not have to be airtight. There is an air gap of 50 millimetres between the existing façade and the new façade modules.

The design, production and installation of the roof modules are all in the hands of a single co-creator. The roof modules are based on timber-framed roof elements. The elements run from the ridge of the roof to the wall plate and their width is equal to that of half a dwelling bay. The roof cladding on the elements is installed offsite at the supplier's location. The underside of the roof modules has to connect to the top of the façade modules at the eaves. This connection has to be virtually airtight.

With regard to the interior activities, one supplier and four executing parties are involved alongside the provider themselves. The supplier designs and delivers the glass elements used on the walls in the bathroom, toilet and near the kitchen counter. The interior activities are carried out by an autonomous team consisting of employees from the organisations involved. A team has competences pertaining to hot and cold water pipe systems, electrical systems, ventilation and architectural finishing. If possible, parts of the pipe systems are delivered as subassemblies. A team takes the already assembled components into the dwelling and carries out their activities there. Within certain limits, they have the authority to make decisions. As a result, no contractor is needed. It is seen as important not to break up a team during the activities. The team members are expected to operate in an interdisciplinary manner as this is essential to avoid waiting times. The teams currently consist of five people, although that number can be reduced to four.

The output of the heating system is fed to existing radiators to heat the dwelling. Hot water is provided by a heat pump located in the installation module, which also contains an inverter, the boiler and the mechanical ventilation unit with heat recovery. The installation module was designed by the provider. The module is produced by the co-creator responsible for the installations and then installed by the provider at the rear of the dwelling. The installations that make up the module are plug and play and can be connected to the dwelling's infrastructure using simple power plugs.

\subsubsection{The design of the assembly}

At the start of a project, a 3D scan is made of a single dwelling. Using this scan, the provider's BIM modeller creates a 3D model of the prototype. This serves as a virtual model of the final product, which is then discussed with the suppliers and co-creators. Any necessary modifications are implemented. If necessary, a prototype dwelling will be upgraded where the co-creators can acquire experience with the project. When residents approve of the prototype, and the decision is made to renovate all dwellings in the neighbourhood, the other dwellings are also scanned. Using these scans, the co-creators' BIM coordinators also 
create 3D models, which are used to further prepare and realise the assembly.

The provider indicated that they were not yet ready to describe the quality to be realised in a manner similar to that used in the automotive industry. This will be done once the co-creators are ready.

\subsubsection{The design of the systems to be assembled}

The design of the façade and roof modules and the glass cladding for the sanitary facilities were covered above. Every project is scanned in $3 \mathrm{D}$. These scans are used to create drawings for the components of the building shell within millimetre accuracy.

The design of the façade modules is dwelling-independent. Given that the connections to the existing window frames are created on site, any deviations between dwellings can be accommodated during that process. The façade modules include imitated stone strip mounted on sheeting plates. The sheeting with the stone strips form a subassembly. The plates are installed offsite on to the new façades in such a way that the joints between the plates match the joints that would be seen in traditional brickwork. As such, each façade element has joints of its own and there are joints between the façade elements. The dimensions of these joints are not specified. After the assembly of the façade elements, they should have the same outward appearance as traditional brickwork. The developed façade modules can be classified as a special system product [Eekhout, 2015].

The production and assembly of the façade modules are handled by different companies. No agreements have been made with the supplier and the assembly company regarding requirements for the connections to other construction parts, such as the existing masonry. The provider is responsible for dimensional control and dimensioning. There was no prior insight into the required assembly time, and this developed along the way. The shared responsibility for production and assembly complicates optimisation. For example, when selecting anchors to attach the façade elements to the existing façade, it becomes difficult to balance the costs of the anchors against required installation time.

The lower façade modules are mounted on to so-called J-anchors. These make it possible to install the façade module at the desired height and move parallel to the existing façade. The second façade module is installed on top of the first. The J-anchors are attached to the existing masonry using other anchors. The physical connection between the add-on façades and the existing façade uses compressible PE band. Previous projects had used, foam that was shaped in situ, but this solution did not yield satisfactory results.

The roof module was designed in collaboration with a co-creator who produces and installs 
the elements. This allows optimisation of the process. No agreements have been made about any quality assessments after the assembly of the elements. The solar panels are attached to the mounted elements. The company in question utilises computer-aided design and computer-aided manufacturing. The production machines can be controlled using data from the building information model, which includes drawing up bills of material and prices. The roof modules that are used can be characterised as system products [Eekhout, 2015]. The design of the roof elements can account for dimensional deviations in the dwelling's width and depth: widthways at the location of the walls that separate the dwellings and depth-wise at the location of the purlins. The connection to the façade is critical because the gutter also has to be connected there. The attachments on the roof elements are installed before the elements are hoisted into place.

In some dwellings, the bathroom, toilet and kitchen are also renovated. Glass plates are used to clad the walls. These are produced offsite by a glass processing company. On site, the plates have to be transported manually. New pipelines are installed between the existing walls and the glass plating, which does not require any milling. The producer of the glass plates creates a 3D scan for the design of the plates for the bathroom and the toilet. The producer creates the design based on the use of spacers alongside the so-called mill system. This ensures there are as few critical fits as possible, as shown in Figure 5.4. For the mirror, a critical fit is unavoidable as it is incorporated into the plane of the glass panels. That means the mirror has to be positioned between two panels. The key characteristics of the assembled plates are the uniform dimensions of the seams, which have an optimum width of 1.5 millimetre. In order to achieve this, the design and production must both be flawless. The developed glass cladding can be characterised as a special system product [Eekhout, 2015].

The producer of the glass cladding uses the design-for-assembly concept for the design. The nominal design of the glass plates is based on a certain spread in the dimensions of the space. This is necessary because the scan has a margin of error. The glass plates are delivered as separate packages for each bathroom. The onsite assembly of the plates is carried out by the multidisciplinary team to the producer's instructions. Using a separate assembly team for glass-related activities would complicate the process inside the dwelling and increase waiting times.

\subsubsection{Findings concerning the realisation of the assembly}

The façade modules are delivered just-in-time, while the roof modules are delivered a few days before assembly. Before mounting the façade modules, the positions for the J-anchors are determined and these are then put in place. The gutters and the mullions in the window frames are removed. For the horizontal positioning of the façade modules, vertical marks 


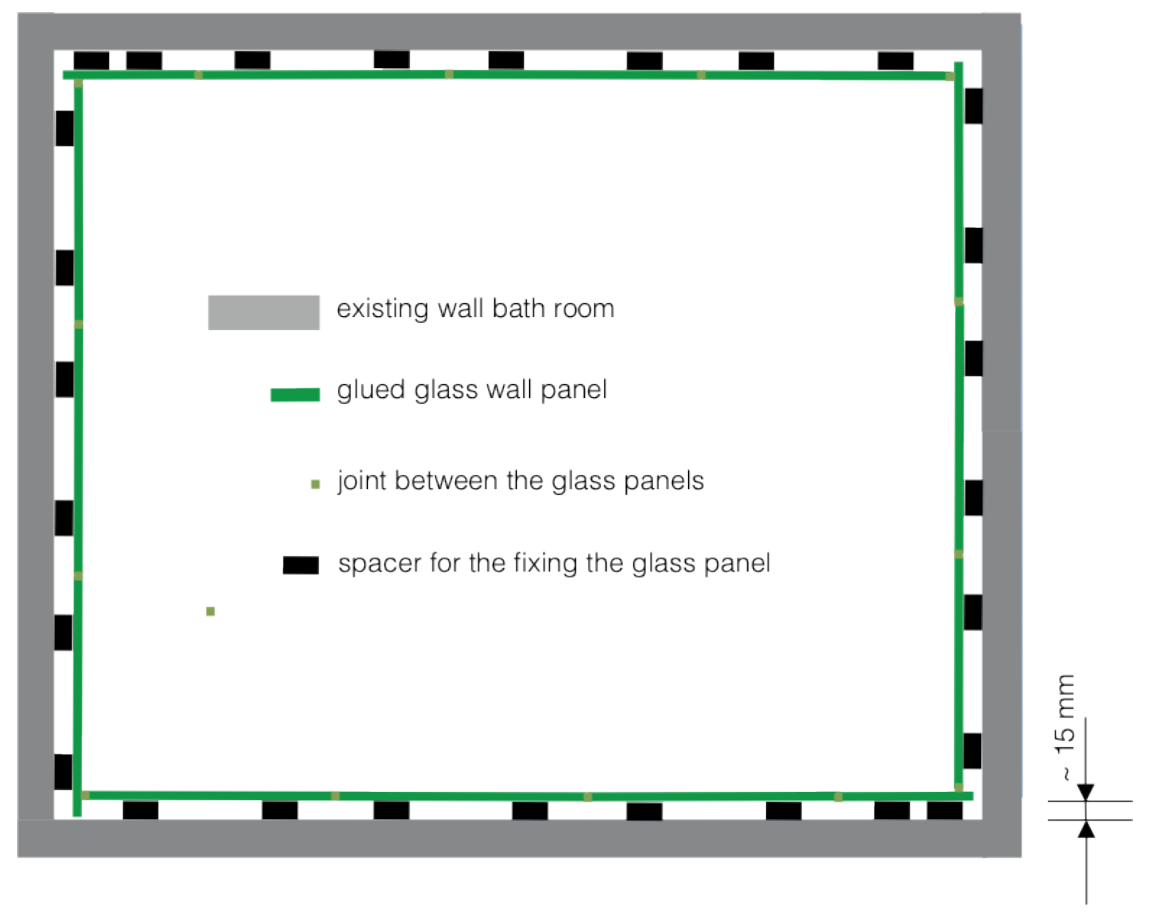

Figure 5.4: Cladding the bathroom walls using the "mill system".

are made on the existing façade. The supplier has installed hoisting facilities on the modules. The modules are attached to the crane, moved into the desired position by hand and then placed on the J-anchors. The procedure for the top elements is the same as that for the bottom elements, with the exception that the former are placed on top of the latter.

The assembly of the façade modules is not fully controlled. Horizontally, free positioning is used. For the vertical and perpendicular positioning, the J-anchors result in forced positioning. Given that the PE band has to be compressed during positioning, the façade modules are mounted on the façade before reaching their desired position. Another concern is that the cranes used are not ideal for the fine movements that this method of free positioning requires: it becomes a case of aiming, rather than positioning. Accurate positioning is only possible by modifying the bottom PE band during the assembly process. It is uncertain whether the desired quality of connection to the existing façade has been realised. After the installation of the façade elements, the connections to the existing window frames are realised. This process is based around onsite carpentry rather than the use of assemblies.

Prior to the assembly of the roof modules, the chimneys and roof tiles are removed. To facilitate the connection between the roof elements and the existing roof, strips of compressible material are placed along the contact points. Assembling the roof modules pro- 
ceeds in a controlled manner, as seen in Figure 5.5. The assembly process does not provide for quality control, so it is not known whether the desired quality of the connections has been achieved.

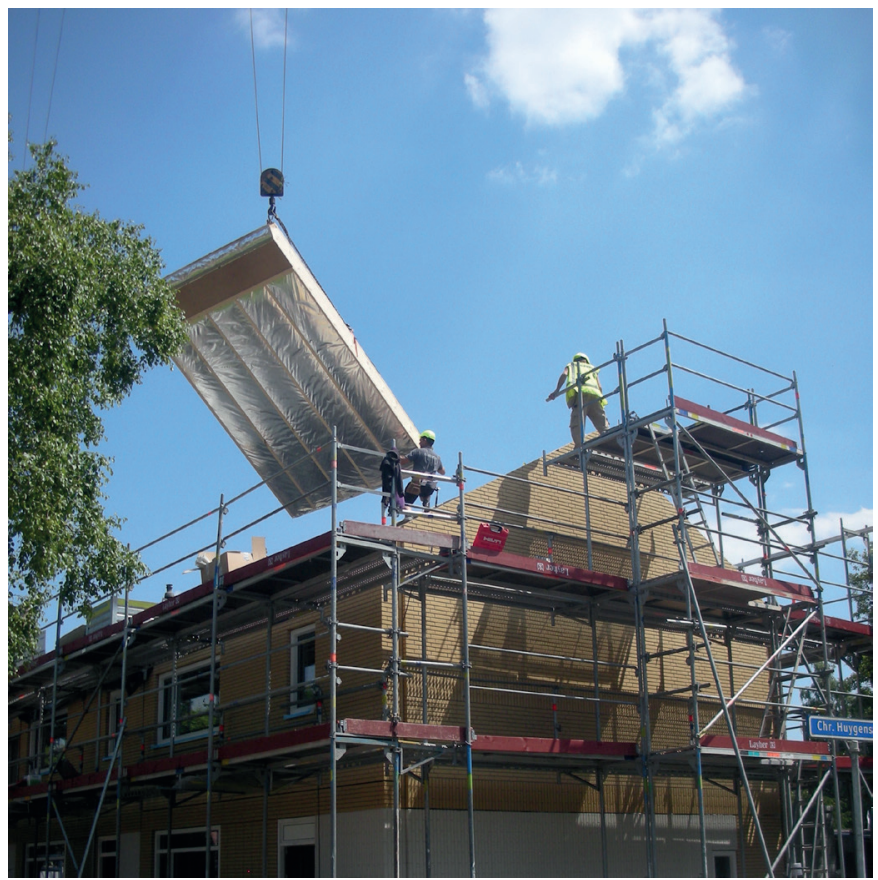

Figure 5.5: Hoisting a roof element into the desired position.

Installing the glass plates in the sanitary areas did not always proceed in a controlled manner. Errors were made when mounting the panels, such as joints measuring 3 millimetres instead of 1.5 millimetre or using an incorrect assembly order for the panels, in which case the mill system (see Figure 5.4) breaks down. We saw that people who have no prior experience with the assembly of the system try to figure it out on their own, rather than consulting the supplied manual or the assembly protocol. Reading the available documentation could prevent such issues during assembly.

\subsubsection{Findings concerning the proposed design-for-assembly method}

Of the three assemblies that were described, only the assembly of the roof modules proceeds in a controlled manner. However, this result cannot be linked to the design model that was used because the designer of the roof modules did not use a phased model. Nevertheless, the geometric variations in the existing roof and the dimensional deviations of the roof ele- 
ments were certainly taken into account during the design phase. This makes this a case of utilising tacit knowledge. Furthermore, the design of the roof modules was tailored to the assembly process. For example, hoisting slings were already installed during manufacture. The roof modules are based on an integral design. The system design and the assembly are handled by the same organisation.

The assembly of the façade modules does not proceed in a controlled manner in that the design and the assembly are not coordinated. The design is tailored to account for the geometric variations in the precise positions of the existing window frames. This, however, does not constitute an integral design. The design and the assembly are handled by different organisations and the system integrator expects these parties to resolve any issues. The lower façade modules can only be installed after they have been modified during assembly.

The assembly of the glass wall panels in the dwellings' interior also does not proceed in a controlled manner. During their design, key characteristics were formulated, the geometric variations of the existing walls were taken into account, assembly protocols were utilised and the realised quality could be evaluated. The disruption appears to be a consequence of insufficient practical experience by the assemblers: they do not yet possess tacit knowledge. It seemed that drawing up an assembly protocol is not enough to realise a controlled assembly: this requires the assemblers to have concrete practical experience.

Generally speaking, the findings reveal that, in this particular case, a system-of-systems approach was used and that it contains characteristics of design-for-assembly. The latter was explicitly used to design the glass wall plates. However, this does not amount to the application of the described model, but rather a design approach. From this case, two points worthy of attention in evaluating the proposed method came to light. These concern the occurrence of minor specific assembly activities and the use of assembly instructions. Given the cost of using assemblers with the required competences for specific assembly activities, these were instead carried out by assemblers without the required competences. By incorporating such assembling in the spatial and functional design, an element of risk is introduced. Even providing assembly instructions offers no guarantees of the proper execution of the assembly since this requires practical experience. The issues that are relevant for the integral approach to design and execution are covered in the proposed design method to be evaluated.

In this case, the provider involved three system suppliers in the system design. One of these was responsible for both the design of a system and its assembly. This assembly went well. The assembly of the other two systems was disrupted. In both cases, special system products were used. As such, it would seem, when using such a system, to be desirable that the party responsible for the design also handles the assembly. 


\subsection{Case 1.3}

\subsubsection{Introduction to case 1.3}

The provider in this case study again operates nationally in The Netherlands and has four regional implementing organisations. Two people were interviewed about this case ${ }^{1}$ : one interview was held with the provider and a phone interview was conducted with one of the suppliers. Furthermore, it was possible to monitor the assembly in detail. ${ }^{2}$

The provider is convinced that assembly is the future of the construction sector. The hours spent on the construction site itself are simply too expensive and only getting more so. Assembly is certainly possible, but it does not combine well with current processes. The current approach is one of improvisation and doing everything at once; also referred to as "firefighting" in the literature. The provider is convinced that construction as an activity needs to be separated from the project approach. In terms of the Stroomversnelling project, the provider has to deliver 2750 zero-energy dwelling transformations, for which they were using a concept approach. Each concept type is linked to a year. After concept 1, with two prototype dwellings and a project with 96 zero-energy dwellings, concept 2 was developed. This concept is all-electric. Power is generated using solar panels. The case study pertains to a project involving 203 zero-energy dwellings based on concept 2. It consists of improvements to the shell and the ground floor, the transition to an all-electric energy source and interior activities.

From the projects so far realised, it had become clear that residents find the combination of insulating the shell and modifying the installations alongside the realisation of the interior activities like the bathroom, toilet and kitchen renovation to be highly disruptive. As a result, in concept 2 , the execution of the interior activities was separated from the improvements to the shell and the installations. Furthermore, it had become clear that a good relationship with the residents of the dwellings to be renovated is essential. To achieve this, overdue maintenance activities were first carried out during Stroomversnelling projects. Further, the people involved in carrying out the transformations are trained to deal with possibly aggressive behaviour from residents.

1 The first interview was held on 7 April 2017, the second after monitoring the assembly, circa 13 December 2017

2 The construction site was visited on 29 and 30 November 2017. 


\subsubsection{Description of the systems to be assembled}

The dwellings in question are built in a row and each dwelling has an extension at the rear. The provider refers to the shell as a tea cosy. The interior activities included consist of transforming the kitchen, the toilet and the bathroom. The onsite activities are carried out by employees of the local organisation and of the businesses that supply construction parts that were produced offsite.

The shell consists of the sloping roof of the dwelling, the flat roof of the extension, the dwelling's front and rear façades and the façade of the extension. The insulation of the shell is to be improved. To do so, the sloping roof is covered in sandwich panels, add-on panels are mounted on the façades and the extension is wrapped in a three-dimensional casing. The ground floor is insulated by blowing insulation material into the crawl-space below the floor. For the transition to all-electric, the equipment to be installed, which consists of an inverter, a heat pump, a warm-water facility and a ventilation unit with heat recovery, is housed in a single unit which is installed in the garden behind the dwelling (the so-called machine room). This "pluggable" unit is supplied by a third party and then installed by the provider. The existing radiators are used to distribute the heat within the property. The ventilation system involves decentralised input and output via the kitchen, toilet and bathroom to the heat recovery unit. To facilitate the air supply, channels are incorporated in the air gap to be created in the façades. These are connected to channels in the roof that lead to apertures in the rooms themselves.

In general, a standardised range of kitchen furniture, glass panels and tiles are used for the interior renovation. These glass panels are part of a concept developed by a glass-processing company. This company is also involved in the zero-energy dwelling transformations described in case 1.2. The concept that was developed for that project was further developed to such an extent that it can accommodate dimensional deviations in the length and width of the bathrooms of up to 50 millimetres. This was made possible by utilising glass corner elements in the four corners of the space. The other panels overlap as shown in Figure 5.6. Radiant heating is installed in the bathroom behind the glass panels and the mirror. The standardised range of kitchen furniture comes from a supplier that is well known to many consumers. This allows the residents of the renovated dwellings to purchase additional units if they so wish. The supplier guarantees availability for twenty-five years. This supplier will likely also handle the installation of the kitchens.

\subsubsection{The design of the assembly}

For the design, production and realisation of the new shell, a 3D scan of the building is made. The result of this scan is a point cloud. This representation of the shell deviates no 


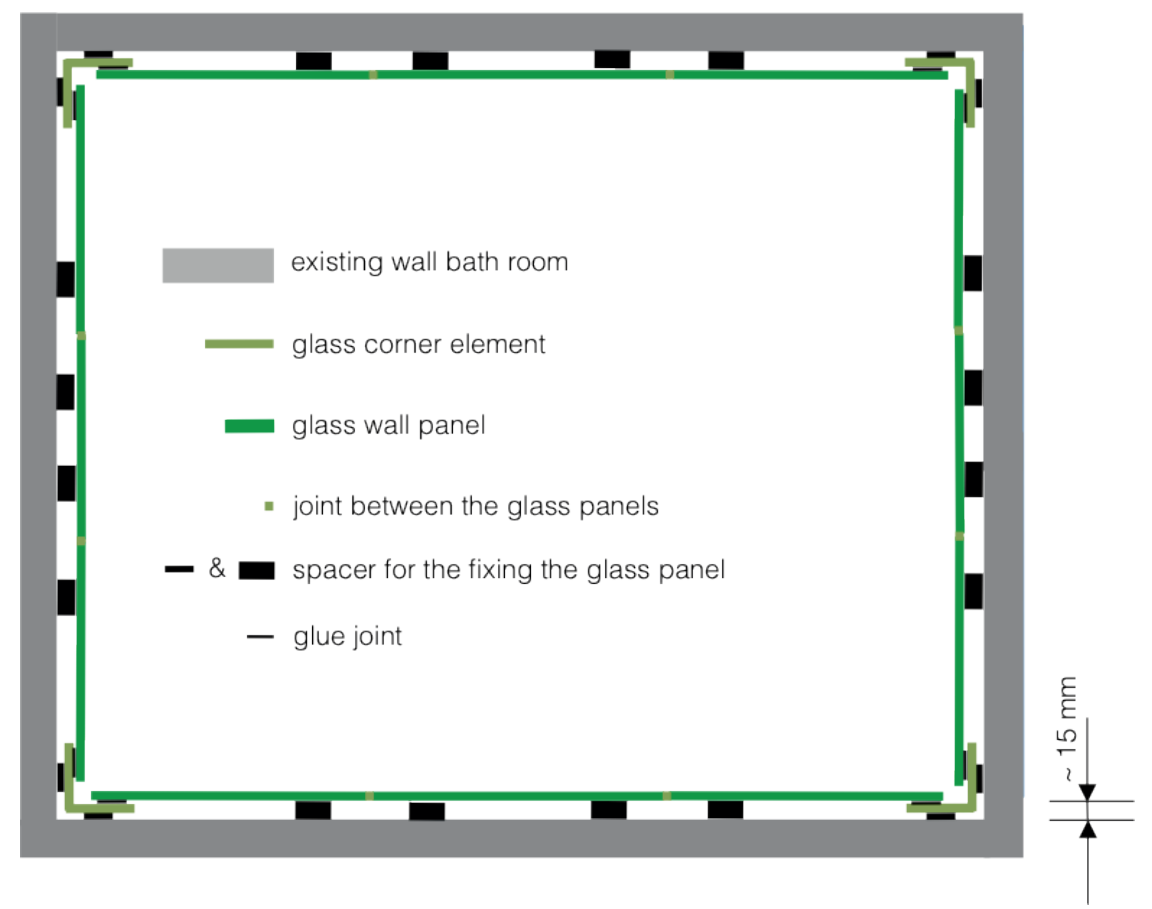

Figure 5.6: Cladding the bathroom walls using the "assembly corner elements system".

more than two millimetres from reality. Based on the point cloud, a building information model is created for the dwelling and the extension. This model serves as the basis for the design of the assembly. In designing the shell, achieving airtightness is of paramount importance as this affects the energy performance and the linked fee that the residents have to pay to the housing association each month: an inferior airtightness results in a lower fee.

The design of the add-on façades was created by the supplier, who is also involved in their assembly. The add-on façades must function as a single airtight casing in the as-built situation, which means the panels of the add-on façade have to provide an airtight connection at their joints. This casing must also have an airtight connection to other systems at the top (to the roof panels) and bottom (to the existing façade). Based on the available representation, the supplier determines the dimensions of the panels and their positioning. The positioning is selected to ensure that the connections between the new and old window frames can be completed without needing extensive onsite carpentry work. The required components for this work, wooden plates and corner elements can be manufactured offsite.

For the sloping roof, the chimneys and roof tiles are removed. Next, the roof surface is fitted out with timber at the contact points for the additional sandwich panels. The roof surfaces created with these sandwich panels must also be airtight and provide airtight con- 
nections to other systems at their edges. The three-dimensional casing for the extension is delivered as a unit to the site. After assembly, it rests on a support that is created at ground level and attached to the existing masonry.

The machine room rests on a concrete plate that is produced off site and then connected to the casing of the extension. For the dwellings in this case study, it was decided not to install the glass panels due to the size of the sanitary facilities, especially in the bathroom. Instead, the "tiles over tiles" solution was used, where new tiles are simply bonded onto the existing tiles. This work is carried out by a tiler. The activities carried out to renovate the interior of the dwellings are not discussed further in this case study since bonding tiles is not an assembly process.

\subsubsection{The design of the systems to be assembled}

The add-on façade panels must perform the usual functions of building façades after assembly. In this regard, the performances that have to be delivered pertain to thermal insulation, airtightness, aesthetic quality and positioning in relation to the existing window frames that allows them to be finished with minimal carpentry work in accordance with the design. The add-on façade panels are mounted onto the existing façades using a vertically oriented attachment system.

The system design of the add-on façade is based on the requirement that the panels must provide airtight connections. The airtightness of the new shell is largely dependent on the connections to the existing façades at the top and bottom. The assembly goals concern the realisation of the connections between the panels themselves and the position of the panels after assembly. The design, manufacture and assembly of the façade panels are handled by a single party. The width of the façade panels is equal to that of the bay of the dwellings and their height is tailored to the dwelling's storey height. The system of add-on façades used in this case is based on earlier systems. The basis of the current system consists of structural insulated panels (SIPs).

The geometric design is realised based on a three-dimensional scan of the existing dwellings. The data from the scan are imported into a three-dimensional drawing program. Using these data, the supplier determines the dimensions of the panels, which are dwelling-related, and the positions of the attachment system. This system serves as an interface and it is based on the bed-hook system ${ }^{1}$. Part of this system is installed on the panels themselves and part is mounted onto the existing façade. A notable aspect of this attachment system is that it

1 This is a tried-and-tested concept for the installation of façade panels. 
manages to position the add-on façade panels in the desired position for the as-built situation while also realising the airtight joints between the panels themselves. In effect, there is forced positioning in all three directions. In this system, the interface functions as a tool for the forced positioning of the add-on façades. The dimensional deviations in the bed-hook system in the as-built situation are accommodated by the add-on façade panels.

The locations of the interface attachment points are recorded in the building information model. The locations of the points to which these interfaces are attached to the existing façade are marked on the existing façades during the onsite work with a total station. At the locations of these attachment points, small holes are drilled into the masonry. These holes are used to determine the locations of the holes to be drilled in the existing façade in order to attach the interfaces. The interfaces are adjusted in the vertical plane using a spirit level.

The dimensions of the add-on façades are also based on the information contained within the building information model. As such, the add-on façades are realised using an integral approach to design, manufacture and assembly. The panels are delivered more-or-less just in time. The supplier also provides the crane that is used for the assembly. They are assisted by employees from the provider's nearest branch. The capacities of the crane are tailored to the desired accuracy with which the panels must be positioned near the interfaces and the rest of the assembly. This system can be seen as a special system product. The entire design of the add-on façade can be seen as state-of-the-art. The supplier and the carpentry firm that realizes the connections to the existing window frames and façades have made agreements about the joinings to be realized on the existing frames and facades. The supplier is responsible for the realization of the planning and execution of the labor-extensive carpentry work.

The new roof skin provides the required thermal insulation of the roof. The performances to be delivered concern the thermal insulation, the airtightness and the aesthetic quality. The roof skin consists of standard sandwich panels with metal skins. These run from the purlin to the wall plate. They are placed on top of the existing roof boarding after removal of the roof tiles. To compensate for the dimensional deviations that are found in the existing wall plates and the deformation of the purlins, wooden slats measuring $45 \times 70$ millimetre are installed above the wall plate and the purlins. This creates an air gap between the existing roof boarding and the underside of the roof panels. The air gaps behind the façade panels and those underneath the sandwich panels must be kept separate. The sandwich panels are standard products, although this application is special. The roof skin must be airtight after assembly. The sandwich plates themselves can be considered airtight. The longitudinal joints of the sandwich plates can also be considered airtight based on the supplier's specifications. In order to achieve the desired performance, the roof skin must be connected in an airtight manner at the locations of the system-to-system connections. This is achieved using PE band for these connections. In doing so, wedge-shaped bands of insulation are 
applied on the façade panels at the locations of the longitudinal joints. Next, the PE band is installed on top of this and on the wooden slats. This must connect to the underside of the sandwich plates. At the location of the side façades, there is a system-to-system connection of the sandwich plates to the top of the façade panels. There, the PE band is applied on top of the façade panels. The roof skin and all associated components are installed by a company that specialises in roofing activities.

The extension can be seen as an add-on to the dwelling. The three-dimensional casing that is to be placed around it provides the thermal insulation. The exterior of this casing must be similar to that of the add-on façade panels. The requirements for this casing pertain to its thermal insulation, airtightness and aesthetic appeal. In this case, the casing consists of a three-dimensional timber frame casing. It is not delivered by the supplier of the façade panels, but rather by a company that produces timber frame roof and façade panels. The casing itself has to meet thermal insulation and airtightness requirements. The same goes for the connections to the existing extension and for the connections to the façade panels. The casing will rest on a horizontal framework that is attached to the existing extension. It is unclear how the casing is connected to the existing extension. The connection to the façade panels is realised using a PE band.

The machine room contains the heat pump, the heat recovery unit, the boiler and the inverter. The machine room is delivered to the site in a fully completed form. It is installed on a separate foundation. To facilitate its positioning in the horizontal plane, four attachment points are incorporated in this foundation. The machine room connects to the casing around the extension. This connection has to meet an aesthetic requirement: the width of the joint must be the same throughout.

\subsubsection{Findings concerning the realisation of the assembly}

Placing the façade panels proceeds in a controlled manner, evidenced by the fairly consistent lengths of the assembly cycles. The presence of an employee from the company that supplies the panels positively contributes to the quality assurance. This employee also operates the supplier's crane. The dimensioning of the interfaces using the holes that were drilled in the façade, their attachment and the installation of the panels all proceed as planned.

The mechanism for forced positioning that is incorporated in the attachment system functions well. After the rough positioning of the panels to a position close to the interfaces, the crane can lower the façade panels in a controlled manner. The forced-positioning mechanism then locates the façade panel in the correct position. The interfaces are designed in such a way that they allow the panels to move parallel to the façade during positioning. 
In theory, a space of twenty millimetres is available for this purpose although it is not known what this figure is in practice. Some of this space is needed to accommodate the dimensional deviations in the panel itself and those which occurred during the installation of the interfaces. Furthermore, the people responsible for mounting the panels appear satisfied that this process goes as planned: they do not focus on fine-tuning the position of the panels. They also lack any information regarding the desired position of the panels in the as-built situation. The panels are therefore not repositioned after being hoisted into place. As a result, the actual position of the façade panels in the as-built situation is not determined.

The joinings between the panels, which are realised using sealing strips, appear to be of good quality. If the sealing strips are correctly placed and the panels are in their desired position, the quality of the connection is ensured. The quality of the connection at the bottom is visibly insufficient. The quality of the connection at the top can only be assessed from a test assembly. The quality of the connections with the existing window frames is insufficient according to the carpenter such that they have to do far more work than agreed. That is, despite the careful preparation, the connection of the window frame in the add-on façade to the existing window frame requires more work than expected. For example, Figure 5.7 shows that the lower edge of the new window frame could be about 50 millimetres too high. From the outside, it was clear that the add-on façade in question was indeed positioned correctly. This discrepancy is only possible if the position of the existing window frames vary vertically. ${ }^{1}$ The carpenter was given the freedom to resolve the situation as they saw fit.

The system design of the add-on façade system can be seen as "state-of-the-art." Unfortunately, key assembly characteristics pertaining to the geometry were not quantified as part of the nominal design. The supplier also failed to determine the realised geometric quality in the as-built situation. As a result, it is not possible to quantify the realised quality, which inhibits further optimisation of the assembly of the system.

1 This may be a consequence of the uneven settling over time of the row of dwellings in question. This was not examined further in the context of this case study. 


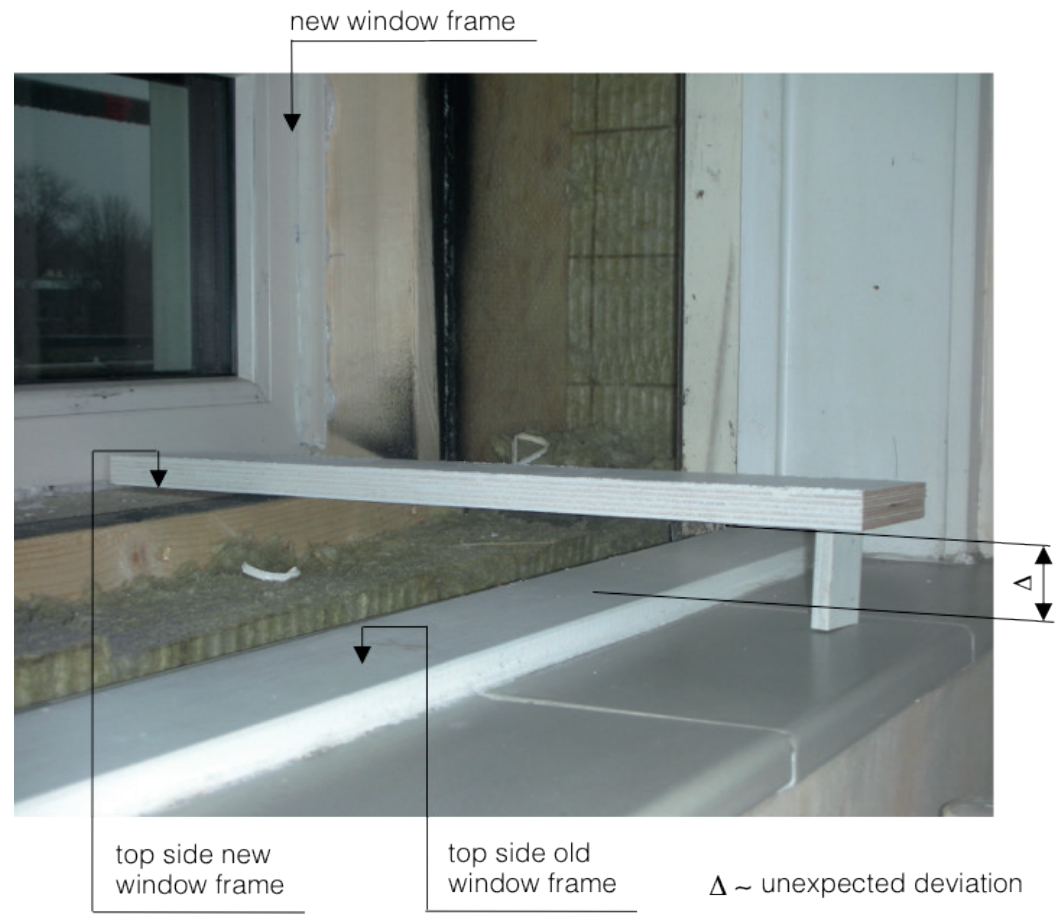

Figure 5.7: The position of the window frame in the add-on façade in relation to the existing window frame.

During the assembly of the sandwich plates, their position in the as-built situation could not be objectively assessed during the observation period. However, the method employed by the people responsible for installing the plates suggests that this is not done sufficiently accurately. The actual position of the panels is hardly verified prior to attachment. Since the panels are mounted consecutively, this results in an accumulation of deviations. The longitudinal position of the panels is determined by eye by ensuring that the plates connect correctly along the bottom edge. If adequate dimensioning and positioning were used, the installation of the panels could proceed in a controlled manner.

Figure 5.8 shows the existing roof at the meeting of a side façade and a front façade, seen from the top. The realisation of the airtight connections of the sandwich panels to the add-on front and side façades does not look robust. The people who place the panels are also responsible for correctly placing the insulation and the sealing strips. This can only be assessed visually. The quality assurance of this assembly process depends on the extent to which the provider's project leader can motivate the workers to do their job properly. In other words: the extent to which employees "wish" to ignore the pressure put on them by the project leader. 


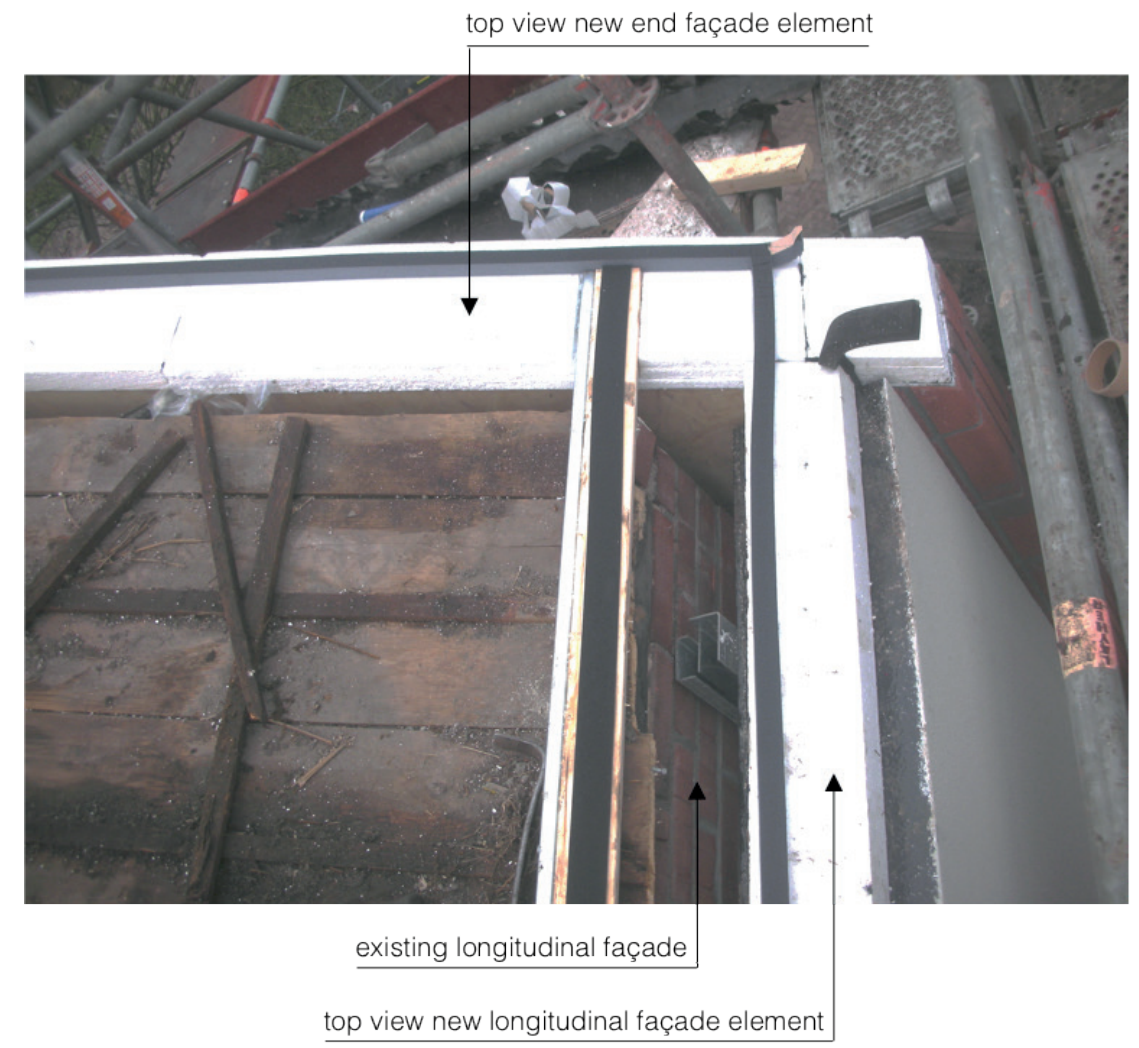

Figure 5.8: The assembly base for the sandwich panels at the location of a front façade and a side façade.

The thermal quality of the extension is improved by adding a casing. It can be seen as a three-dimensional timber-frame element. Visible deformation occurs during the hoisting process. This is a case of free positioning and, during this free positioning, the PE band between the extension and the façade panels has to be compressed. Both the desired position and the realised position are unclear. The carpenters spent a long time adjusting the position of the casing after its initial positioning. The quality of the connections at the bottom appears to be insufficient and they are certainly not airtight. The desired connection to the façade panel cannot be realised during the positioning exercise due to the method employed. The PE band only functions as a sealant when it is compressed and this is practically impossible to realise in a controlled manner when using free-positioning. The positioning process therefore seems uncontrolled. Additionally, it is difficult to correctly position a deformed component and this process required many people. There is no clear procedure for quality assurance. As such, the assembly of the casing is classified as uncontrolled. 


\subsubsection{Findings concerning the proposed design-for-assembly method}

Of the three assemblies described above, that of the add-on façade system proceeds in a controlled manner. Unfortunately, the system-to-system key characteristics are of insufficient quality. The supplier has developed the resulting assembly after several years of system development. As such, the fact that the assembly of this system proceeds in a controlled manner cannot be linked directly to any applied design method. The system is based on experience combined with the use of the best available technology. Regrettably, the supplier does not have any information about the system's key characteristics, which makes it impossible to optimise the system in a structured manner.

The assembly of the roof sandwich panels does not, but could, proceed in a controlled manner. To realise this, an assembly protocol must be developed whose application will demonstrably lead to realising the key characteristics. This protocol needs to be developed in such a way that quality assurance becomes part of the assembly process. For example, the location and execution of the PE band joints could be made part of the assembly process. These joints could then be photographed as part of a quality-assurance process.

The assembly of the casing for the extension does not proceed in a controlled manner. The reason for this is that little attention has been given to the assembly of this three-dimensional part. This is evident from the deformation that occurs during the hoisting process, the positioning method that is used and the quality of the connections along the bottom and where it joins the dwelling's façade.

The conclusion is that a system-of-systems approach was used in this case. However, its substantiation at the level of the system-to-system connections was not given sufficient attention. The connections are not robust, which makes their quality dependent on the execution. Considering the system design, which is based on a functionality to be realised, the design of the add-on façade system illustrates clearly that an integral approach to both the manufacture and assembly processes is certainly possible. However, key characteristics that needed to be realised with the assembly were not formulated and no measurements have been conducted to determine the feasibility of the process, which makes it impossible to further optimise these processes.

This case study has brought two desirable changes to the proposed design method to light. These concern the system design and the realisation of the assembly. The first change pertains to the robustness of the system design with regard to realising the key characteristics. This insight came from the modified design of the glass cladding used in the bathrooms. By using a corner element in combination with an overlapping connection, the robustness of the system with regard to dimensional deviations in the assembly base were increased considerably. Such robustness is desirable in all constructions that are realised through assem- 
bly. The second change concerns quality assurance during the realisation of the assembly. This needs to be made part of the assembly process itself so that the realised quality is no longer dependent on the degree of oversight. This would be possible since the realisation of the key characteristics can always be linked to an observable situation or a measurable unit. This facilitates a systematic approach to quality assurance.

In this case, the provider involved the supplier of the add-on façade system in the system design. The supplier is responsible for both the design and the assembly, both of which proceeded in a controlled manner. For realising the casing of the extension and the new roof skin, standard products are used, albeit in a specialised manner. The parties responsible for realising the associated assembly work have limited experience with this application. As a result, the quality at the system level is not safeguarded. The provider has not sufficiently fulfilled the role of system integrator.

\subsection{Case 1.4}

\subsubsection{Introduction to case 1.4}

The provider in this case is once again a nationally operating provider in The Netherlands with regional construction companies that operate all over the country. In general, these companies operate independently. The Stroomversnelling project is organised by the head office, which supports other Stroomversnelling projects that are carried out by the regional construction companies. In this case study, two interviews ${ }^{1}$ were conducted; one with the provider and one phone interview with an employee of the architectural firm involved in the project. It was not possible to monitor one of this provider's projects. The provider was to realise all 2,775 Stroomversnelling dwellings on a project-by-project basis. In this manner,70 dwellings were renovated in April 2017. At the time, the provider was developing "its" ideal concept. The approach described here had already been tested during one project. The acquisition of projects and project preparation are handled by the head office. An external architectural firm is used to prepare plans. It also draws up the documentation for the building aesthetics committee and consults with the head office about the architectural details that it designs. When it comes to the execution, organisations that are part of the conglomerate are used whenever possible. If these organisations lack experience with the zero-energy approach, the execution of the project is supported by head office.

The provider is a proponent of the philosophy of having the right construction product at the right place. That means using the assembly method when it makes sense to do so. During previous zero-energy projects, add-on façades that were produced offsite and so-called instal-

1 The interview with the provider was held on 29 March 2017, while the interview with the employees of the architectural firm was held on 5 April 2017. 
lation columns were used. Since the experiences with both solutions were unsatisfactory, neither are now being used. Executing the interior activities in an occupied dwelling did not go well either. The interior activities are no longer part of the provider's standard services. If a buyer wishes, one of the provider's regional organisations can take care of the interior activities.

The primary goals of this provider's zero-energy approach are meeting the quality standards stipulated for the Stroomversnelling project, reducing the overall costs, reducing the preparation costs and reducing the costs and risks of the activities. As of April 2017, the provider's services consisted of the processing of standard construction products and installing components at the construction site. In terms of energy, the projects are all-electric: solar panels on the roof supply power to the dwellings.

\subsubsection{Description of the services}

The services provided consist of the transition to all-electric power and insulating the shell including the ground floor. To provide heating, the existing radiators are used in combination with a heat pump, which also heats water for domestic use. For the ventilation, distributed inleds with heat recovery is used.

As part of the upgrading, the shell, consisting of the façades and the roof, is heavily insulated. The glass in the façades is replaced and insulation glass panels are placed on the exterior of the façade. These are fitted on site. In order that each individual dwelling meet the airtightness requirements, the existing wall cavities are filled with foam. This is especially important for sealing the window frames to the existing exterior façade. Standard sandwich panels are placed on the roof. The ground floor is insulated from below with insulation foam. This also improves the airtightness of the floor. To install the new glass with its improved insulation characteristics, the existing glass is removed, but not the window frame itself. The existing window frame is used to determine the correct position of the new window frame. The new glass is then installed in the new frame.

\subsubsection{Preparing for the execution}

This consists mainly of ordering the requisite materials and equipment. Before the start of the activities, any light fixtures, awnings, antennae and other features are removed from the façades, and will be replaced later. On the roof, the roof tiles, gutters, chimneys and, if applicable, windows are all removed. The battens are left in place. Based on aesthetic demands, the attachment points at the locations of the purlins have been leveled. The sandwich panels are installed on top. 


\subsubsection{The execution}

First scaffolding is erected. From this, the insulation panels are mounted. These are glued onto the existing façade, after which each panel is attached with three screws using a "blind" attachment. Individual stone strips are applied to mask the vertical joints.

The connection to the sandwich panels on the roof is realised by cutting the top edges of the insulation panels at an angle and filling the joints between the panels with foam. The new gutters, including the flora and fauna facilities, are attached to the sandwich panels with brackets.

\subsubsection{Findings concerning the proposed design-for-assembly method}

The services of this provider are based around the processing of standard semi-finished products at the construction site. This method does not meet the assembly principles of this study. As a result, there are no findings concerning the organisation and realisation aspects in terms of assembly.

In this case, it became clear that the provider in question interprets the requirement regarding the airtightness of the dwellings differently than the other providers. This provider believes that the requirement applies to each individual dwelling, which partially affects their choice of an insulation method for the façades. In comparison, the provider in case 1.3 believes that this requirement refers to the entire block that the individual dwellings are part of. In case 1.4, no desirable changes to the proposed construction assembly design method came to light.

\subsection{Overall findings regarding the proposed design-for-assembly method}

This section summarises the findings from cases 1.1, 1.2 and 1.3. Following this, in Section 5.11, their consequences for the proposed construction assembly design method are described.

\section{Summary of the findings regarding the realisation of the assemblies}

\section{Case 1.1}

In this design, there was no explicit focus on the impact of geometric deviations resulting from dimensional variations in the construction products or from the assembly. The design 
of the assembly process did recognise that its design affects the final result. The key characteristics to be realised were recognised, but not specified. The effects of these deviations on the system-to-system design are partially described in a qualitative manner. Guidelines were used to facilitate the realisation of the assembly. The impact of the guidelines is unknown and it was not possible to monitor the assembly process in action. This case did not produce any insights based on which the proposed design method could be enhanced.

\section{Case 1.2}

In this case, a system-of-systems approach was used, which did include characteristics of design-for-assembly. It turned out that it is important to avoid having to assemble small systems that consist of special system products. If this is not possible, these activities can possibly be carried out by a non-specialised organisation that is already involved in project realisation. To do so, clear instructions must be available and the organisation in question must have ample time to acquire the necessary competences in advance. Written instructions alone proved to be insufficient. The insights from this case can be used to improve the proposed design method.

\section{Case 1.3}

In this case, two desirable changes to the proposed design method came to light. The first change concerns the robustness of the system design with regard to the realisation of the key characteristics. The second change concerns quality assurance during the realisation of the assembly, which should be made part of the assembly process itself. These insights can be used to change the proposed design method.

\subsection{Findings regarding the organisation of the assembly design and the assembly process}

In relation to the design of the assembly process, this section covers the choice of a tendering method by the buyers and the choice of suppliers by the providers. Following this, the findings regarding the proposed design method are covered.

\section{The choice of tendering method}

For the Stroomversnelling project, a design-build-maintain approach was used given the total cost of ownership. Seen from the buyer's perspective, and considering the complexity of the assembly project, there is no reason to question this choice. This project does not align with the competences of the buyers or those of a supplier and, therefore, the designbuild-maintain approach offers providers the opportunity to realise the design of the assembly as they see fit. It is therefore left to the provider to substantiate this design with or without input from suppliers. 


\section{The choice of suppliers}

Section 4.11 described the possible contributions of suppliers to the design and realisation of the assembly process. Based on the findings described in the cases, one can determine whether the provider had selected appropriate suppliers. The basic principles are that the provider's tasks and responsibilities should be clear and that the suppliers are competent. Considering the available information and the product architecture chosen by the providers, only cases 1.2 and 1.3 are relevant in this regard.

\section{Case 1.2}

In this case, the provider does not carry out any assembly activities; these are carried out by the co-creators. This provider has involved all the individual co-creators in the design of the assembly. As a result, the provider is only responsible for the design of the system-to-system connections. However, in this case, it was not possible to observe the realisation of all the system-to-system connections during an actual project. The provider's contribution to the design of the assembly therefore cannot be assessed.

In this case, the assemblies of two special system products (the add-on façade elements and the glass panels in the bathroom) did not go well. With both, one party was responsible for the design and manufacture and another party for the assembly. Given that special system products are often produced at a single location in the Netherlands, it makes sense that these are assembled by other organisations that are active in the region of installation. This turns out to be a source of disrupted assemblies. In such cases, it is in the provider's best interest to ensure that the design of the manufacture and the design of the assembly are properly coordinated. In practice, this could be realised by representing the assembly with a flowdown and creating a template for the assembly of the product in question based on this information. This template could then be discussed with the intended co-creators prior to the assembly activities.

\section{Case 1.3}

In this case, the provider conducts some of the activities concerning the realisation of the system-to-system connections. Suppliers were also brought in to carry out some of the assembly activities. This provider involved each individual supplier in the design of the assembly. As a consequence, the provider is responsible for the design of the system-to-system connections. During the monitoring of an actual assembly, it became clear that these are not always of sufficient quality.

In this case, the supplier of the add-on façades brought in by the provider performed well. The assembly of the two types of standard products was disrupted, or the quality to be realised was not safeguarded. The standard products were used in a non-standard manner and the suppliers were not responsible for the design of the assembly. It appears that using standard products in a novel manner can be a source of disrupted assembly processes. 


\section{The consequences for the proposed design-for-assembly method}

In the proposed design-for-assembly method, it was assumed that suppliers of special system products are always also responsible for their assembly. It turns out that this is not always the case in the construction sector. Furthermore, the design method assumes that assembly organisations are capable of correctly executing an assembly that was designed by a third party. This is also not always true. The design method must therefore be modified with regard to the selection of suppliers to ensure that the designed assembly process, particularly when standard products are to be used in a non-standard manner, is followed correctly.

The proposed design-for-assembly method acknowledges the design of the system-to-system connections. This case study including four dwelling transformation projects, has also made clear that it is desirable to clearly define the responsibilities relating to the design of an assembly.

\subsection{The results of the case study}

The research sub-question that needed to be answered in this chapter was:

To what extent can the assembly process of dwelling transformation projects be improved when applying the proposed design-for-assembly method and how can the proposed design-for-assembly method be improved?

This section provides the answers to both sub-questions.

\subsubsection{Improving the assembly process of dwelling transformation projects when applying the proposed design-for-assembly method}

Many of the findings described in this case research turn out to be related to design aspects of the assembly. These aspects often have a direct link to the topics that are addressed as part of the proposed design method. In very general terms, the use of the design-for-assembly method leads to the systematisation of artisanal construction activities, which allows them to be realised as assemblies. The cases also show this to be possible. The findings often concern the gap between the parties involved in the design and execution of the assembly. The case study showed that the proposed design-for-assembly method can help in recognising these gaps in practice. A consistent application of the method avoids gaps between the parties involved in the design and realization of dwelling transformation projects that arise from assembling parts produced off-site. The technological development of the add-on façades shows that the systematisation of traditional construction requires product 
development. When applying the proposed design-for-assembly method, the importance of system-to-system connections and joinings is recognised. This can lead, for example, to the system-to-system connections of the add-on façades and roofs system being established through an assembly process. The proposed design-for-assembly method can facilitate this development or transformation.

When using the proposed method for small-series manufacturing, as described in this case study, flowdowns will generally be available for the assembly processes. There is therefore no need for improvisation, which will increase safety for employees. Although it was not an explicit part of the research, it became clear that the use of the proposed design-for-assembly method will have a positive effect on labour productivity. The construction sites visited in this case study produced less construction waste than normal. The construction parts that needed to be assembled onsite, were delivered to the construction site in a finished form. The proposed design-for-assembly method supports the use of this assembly concept and therefore also helps to minimise the amount of construction waste.

At the end of this case study, it became clear that many developments had taken place since its initial start. For example, the provider in case 1.2 decided to switch to a different type of add-on façade, one that was easier to position correctly than the one described in Section 5.7. Furthermore, the system design for the glass panels used in bathrooms has been developed further. Also the system's ability to accommodate dimensional variations became far more robust. Finally, the case study showed that there are no restrictions on the use of the assembly approach for dwelling transformation projects in the Netherlands. This also appeared to be the case in practice, and it has been reported that house transformations can be completed in one single day [Oostra, 2017].

\subsubsection{The improvement of the proposed design-for-assembly method}

Based on the findings described in Section 5.10, some modifications are required in the proposed design-for-assembly method. This subsection provides an overview of the required modifications. They are summarized in Table 5.1. The manner how the required modifications have been processed in the adapted design-for-assembly method is described in Chapter 8.

\section{Demand specification}

During the demand specification phase, a number of functional requirements are formulated. From these, requirements pertaining to the assembly process can be derived. These findings are in line with the proposed design-for-assembly method. 


\section{Spatial and functional design}

It turns out that it is desirable to avoid the use of small systems that consist of special system products. This aspect is not recognised in the proposed design method, so a change in this regard is desirable.

\section{System design}

The design of the cladding for the bathroom revealed shortcomings in that the systems to be used must be robust in the sense of having the ability to accommodate geometric variations. Based on this finding, systems can generally be applied in this design phase. The proposed design-for-assembly method needs to be changed in this regard.

\section{Nominal and variation designs}

During the evaluation of the four dwelling transformation projects, no findings came to light that suggested a desirable change to this phase of the proposed design-for-assembly method.

\section{Preparations of the assembly}

Similarly, no findings came to light that resulted in a desirable change to this phase of the proposed design-for-assembly method.

\section{Execution of the assembly}

It was observed that providing instructions does not necessarily lead to the realisation of the desired quality. Those who execute the assemblies must also possess the appropriate skills before starting the assembly activities. The proposed design-for-assembly method could be changed in this regard.

\section{Completion of the assembly}

Although this is desirable, it proved to be impossible to assess the quality of the described assemblies during their realisation. The proposed design method needs be changed in this regard. 
Table 5.1: Findings regarding the evaluation of the proposed design-for-assembly method.

\begin{tabular}{|c|c|c|c|c|c|c|c|c|}
\hline \multicolumn{8}{|c|}{ phases of the proposed design-for-assembly method } & \\
\hline \multicolumn{3}{|c|}{$\begin{array}{l}\text { f preparation of the assembly } \\
\text { g execution of the assembly } \\
\text { h completion of the assembly }\end{array}$} & \multicolumn{2}{|c|}{$\begin{array}{l}\text { d nominal design } \\
\text { e variation design }\end{array}$} & \multicolumn{3}{|c|}{\begin{tabular}{|l|} 
a demand specification \\
b spatial and functional \\
design \\
c system design \\
\end{tabular}} & \\
\hline 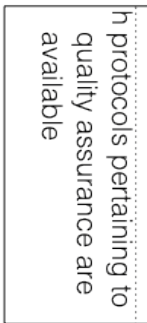 & 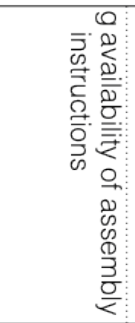 & 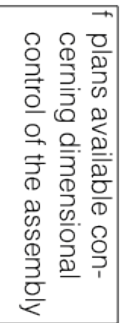 & 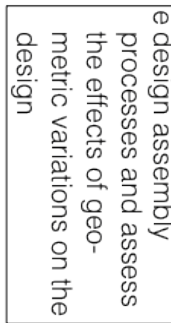 & 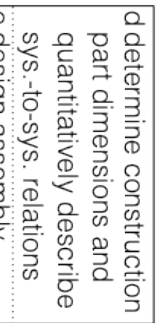 & 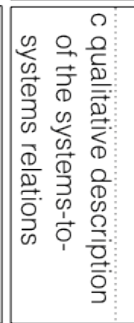 & 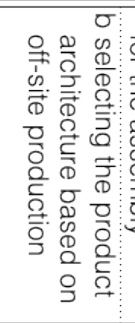 & 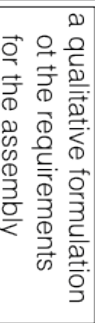 & 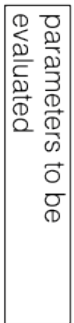 \\
\hline 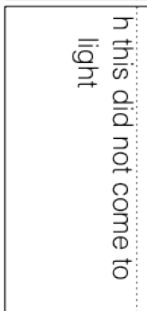 & 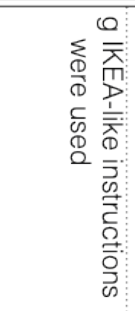 & 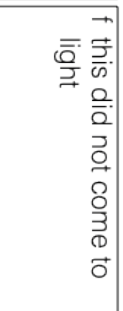 & 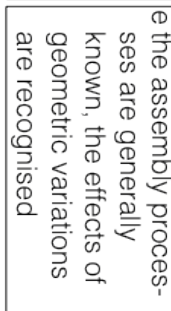 & 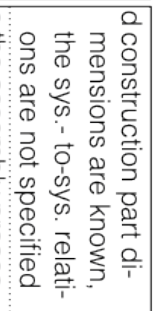 & 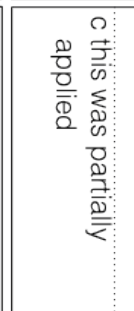 & 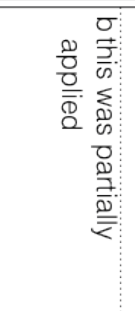 & 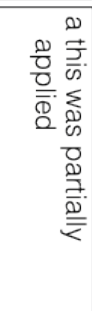 & 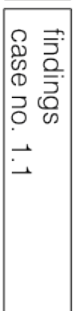 \\
\hline 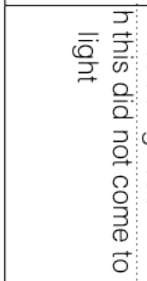 & 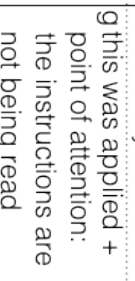 & 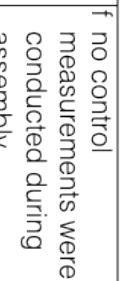 & 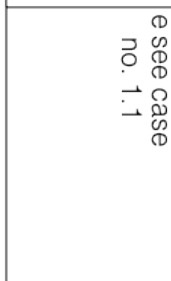 & 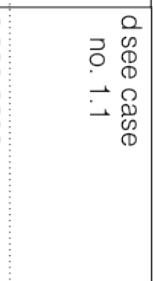 & 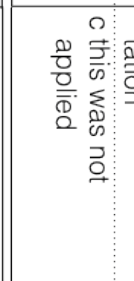 & 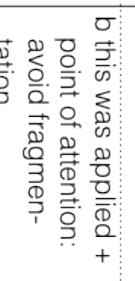 & 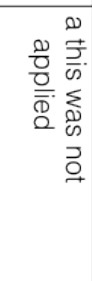 & 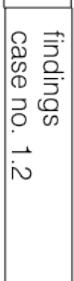 \\
\hline 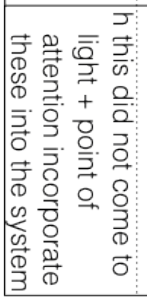 & 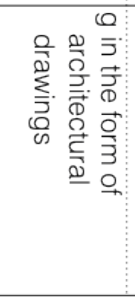 & 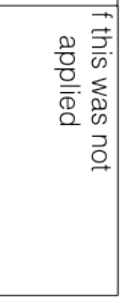 & 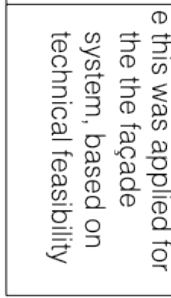 & 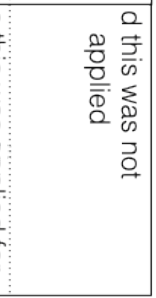 & 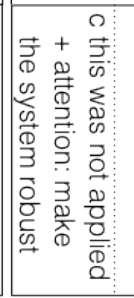 & 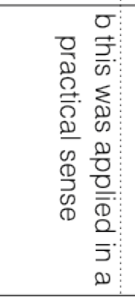 & 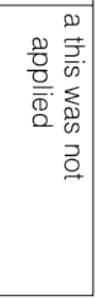 & 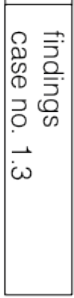 \\
\hline 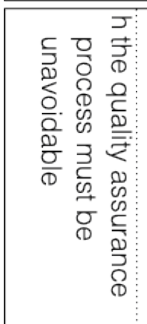 & 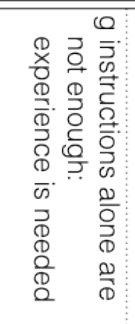 & 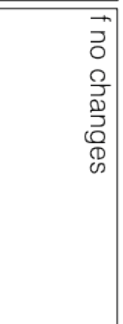 & 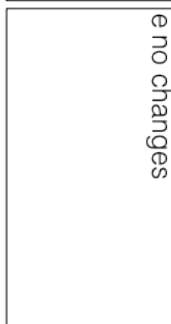 & 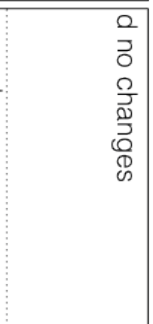 & 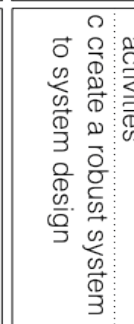 & 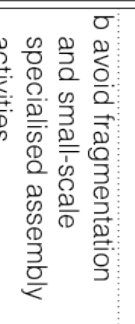 & 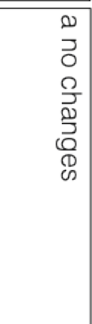 & 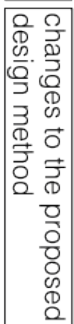 \\
\hline
\end{tabular}





\section{A case study of an utility building project}

\section{Contents}

6.1. Introduction

6.2. The utility building project to be realised

6.3 The characterisation of the utility project

6.4 Goals of the case study

6.5 Methods used in the case study

6.6 Description of the construction organisation

6.7 The design of the assembly

6.8 Findings concerning the realisation of the assembly

6.9 Feasibility of the assembly process for the supporting structures

6.10 Findings regarding the organisation of the design and realisation process

6.11 The results of the case study

6.11.1 Improving the assembly process of utility buildings by applying the proposed design-for-assembly method

6.11.2 The improvement of the proposed design-for-assembly method 


\subsection{Introduction}

The utility building case study was conducted to evaluate the first draft of the design-for-assembly method for construction and infrastructure projects ${ }^{1}$. The research question that will be answered in this chapter is:

To what extent can the assembly process of utility building projects be improved by applying the proposed design method and how can the proposed design method be improved?

Section 1.3 in Chapter 1 described the conditions for choosing appropriate objects for the case studies. The primary condition is that the product architecture must be based on the use of structural parts that are produced offsite. With the exception of its foundations, this holds for this construction project, which makes it a suitable subject for a case study. The remainder of this chapter is structured as follows. This Section describes the construction project. Sections 6.2 to 6.4 cover the case study's characterisation, goals and method of execution respectively. Following this, Sections 6.5 to 6.7 describe the organisation method, the design and the findings. To support the applicability of the process feasibility concept for the proposed design method to be evaluated. Section 6.8 considers the possibilities to execute assembly processes in the construction sector in a controlled manner. The findings regarding the organisation of the design and realisation process are described in Section 6.9. Finally, Section 6.10 discusses the results of the case study.

\subsection{The utility building project to be realised}

On request of a tenant, a project developer, is developing office space facilities with a gross surface area of $3,000 \mathrm{~m} 2$. The construction location is adjacent to a main road. Based on the tenant's needs, the developer had a preliminary design ${ }^{2}$ drawn up. After going through the permit acquisition process, the developer sells the yet-to-be-realised office space, the rental contract and the permits to an investor. This transaction is based on the gross initial yield for the investor.

The developer and the investor agree to deliver the office to the tenant as a building shell. The desired quality should be in line with the Dutch building regulations and as represented in the preliminary design. The effects of the location have been taken into account.

1 Also referred to as 'the proposed design method'

2 For a preliminary design, the level of detail is equivalent to the system design as introduced in Chapter 4. 
With regards to quality management, the parties agree that the finished office will satisfy the requirements of the Buildings Decree Dutch building regulations. The investor will accept the building based on the calculations made by their advisors, which show that these requirements are met, and on documentation showing that the building was realised in accordance with the plans.

When signing the rental contract, agreements were made about the desired construction period. It was agreed that the building shell would be realised in six months. According to the developer, this is roughly half the normal time for such a building. One of the ways in which time would be saved is by viewing the design and the realisation as a single process, thereby eliminating the usual gap between these phases. Given the desired rapid realisation, the system design's product architecture, except the foundations, is based on the use of construction parts that are produced offsite. By restructuring the design and realisation phases, the developer aims to significantly reduce the construction time, lower construction costs, have more control over the realised quality and avoid being faced with additional work. In the remainder of this case description, the developer will henceforth be referred to as the project's client.

\subsection{Characteristics of the utility building project}

This case study project pertains to the design and realisation of an office building consisting of three wings, two of which have two storeys each. The third wing is located between and at right angles to the other two. The third wing is located between and at right angles to the other two. Most of this so called "body section" has three storeys, with an installation room on top for the various HVAC systems. In order to be able to generalise the findings, the case needs to be characterised in relation to generic utility building projects. To this end, the following characteristics have been defined and are used:

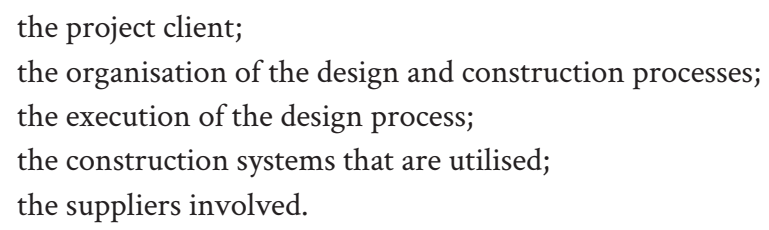

\section{The project client}

The project client of the office is a developer of residential and office properties. This developer differs from other developers in the way in which they realise projects: whenever possible, they have projects realised by suppliers of construction parts that are produced offsite. These parties are made responsible for most of the assembly activities. The developer facilitates the design process in such a way to ensure that the assembly process can proceed as smoothly as possible. 


\section{The organisation of the design and construction processes}

Based on the system design, the client first assessed potential suppliers' interest in participating in this project. Based on this assessment, certain suppliers were selected and involved in the design process. During this process, Building Information Modelling (BIM) was used. After the design phase, agreements were made between the project client and the various suppliers. This approach ensured that the suppliers knew exactly what was expected of them prior to the start of the project.

\section{The execution of the design process}

The client facilitated the development of the Building Information Model by bringing in another organisation to develop this model. The system design was created in collaboration with the various suppliers. Specific attention was given to the realisation of the interfaces between systems and the executability of the assembly of the individual systems. This method can be seen as a form of concurrent engineering ${ }^{1}$.

\section{The construction systems that are utilised}

The building consists of systems that are frequently used in utility construction. Their application was already being described in the professional literature around a decade ago.

\section{The suppliers involved}

The suppliers involved in this project are leaders in their respective fields. They use modern production methods and assembly techniques. They are part of the group of black-box suppliers, introduced in Section 4.11.

\section{Production characteristics of this project}

With regards to the classification of the assembly process as described in Section 2.8, this project can be seen as a one-off production that is not dissimilar to the assembly of ships, buildings and industrial installations. In its realisation, systems were used that are quite common in the utility construction sector and which have already been assembled many times in the past. The dimensions and weight of the construction parts to be assembled are such that no special transport or heavy lifting gear are required. The principles outlined in Section 4.2 and the geometric variations described in Section 5.3 are applicable in this case study. The geometric variations are the cause of a field problem as introduced in Section 2.10. Section 3.2 explained that the construction sector does not have a technological rule to resolve such issues in a structured manner.

The utility project of this case study does not differ from other projects on the basis of the building to be realized, but by the way in which the design and realization process are

1 In the Dutch construction sector, such an approach is known as "bimming." 
organised. The design process of the assembly affects the information available during this process, but not the field problem itself. As a result, this case can be seen as representative of one-off production in the construction sector.

\subsection{Goals of this case study}

At the start of this case study, the desired outcome was an evaluation of the proposed design-for-assembly method described in Chapter 4. During the case study itself, it became clear that the dimensional deviations of the assembled supporting structure in the horizontal transverse direction were insufficiently managed, resulting in undesirable misalignments. These caused issues with the assembly of other systems, such as the curtain wall and the finishing of the roof edges. Given that the proposed design-for- assembly method is based on the premise that the assembly process can be executed in a controlled manner, this finding challenged that supposition. It was therefore decided to expand this case study and address the misalignments that occurred with one of the supplier's project leaders. The project leader was also surprised to learn about the misalignments, which he claimed were entirely unnecessary. He supported this claim by referring to the recent assembly of the supporting structure of a nine-storey building. During that project, the misalignments were kept under control. Knowing that, it was decided to discuss the method used for that project in more detail with this project leader. This discussion is described in Section 6.9.

\section{Evaluation of the proposed design-for-assembly method}

The results of the case study evaluation concerning the proposed design-for-assembly-assembly method relate to both the system-of-systems design of the entire assembly and to the assembly design for the individual systems. Further, this case study enabled us to present options to the suppliers involved in this project. The results of the case study are represented schematically in Figure 6.1.

\section{Research supporting structure}

The proposed construction assembly design method is based on the premise that assembled systems can be realised in a controlled manner as described in Section 4.2. This evaluation of the supporting structure has been conducted to determine whether this supposition is correct. The design method is deemed a success if the parties involved have realised a supporting structure in a demonstrable manner where the key characteristics of the system have been realised without the use of any special techniques and with negligible rework. 


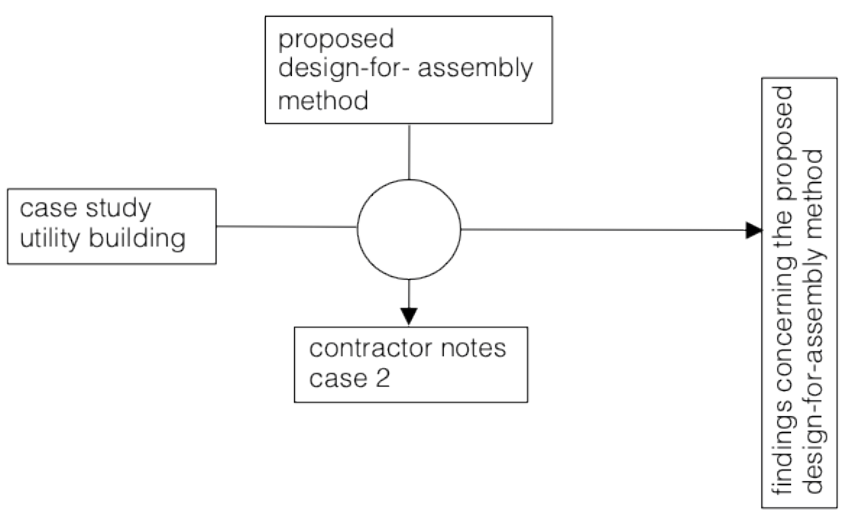

Figure 6.1: Results of the utility building case study.

\subsection{Methods used in the case study}

Ideally, a case study would cover the entire design and realisation process. Unfortunately, this was not possible since the building information model of the office had already been completed by the time this case study commenced. It was therefore not possible to witness the design process itself. Instead, the creators of the building information model were interviewed. In order to actually assess the design of the assembly, its realisation was monitored. The methods used in this case study cover the following steps:

- Gathering information about the organization of the realisation process and the design intention of the building to be realized.

- Gathering information about the design process that was used.

- Monitoring the executed assemblies.

- Describing the findings pertaining to the realisation of the assembly.

Describing the findings pertaining to the proposed design method.

The first steps were carried out by conducting interviews with the client and the creators of the building information model ${ }^{1}$. Given that these interviews were designed to learn more about the vision and method, they were open-ended in nature. As described in Chapter 4, the aspects of the proposed design-for-assembly method that we wished to evaluate were discussed during these interviews.

The monitoring was conducted by closely observing the realisation of the assembly at the construction site $^{2}$. Given that the assembly involved a number of systems that are each

1 These interviews were held between 16 and 21 April 2016.

2 The monitoring was conducted between May and December 2016. 
made up of dozens of similar assemblies, it was possible to detect any irregularities that occurred. Such irregularities were seen as indicators of shortcomings in the design. It was often possible to discover the cause of the issue by talking to the assemblers. Being present at the construction site also made it possible to learn more about the assembly and layout plans.

As in the previous case study on the transformation of dwellings, the findings from the monitoring of the assembly process form the basis of the evaluation of the proposed design-for-assembly method. The evaluation of the findings is based on the method described in Section 1.5 and executed in a manner similar to the one described in Section 5.4. For this case, the client decided to use a tendering method that was not anticipated when the proposed design-for-assembly method was developed. The findings pertaining to the proposed construction assembly design method and the organisation of the design and realisation process are described in Section 6.9.

\subsection{Description of the construction organisation}

According to the project client, designing the construction amounts to integrating the constituent systems. Further, they consider this system integration to be largely a matter of logical thinking. They therefore employ the following approach:

Realise the building without involving a construction company as a head contractor. Limit the number of system suppliers.

The delivery and assembly of a system should be executed as a single continuous process. Assembly organisations and suppliers of systems are responsible for realising the assembly. Activities are carried out sequentially, only one party is working on the construction site at any one time ${ }^{1}$.

The quality of the activities being executed is safeguarded by the party who is next in line: if B follows A, then B will assess the quality of A's work and either accept or reject it. When it comes to seams and joinings: if $\mathrm{B}$ comes after $\mathrm{A}$, then $\mathrm{B}$ is responsible for everything necessary to connect to A's work. After all, B is accepting the quality of A's work.

- Parties must honour the agreements made regarding the starting time of their activities, and they must meet the agreed lead times.

The structural design has strict demarcations between systems.

The commonly used concept of "or equivalent" does not apply.

The work is realised exactly as shown in the building information model.

1 The project client safeguards this through access-control measures at the construction site. 
The assembling parties are also responsible for the removal of packaging materials and any other waste.

- The client is responsible for the aesthetics at the detailed level ${ }^{1}$, both of the design and its realisation.

Based on the system design, the client approached prospective supplying parties about the realisation of one or more component systems. Based on this, the input from the intended suppliers and the client's desired aesthetics, the project was designed and recorded in the form of a building information model. This model basically contains all the information needed to realise the building, including the finer details. By involving the suppliers, the work preparation will be completed before the contracts with the suppliers are signed. Based on the building information model, the suppliers and the project client will reach agreements over deliveries, activities, lead times and costs.

The way that the design and realisation process is organised in this case differs from that described in Section 4.11. Although it does involve an engineering and build approach, the realisation is conducted entirely through subcontracting specific activities. A consequence is that there is no need for a system integrator on the contractor's side. System integration is realised by involving the system suppliers in the development of the building information model. The client serves as the facilitator on the supply side, safeguards the aesthetic aspects based on the system design and facilitates the entire process.

\subsection{The design of the assembly}

In addition to information about the systems that are used, the system design also provides information about the site, the position of the construction, the possible placement of hoisting equipment and the accessibility of the assembly location.

Based on the system design, the design of the assembly process is based on the following systems:

the ground floor (the first floor);

the supporting structure, including the storey floors, the roof and the floor edges;

the timber-frame inner cavity walls;

1 During a previous project, the client used "defining details" that were created by an architectural agency, but this was not successful. It led to details that, when realised, did not fit the client's vision. They believe that working with defining details is only useful if these are realised in collaboration with the prospective executing parties. This was clear from an example where an architect created a circular design and the supplier produced something with facets. 
the curtain walls, including glazing, panels and aluminium finishing;

the climate-control installations.

The above systems will be the sources of the geometric variations that occur. During the design phase, the basic principle is that the construction parts that make up these systems should require no processing whatsoever at the assembly location. The foundation serves as the basis for the entire assembly. In addition to the aforementioned systems, the building also consists of ceilings, insulation, cable ducts, roof edges, roof cladding, window frames, staircases and an elevator shaft. Although these construction parts are attached to other systems; their realisation did not form part of our case study. Most of the foundations and all of the masonry forming the outer façade were realised on site.

The following relationships exist between these systems:

The foundation is the assembly base for the ground floor.

The foundation is the assembly base for the supporting structure.

The foundation and the supporting structure are the assembly base for the timber-frame inner cavity walls.

- The supporting structure is the assembly base for the curtain walls.

- The supporting structure is the assembly base for the climate-control installations.

The sources of the geometric variations that occur in the design of the assembly of an office building are represented in Figure 6.2.

In the nominal design, attention was given to the hoisting path for each system, the possible dimensional deviations that might occur and the available space for positioning and attachment. Based on these considerations, the contours required for the assembly of the construction parts for each system were determined in collaboration with the supplier. This is the space that a part of a system may take up in the as-built situation, based on the space needed to position and attach the part and also accommodate any dimensional deviations. The relevant product standards were employed with regards to the possible dimensional deviations.

Based on the contours, the suppliers produced building information models for the various construction parts. These were then added to the building information model of the building as a whole. For each construction part, its position in relation to a global axis system was defined. Provided this design is realised, the construction part will provide the desired functionality. For example, the timber-frame elements serve as casements for the window frames that will be added later. For example, the timber-frame building elements serve as frames for the windows that will be added later. The position of these elements in the vertical direction is determined on the basis of that of windows to be assembled later. 


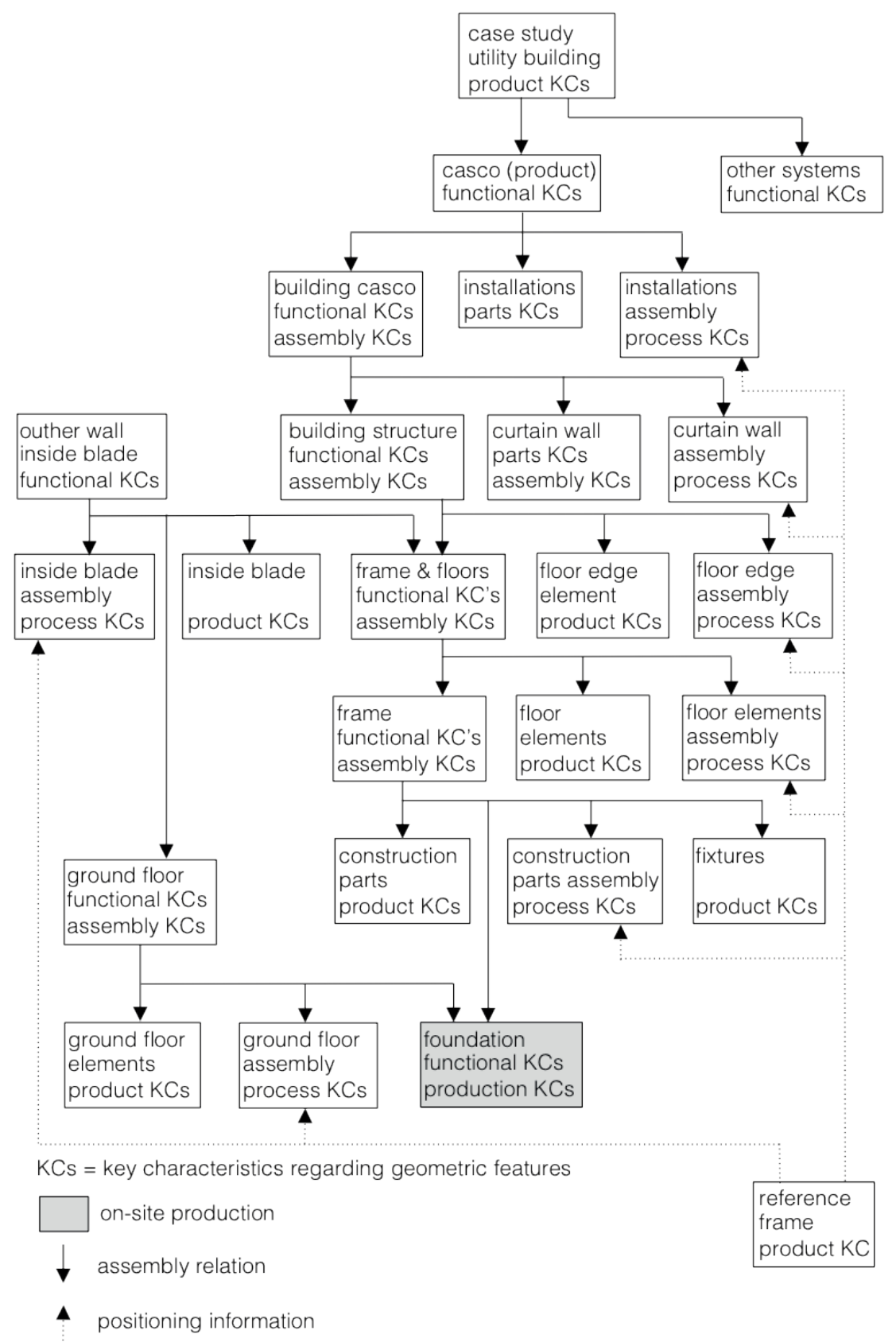

Figure 6.2: Sources of geometric variation in the design of the assembly of a utility building. 
The interfaces between the systems were executed by the suppliers involved. For example, the design of the joinings linking the timber-frame elements to the steel construction was carried out by the suppliers. The supplier of the timber-frame elements informed the supplier of the steel construction about the facilities that have to be present in order to attach the timber-frame elements to the steel structure.

Furthermore, extensive attention was given to the assembly order by the various suppliers. The goal was to have each supplier conduct all their activities in a single continuous period, an ambition that requires strict demarcation. This is unusual with traditional architectural design. The demarcation was included in the building information model by assigning different colours to the various construction systems. The positioning of the ducts and pipelines for sanitary facilities, water, ventilation and electrical cabling were also included in the model.

In the design, the interface between the supporting structure and the curtain walls was described in some detail. It was agreed that a space of 20 millimetres would be available between the edges of the floor construction and the stiles of the curtain walls. It was also agreed that the supporting structure should include facilities to attach these stiles and this facility was then further specified. The interfaces used to attach the curtain walls to the supporting structure form part of the curtain walls.

The building information model was developed by the parties involved with the goal of ensuring that the representation of this model would be fully in line with the finished building: 'as designed' is identical to 'as built'. For verification purposes, a clash detection ${ }^{1}$ was carried out. The resulting building information model was accepted by the suppliers and served as the basis for the various contracts that were drawn up. This model was also used as a basis for the suppliers' assembly and layout plans. To ensure the assembly process proceeded as optimally as possible, agreements were made about the layout of the assembly site, the hoisting facilities to be used and the axis system to be created at the location itself to facilitate the dimensioning and dimensional control of the assembly.

The geometry of the assembly was defined in the building information model using a local three-dimensional axis system. The position of this system was reproduced by the client at the assembly location with markings. In this system, the grid and bay dimensions ${ }^{2}$ are defined on a horizontal plane. In the vertical direction, the geometry was recorded by

1 This determines whether construction parts of different systems occupy the same space.

2 Grid dimensions represent the structure of the construction in the longitudinal direction, while the bay dimensions represent the transverse direction. Generally speaking, longitudinal dimensions are greater than transverse dimensions. 
defining the elevation of the finished ground floor in relation to the Amsterdam Ordnance Datum (NAP). This elevation is 0 millimetre above NAP.

For planning purposes, the client made a computer-assisted planning system available. The goal was to ensure that the suppliers honour their agreements and start and complete their assembly activities on time. The parties involved expect the assembly to be realised in accordance with the building information model and the planning that was drawn up.

\subsection{Findings concerning the realisation of the assembly}

The realisation of the assembly is described for each system using the following items:

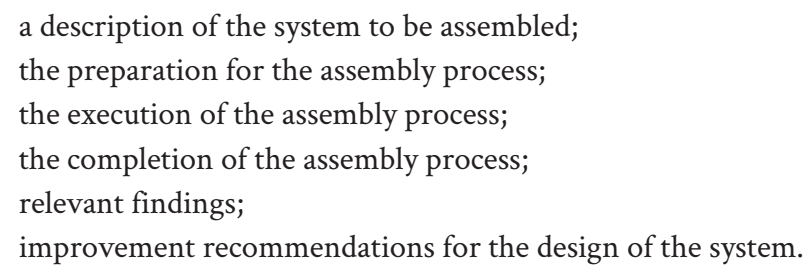

Before explaining the realisation of the systems, the basis of the assembly - the foundation - is described. Its desired geometric quality, its delivery and any relevant findings are described below.

\section{The foundation}

Concrete foundation beams serve as the assembly base for the ground floor and for the steel construction. To perform this function, these beams must possess a certain geometric quality. The sides and the underside of these foundation beams are thermally insulated. To facilitate the positioning and attachment of the steel construction, anchor points are set into the foundation beams.

The geometric quality of the foundation is represented by its position in relation to the three-dimensional axis system used for the assembly. The position of the beams, including their insulation, on the horizontal plane is not considered a key characteristic. It is enough that there is sufficient space to install the elements that make up the ground floor and the anchor points. The vertical position of the beams determines the elevation of the underside of the ground floor. This position is also not considered to be a key characteristic although the positions of the anchor points for the steel construction are. These are formulated in the standard way for steel constructions. In effect, the positioning of the entire set of anchor points for a single anchoring can deviate by a specified amount in the $\mathrm{X}$ and $\mathrm{Y}$ directions on the horizontal plane, referred to as the tolerance. 


\section{The completion}

Once the foundation was completed, the positions of the included anchor points were measured and any deviations were determined. For a number of the anchor points, the deviations were twice that in the relevant standard. The positions of the beams and the insulation were not part of the scope of this study. The entire foundation, including the anchor points, was accepted by the company that would build on it as its assembly base.

\section{Findings}

In assessing the process that was used to realise the positions of the anchor points, it was assumed that the deviations would have a normal distribution. This makes it possible to quantify the degree of process control when placing the anchor points using the process feasibility (Cp) that was introduced in Section 2.2.

To calculate the process feasibility, the tolerance that the applicable standard allows was used. The results are shown in Figure 6.3. The anchors are grouped per set of four anchors using a template. That is why the assessment was also carried out per set of four anchors. In both directions, the process feasibility is significantly less than 1, which leads to the conclusion that the process applied for positioning the anchor points fails to meet the requirements for processes that have to be statistically controlled.

\section{Recommendations for improving the design of the assembly base.}

At the start of this study, the foundation had already been poured. To gain further insight into the possibilities for realising anchor points in the correct positions, one could measure these points before pouring the foundation's concrete. Based on this, it would be possible to diagnose the detected dimensional deviations and draw up improvement recommendations for this process.

\section{System: Ground floor (first floor)}

The ground floor is made up of several layers. The bottom layer consists of hollow-core slabs ${ }^{1}$ that provide vertical strength as well as the floor's thermal insulation. To that end, the hollow-core slabs consists of a top layer of concrete with a layer of insulating material below it. The other layers of the floor are not assembled but realised on site.

The hollow-core slabs are placed on top of the foundation beams by the supplier of the supporting structure. They are produced according to the provided specifications, which is in turn are based on information from the building information model. As a result of the required differences in width, length and openings in the slabs, there are many variations

1 Also known as voided slabs, hollow-core planks or simply concrete planks. They are essentially slabs of concrete and are commonly used in the construction of multi-storey buildings. 

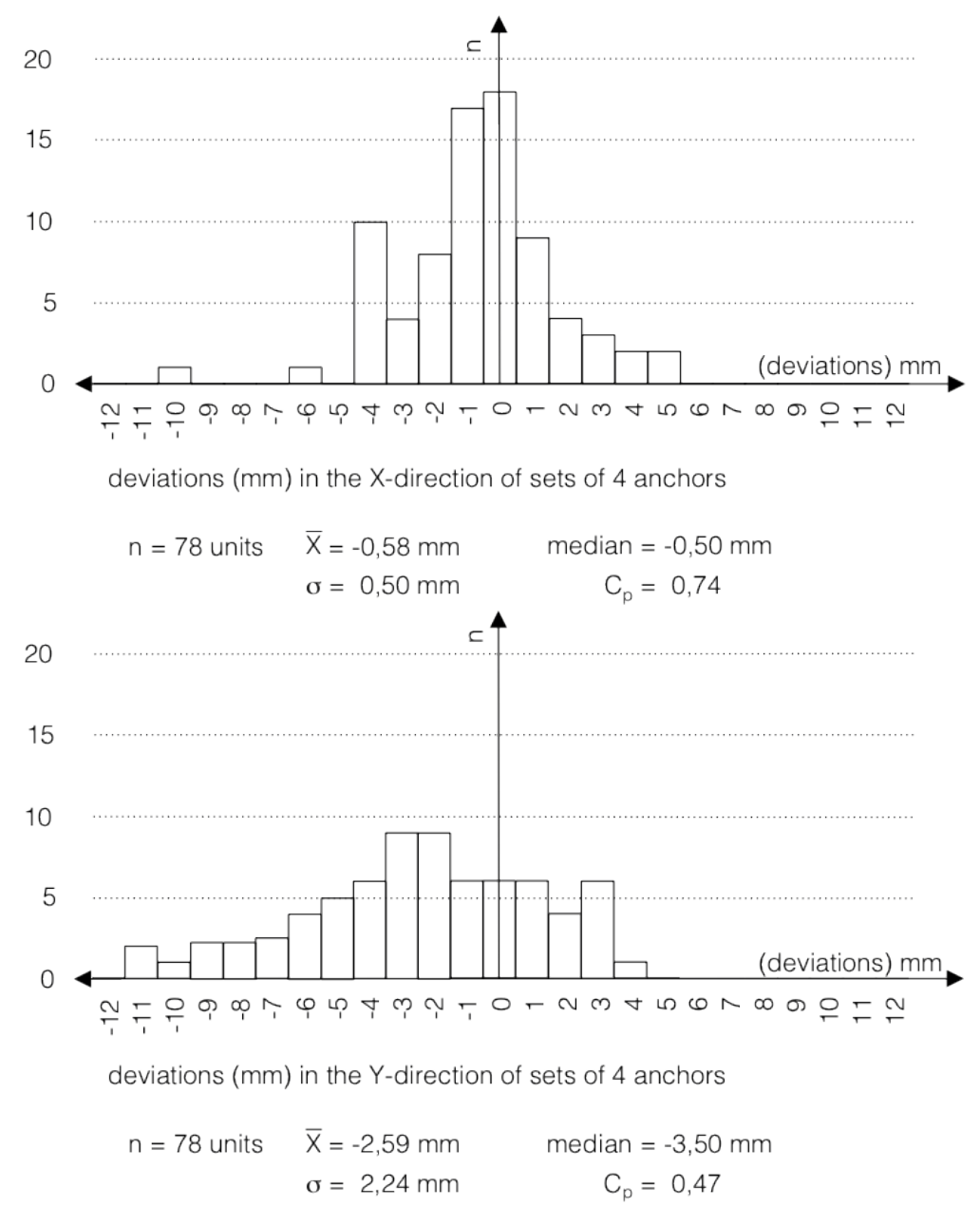

Figure 6.3: Measured dimensional deviations in anchor points and the degree of process feasibility.

between them. A total of 126 slabs are used, with 62 different specifications. The manufacturer works to tolerances of $\pm 28 \mathrm{~mm}$ (length) and $\pm 4 \mathrm{~mm}$ (width).

In the western regions of the Netherlands, it is common to suspend sewer pipelines from the ground floor, in this case from the hollow-core slabs,. To do so, apertures must be made in the slabs at the locations of the intended rising points for the downpipes. During the offsite production, these apertures are only made in the concrete layer of the hollow-core slabs, not in their insulation layer. In the offsite production, the unhardened concrete was removed where a pipeline was to pass through a hollow-core slab to avoid drilling holes in 
the concrete once site. A very generous 200 by $200 \mathrm{~mm}$ aperture was left in the concrete layer to facilitate a $100 \mathrm{~mm}$ diameter pipe.

\section{Preparation of the assembly}

The manufacturer of the hollow-core slabs prepared for the assembly by producing a drawing entitled "for execution" and a freight schedule. Among other aspects, the drawing illustrates where each slab should be placed and where the assembly should begin. The freight schedule was drawn up based on this information. The waybills provide information about the manner in which the slabs are stacked for transport so that they are in the correct assembly order, thereby avoiding additional work at the assembly location. To facilitate the correct positioning of the slabs, the supplier recommends positioning each slab relative to the underlying structure in order to prevent the propagation of geometric deviations in the transverse direction. The supplier responsible for positioning the hollow-core slabs had at this point accepted the foundation as the assembly base. This party prepared for the assembly work by renting hoisting equipment. The assembly supervisor did not have the "for execution" drawing available when the assembly process began.

\section{Execution of the assembly}

Two eight-hour days were allocated for placing the 126 slabs. In total, roughly eighteen hours was spent on this task. The nominal duration of a single placement cycle is three minutes, excluding the time it takes to relocate the hoisting crane. Including this relocation raises the nominal cycle time to 4 to 5 minutes. At this rate, the assembly process would have only taken eight hours. In practice, the average realised cycle time including relocating the crane was around 8.5 minutes.

Additional time was needed to remove insulation from the underside of the hollow-core slabs, search for information, locate slabs, replace slabs (reworking), drill apertures, remove reinforcing bars from the foundation and extra relocation movements of the crane. It was necessary to drill apertures in one of the slabs due to supplier error. Insulation was removed from many of the slabs to facilitate their placement and create space for pipelines. The insulation that was removed was left in the building's crawl-space.

\section{Completion of the assembly}

On completion, the ground floor becomes part of the supporting structure. 


\section{Findings $^{1}$}

The assembly was classed as uncontrolled based on the realised cycle time and the onsite removal of insulation. This was due to shortcomings in the design, the preparation and the process that was used in making the apertures. The accuracy of the assembly process used for the slabs was in the order of five millimetres. Given the weight of the hollow-core slabs, this is quite low. In an adequate design, such a degree of accuracy would be acceptable.

The shortcomings identified were:
A Incorrectly placed insulation on the sides of the foundation.
B Incorrect information about the positioning of the slabs.
C Insufficient preparation for the assembly.

\section{Ad. A The incorrectly placed insulation on the sides of the foundation.}

The incorrectly placed insulation is the result of inaccuracies in the design or faults that occurred during the preparation of the foundation.

\section{Ad. B The incorrect information about the positioning of the slabs.}

The incorrect information about the positioning of the slabs is the result of using their nominal dimensions and the positions of the foundation beams to determine the positions of the slabs. In particular, the lengthwise tolerances of the slabs and the dimensional deviations in the foundation beams were not sufficiently taken into account. The latter were not considered at all. The result was that the assemblers were faced with conflicting information with the information contained in the "drawing for execution" not matching the actual situation.

\section{Ad. C The insufficient preparation of the assembly.}

The assembly of the slabs proceeded in an improvised manner as a result of insufficient preparation. The assemblers did not have adequate dimensioning information, as the grid dimensions were not represented on the foundation beams. Furthermore, they were insufficiently informed about the system to be assembled. The positions of the rising points of the sewer pipelines did not match the apertures in the slabs. Figure 6.4 illustrates how the rising points of the pipelines are positioned. The realisation of the apertures for the rising points was not prepared as an assembly, the positions of most rising points were incorrect. However, the manner in which the rising points were placed does allow adjustment.

1 This section covers aspects that relate to the design of the assembly. Omissions resulting from ignoring the manufacturer's recommendations are not described. One example is not using all the information available in the supplier's drawings. 


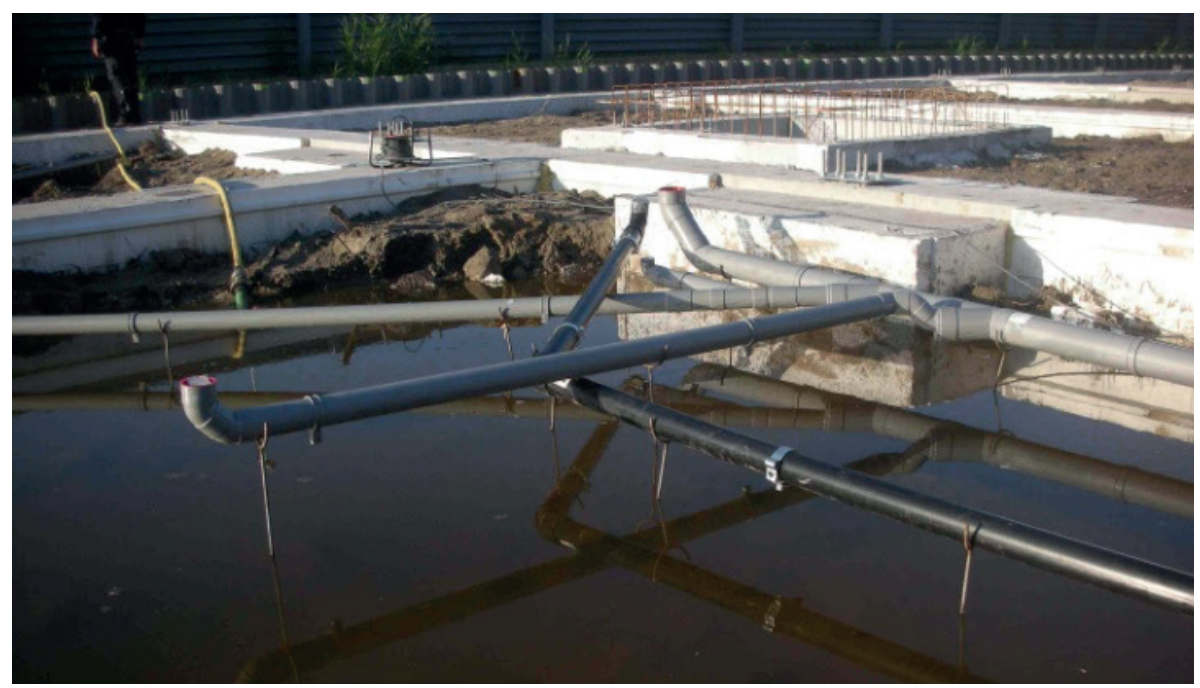

Figure 6.4: The sewer pipelines with metal supports and raising points.

\section{Recommendations for improving the design of the system}

The nominal position of slabs should be determined relative to the grid lines so that geometric variations in the dimensions of the foundation beams do not affect the positioning of the slabs.

The hollow-core slabs used in this case are industrial products whose tolerances must be accepted based on practical considerations in their construction process. When creating the building information model, the maximum dimensional deviations need to be taken into account. This can be expressed in the positioning of the slabs and the allocation of tolerances. It must be such that the key characteristics can be realised. A practical solution is to indicate a contour within which the slabs must be positioned, both in the building information model and in the information for the execution.

The realisation of the rising points for the sewer pipelines can be prepared as an assembly. This is possible by viewing their position as an assembly key characteristic. This will also make it possible to remove the insulation at the locations of the apertures in a timely and appropriate manner.

The drawings entitled "for execution" were to be used as layout plans. However, these were difficult for the assemblers involved in this case to use, both in terms of the information they provide and with regards to the physical execution. The information appears to be intended more for the dimensioning of the assembly than for the actual execution of the assembly. Layout plans should contain only information necessary for the assembly of the slabs, i.e. unambiguous construction part-related information about the action to be 
performed and the desired position in relation to a clear datum reference frame. In this case, A1-sized paper drawings were used. These are fine in dry and calm conditions but, in this day and age, more robust methods to represent layout plans are available.

In order to implement these recommendations, flow-down schematics would be highly useful. With these, all aspects of the design and realisation can be identified, and it is possible to anticipate the required tools, adequate layout plans and the necessary skills. The main requirements of such a flow-down are the product key characteristics that the end-user wants realised.

\section{System: Supporting structure including storey floors, the roof and the floor edges}

The supporting structure consists of steel columns, steel beams, steel stability systems, the floors and the roof including the floor edges. The length of the columns is tailored to the height of the building's storeys. The anchors in the foundation form the assembly base for the supporting structure. The columns are located in the façade zone and the beams are attached to the columns. The columns and beams form frames. The upper floors rest on these frames and also form the connections between the frames placed in the façade zones. The floors and the roof consist of hollow-core slabs upon which a layer of concrete is poured after assembly, which allows them to function as a constructive slab.

During the assembly phase, the frames are unstable, which means that temporary fixtures have to be put in place to provide the necessary stability. After positioning the hollow-core slabs and filling the seams between the slabs, and after these seams have sufficiently hardened to perform their structural function, the construction is stable and the temporary fixtures can be removed. Due to this requirement, such constructions are generally assembled one construction layer at a time, as was the case in the development of this office building.

The construction described above serves as the assembly base for the assembly of the curtain wall. To facilitate this, the construction features an edge, the so-called floor edge, at the level of the storey floors and the roof. This edge is used to attach the stiles of the curtain walls and close off the gap between the frames and the curtain walls. The stiles are attached to the floor edge with an interface. During the design phase, the building information model indicated that a $20 \mathrm{~mm}$ gap should be present between the floor edge and the stiles. The model also provides the requirements for the facility used to attach the interfaces, one of which is that it should be smooth and vertical.

The timber-frame inner cavity walls are also attached to the frames. To realise this, the supplier of the inner cavity walls and the supplier of the frame components have agreed that the frames will feature a facility for this attachment. 


\section{Preparation of the assembly}

Based on the building information model, manufacturing drawings for the components of the support structure were created. These components were then manufactured in a factory. To facilitate the installation of the steel construction, isometric representations of the construction were produced in which all construction parts are represented along with position numbers. These numbers are also included on the labels that are attached to the various components. The execution of the assembly is to an extent described in the assembly, safety and health plan.

To position the hollow-core slabs, the manufacturer has created drawings for the execution. These indicate the order in which the slabs should be positioned. The slabs are delivered to the assembly location based on this predetermined order. The manufacturer assumes that the slabs will be positioned directly from the truck on which they are delivered. The preparation for the assembly consists of producing the isometrics of the steel construction and drawings for the installation of the hollow-core slabs.

\section{Execution of the assembly}

Although assembling the supporting structure is an unstable process, no notable issues arose. The cycle time for the assembly of a column, which only involves a single assembly connection, is around 3.5 minutes. The stability of the columns is initially not safeguarded. Later, fixtures are put in place, which involves positioning the columns vertically using a spirit level. The cycle time for installing the beams is longer than that of the columns and depends on the number of connections to be made. The installation time for a beam with four connections can be as long as 40 minutes. In such cases, the crane is made available 10 minutes earlier. The installation process is also unstable due to the lack of coordination between supply, interim storage and installation of the steel construction parts. Furthermore, the realisation of some connections takes a very long time.

Positioning the hollow-core slabs on the steel construction can, in theory, be done using the execution drawings. However, these drawings are not always clear to the assemblers because of missing information concerning the assembly base and the frames. This creates a significant chance of errors being made when positioning the slabs. When there are delays in assembling the steel construction, it becomes impossible to assemble the slabs directly from the truck. The slabs then have to be stored in the interim. Since this was not expected, the storage becomes somewhat haphazard, and results in several damaged slabs. Furthermore, since these could not be repaired, new slabs had to be ordered.

Once the seams between the hollow-core slabs were filled, the steel floor edges were installed. These are positioned relative to the steel beams. After this, concrete was poured to fill the gaps between the steel edges and the hollow-core slabs. During the assembly process, 
only any misalignments of the columns were assessed, any dimensional deviations that occurred were not monitored.

\section{Completion of the assembly}

To facilitate the completion of the assembly, the positions of the supporting structure and the floor edges were measured. Based on these measurements, the deviations relative to the design dimensions were determined. These were greater than what was contractually agreed and, as a result, the building was wider and longer at the floor edges than what was indicated in the building information model. This meant that the curtain wall and the glazing units that had already been produced would no longer fit around the building. This issue was partly resolved by removing concrete, repositioning the construction parts in question, re-fixing them in place and then pouring more concrete. However, this was not enough to avoid having to produce new glasswork.

\section{Findings}

The assembly, safety and health plan was incomplete. Insufficient attention had been given to the stability of the construction during assembly. The company responsible for the assembly took remedial measures, but these were inadequate, put in place too late and their realisation could not be assessed by the assembly supervisor.

Despite knowing that the dimensional deviations in the anchor points exceeded the norm, the columns were nevertheless placed on the anchor points. The steel construction columns are fixed in place using jack posts and then vertically set using a $1.5 \mathrm{~m}$ spirit level. The assemblers assumed that having the bubble between the lines provided sufficient accuracy, which proved to be the case with the realised accuracy being within $1 / 500^{2}$, which is in line with the standard that the assemblers are used to working with. The upper floor columns are installed on the already assembled construction elements, again fixed in place with jack posts and positioned with a spirit level. When using this method of positioning, the dimensional deviations in the frames accumulate. The maximum deviation of the three-storey building section amounts to the sum of the dimensional deviation in the anchoring plus three times the acceptable misalignment of a column. At the top of a three-storey building, the maximum deviation is around 31 millimetres. The positioning method used here is shown schematically in Figure 6.5.

The floor edges are positioned in relation to the steel beams using a tape measure. This method does not allow accurate positioning. As a result, the dimensional deviations of

1 Only one shoring cable was used for the body section of the building, on the side that faces the road. This was not adequate to guarantee the stability of the structure during the positioning of the hollow-core slabs.

2 The tangent of the column skew angle. 
the floor edges are typically $35 \mathrm{~mm}$ in relation to the grid dimensions. It was contractually agreed that the space between the floor edges and the stiles of the façades should be 20 $\mathrm{mm}$. However, this dimension is more an indication of the space that the façade assembler needs to be able to fill the seam between the façade stiles and the floor edges. In practice, the dimensional deviations of the floor edges were not taken into account in the design.

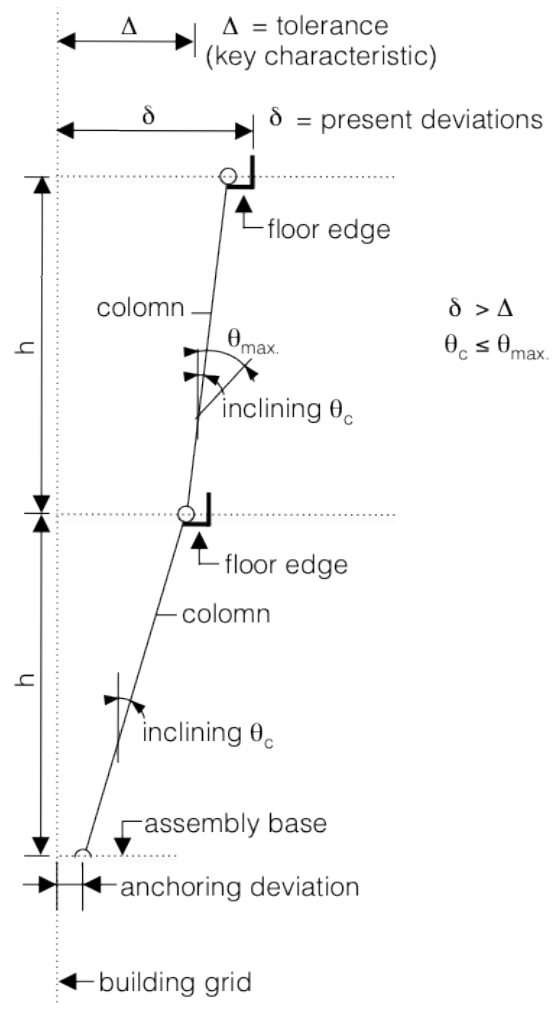

Figure 6.5: Schematic representation of the position of the assembled columns that are vertically positioned in relation to the assembly base using a spirit level.

During the assembly of the construction, the construction parts appeared to have been manufactured to sufficient accuracy. All the connections could be realised with some effort and only a few corrections had to be made to the parts. During the assembly of the steel components, a lot of time was spent moving the construction parts around as these construction parts had regularly been put in the wrong place. Through, for example, having to search for columns, much longer cycle times were required. Furthermore, progress was disrupted because the grout between the baseplates of the columns and the foundation was not put in place on time, the seams between the hollow-core slabs were filled too late and mobile scaffolding or a cherry picker was not available when needed. The latter issue is attributable to the incomplete assembly, health and safety plan. 
The assembly plans for the steel construction parts were generally clear. However, on multiple occasions, the wrong component was placed in the hoisting slings and one beam was incorrectly positioned and attached upside down. As a result, dimensional deviations occurred in the frames. The clarity of the assembly plans was not aligned with the assemblers' skills. In effect, the assemblers were expected to have knowledge and insights that they often lacked.

The positioning of the hollow-core slabs was chaotic, and the process was unstable. Since, the grout between the column baseplates and the foundation was often put in place too late, which was a consequence of tardy deliveries, the anticipated positioning order of the hollow-core slabs was not followed. Furthermore, the assembly supervisor wanted to place the slabs contiguously, which meant the next slabs had to be looked for in the temporary store, and this wasted a lot of costly hoisting capacity.

A number of hollow-core slabs were placed in the wrong positions and a number of slabs were incorrectly positioned perpendicular to the span. However, the workers responsible for positioning the slabs did so very carefully and took great care to position the slabs correctly. The fit between the skills of the assembly supervisor and the information available in the drawings for the execution was not optimal. The positioning of the hollow-core slabs for the second and third storey floors and the roof floor went a lot better. An uninterrupted assembly cycle typically took six minutes to complete.

\section{Recommendations for improving the design of the system}

The construction concept that was used proved to be unstable during the assembly phase. Despite this aspect not being covered in the assembly, health and safety plan, the client nevertheless accepted them. This omission could be avoided by incorporating this aspect as early as the design of the construction stage. The manner in which the assemblers safeguard the construction's stability should be determined by the designers and described in the assembly, health and safety plan. The client can then assess this issue. How the stability is safeguarded during assembly should not hinder the assembly of other systems - in this case, the hollow-core slab floor and the timber-frame inner cavity walls.

An important characteristic of an assembly process is the controllability of geometric deviations. In general, the assembly process that is used should deliver the required control. The actual control over an assembly process of a supporting structure can become evident from studying a construction that was realised using the process in question. The degree of controllability can be expressed using the previously discussed process feasibility (Cp). Only when it is clear that the desired process feasibility of a certain assembly process can be achieved, should the process be utilised. If the feasibility of an assembly process is not known, it can be estimated using a variation flow-down. 


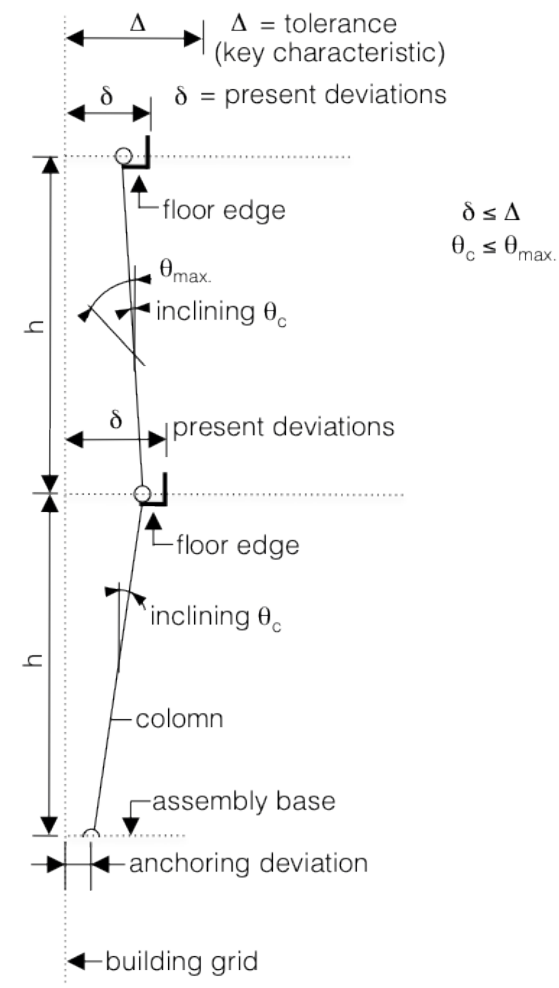

Figure 6.6: Schematic representation of the assembled columns that are positioned in relation to the grid dimensions based on acceptable dimensional deviations.

The dimensional deviations that occur in the construction system used here can be controlled by not basing the positioning of the columns on the acceptable misalignment, but rather on the contractually agreed maximum deviation. This method is shown in Figure 6.6. It is known as "to plumb system" [Hoof, 2003]. The deviations shown in Figure 6.6 could be measured with a vertical laser. A flow-down of the assembly process represented in Figure 6.6 is shown in Figure 6.7. Using this flow-down, in combination with measurements, it is possible to determine the process feasibility of the represented process.

In addition to the key characteristics of the products to be realised, the flow-down shown in Figure 6.7 also contains aspects related to skills and tools. When it is decided to use a vertical laser for positioning, it is important that the assemblers can operate it. Additionally, the assembly drawings need to be based on the use of this type of laser.

The flow-down in Figure 6.7 shows that the floor elements are positioned after the frames have been attached. However, given the dimensions and weight of the elements, it is likely 


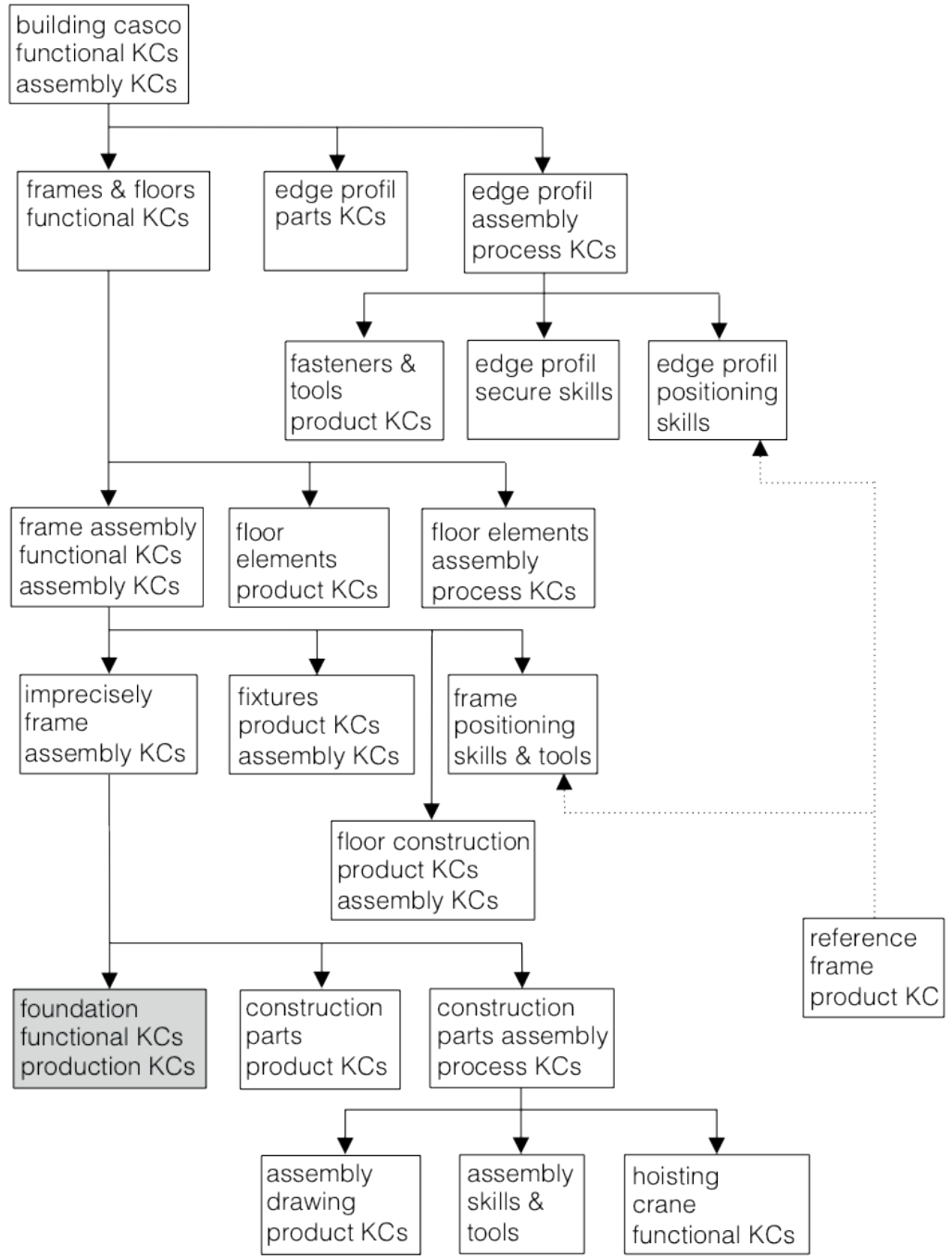

$\mathrm{KC}$ 's = key characteristics regarding geometric features

on-site production

$\downarrow$ assembly relation

4 positioning information

Figure 6.7: Variation flow-down of a supporting structure that consists of façade frames and hollow-core slabs. 
that these frames will shift somewhat during the positioning of these elements. However, the extent to which this happens can only be determined on site. This indicates that flowdowns are more suitable for describing assembly processes than for determining the process feasibility. Even if there are no measurements available, they can be used to estimate process feasibility. If the feasibility is deemed too low for a given process, designers may decide to include more control measurements to avoid rework. Section 6.9 covers the assessment of process feasibility of the construction in this case in more detail.

During the onsite assembly of the hollow-core slabs, it became clear that the execution drawings provided for the assemblers did not serve the intended function. One reason for this was the lack of any information about the grid numbers on the steel construction relative to the desired location of the slabs. Agreement between the drawings and the existing structure was therefore difficult to realise. A very practical issue was the difficulty in using A1-size paper drawings in typical Dutch weather.

\section{System: Of timber-frame inner cavity walls}

The closed façade parts within the building consist of timber-frame inner cavity walls. These mostly perform the physical function required of these façade parts. The foundation beams, hollow-core slabs and steel frames serve as the assembly base. In construction terms, the panels' undersides rest on J anchors, and their sides and top are attached to the frames. The J anchors are attached to the foundation beams, hollow-core floor slabs or floor edges using anchors. At some locations, the inner cavity walls serve as the assembly base for the window frames that will be installed later. The inner cavity walls are delivered on hoisting blocks. There is no direct link between their placement on the blocks and the assembly order. The cavity walls have the same height as a storey of the building, while their width ranges from 1.2 to $6 \mathrm{~m}$, with $3.4 \mathrm{~m}$ being the most common width.

\section{Preparation for the assembly}

The manufacturer had devised a positioning plan for the inner cavity walls,. Their positioning is determined by the position and elevation of the $\mathrm{J}$ anchors. These are indicated on the plan in relation to the ordnance datum, the bay dimensions and the steel construction. After placing the inner cavity walls on their anchors, both the translation and the rotation of the elements are restricted. The elements can only rotate along the "anchor line" and, in theory, move in parallel to the $\mathrm{J}$ anchor. The position of the top and sides in relation to the frames can be adjusted using spacers.

\section{Execution of the assembly}

The execution consists of three phases, namely:

Installation of the $\mathrm{J}$ anchors on the base assembly;

2. Placing the inner cavity walls onto the anchors with the hoisting equipment and fixing 
them along the top edge with a provisional attachment to a frame, accurately repositioning the element and then permanently attaching it to the frame. The positioning and attaching are sometimes done later due to the limited availability of the hoisting equipment;

3. Attaching the elements to the frames.

\section{Completion of the assembly}

Upon completion, it transpired that the window frames could not be installed in the cavity wall elements. This was probably attributable to errors in the panels but it is also possible that the elements became deformed due to extended atmospheric exposure. The issue was resolved by increasing, on site, the size of the grooves in the elements. The window frames are placed within these grooves.

\section{Findings}

The findings are described for each phase of the assembly

Phase 1: Installation of the anchors.

The assemblers lacked adequate information on the positioning of the anchors. Lacking bay dimensions on the assembly base, the position was derived from the position of the anchoring points for the steel columns. The deviations present there were therefore incorporated in the positions of the J anchors. The J anchors are attached with bolts and their vertical position was adjusted to the required level using a laser level. Spacer strips were used if necessary. Using this method, a vertical accuracy in the order of one or two millimetres can be achieved. After identifying the positions, the installation of the $\mathrm{J}$ anchors proceeds in a controlled manner. Identifying the positions is illustrated in Figure 6.8. This figure shows how the assembled steel construction was used as a datum reference frame for positioning the anchors.

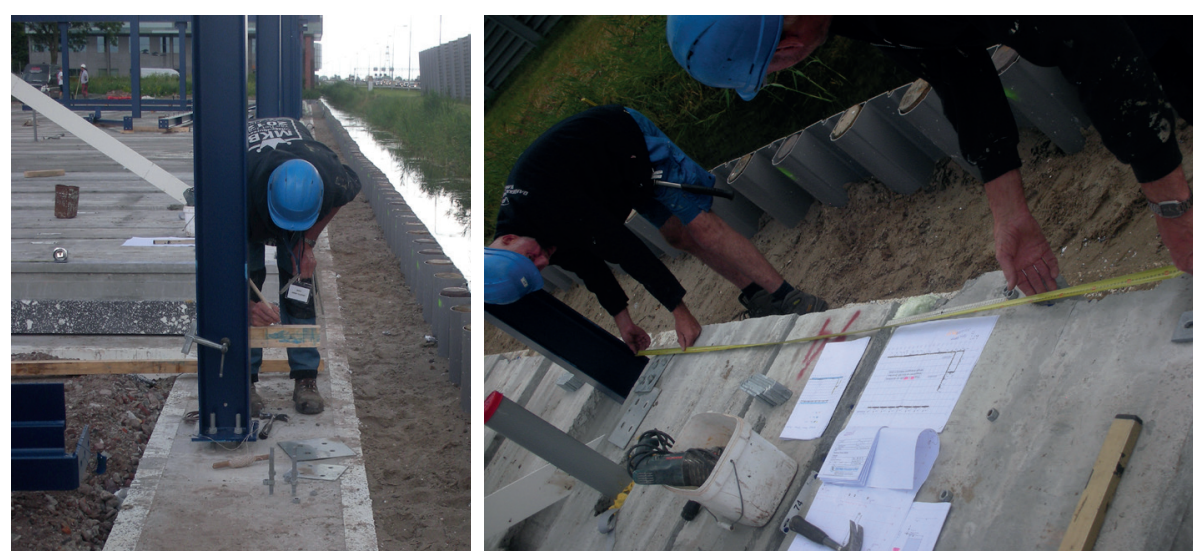

Figure 6.8: Finding the information required for positioning the anchors. 


\section{Phase 2: Positioning the elements}

The inner cavity walls that are placed on the hoisting blocks feature hoisting straps for attachment to the hoisting facility and are then carried close to their final destination. As the elements are slowly lowered, the carpenters position the inner cavity walls in relation to the anchors. Once the walls rest on the J-anchors, their upper edges can be positioned correctly. In this positioning, $1.5 \mathrm{~m}$ long spirit levels are used. Given the bolts in the head plates and the electric cabling ducts, this process is not fully controlled. Some breaking work is required to position the elements.

The cycle time for the most common inner cavity wall elements was 10 minutes. This was largely achievable due to the chosen position of the inner cavity walls relative to the steel construction that made their positioning with the crane an easy task. There was no need to move the elements horizontally. For larger rectangular elements, the cycle time was around 15 minutes. Positioning one-off inner cavity wall elements under an overhang took roughly 45 minutes because the overhang blocked the hoisting pathway. This hindrance was circumvented by adding a second strap to the inner cavity walls in question during the assembly process. During assembly, this strap could be placed on the crane's second winch on the other side of the obstruction.

Positioning the inner cavity walls alongside the steel stability systems proved difficult because of the electric cabling ducts, bolt heads, nuts or bolt shanks that got in the way. As a result, it was necessary on site to remove plating from the timber-frame inner cavity walls and also change the position of the inner cavity walls. In theory, the joinings between the inner cavity wall elements should be equal on the interior side. This was not the case, but this was not seen as a key characteristic of the assembled inner cavity walls.

\section{Phase 3: Attachment to the columns}

The sides of the elements were attached to the frames using bolts. No complications arose during this process.

In general, the conclusion is that the assembly of the timber-frame inner cavity walls proceeded in the manner intended in the design. However, the assembly was not entirely controlled and the inner cavity walls that serve as the assembly base for the window frames had to be modified after their placement.

\section{Recommendations for improving the design of the system}

In the design, the elements are positioned on the horizontal plane in relation to a grid line. However, this line is not present on the assembly base. The assemblers resolved this issue by constructing the grid line themselves based on the steel columns' anchor points. However, this resulted in some inaccuracy. The assembly process could be improved by utilising a clear reference that the assemblers could immediately use when they start the positioning 
process. Other disruptive factors were the presence of electric cabling ducts, bolt heads, nuts and bolt shanks within the wall elements' manoeuvring space. In some instances, this made it impossible to achieve the desired positioning.

The preparation for the assembly process is based on the assumption of there being an unobstructed hoisting path. For 90 percent of the elements, this was the case. As a consequence, the assemblers had to improvise with 10 percent of the elements. The impact of this on the lead times and the use of the hoisting crane was disproportionate. As such it would be desirable to prepare clear hoisting paths for all elements, and this would probably make it possible to realise a process feasibility $(\mathrm{Cp})$ greater than one for this assembly process. To achieve this, the key characteristics need to be recognised, defined and recorded.

\section{System: Curtain wall, including glazing, panels and aluminium finishing}

The selected façade manufacturer was to deliver and assemble the required curtain walls with a surface area of about $750 \mathrm{~m} 2$. The curtain wall was delivered to the construction site in the form of custom-made stiles, ridges and glazing. Adjacent to the floor and ceiling edges, opaque panels were incorporated in the façade rather than glazing.

The curtain wall is attached to the construction by attaching the stiles at a centre-to-centre spacing of $1.2 \mathrm{~m}$ to the floor edges. The ridges are connected to the stiles using simple attachments. The glazing is positioned in the stiles and ridges using a crane. Before the stiles are attached, the façade manufacturer positions all the stiles and ridges for an entire façade area using temporary supports. Once the positioning is correct, the stiles are attached to the floor edges using interfaces that can accommodate geometric variations in the floor edge provided these do not exceed the maximum outlined in the building information model. After this step, the glass and the panels can be positioned, and the finishing of the façade commence.

\section{Preparation for the assembly process}

The façade manufacturer had produced assembly drawings, based on the building information model, on which the dimensioning of the stiles and ridges in relation to the grid lines and reference dimensions is indicated. These are positioned in relation to the reference frame of the entire building.

Prior to the start of the assembly, the façade manufacturer measured the edges along which the stiles would be attached and the locations of the attachment points. This showed that neither the positions of the edges nor the locations of the attachment points were in line with the building information model. Next, a plan was developed for the necessary corrections to the edges and the attachment points, and possible modifications to the curtain wall. 
Only after these corrections were carried out, could the assembly of the façade commence.

\section{Execution of the assembly}

The assembly of the curtain wall proceeded without any issues and in a controlled manner. This was due to both the product itself and the assembly process that was used. The process was properly directed and the assemblers had sufficient experience. After they had been installed, it became clear that a number of the windows were damaged. It is unclear when this damage occurred.

\section{Completion of the assembly}

The curtain wall was accepted by the client once the damaged windows were replaced.

\section{Findings}

In carrying out their work, the assembler created their own reference frame on the building. Figure 6.9 illustrates that the framework of stiles and ridges was held together and positioned during assembly using straps. This seemingly haphazard method was in fact part of a controlled assembly process. Given that the assembly process proceeded without issues, it is deduced that the system design of the assembly was properly executed. The supplier of the curtain wall can be considered a black-box supplier, as described in Section 4.11.

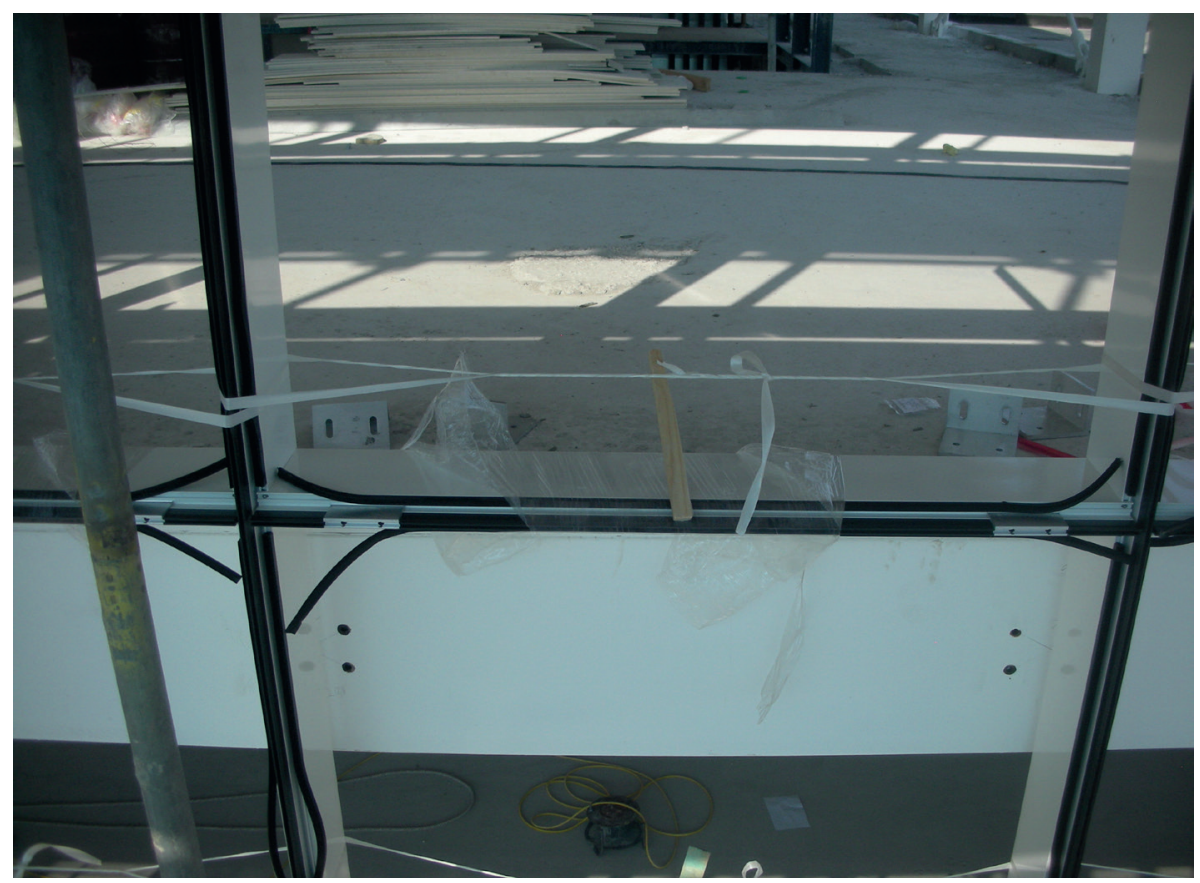

Figure 6.9: Positioning the curtain wall prior to the attachment of the interfaces. 


\section{Recommendations for improving the design of the system}

The findings on this particular system do not lead to any improvement recommendations. After assembly, no control measurements were taken so it is not possible to assess the process feasibility.

\section{System: The climate-control installations}

The climate-control installation is a mechanical system consisting of a climate chamber and equipment with attached ducts for the intake and outflow of air. The climate chamber is located on top of the building, while the equipment and the ducts are located between the underside of the floors or the roof and ceilings. The supporting structure of the building therefore serves as the assembly base. The equipment and the ducts are attached to the base with anchors, for which no facilities were included in the structure. As such, the anchors were cut to size on site.

The ducts for the intake and outflow of air are connected to the climate chamber. The required apertures in the floors were included in the building information model. The installation company was experienced with assembling such installations. There were few complications during the assembly process, although finding the correct dimensions for positioning the equipment and the ducts was not easy.

\section{Recommendations for the design of the system}

During the assembly process, the installation company positioned parts in relation to another system that had already been installed. This method is inherently undesirable since it is uncertain whether existing systems are in the correct position. It should be possible to position this system based on a reference frame. In a construction that is realised through an assembly process, it should also be possible to cut the anchors to the right lengths offsite.

\subsection{Feasibility of the assembly process for the supporting structures}

The concept of the feasibility of a process was introduced in Section 2.2. It can be used to assess the probability of realising a key characteristic of a product when following a certain process. In this study we are concerned with an assembly process and aim to determine whether the principles used in the proposed design method described in Chapter 4 are realisable in practice. In this case study, it was determined to what extent the feasibility of the manufacture and assembly processes used by a system supplier can be assessed. If the so-called process feasibility value is above one, the principles used in the proposed design method described in Chapter 4 are deemed realisable. This section concludes with an assessment of the applicability of the process feasibility approach for the design of the assembly of objects in the built environment. 


\section{Determining the process feasibility of manufacture and assembly processes}

In order to assess the process feasibility of manufacture and assembly processes the following aspects are described:
Identification of the key characteristics of a supporting structure.
Determination of the key characteristics of a supporting structure's assembly during the design phase.
Verification of the realisation of a supporting structure's key characteristics during the realisation phase.

\section{Identifying the key characteristics of a supporting structure}

The key characteristics of a supporting structure relate to the realisation of the supporting function as well as to visible deformation, damage and the quality provided as an assembly base for other systems. An example of the latter key characteristic is the acceptable dimensional deviation of an attachment point of an interface that is essential for the assembly. It was described In Section 4.6 how an assembly key characteristic can be formulated for such a point. Such a key characteristic can be expressed in terms of the point's nominal position in relation to the $\mathrm{X}$-, $\mathrm{Y}$ - and Z-axes of the reference frame. The acceptable dimensional deviations in each direction must also be defined and will relate to the interfaces that are to be attached there.

\section{Determining the key assembly characteristics of a supporting structure during the design phase}

In order to utilise a key characteristic in realising an assembly, one has to be able to determine its feasibility during the design phase. The key characteristic of the position of a point in relation to the reference frame depends on any deformations in the as-built situation and the manufacture and assembly processes that are used by the system supplier in question. The deformation in the as-built situation can be determined through calculation and it is then possible to, for example, modify the dimensions of the parts to be assembled. The impact of the manufacture and assembly processes can be estimated with the help of a flowdown, as shown in Figure 6.7, or could be known based on prior experiences.

In the other somewhat similar construction that was discussed with the supplier, the location of the storey floors was defined as an assembly key characteristic of the supporting structure. This addressed the acceptable horizontal dimensional deviations for a nine-storey building. This was seen as a key characteristic because the supporting structure serves as the assembly base for the façade. Based on this, the space for adjusting the interfaces of the façade was dimensioned. The key characteristic in question was based on the material-specific standards set in the Eurocodes. The dimensional deviation along the horizontal axis was of the order of several tens of millimetres in this specific nine-storey project. 
As in the case being discussed here, the supporting structure of the nine-storey object also consisted of façade frames and hollow-core slabs.

\section{Verification of the realisation of a supporting structure's key characteristics during the realisation phase}

The realisation of a key characteristic during the assembly of a supporting structure was discussed with the supplier of the supporting structure that manufactured the columns and beams and assembled the entire supporting structure. During the manufacturing stage, quality was regularly assessed. During assembly, this quality verification was based on the applicable requirements. The supplier does not have a description of the assembly processes used by the assembly for this construction The knowledge regarding this aspect is only present in the form of tacit knowledge and it is simply assumed that this knowledge is somehow available when it is needed.

The client explicitly mentioned to the supplier the importance of realising the key characteristics. Furthermore, they prescribed the use of the so-called "to plumb system" in order to control dimensional deviations during assembly. In order to realise the key characteristics of the supporting structure in the as-built situation, the supplier carried out an additional verification of the dimensional deviations. The assembly process that was used is quite similar to the assembly process that is represented as a flow-down in Figure 6.8. The dimensional deviations of the columns once positioned were only assessed using a total station, and extra fixtures may have been used.

By utilising a "to plumb system" and a modified assembly process, the supplier was able to realise the key characteristics for the discussed case without any major issues. The horizontal dimensional deviations of the individual columns of which there were about $1 / 500$, and the horizontal dimensional deviations at the locations of the storey floors were in line with the acceptable dimensional deviations. To achieve this, the supplier adopted the best practical means. It is not known to what extent the remaining dimensional deviations in the as-built situation were a result of deformations, the manufacturing method or the assembly process.

\section{Applicability of the process feasibility approach for constructions}

For the case described in this chapter, the supplier of the supporting structure was unable to realise the assembly key characteristics, although they had managed to do so for a different project. In both cases, there was a causal relationship between the assembly process that was used and the realisation of the key characteristics. Both involved dozens of columns and storey floors. Based on these similarities, the process feasibility approach appears to be applicable for assemblies that involve the realisation of supporting structures consisting of steel façade frames and hollow-core slabs. 
It is important to note that, based on the aforementioned findings, it cannot be concluded that the process feasibility approach is applicable for all systems in a product architecture that is based on construction parts that are produced offsite. However, if an assembly process can make use of a total station and the construction part in question can be positioned and attached with sufficient accuracy, this approach is likely to be applicable. Given this finding, the principle described in Section 4.1 with regards to the applicability of the process feasibility approach for the proposed assembly design method appears to be feasible.

\subsection{Findings regarding the organisation of the design and realisation process}

The findings related to the organisation of the design and realisation process concern the choice of the tendering method and the choice of suppliers, seen from the perspective of being able to design the assembly. Both aspects are described below. Following this, the findings regarding the design method being evaluated are addressed.

\section{The choice of tendering method}

In the approach adopted, the developer strives to achieve system integration. The basic principle is that they want to avoid bringing in a construction company to serve as a head contractor. In order to create a design for the project, the developer had an architectural firm draw up a design for the office building they were to realise, detailed down to the system design level. Consultants then assessed the feasibility of the design. To realise the project, the developer brought in system suppliers. Prior to the start of the project, they worked together to develop a building information model of the office building to be realised. A number of rules for the demarcation of the systems were employed. The developer facilitated this process, although they did not contribute to the realisation of the model. Based on this model, the developer drew up contracts with all the system suppliers regarding the activities they were to carry out. For these contracts, only the general terms and conditions of the suppliers were applicable.

The developer's chosen tendering method involved a transparent process in which everyone knows what to expect. Subcontracting was explicitly excluded. The developer bears no responsibility for the design of the assemblies. Through the agreements made between the developer, the user of the office and the investor, the developer benefits from an unhindered assembly process.

\section{The choice of suppliers}

Section 4.11 addressed the possible contributions of suppliers to the design and realisation process of the assembly. Based on the findings from this case study, it is possible to assess whether the developer chose appropriate suppliers and whether these suppliers were com- 
petent with regards to their inputs to the design of the assembly. The contributions of the suppliers for the following systems are covered:

supporting structure, including floors and floor edges;

timber-frame inner cavity walls;

curtain wall, including glazing, panels and aluminium finishing;

climate-control installations.

\section{Supplier of the supporting structure}

When developing the building information model, the supplier involved did not devote sufficient attention to the unavoidable geometric deviations in the supporting structure and how these would affect the positions of the floor edges. In the execution of the assembly, the hired assembly supervisor and the assemblers proved not to have the desired competences. This is remarkable, given the experience and history of the organisation in question. Their performance was not in line with what might be expected from a "black box" supplier, as described in Section 4.11.

\section{Supplier of the timber-frame inner cavity walls}

When developing the building information model, this supplier gave insufficient attention to the presence of head plates, bolt shanks etc. Furthermore, the information provided to the assemblers was inadequate. As a consequence, they had to go looking for a reference frame to facilitate the positioning of the various elements. Although the organisation did use its own people, their performance was not fully in line with what might be expected of a "black box" supplier.

\section{Supplier of the curtain wall, including glazing, panels and aluminium finishing} This supplier's performance was fully in line with what could be expected from a "black box" supplier.

\section{Supplier of climate-control installations}

This supplier's performance was entirely in line with what might reasonably be expected of a "black box" supplier.

\section{The consequences for the proposed design-for- assembly method}

In order to successfully apply the proposed design method, it is desirable that the involved suppliers are competent, or that a competent system integrator is involved in the design of the assembly. In this regard, the design method should be modified to ensure that the design of the assembly is in line with the individual suppliers' competences. This can be achieved by assessing the competences of a supplier through asking them to develop and deliver a flow-down. This modification to the design method should not alter responsibility with regards to the design of the assemblies. 


\subsection{The results of the case study}

The utility building case study was conducted to evaluate the first draft of the design for assembly method for use in construction and infrastructure projects. The research question to be answered in this chapter was:

\section{To what extent can the assembly process of utility building projects be improved when applying the proposed design method and how can the proposed design method be improved?}

The two elements of the research question can now be answered.

\subsubsection{Improving the assembly process of utility buildings by applying the proposed design-for-assembly method}

When applying the method, the assembly of the entire object is broken down into the assembly of various systems. The assembly order can then be optimised and interfaces ensure successful interactions between the systems. The specification of the interfaces is based on the geometric variations that have to be accommodated as a result of variations in the production and assembly of the systems.

The proposed design-for- assembly method can be seen as a means to achieve a structured transformation of the demand specification into the execution of the assembly. Key aspects are the phasing of the realisation process and the structure and substance of the information streams between the various phases. The application of the design method therefore contributes to closing the gap between the design and the execution of projects that can be classified as one-off productions.

When using the proposed design method for one-off productions, such as the one described in this case study, flow-downs are generally available for the assembly processes. These prevent the need for improvisation, which increases the safety of employees. Although no explicit research was conducted into labour productivity, it did become clear that the use of the proposed design method has a positive effect on this. Assembling the individual systems can be optimised with regards to the use of manpower and equipment, reworking is avoided and the geometric tolerances to be realised are based on the processes used.

In the case studied, construction waste was produced despite attention being given to this aspect in the design of the assembly. This was a consequence of deviating from the plans and the occurrence of larger geometric deviations than foreseen. Both causes are generally avoidable, and using the proposed design-for- assembly method can contribute to this. 


\subsubsection{The improvement of the proposed design-for-assembly method}

This sub-section describes the findings that relate to the evaluation of the proposed design method. This evaluation considers the entire proposed method, and experiences with the applied systems have also been recorded. In this case study, the phasing promoted in the proposed design method was not explicit. The nominal design phase and its assessment were carried out simultaneously using concurrent engineering approaches. The findings are summarized in Table 6.1 and how the required modifications have been processed in the adapted design-for-assembly method is described in Chapter 8.

\section{Demand specification}

In this case, it became clear that the contribution of the assembly approach to the realisation of the demand specification was not explicitly recognised. Nevertheless, due to the field problem identified in Section 2.10, the proposed design method is not modified.

\section{Spatial and functional design}

The substantiation of this phase is generally the same as in the proposed design-for-assembly method. For example, due to the desire for a rapid realisation, a product architecture is applied that allows the use of construction parts without any adjustment.

\section{System design}

In this case study, the basis for applying the assembly of systems approach was determined by the chosen product architecture. Further, a number of principles were applied that proved crucial in realising the desired assembly processes. The main principles are:

Limit the number of system suppliers.

Strictly demarcate between systems as part of the architectural design.

The delivery and assembly of a system must be conducted as a single continuous process.

- The activities are carried out sequentially: only one party is working on the construction site at any one time.

- With regards to seams and joinings: if B follows A, B is responsible for everything necessary to connect to A's work.

In this case project, the system design had been substantiated to such an extent that the client could approach specific suppliers to realise one or more component systems. The proposed design-for-assembly method needs to be modified with regards to the above mentioned points.

\section{The nominal design}

For this project, the space required for the hoisting path up to the final positioning was defined for a number of construction parts. The required size of the hoisting path depends largely 
on the desired room for manoeuvre. Furthermore, contours were defined for the positioning and attachment of parts for which dimensional deviations are relevant. If these contours match the nominal dimensions, there is no room for any dimensional deviations in the construction part in question. During the nominal design phase, the method should give more attention to the hoisting path, the required contour for positioning based on the construction parts' maximum dimensions, and any head plates, bolt heads and shanks, and dimensional deviations in the already assembled construction parts and any pipelines that are already in place.

\section{Variation design}

The nominal design was not explicitly assessed. Based on the findings, it is concluded that a number of shortcomings could have been avoided during the execution phase. In particular, this concerns the assessment of the acceptable dimensional deviations at the locations of system-to-system connections, the possibility of accommodating these dimensional deviations and the availability of hoisting paths for all components. The proposed design-for-assembly method requires adaptation with regard to addressing the availability of hoisting paths for all building components. It should be noted that shortcomings, such as those caused by the unforeseen deformation of formwork, are always possible. It is up to the people involved to recognise such potential risks.

\section{Preparation of the assembly}

Based on the assessed design, preparations were made for the assembly. The assessed design contained all the information necessary to realise the assembly. During the preparation, it is desirable to extract the essential information. This involves an interplay between the assembly plans, the tools and the competences of the assemblers. During this case study, it became clear that this had not taken place. Although what amounts to optimal preparation for assembly depends on the specific sector, there are a few general principles that apply. These are described below.

For the assembly of constructions, it is common to use drawings for which the architectural principles of dimensioning are used. A chain dimensioning method is used in which the listed dimensions are derived from the nominal design. Chain dimensioning is only feasible for the purposes of positioning if there are no dimensional deviations. In construction work, this dimensioning method is therefore practically unusable. The information provided for the assembly must be based on parallel dimensioning, as described in Section 4.9.

Another consequence of the architectural drawing approach is the use of double dimensioning for the positioning of construction parts based on the nominal design. Once again, this method can only work if there are no dimensional deviations. For assembly drawings, single dimensioning should be used as illustrated in Figure 6.10. On a note of caution, this does require careful control of the on-site dimensioning. Further, single dimensioning is only possible if a reference frame is available on site. 
The experience gained during this case study identified that an addition to the method is desirable with regards to the preparation and verification of the quality realised in the assembly process.
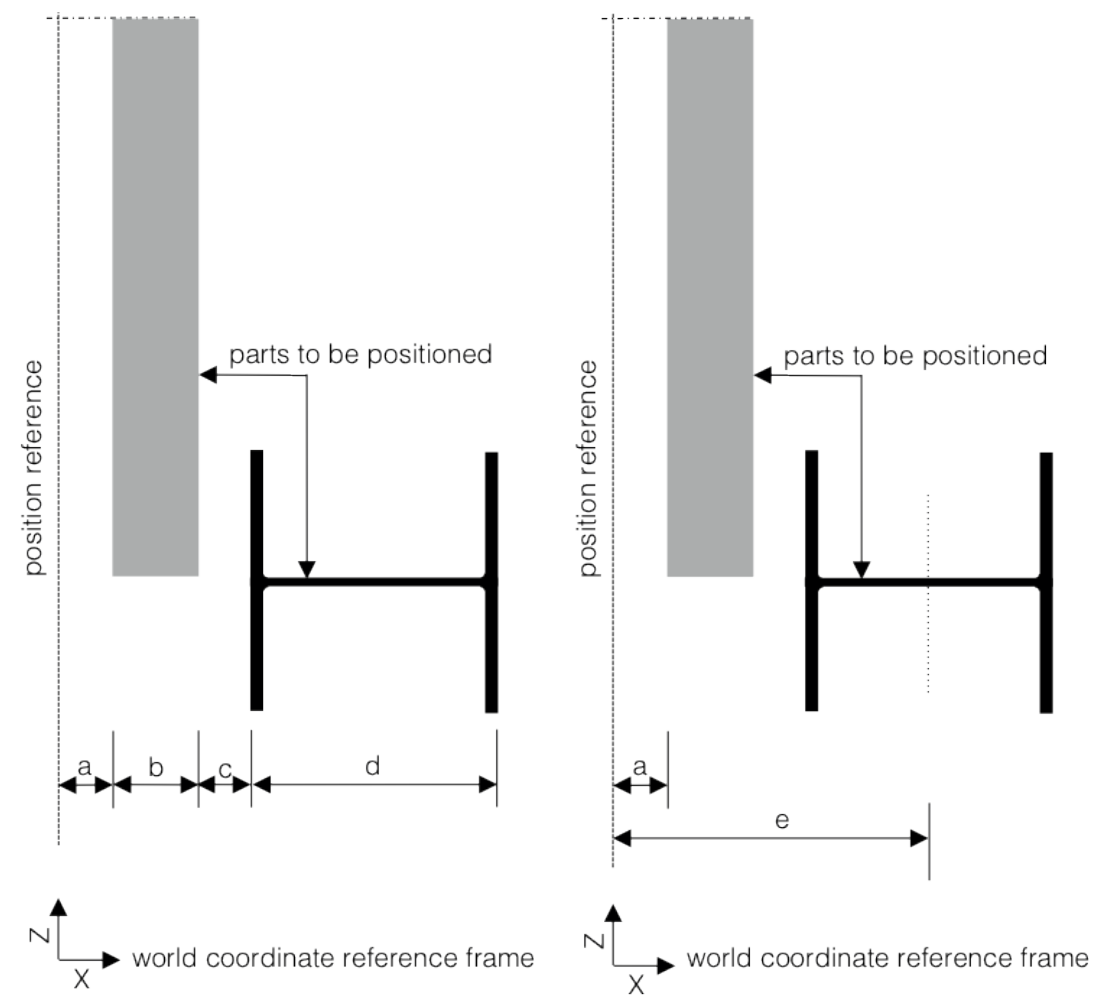

Figure 6.10: Dimensioning for the purposes of positioning: chain dimensioning on the left, parallel dimensioning on the right.

\section{Execution of the assembly}

With the exception of the logistical preparations at the assembly location, the realisation of the assembly should boil down to executing what has been prepared and conducting the inspections specified as part of the design. During this case study, it became clear that assembly plans are based on information that is not always available at the assembly location. Examples of missing information include north-facing arrows, gridlines and numbers and ordnance dimensions. The proposed method therefore requires adjustment with regard to the information provided for the actual assembly.

\section{Completion of the assembly}

The building is completed by creating the verification documentation for the assembled systems. These documents must refer explicitly to the key characteristics to be realized. Here, the proposed method requires adjustment. 
Table 6.1: Points for attention in the proposed design-for- assembly method being evaluated.

\begin{tabular}{|c|c|c|c|c|c|c|c|}
\hline \multicolumn{7}{|c|}{ phases of the proposed design-for-assembly method } & \\
\hline \multicolumn{3}{|c|}{$\begin{array}{l}\text { f preparation of the assembly } \\
\text { g execution of the assembly } \\
\text { h completion of the assembly }\end{array}$} & \begin{tabular}{|l} 
d nominal design \\
e variation design
\end{tabular} & \multicolumn{3}{|c|}{\begin{tabular}{|l|} 
a demand specification \\
b spatial and functional \\
design \\
c system design \\
\end{tabular}} & \multirow[b]{2}{*}{ 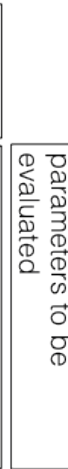 } \\
\hline 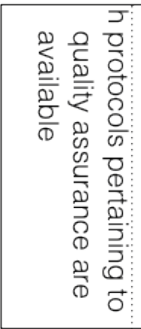 & 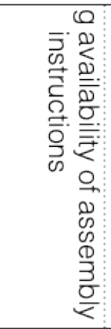 & 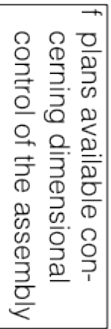 & 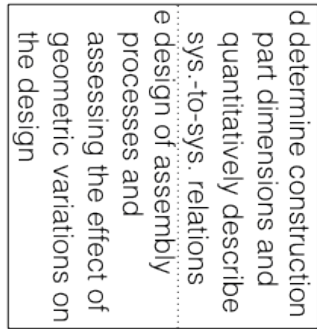 & 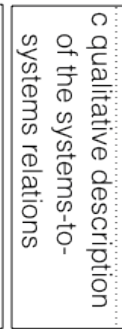 & 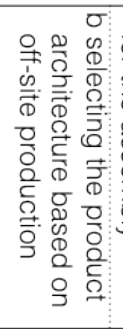 & 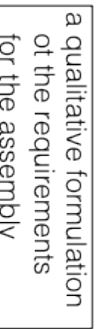 & \\
\hline 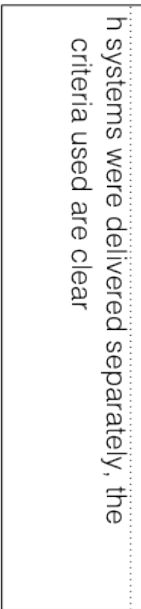 & 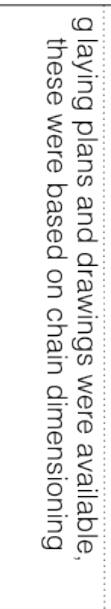 & 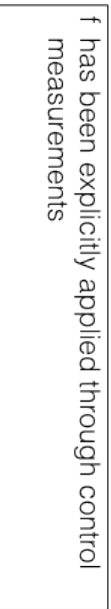 & 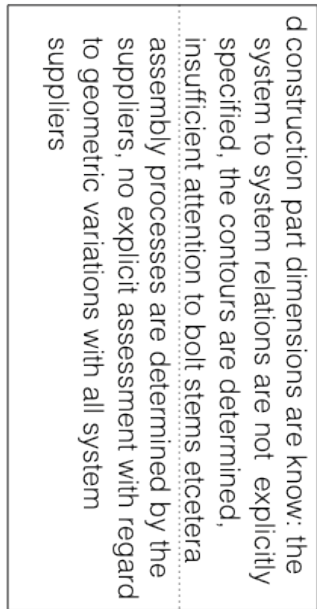 & 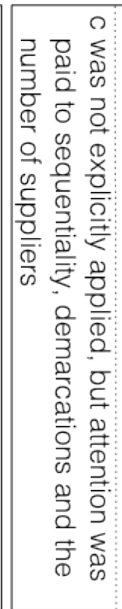 & 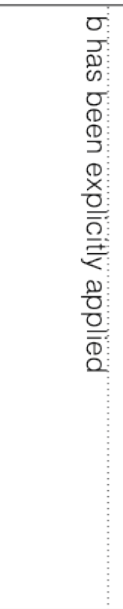 & 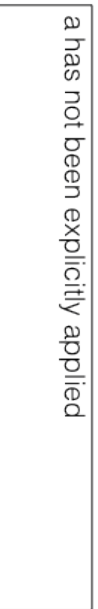 & 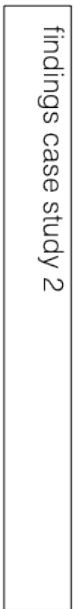 \\
\hline 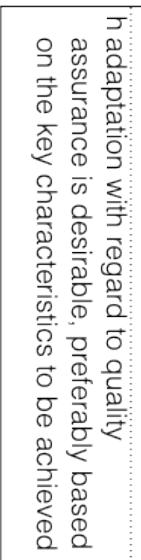 & 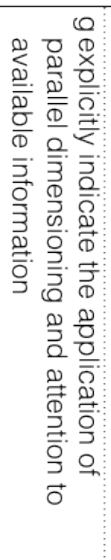 & 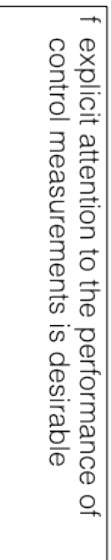 & 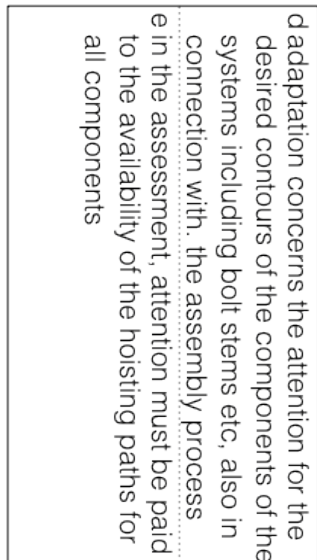 & 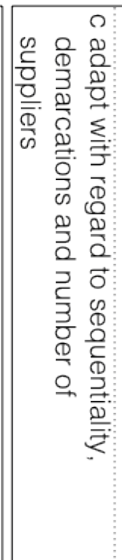 & 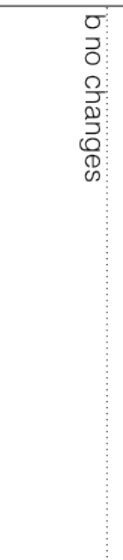 & 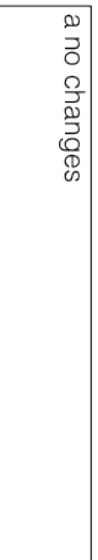 & 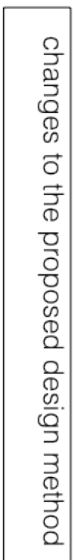 \\
\hline
\end{tabular}





\section{A case study of an infrastructure project}

\section{Contents}

7.1 Introduction

7.2 The infrastructure project to be realised

7.3 Characteristics of the infrastructure project

7.4 Goals of the case study

7.5 Case study methodology

7.6 Case study pedestrian bridges

7.7 Findings pertaining to the organisation of the design and realisation process

7.8 The results of the case study

7.8.1 Improving the assembly process of infrastructure projects by applying the proposed design-for-assembly method

7.8.2 The improvement of the proposed design-for-assembly method 


\subsection{Introduction}

The infrastructure project case study was conducted to evaluate the first draft of the Design-for-Assembly method for construction and infrastructure projects ${ }^{1}$. The research question that will be answered in this chapter is:

\section{To what extent can the assembly process of infrastructure projects be improved by applying the proposed design method and how can the proposed design method be improved?}

Section 1.3 explained that the product architecture of the cases to be selected for the case studies must be based on the use of construction parts that are produced offsite. With the exception of the foundation, that is the situation for the design and realisation of the infrastructure project in this case study. Section 7.2 describes the selected infrastructure project. Sections 7.3 to 7.5 cover, respectively, the characterisation, the goal and method of execution of the case study. Next, Section 7.6 addresses the design and its realisation. The findings regarding the organisation of the design and realisation process are described in Section 7.7. Finally, Section 7.7 discusses the implications of the research findings for the proposed design-for-assembly method.

\subsection{The infrastructure project to be realised}

Many Dutch cities are characterised by their canals. To cross these, one needs bridges. Bridges differ in terms of their primary function based on the type of traffic they are to support and whether they are fixed or moveable. Moveable bridges are often placed at locations where ships have to pass by and where the clearance height of a closed bridge would be insufficient to allow those ships to pass under. This case study pertains to a set of fixed bridges for light traffic (i.e. non-motorised) that must be able to support a load of $5 \mathrm{kN} / \mathrm{m} 2$. In Rotterdam alone, there are 775 of such bridges. In the Netherlands as a whole, that figure could be as high as 10,000 . With an average lifespan of forty years, this means that 250 of these bridges are in need of replacement every year. Their span is generally less than 25 metres and their width is typically around 2 metres. A bridge's lifespan depends largely on the materials that are used. For the bridges in Rotterdam that are the subject of this study, the lifespan is about 40 years. Between 2010 and 2016, Rotterdam was facing the challenge of replacing 35 of such bridges. In subsequent years, dozens of bridges will need to be replaced each year.

1 Also referred to as 'the proposed design method' 
In practice, the replacement of bridges for light traffic is often carried out using bridges that are produced offsite. With this approach, the on-site activities are limited to the realisation of the bridge's foundation and the connections at the surface level and the access points. In this case study, the research focussed on the extent to which the design-for-assembly approach can be used in replacing bridges for light traffic in urban areas throughout the Netherlands on a large scale. The core principle is creating a design that allows benefits of scale to be realised by utilising offsite production as much as possible.

\subsection{Characteristics of the infrastructure project}

The case study addresses a subset of the objects in the built environment, i.e. fixed bridges for light traffic with a maximum span of around 25 metres and a width of circa 2 metres. Such bridges are found in urban areas and can be produced entirely offsite. The results of the case study will only be relevant for bridges that belong to this subset. This case involves a public client who has tendered for the realisation of a number of pedestrian bridges through a design-and-construct contract and a reference design. The design-for-assembly of other and particularly larger bridges, such as railway bridges, therefore falls outside the scope of this case study [Cools et al., 2017].

\section{Characterisation of the case study}

In terms of classifying the expected assembly process, as described in Section 2.8, this project can be classified as a one-off production since only one bridge is to be realised at each location. The specific project concerns eight such bridges, for each of which the width and span may vary.

The principles outlined in Section 4.2 and the geometric variations covered in Section 5.3 are applicable in this case study. The geometric variations are the cause of the field problem introduced in Section 2.10. Section 3.2 explained that the construction sector does not have a technological rule to resolve these issues in a structured manner. As a result, this case can be seen as a representative of one-off production in the infrastructure sector.

\subsection{Goals of the case study}

Except for its foundation, the bridge in this case study is produced entirely offsite. The goals related to the conceptual design method being evaluated are limited to the system-of-systems design of the entire assembly. Further, the case study aims to present options that the contractor could adopt to further improve the design of the assembly in question. These contractor notes are formulated as recommendations and are provided directly to the con- 
tractor. Both goals are represented schematically in Figure 7.1.

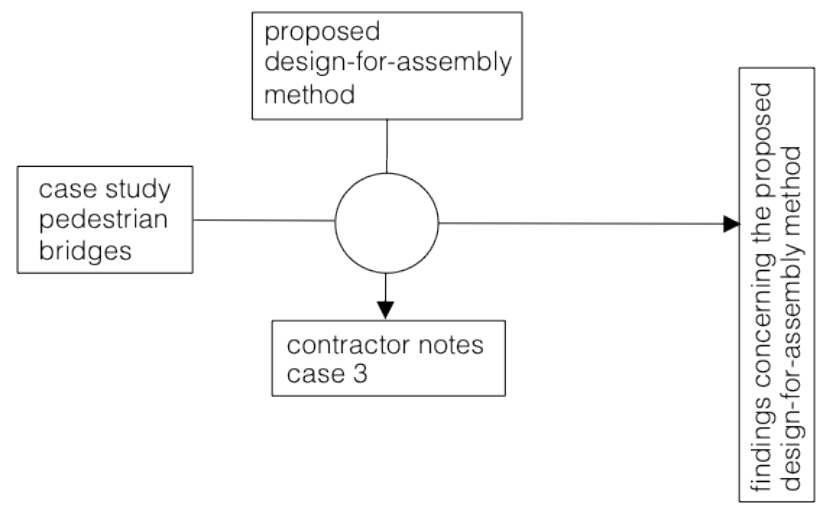

Figure 7.1: Goals of the pedestrian bridge case study.

\subsection{Case study methodology}

Ideally, the case study would cover the entire design and realisation process. Unfortunately, this was not possible as, by the time this case study commenced, the project to replace pedestrian bridges had already been ongoing for a number of years. However, it was possible to gather information about the design process and the assembly of a bridge. As in the previous case studies, interviews were conducted, and the assembly process was monitored. Due to the specific focus of this case study, the questions used during the semi-structured interviews differ from those of earlier case studies. Therefore, the actual questions used are covered in more detail. The supplier of the bridge, a so-called Parks-Nature park bridge, did not see any point in discussing the design of its assembly since this would be handled by a highly experienced individual and was not described in any form. However, the on-site assembly of the bridge was closely monitored.

The findings from the monitoring of the assembly form the basis for the evaluation of the proposed design-for-assembly method, like in the dwelling transformation case study. The mapping that was used is based on the method described in Section 1.3 and executed in a manner similar to the one described in Section 5.5. The findings pertaining to the organisation of the design and realisation process are described in Section 7.7.

\section{The interviews}

Interviews were conducted with the asset manager in question and the constructor of the 
bridges $^{1}$. Both were employed by the project client. Prior to his interview, the asset manager provided information about the project and submitted their chosen method [Gemeente Rotterdam, 2010]. During the interview, the following topics were covered:

The vision pertaining to the utilisation of the scope of the project.

The project organisation.

The allocation of responsibilities.

The goal was to learn more about how this municipality operates as the client of an ongoing multi-year project that consists of conceptually similar tasks.

\subsection{Case study pedestrian bridges}

The following aspects of this case study are covered in this section:

The standardisation.

The organisation of the process.

The description of the systems to be assembled.

The design of the assembly.

Findings with regard to the execution of the assembly.

Findings with regard to the organisation of the design and realisation process.

\section{The standardisation}

The scope of the project is such that standardisation is desirable. This would allow for the simplification of the permit acquisition process, deliver the desired unified urban appearance, and limit the costs of realisation and maintenance. If standardisation is not possible, the entire permit acquisition process has to take place for each bridge replaced. An important aspect of this is receiving a positive recommendation from the building aesthetics committee. This commission oversees all built objects in the municipality, including the replacement of pedestrian bridges. This fact was utilised by the municipal services when seeking standardisation. It was substantiated by clustering the projects into so-called families. The clustering is based on the zoning used in the municipality's so-called "City Vision prosperity"2. It represents the so-called Rotterdam Style. With regard to bridges, there was a focus on the design and material used in modular components such as bridge decks and guardrails. Based on the City Vision, five families of pedestrian bridges were identified including "Singels and Parks Tuindorp idyll," "Back to the Small Size," "Neighbourhoods

1 These were held on 22 June 2017.

2 Koepelnota welstand 
1970 - 1985" and "Parks-Nature park." The bridges within a single family are all made using the same modular components although their geometry depends on the span and width of the bridge in question.

Based on the described families within the Rotterdam Style, the key requirements and the available budgets for realisation and maintenance, a design brief was drawn up for each family. Next, potential contractors were asked to develop proposals for this project in the form of a competition. For this, the contractors brought in designers and producers. They were explicitly asked to come up with innovative proposals with regard to the material used. The designs of the five winners were presented to the building aesthetics committee and prototypes then realised using construction teams. These teams consisted of representatives from the contractor and the client. Upon completion, the municipality takes ownership of the design families, which means they can be used to replace other pedestrian bridges. The case monitored is a subsequent iteration of a bridge that forms part of the "Parks-Nature park" family.

\section{The organisation of the process}

Replacing the pedestrian bridges is a process with a lead time of a number of years. For each area, the bridges to be replaced are assessed and reference designs for the new bridges are created from the aforementioned five families. Next, the municipality issues a "design and construct" tender, using the already assessed family members as the basis for the reference designs. The practical design through to assembly aspects are left to the contractor and any third parties they involve. The contractor and the subcontractors have complete freedom in optimising their processes.

\section{The description of the systems to be assembled}

This study only addresses the Parks-Nature park bridge design. The entire bridge consists of the foundation, the landing, the bridge deck construction, the guardrails, and the anchoring of the bridge deck to the foundation. The bridge deck construction and the guardrails have already been assembled by the producer. These are made entirely of composite material. Given the limited weight of the bridge, a steel foundation ${ }^{1}$ can be used. The foundation, which consists of two concrete beams, and the landings are realised on site. The anchoring consists of four steel anchors, which are also installed on site. The assembly process therefore amounts to positioning the bridge on the foundation and the realisation of the anchoring. The bridge in question has a span of circa 17.5 metres and is shown in Figure 7.2.

As a result of the materials used, the weight of the monitored bridge is around 7,000 kilograms. This not only facilitates the entire off-site production but also allows the type

1 is is a type of foundation where, because of the light loads, the load is not transferred to a specified deeper layer of soil through piles driven into the ground. 
of foundation selected. As a result, the entire construction should remain in more-or-less the same position in relation to the ground level for its entire lifespan. A heavier bridge would not only require a piled foundation, but also the regular raising of the paths leading up to the bridge, which normally sink into the peaty soil found in the western regions of the Netherlands. The limited weight of the bridge also makes it possible to transport and assemble it using relatively simple hoisting facilities. Considering the locations where this type of bridge is used, that fact is of paramount importance.

Thus, the selected system design makes it possible to produce the bridges offsite and allows a simple foundation. As a result of the chosen design, the assembly activities to be executed are limited to positioning the bridge in place and anchoring the bridge to its foundation.

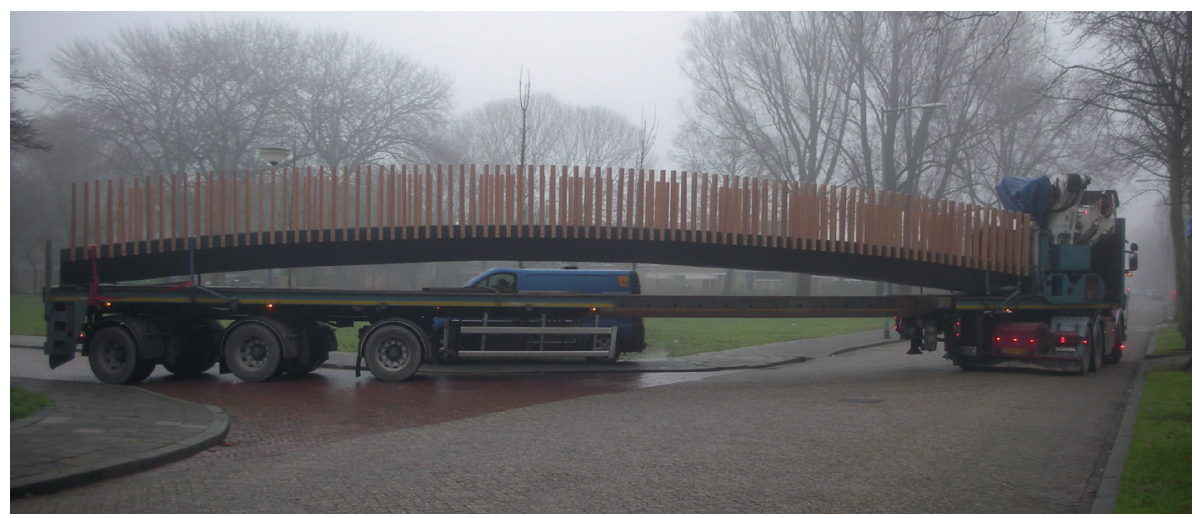

Figure 7.2: Transporting the Parks-Nature park bridge.

\section{The design of the assembly process}

This concerns the transport of the bridge to the vicinity of its final location, the positioning of the bridge on its foundation, and the installation of the anchoring system. As the bridge's family name suggests, this bridge is designed for use in a park environment. In the case studied, the distance between the main road and the bridge's location is around 250 metres. Although there were some trees along the way and the path is unpaved, it was decided to transport the bridge to within the vicinity of the location using a special transport truck. A crane is mounted on this truck. The bridge is then placed on its foundation using a hydraulic crane that was already positioned on site and this truck. The contractor also made use of the hydraulic crane for the on-site production of the landings and the foundation.

The anchoring consists of wire ends with a diameter of 24 millimetres. Once the bridge has been positioned, these are glued into the concrete foundation beams using resin anchors. The required attachment holes, with a diameter of 50 millimetres, are drilled before the bridge is positioned. The locations of the holes were determined by the contractor using a 
crude measurement method. Placing the bridge on its foundation involves free positioning. The assembly is complete once the anchors are in place. The method of hoisting the bridge with two cranes was chosen by the contractor's executor.

\section{Findings with regard to the execution of the assembly}

The execution of the assembly was postponed several times due to manufacturing problems involving the guardrails. For this bridge, balusters were used with which the parties involved had no prior experience. As a result, the footpath leading up to the bridge was closed off for a few weeks longer than originally intended. The issues that arose with manufacturing do not match the principles of the selected family approach, this was not the first time that this type of bridge has been used. According to the contractor, only one organisation could produce the required guardrails, which for the guardrails apparently did not involve a controlled process. The fact that on-site installation of the balusters was not an option is clear from Figure 7.2, which shows the bridge being delivered to the site.

The process of transporting the bridge and hoisting it into position proceeded as planned. To hoist the bridge, hoisting straps were placed near the bearings at each end of the bridge. As a result, the distance between the anchor points was likely to be larger than the theoretical dimension due to flexing between these lifting points. This is based on the reasonable assumption that the mould used to manufacture the bridge would have matched the theoretical dimensions. The positioning process was not controlled and it took some effort to position the bridge close to the fixing holes that had been drilled in the foundation, Next, it transpired that one hole was in the wrong position. To drill a new hole, one side of the bridge had to be lifted with the hydraulic crane. Even after this, it was not possible to install the anchor, forcing them to drill again. Based on the issues in positioning the bridge, it can be concluded that the entire process of positioning and anchoring the bridge did not proceed in a controlled manner, as illustrated in Figure 7.3. It is unclear to what extent the issues can be attributed to deformations that occurred during the assembly process.

\section{Findings with regard to the organisation of the design and realisation process}

The client has transformed the preservation of its pedestrian bridges from an object-oriented approach to a systems approach. This systems approach is context-controlled and makes optimal use of the available options for offsite production in combination with serial production. By using a reference design, the contractor has complete freedom to structure their onsite activities as they see fit.

In this case, the client's approach shows many similarities with the method represented in Figure 2.2. By linking the preservation project concerning the bridges in question to the building aesthetics committee's "City Vision prosperity", it became possible to define a design request that allowed the development of an object-independent product architecture. 
By organising the design challenge, "DFX in the large" was substantiated and, by using reference designs, contractors were given the opportunity to substantiate "DFX in the small".

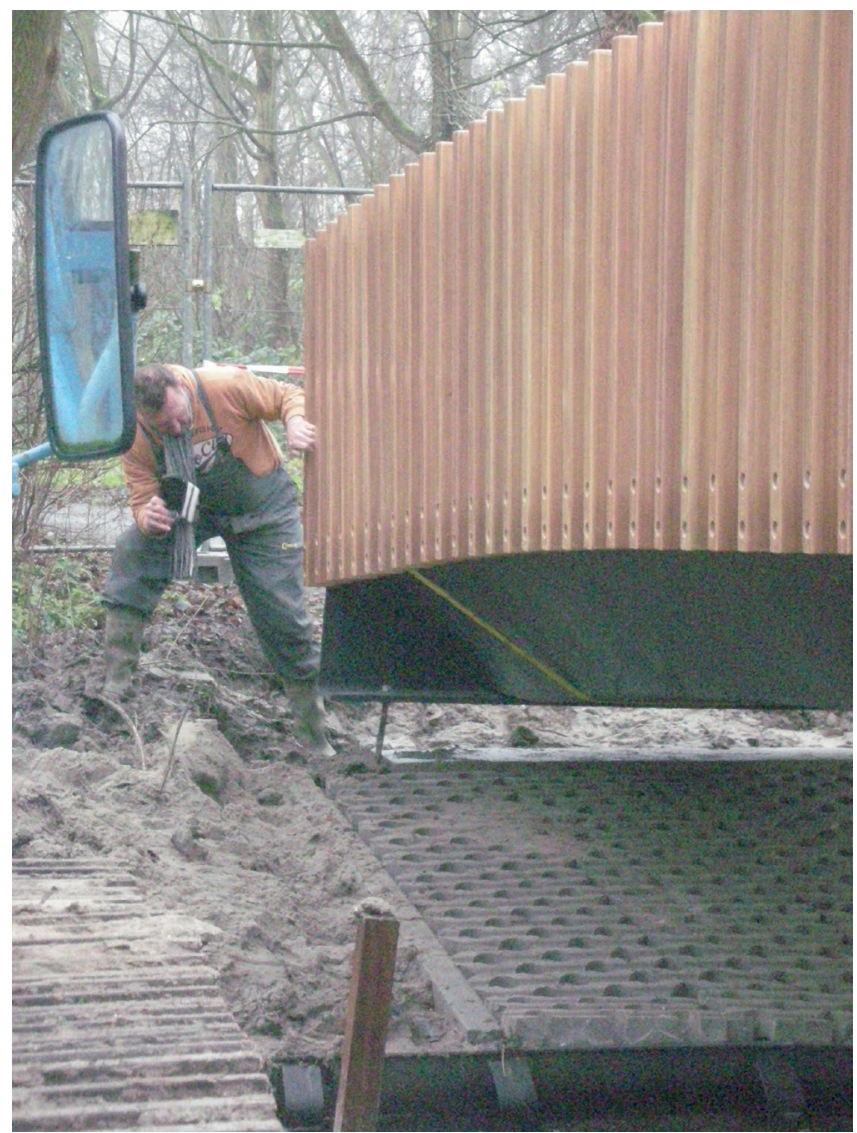

Figure 7.3: Positioning a Parks-Nature park bridge.

\subsection{Findings pertaining to the organisation of the design and realisation process}

The proposed design method was developed for an object-oriented approach. This case demonstrates that there are situations in which a system-oriented approach is both desirable and feasible. With regard to this aspect, the conceptual design method needs to be expanded. No changes are needed with regard to the design of a concept-related product architecture and the tendering method that was used. The aforementioned change is described in Chapter 8. 


\subsection{The results of the case study}

The research question to be answered in this chapter was:

To what extent can the assembly process of infrastructure projects

be improved by applying the proposed design method and how can

the proposed design method be improved?

The two sub-questions in this research question are now answered.

\subsubsection{Improving the assembly process of infrastructure projects by applying the proposed design-for-assembly method}

The relevance of this case study is in its use of the product family concept in order to efficiently realise infrastructure for light traffic in primarily urban areas. This approach offers many possibilities for the efficient realisation and maintenance of infrastructure in general, and of urban infrastructure in particular. It is interesting that this approach was initiated by the client and that they also managed to realise innovations with regard to the material used with this proactive approach. With regard to the object-oriented approach, the proposed design method must be adjusted.

If the developed design method is applied to projects that are somewhat similar to the project in this case study, the family concept can again be applied enabling the realization to be carried out as efficiently as described for this case.

The effects in terms of the increased safety of employees are similar to those described in Section 6.11. If the use of the design method results in the execution method described in this chapter, it will do much to increase labour productivity in the construction sector. This is because it involves the greater use of repeatable design and offsite manufacture, and limits onsite activities to the positioning of the bridges. When it is possible to carry out all production offsite, construction waste is essentially eliminated.

\subsubsection{The improvement of the proposed design-for-assembly method}

The findings are described and summarized in Table 7.1. The manner in which these are incorporated in the adapted sign-for-assembly method is covered in Chapter 8.

The main aspects of this case are the manner in which the municipality was able to form 
families of pedestrian bridges and create their unique designs. This meant the permit acquisition process was greatly simplified, extensive offsite production was made possible, and the foundation was designed to optimise the manufacture and assembly processes. These improve labour productivity when it comes to replacing existing bridges.

The actual assembly process of the bridge was clearly not controlled although it was seen as a routine operation. Although this was certainly the case for the parties involved, it did not proceed as such unless the assembly witnessed is considered normal for this type of bridge.

During this case study, several points warranting attention in the proposed design method came to light. These concern the applicability of product families, the chosen design, the timely availability of the systems to be used, the deformation of construction parts during hoisting and the positioning method. With regard to the product families, it is desirable to consider the scope of a project in light of the possibility of identifying product families. The chosen design should be based around maximum offsite production. The availability of systems should be assessed in a timely manner. When hoisting construction parts, it is advisable to be mindful of the deformations that may occur and how these affect the positioning and attachment processes. The positioning method is relevant with regard to the controllability of the cycle times and the desired degree of accuracy of the assembly. 
Table 7.1: Points of attention pertaining to the proposed design-for- assembly method.

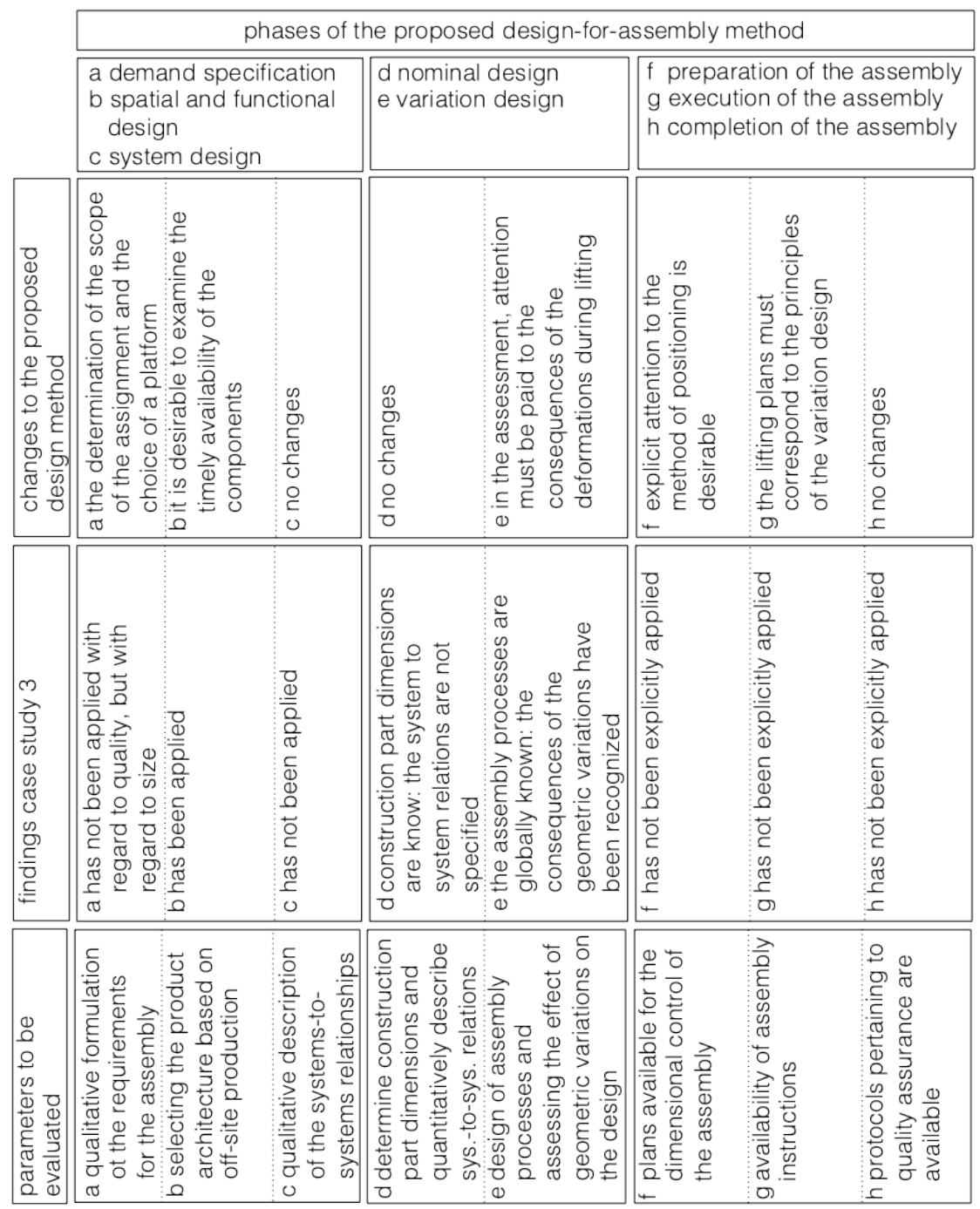




\section{The final version of the design-for-assembly method}

\section{Contents}

8.1 Introduction

8.2 The results from the series of case studies

8.2.1. The desired modifications

8.2.2. The organisation of the design and realisation of assemblies in the built environment

8.2.3 Specification of the design method

8.3 The principles of the design method with regard to assembly as a production method

8.4 Principles of the design-for-assembly method

8.5 The final version of the design-for-assembly method

8.5.1 Phase 1: Design of the typology

8.5.2 Phase 2: Framework conditions

8.5.3 Phase 3: Selection of the product architecture

8.5.4 Phase 4: Design of the system-of-systems assembly

8.5.5 Phase 5: Nominal design of the assembly

8.5.6 Phase 6: Assessment of the feasibility

8.5.7 Phase 7: Preparation and execution of the assembly

8.5.8 Phase 8: Completion of the assembly

8.6 The design-for-assembly method and the potential applications

8.7 A validation of the developed design-for-assembly method

8.7.1 From building to assembling in residential construction

8.7.2 From building to assembling in non-residential construction

8.7.3 From building to assembling for infrastructural projects

8.7.4 The overall results of the validation exercise for the design-for-assembly method

8.7 Conclusion regarding the final version of the design-for-assembly method 


\subsection{Introduction}

This chapter provides the final version of the Construction Assembly Design method. The conducted case studies (see Chapters 5, 6 and 7) provided sufficient reason to make some modifications to the proposed construction assembly design method described in Chapter 4. This was addressed by answering the following question:

What adjustments are needed to the first version of the design-for-assembly method for construction and infrastructure projects to accommodate the findings from the series of case studies?

The required adjustments are clarified in more detail in Section 8.2. In Section 8.3, principles for the assembly of objects in the built environment are explained. It should not be forgotten that not every design of object is suitable for realisation by means of an assembly process. Section 8.4 provides an overview of the main principles of the developed construction assembly design method. The final version of the construction assembly design method is described in detail in Section 8.5. The application possibilities of the method are discussed in Section 8.6. Section 8.7 reflects on the results of the validation process and Section 8.8 draws conclusions with regard to the developed final version of the construction assembly design method.

\subsection{The results from the series of case studies}

The desired modifications to the proposed design method, based on the series of case studies, are described and summarised in Table 8.1. This shows that every phase of the proposed construction assembly design method is in need of some degree of modification. Furthermore, the findings with regard to the desired modifications to the design method and the organisation of the design of assemblies in the built environment are also covered. This section concludes with a modified specification of the design method as described in Section 4.1.

\subsubsection{The desired modifications}

The desired modifications of the proposed construction assembly design method as represented in Figure 4.2 are now described for each phase.

\section{Demand specification}

The relevance of the demand specification is evident from case study 3 (Chapter 7). 
Table 8.1: The results of the case studies.

\begin{tabular}{|c|c|c|c|c|c|c|c|c|}
\hline \multicolumn{8}{|c|}{ phases of the proposed design-for assembly method } & \\
\hline \multicolumn{3}{|c|}{$\begin{array}{l}f \text { preparation of the assembly } \\
g \text { execution of the assembly } \\
h \text { completion of the assembly }\end{array}$} & \multicolumn{2}{|c|}{$\begin{array}{l}\text { d nominal design } \\
\text { e variation design }\end{array}$} & \multicolumn{3}{|c|}{$\begin{array}{l}\text { a demand specification } \\
\text { b spatial and functional } \\
\text { design } \\
\text { c system design } \\
\end{array}$} & \\
\hline 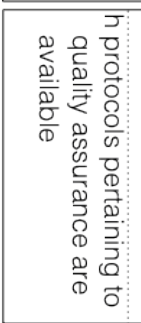 & 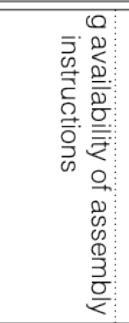 & 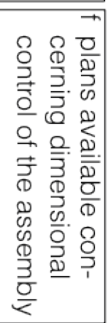 & 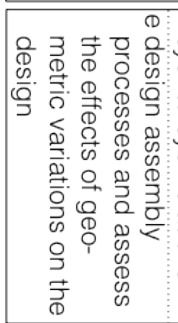 & 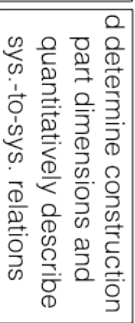 & 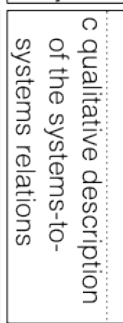 & 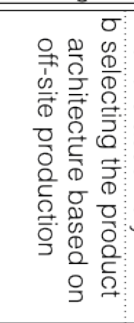 & 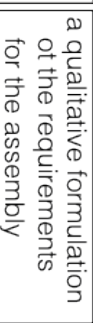 & 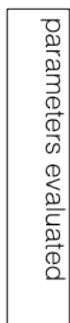 \\
\hline 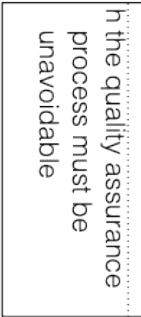 & 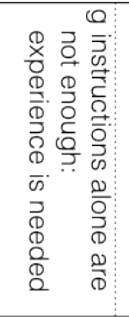 & \begin{tabular}{l|l}
$\overrightarrow{3}$ \\
0 \\
0 \\
0 \\
0 \\
0 \\
0 \\
0
\end{tabular} & 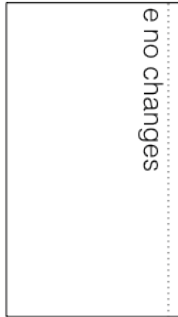 & 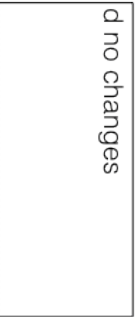 & 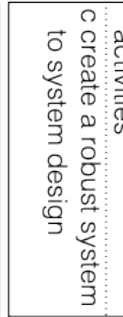 & 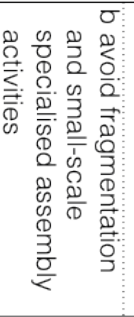 & 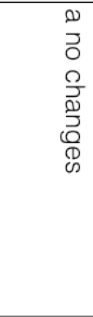 & 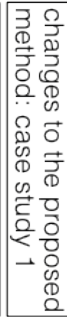 \\
\hline 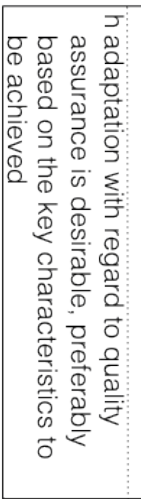 & 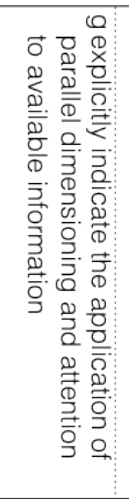 & 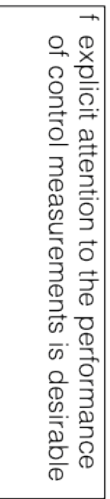 & 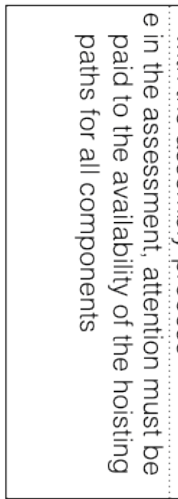 & 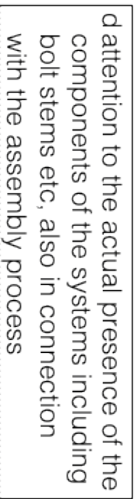 & 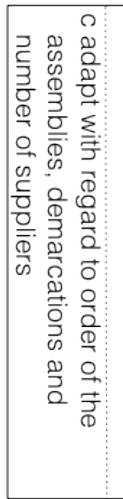 & 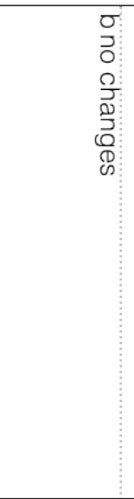 & 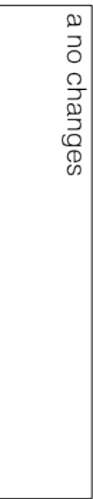 & 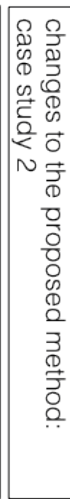 \\
\hline 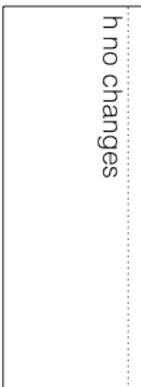 & 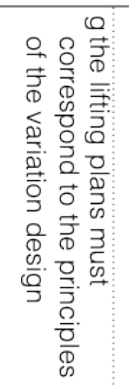 & 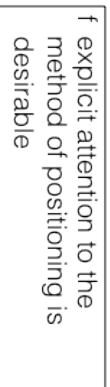 & 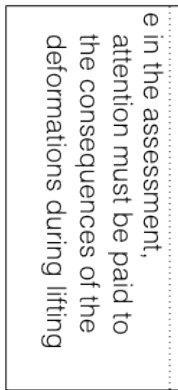 & 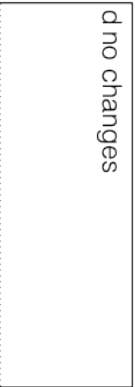 & 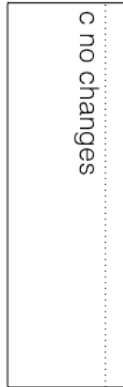 & 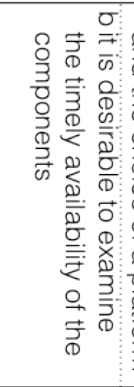 & 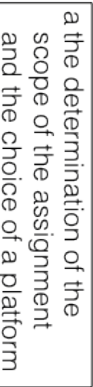 & 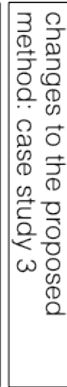 \\
\hline
\end{tabular}


Concerning bridges in need of replacement, a typology was developed for specification purposes. For each type of bridge, a demand specification was then developed of which the architecture to be realised as described in the typology forms a part.

In terms of the design of the object's assembly, it is desirable to assess whether the object in question, or components thereof, are part of a collection of objects that share a similar design brief. If this is the case, the design concerns a system rather than an object. In the event of a systems approach, the factors that affect the potentially desired variability can be assessed to facilitate the development of product families or platforms. In case study 3 , these factors were the rural and urban contexts.

\section{Spatial and functional design}

The relevance of the spatial and functional design is abundantly clear when looking at case study 1 (Chapter 5). Due to the unavoidable fragmentation in this case, it was decided to work with autonomous teams. Similarly, in case study 2 (Chapter 6), this was also relevant and led to many hours of waiting around for specific assembly crews.

In terms of designing the product architecture of an assembly, too many systems and a fragmented assembly of systems should be avoided. If an assembly is fragmented, one could consider incorporating it into the assembly of a different system.

\section{System design}

The system design proved its relevance in all three case studies. For an efficient assembly, the following aspects should be considered:

the availability of the systems to be assembled;

the continuity of the assembly processes;

the robustness of the systems to be assembled;

the feasibility of the system-to-system joinings.

It needs to be possible to assess the feasibility of realising the assembly based on its system design.

\section{Nominal design}

A nominal design was not developed in any of the case studies. The only design was that of the foreseen as-built situation. Based on the insights described in Sections 2.10 and 3.2, a nominal design phase had been incorporated in the design method. Furthermore, the design method needs to consider the process of positioning the construction parts using cranes: the space taken up by hoisting straps, slings, end plates, foot plates, bolt shanks and existing pipelines must not be overlooked. 


\section{Variation design}

In the case studies, variation designs were not used, although the relevance of including such a phase was clear. It was also seen that a focus on the deformations that may occur during assembly is also desirable as part of the design method. This is because it is often impossible to assemble a deformed construction part in a controlled manner. Furthermore, it is desirable to assess the availability of the hoisting paths that will be required during the assembly.

\section{Preparation of the assembly}

During the case studies, it became clear that the assemblies were often not optimally prepared: The correct dimensions were often unclear. Therefore, as part of the design method, there should be a focus on preparation at the system level, rather than at the construction part level. The main goal is to ensure the key characteristics are feasible and can be achieved, and whether these key characteristics are met in the assembly process should be assessed. For each system to be assembled, its position in relation to a geodetic datum should be recorded. The required positional accuracy of a system at the assembly location of the various systems must be in line with the tools that are used in positioning the construction parts.

\section{Realisation of the assembly}

The case studies show that the construction sector often utilises chain dimensioning. When designing assemblies, this is asking for trouble and, instead, parallel dimensioning should be used in assembly plans. Further, one should ensure that the assemblers have the requisite experience and also conduct a test assembly if there is any doubt. This should not be left until the first few cycles of an assembly process since these are inappropriate for this purpose.

\section{Completion of the assembly}

Only in case study 2 (Chapter 6) was there any explicit attention given to ensuring the quality of the assembly of systems. This is still seen as an essential component and, when designing the assemblies, it should always be possible to safeguard the quality achieved during assembly. Consequently, the necessary activities should be incorporated in the design.

\subsubsection{The organisation of the design and realisation of assemblies in the built environment}

The organisation of both the design and the realisation of an object must be robust when it comes to the division of responsibilities that is common in the construction sector, and especially with regard to the realisation of the key characteristics. Case study 2 showed that the realisation of the assembly of an object can be achieved based on either the system 
design or, after completion, on the variation design. The involvement of a so-called system integrator is not always necessary.

In those cases where a design-and-build method is used, and the contractor opts for the assembly approach, the contractor can either control the assembly of systems based on the system design or on the finished variation design.

\subsubsection{Specification of the design method}

The case studies show that assemblies can be realised using tendering methods that are already common in the construction sector. In response to this finding, the specification of the design method as described in Section 4.1 is modified. The following specification is proposed for the design method and included in Section 8.4:

Using the design-for-assembly method for objects in the built environment results in a controlled and efficient realisation. The design method should be able to be realised in a transparent manner and, during each phase of the design, result in a verifiable design with regard to its controlled and efficient realisation. Such a design can be used when tendering for the realisation of the assembly. The method should be usable by a building technologist.

With a design method that meets this specification, the responsibilities with regard to the design and realisation will be recorded during each phase. It will then be possible to implement the findings of the Dutch Safety Board [Onderzoeksraad Voor Veiligheid, 2012; 2016].

\subsection{The principles of the design method with regard to assembly as a production method}

The principles with regard to the assembly of objects in the built environment are first and foremost based on the ability to display them in a world coordinate frame in a manner similar to that of a one-off assembly to be realised through an assembly process that is exposed to the elements. The case studies have shown that, in order to be able to prepare for an assembly, it is important to be able to determine the position of each component during and after the assembly process. The following must be clearly present and stated for each assembly involved:

The composition of the assembly to be designed.

The design intent of the assembly to be designed.

The relationships between it and other systems to be assembled.

The deformations that occur. 
5 The process capabilities or the assembly processes.

6 The representation of the assembly.

7 The availability of a reference frame.

All seven points are explained in more detail below.

\section{The composition of the assembly to be designed}

In order to design the assembly of an object in the built environment, such as a building or a infrastructure project, it has to be possible to view it as a collection of systems, a so-called system of systems. It is made into a single whole - the desired construction - through the realisation of the system-to-system relationships.

\section{The design intent of the assembly to be designed}

The design intent of a construction to be assembled concerns the technical system. It consists of the realisation of the technical and aesthetic specifications, which are defined in measurable quantities that can be derived from the demand specification. The position of a system to be assembled in a world coordinate frame can be determined based on its design intent. For the purposes of the assembly design, this is based on the realisation of the so-called key characteristics of this system.

\section{The relationships between the systems to be assembled}

The relationships between the systems to be assembled can be divided into constructive and geometric relationships. The constructive relationship consists of a force or moment to be transferred, which is achieved through an interface. A geometric relationship concerns the positions of parts in relation to each other. This is represented in the specification of the joinings between these parts.

\section{The deformations that occur}

An ongoing assembly of a construction and the assembly base are subject to deformations during the assembly process. This can lead to permanent deformations. It must be possible to assess the deformations that occur over time to a sufficient degree of accuracy. This accuracy depends on the functionality of the interfaces.

\section{The process capabilities of the assembly processes}

In general, the construction sector utilises established assembly processes. These are not dependent on a particular design. That means they can also be represented and described without there being an object-related design.

The specification prescribes that the method to be designed should result in the efficient realisation of the objects in the built environment. To this end, it is assumed that the process feasibility ( $\mathrm{Cpk}$ ) of the assembly processes used in the construction sector is greater than one. 


\section{The representation of the assembly}

With the help of an assembly model it must be possible to realise the assembly. The description given by Sudarsan et al. [2006] is utilised to clarify this model. A building information model is used as the framework for this information.

\section{The availability of a reference frame.}

At the assembly location, a three-dimensional reference frame needs to have been established. This should be accessible to such an extent that it can be used as a geodetic datum. The position of construction parts is then determined in relation to this reference frame. In case study 2, it became clear that assemblers do not always have access to such a reference frame. In such a situation, the position of a construction part is often determined during assembly based on the position of a previously assembled construction part: In other words, chain dimensioning is used with its associated risks.

\subsection{Principles of the design-for-assembly method}

The design-for-assembly method that was evaluated through the series of case studies is based on a modification of the design method that is commonly used in the construction sector. During the evaluation, it became clear that the choice of product architecture forms the basis for the design of the assembly. Without this basis, the applicability of the assembly concept can be called into question. It could lead to a design that is not entirely based on the assembly approach, which is an undesirable situation for any stakeholder. Given that choosing a product architecture is not recognised as an issue in the conventional design method, it was decided to classify the design of an assembly as a specific design method. It is structured in such a way that the applicability of the assembly approach can be determined early in the design process.

Designing the assembly of an object in the built environment should be fully tailored towards its efficient realisation. All the functionality required with an assembly should be known at the start of this design process. All views relevant to a design should be incorporated in the design specification. This also applies to other approaches such as design for climate change, design for adaptation and design for a circular economy since such design perspectives are all preconditions for the assembly to be designed. The method for the assembly design is therefore primarily tailored towards the efficiency of the assembly to be realised, given its design intent. One option is to express this efficiency in the form of the value creation per unit of time to be realised with a certain design. 
For the design-for-assembly method, the following principles apply:

The design method should be structured in a top-down manner.

The design method concerns the functionality to be realised and the duration of the realisation process.

When using this design method, the functionality realised in the as-built situation is similar to that in the specification.

- The producers of construction parts produced offsite consult the relevant design for manufacturing aspects.

Designing the assembly is one of the competences of the building technologists involved. In addition to building technologists, structural and cost engineers are among those involved in designing the assembly.

- The design method is structured in such a way that suppliers can participate in it.

- In representing the design of the assembly of objects, the same representation as used for construction systems and parts should be employed.

- The results of the assembly design are described for each phase in the building information model. This model can therefore also be used to monitor the quality of the systems to be designed and assembled.

These principles form the "input" for the design method as described in section 8.5.

\subsection{The final version of the design-for-assembly method}

The design method of the assembly is based on section 8.4 and consists of eight phases. These are:
Design of the typology.
Determining Framework conditions.
Selection of the product architecture.
4 Design of the system-of-systems assembly.
5 Nominal design of the assembly.
6 Assessment of the feasibility of the assembly.
7 Preparation and execution of the assembly.
8 Completion of the assembly.

The final design-for-assembly method is represented schematically in Figure 8.2 and is discussed in more detail in the remainder of this section. The process steps of the first draft of the design-for-assembly method are represented in Figure 8.1. 


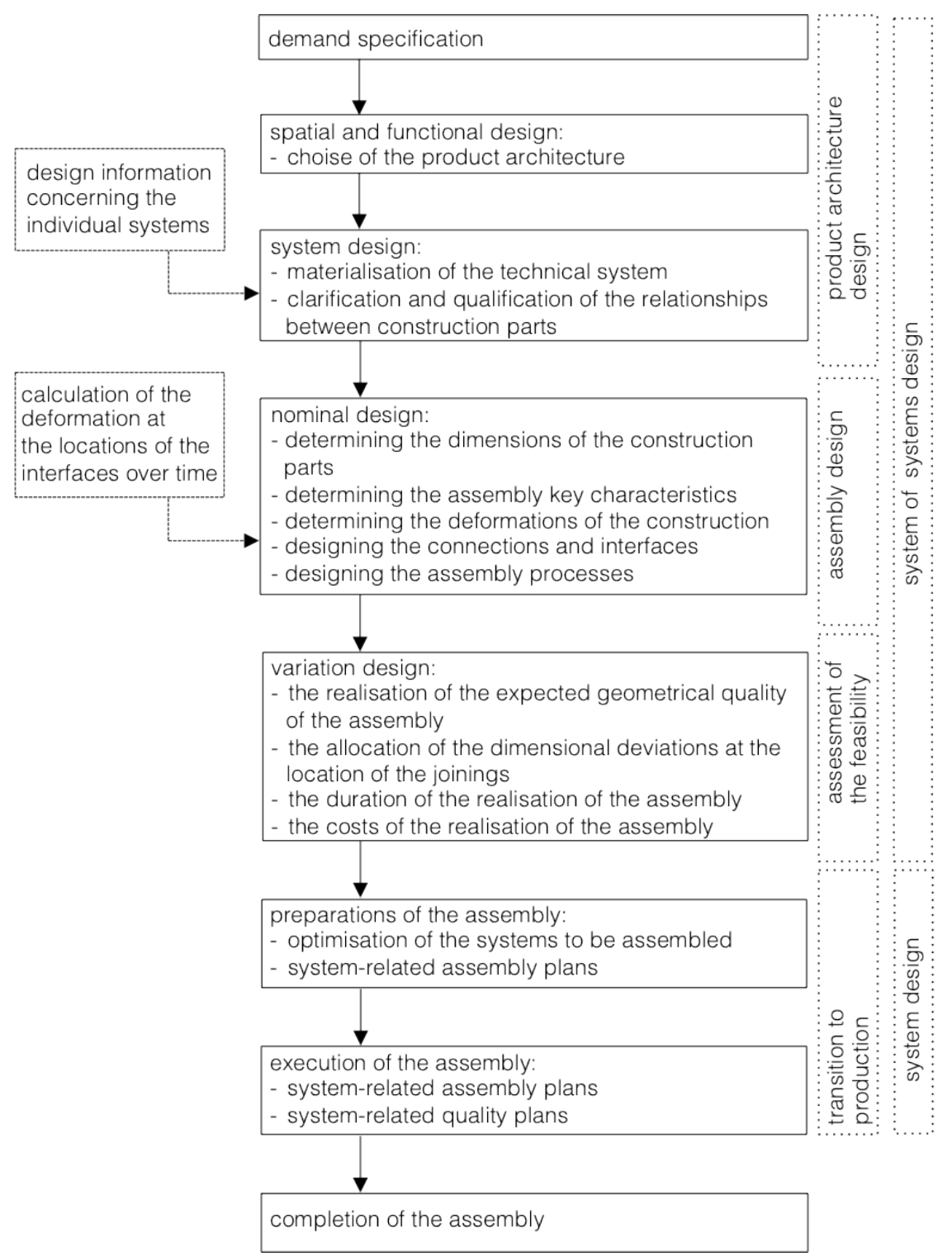

Figure 8.1: The process steps of the first draft of the design-for-assembly method 


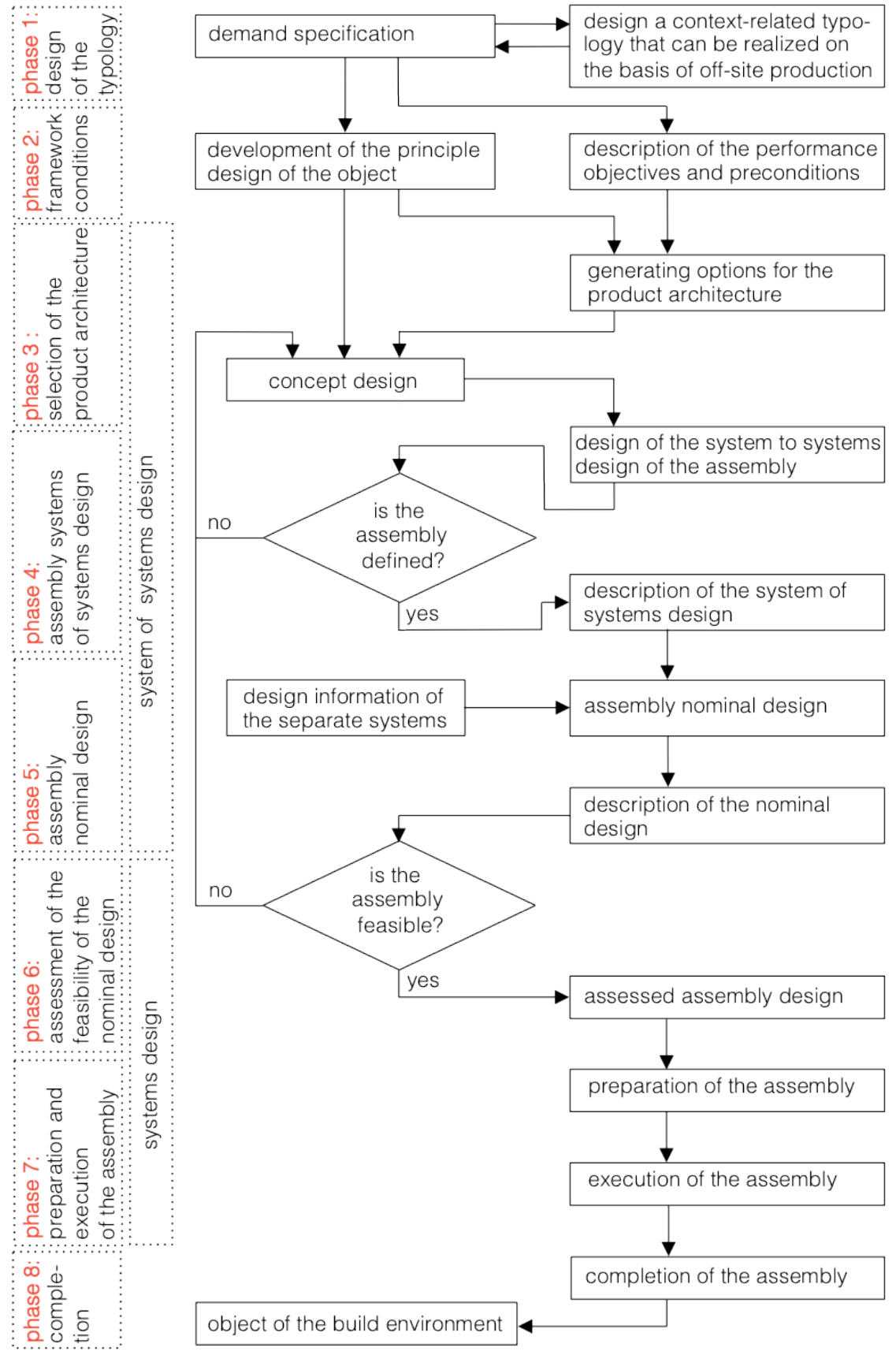

Figure 8.2: The final version of the design-for-assembly method. 


\subsubsection{Phase 1: Design of the typology}

In situations where integration within the context of a number of surrounding buildings or infrastructure objects is an aspect of the design intention, a typology of the object can be developed for the purposes of demand specification. This typology represents the composition of the systems to be produced offsite with which the new object can be put together. It can be represented using a morphological map [Boeijen et al., 2013]. For projects that involve the integration of objects in several contexts, the typology can be developed by combining the characteristics of the context and the systems to be produced offsite with which these objects can be put together. Again, this typology can be represented using a morphological map. The design of the typology is shown in Figure 8.3.

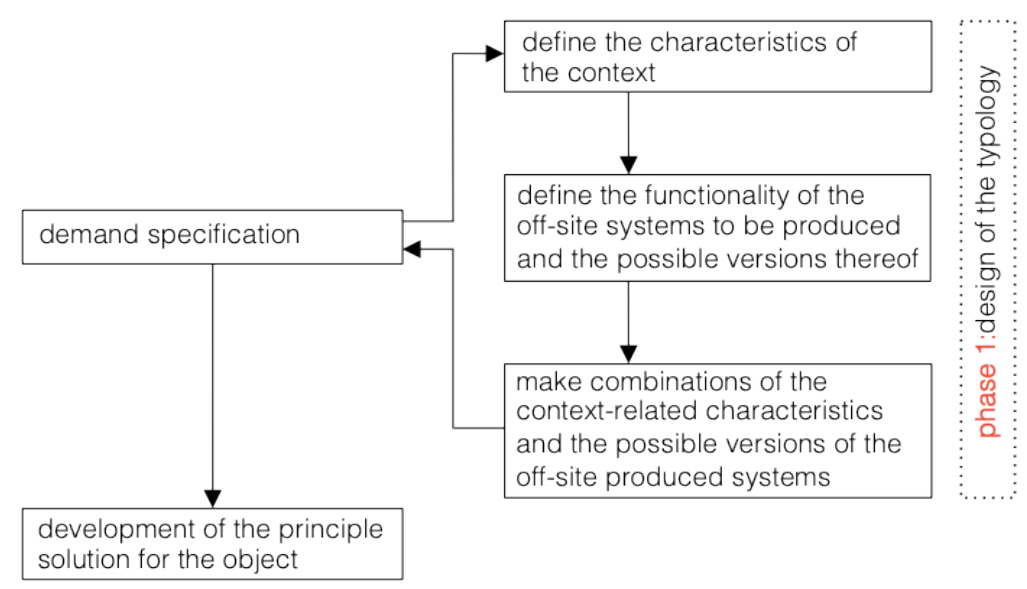

Figure 8.3: Design of the typology.

\subsubsection{Phase 2: Framework conditions}

Based on the demand specification, the performances to be realised with regard to the planning and associated preconditions can be determined for the assembly design. This can be done concurrently with the development by third parties of the principle solution for the object to be realised, see Figure 8.4.

In order to assess the applicability of the assembly approach for the object in question, the onsite logistical situation and the possible supply routes for construction parts that are produced offsite need to be described. This will reveal the maximum dimensions of the parts that will allow them to be brought in from offsite and manipulated at the assembly location in order to realise the assembly. To gain insight into the physical load-bearing capacity of 


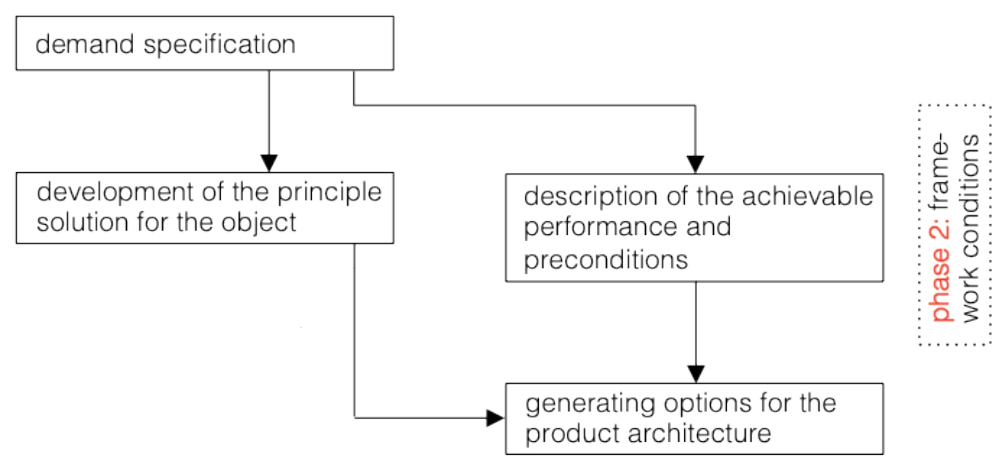

Figure 8.4: Framework conditions.

the construction site, information is required about the soil conditions and the possible availability of hard surfaces. It is then possible to determine what hoisting facilities and auxiliary structures can be utilised. It is essential to take account of possible long periods of rain, caused by climate change, leading to soft ground.

In order to comply with the acceptance plan described in the demand specification, it is desirable to already recognise at this stage those aspects that may be relevant for the design of the assembly. One example is a description of the relation between the realisation time and the value to be created.

\section{Design result}

In this phase, no decision about the application of construction parts that are produced offsite has yet been made. In order to make this decision, it is essential to have insight into the performance to be realised and the applicable preconditions with regard to location, foundation, realisation time and acceptance by the client. It is desirable to incorporate all the available information in the building information model.

\subsubsection{Phase 3: Selection of the product architecture}

Based on the principle solution (phase 1) and the modular or integral approaches selected for similar objects (phase 2), the options for the product architecture to be used can be identified and described. It is also advisable to consult other sectors, such as shipbuilding or the offshore industry, since this may bring fresh insights with regard to the assembly possibilities. By confronting the possibilities with the framework conditions, potentially promising options can be identified. The selection process for a product architecture is represented schematically in Figure 8.5. 
A value analysis conducted by a cost engineer (i.e. value engineering), can be helpful in the process of selecting the most promising options for the principle solution by identifying the product architecture. If there are no promising options, an alternative principle solution (phase 1) must be developed.

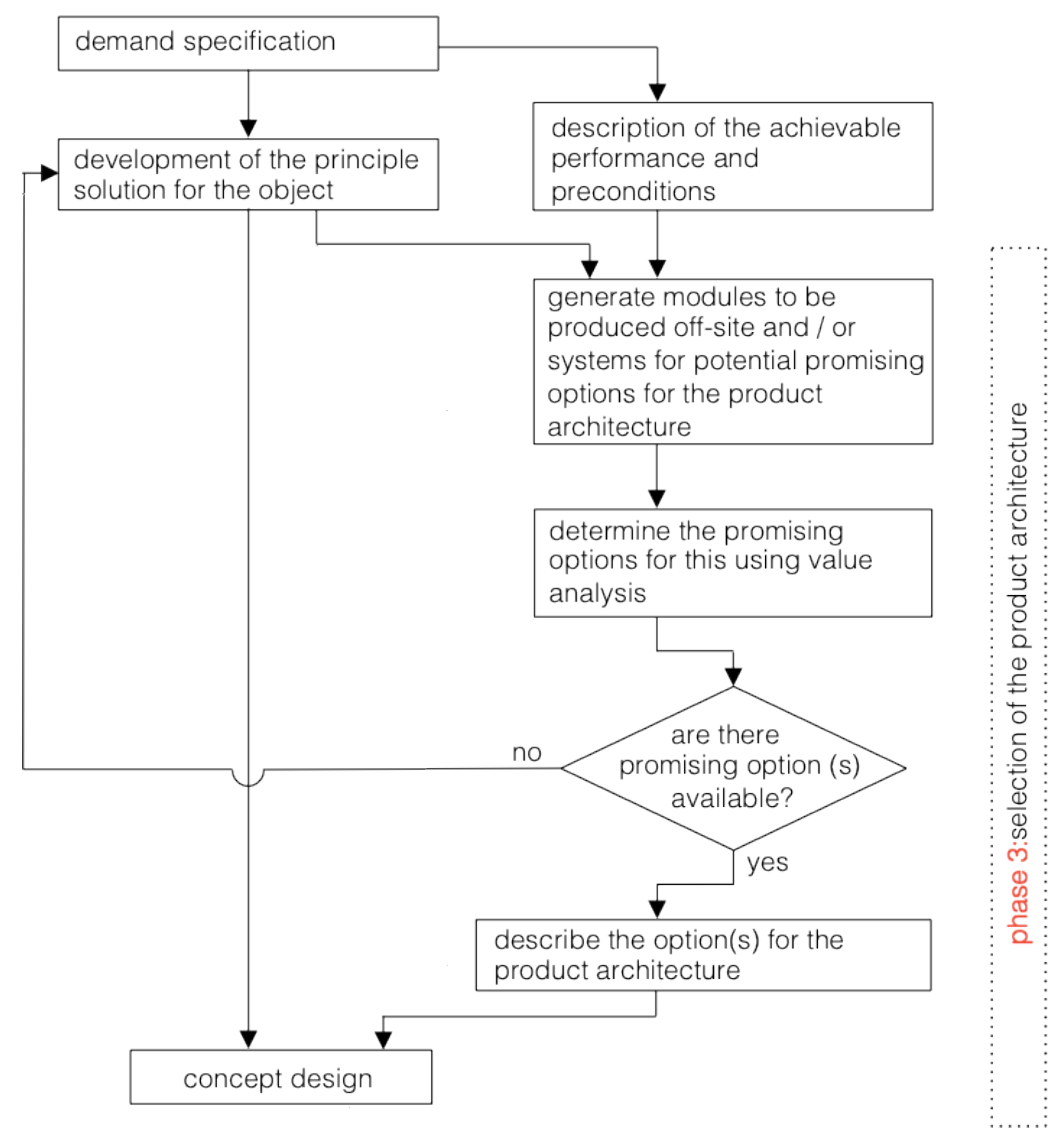

Figure 8.5: The selection of the product architecture.

The most promising options for the product architecture can be represented using a breakdown structure as represented schematically in Figure 8.6 [Eppinger et al., 2012]. As part of the breakdown structure, eligible assembly processes can also be described in a general manner. The promising options for the product architecture and the principle solution form the basis for the concept design. 


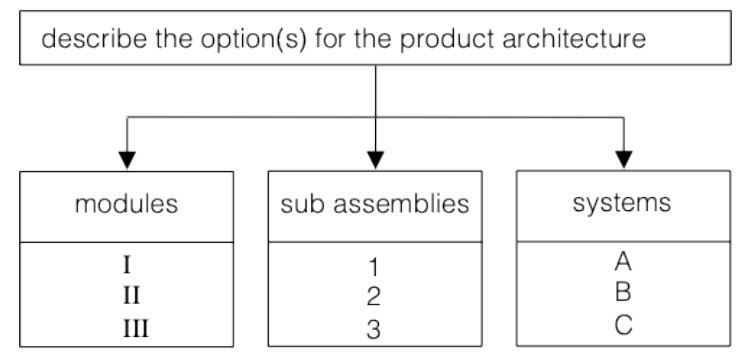

Figure 8.6: The most promising product architecture options.

\section{Design result}

This consists of the concept design, the promising options for the product architecture, the possible assembly processes and the framework conditions. A breakdown structure can be used to describe the product architecture options. The concept design should also provide information regarding the aesthetics of the joinings between parts. These can be represented more accurately using principle details.

\section{Bringing in the supplier chain or contractor}

Based on the choice of product architecture, suppliers, with or without the involvement of a system integrator, can continue to work on the design and the realisation of the assembly.

\subsubsection{Phase 4: Design of the system-of-systems assembly}

Using the system-of-systems design approach, one determines, based on the chosen product architecture and the framework conditions, which systems, produced offsite, can best realise the concept design. During the utility building case study (Chapter 6), the relevance of the system design in relation to the efficient assembly of the systems became apparent. The system design determines which sub-systems are applied, how these are delineated, the relationships between them, and the assembly's optimal sequencing. It was concluded in Chapter 6 that these are crucial aspects for the efficient assembly of objects in the built environment. As a result, these aspects are an explicit part of the system-of-systems design.

The primary question related to the system-of-systems design concerns the extent to which the concept design can be realised through assembly processes. The extent to which this is possible is largely determined by the required aesthetics of the joinings in combination with the system-of-systems design of the assembly. This became clear during the dwelling-transformation case study (Chapter 5). In this project, glass cladding was used to renovate bathrooms. Although the variations in the dimensions of the existing bathrooms were taken into account during the design and realisation process, the proposed assembly turned out to be unrealistic in practice. The intended solution of scanning each individual bathroom 
proved to be too costly. During the third case study of residential dwellings, it transpired that a system-to-systems interface had to be developed for the process of cladding bathrooms with glass elements to work. This interface was robust in terms of its ability to accommodate the variations in the dimensions of the existing bathrooms, which facilitated the efficient realisation of the required aesthetics of the joinings. This interface eliminated the need to scan all bathrooms, and measuring a small selection of bathrooms was sufficient. This robust solution made it possible to utilise the glass elements favoured by residents.

In a system-of-systems assembly design, it is therefore important to address the question of whether the assembly of a system is feasible given the desired aesthetics of the system-to-system joinings and any other preconditions.

In the system-of-systems design, the following topics should be covered and based on the chosen product architecture and the concept design:

Decomposition of the concept design.

Gathering information for the templates of the systems.

Preferred dimensions, continuity and delineation.

Optimisation of the sequencing.

System-to-system connections.

Feasibility of the assembly.

These aspects are represented schematically in Figure 8.7 and then described and explained.

\section{Decomposition of the concept design}

The first step consists of breaking down the concept design into systems for offsite production. Given that the concept design is based on a promising product architecture option, such a breakdown should be possible. Provided the breakdown results in functionally described systems, these then have to be materialised. For example, in the utility building project, this is reflected in the choice of a steel framework as the supporting structure.

\section{Gathering information for templates of the systems}

To realise the system-of-systems design, it is essential to have information about the systems that are described in the breakdown. In line with the "assembly-oriented design" approach used in designing industrial products, so called system templates can be drawn up for these systems [Demoly et al., 2009]. This process integrates the design of the product and the design of the assembly. As such, a template must contain all the information relevant to the assembly. An example template for construction systems is shown in Figure 8.8. 


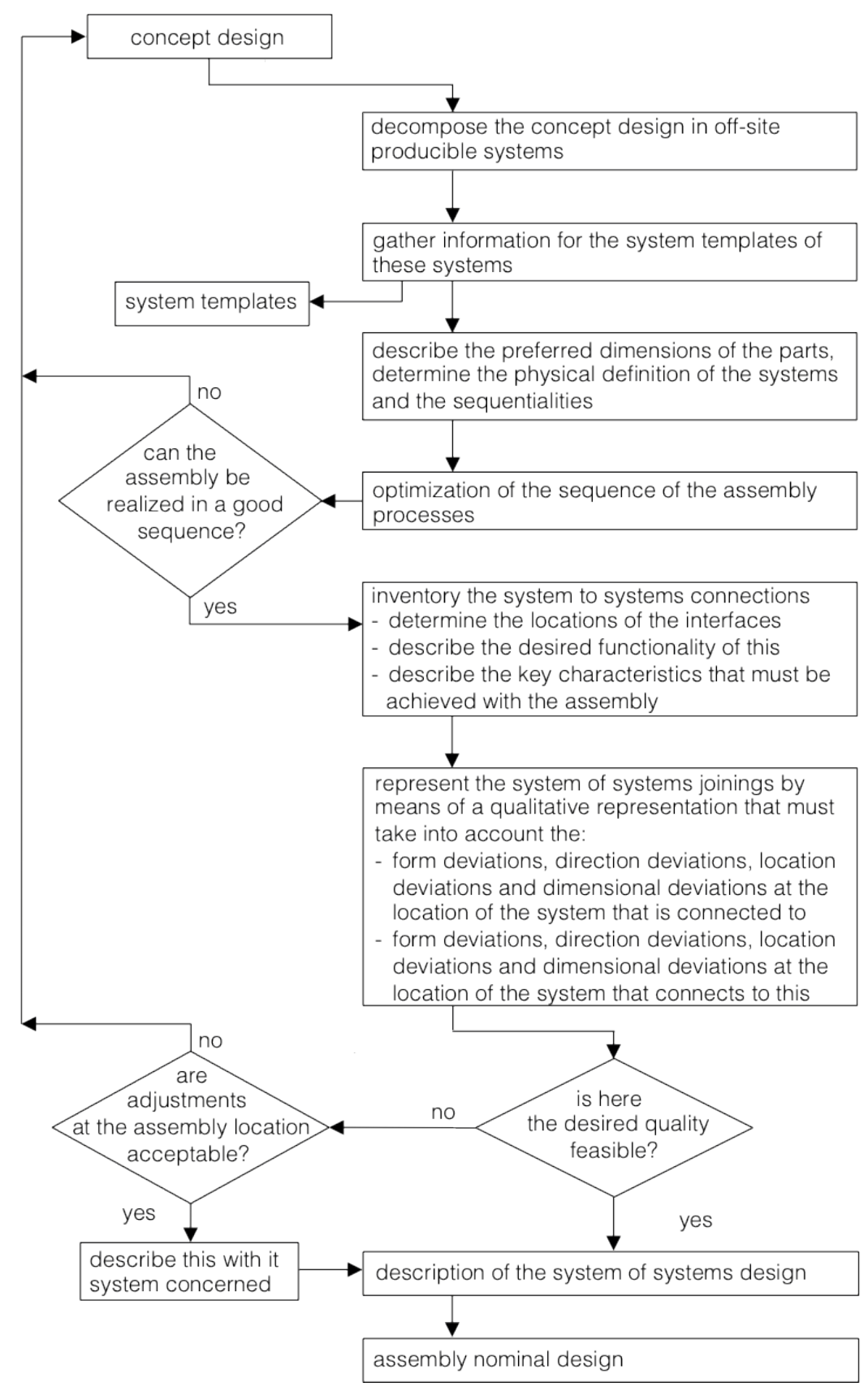

Figure 8.7: The system-of-systems design of the assembly. 


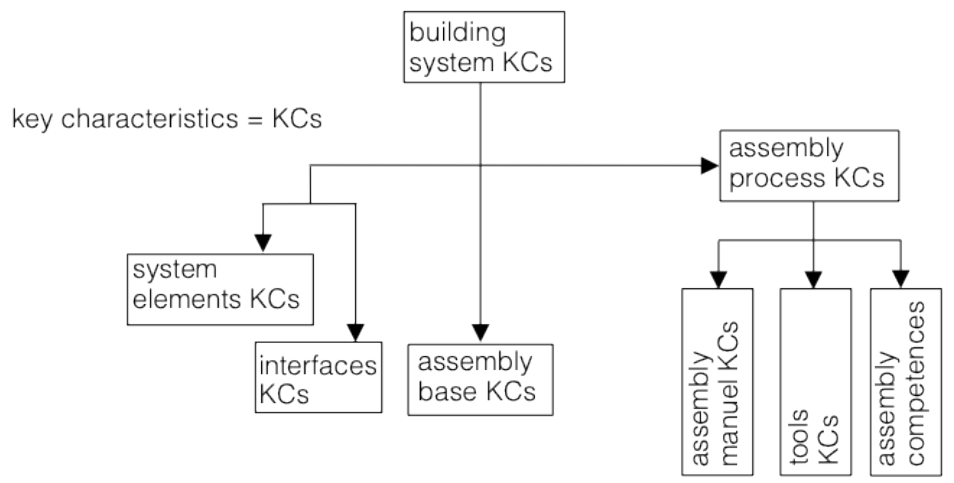

\begin{tabular}{|c|c|}
\hline 1 representation of the system (nominaal) & 2 assembly process \\
\hline $\begin{array}{l}\text { - based on the lack of dimensional } \\
\text { deviations in the elements, the geometry } \\
\text { of the 3-dimensional system boundary is } \\
\text { indicated in the as-built situation } \\
\text { - the critical points of the elements can be } \\
\text { defined }\end{array}$ & \multirow[t]{2}{*}{$\begin{array}{l}\text { - the dimensions of the elements desired } \\
\text { - tor assembly are known } \\
\text { assembled can be determined } \\
\text { - the positioning points can be determined } \\
\text { - the cycle time of the assembly is known } \\
\text { - a method for monitoring quality is } \\
\text { available }\end{array}$} \\
\hline 3 geometry and tolerances (as built) & \\
\hline \multirow{4}{*}{$\begin{array}{l}\text { - the system boundaries can be } \\
\text { determined in the as-built situation, } \\
\text { based on a certain flow-down, with } \\
\text { sufficient control over a 3-dimensional } \\
\text { reference frame, these relate to: form } \\
\text { tolerances, direction tolerances and } \\
\text { place tolerances at the lack of } \\
\text { dimensional tolerances of the elements } \\
\text { - the expected dimensional deviations in } \\
\text { the elements are known }\end{array}$} & \\
\hline & 4 attaching \\
\hline & $\begin{array}{l}\text { - there is information about stabilizing the } \\
\text { elements during assembly } \\
\text { - the location of the interfaces can be } \\
\text { determined } \\
\text { - the type of interface is known } \\
\text { - the quality of the assembly basis can be } \\
\text { determined }\end{array}$ \\
\hline & 6 facilities on location \\
\hline 5 delivery times and quantities & \multirow{2}{*}{$\begin{array}{l}\text { - information about the desired bearing } \\
\text { capacity of the location is available } \\
\text { - information about interim storage is } \\
\text { available }\end{array}$} \\
\hline $\begin{array}{l}\text { - information about delivery times and } \\
\text { quantities is available }\end{array}$ & \\
\hline
\end{tabular}

Figure 8.8: Example of a construction system template.

Creating a construction system template is seen as a way to gather all the information required for the application of a construction system that is produced offsite. Since this is not object-related, it is possible to draw on past experiences with a system and provide insight into the extent to which information is, or should be, available on a system. If the desired information is missing, this can be seen as a warning sign with regard to the controllability of the assembly process. The illustrated template includes six aspects that are explained in more detail below. 


\section{Representation of the system}

This concerns the representation of the system assuming no dimensional deviations in the parts and error-free assembly of the components. The position of the system in the three-dimensional space can be indicated based on the position of certain points on the individual components. These positions should refer to the as-built situation and these points are known as the critical points.

\section{Assembly process}

The efficiency of assembly processes largely depends on the number of cycles gone through and the duration of a single cycle. In this context, information about the desired dimensions and mass of the parts is desirable. The same is true for information about the positioning points, which can be used to facilitate the positioning of the parts. Information about the quality control to be executed at the system level must also be available and should describe how quality in the as-assembled situation can be assessed.

\section{Geometry and tolerances}

This information relates to the as-built situation. Dimensional, directional and positional deviations will occur as a result of the assembly process, as well as due to dimensional deviations in the parts themselves. It is desirable to describe these independently of each other in the template. When it comes to the manageability of the assembly, the aforementioned deviations must be described in relation to a certain flow-down. Among other things, it should indicate what measurement equipment is to be used during positioning and what competences are required of the assemblers. For the purposes of designing the assembly, it must be clear how the aforementioned deviations are expressed at the limits of a system. How vertical is a vertical system limit? How straight is a straight system limit? How perpendicular is a perpendicular angle? How accurate have the parts been positioned and attached, including in relation to each other? Based on this information, it is possible to define the system limits in relation to a three-dimensional system. The expected dimensional deviations can be indicated in relation to the positioning points.

\section{Attaching}

In addition to information on the interfaces, information about the assumed geometric variations at the site of the assembly base is also relevant since this is an important design aspect of the base.

\section{Delivery times and quantities}

The timely gathering of delivery-related information can prevent many problems. Trade products may not always be available in the quantities required.

\section{Onsite provisions}

Even though it may be assumed that a construction system will be assembled immedi- 
ately after its delivery to the construction site, it is advisable to anticipate the possibility of requiring intermediate storage. If such storage is required but not available, construction parts will be left around the assembly location. This results in a loss of quality with potential consequences.

\section{Preferred dimensions, sequencing and delineation}

The assembly processes for construction systems may be based on certain dimensions of the parts to be assembled. This aspect should be described in the template. When determining the sequencing, it becomes clear in what order the assembly can be realised. The system limits are clarified by indicating or describing the delineation between systems. This is particularly relevant when it comes to realising the system-to-system joinings and interfaces. In determining the sequences, it becomes clear in what order the assembly can be realised. The sequencing drawn up during this design phase is intended to be used as a starting point for its optimisation. The fragmentation of assembly processes should be avoided.

\section{Optimising the sequencing}

In the assembly of most construction systems, a crane and assembly teams with certain competences are utilised. Given that their deployment is costly, it is desirable to carry out assemblies in a sequential manner that avoids waiting times. In addition, it is desirable to avoid the realisation of small specialised assemblies using specially trained teams. To this end, it is advisable to simulate such assemblies in a stylised manner on paper. The information from the template, the preferred dimensions of the construction parts, the delineation and the sequential order that was drawn up earlier can all be utilised for this. This sequential order can be represented using the design structure matrix. An example of this is shown in Figure 8.9.
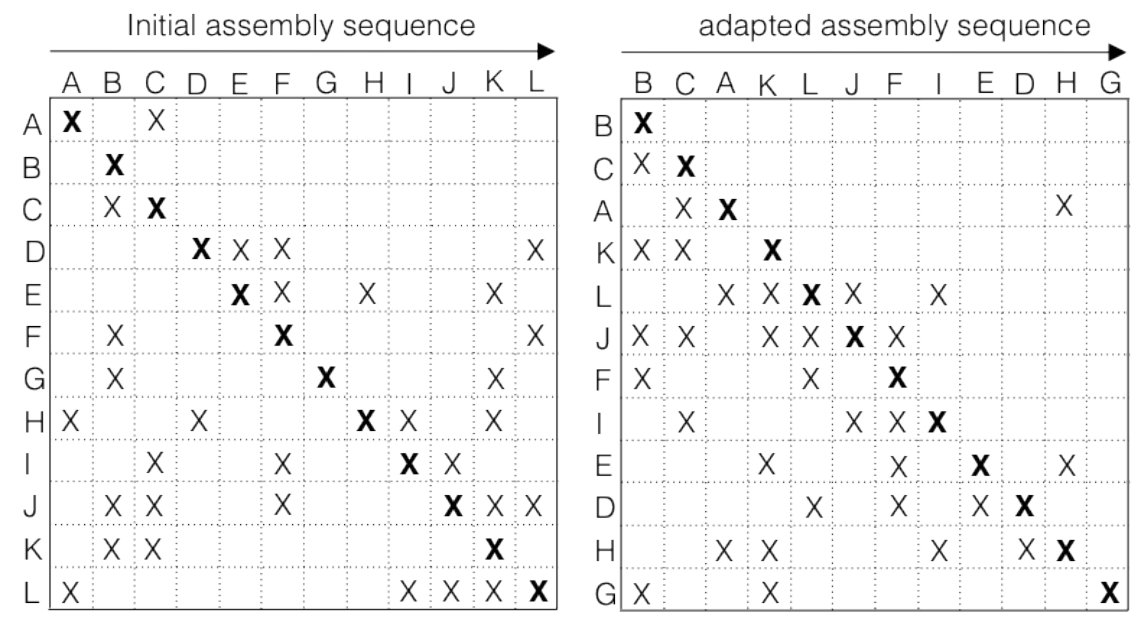

Figure 8.9: Optimising the assembly order using the design structure matrix [from Fine, 1998]. 
In the left-hand design structure matrix shown above, the initial proposed assembly order of the systems is shown both vertically and horizontally. Where there is some form of assembly relationship between systems, this is represented with an " $\mathrm{X}$ ". The actual assembly order is shown vertically. From the left matrix, it becomes clear that the assembly of system $\mathrm{H}$ is related to the assembly of systems A, D, I and K. However, I and K are assembled after $\mathrm{H}$ ! If these relationships have complications for the intended assembly process, it is worth considering rearranging the assembly order. In the right-hand matrix, the sequence of the assembly order has been optimised. A relevant example of where this approach is helpful was the European Medicines Agency building in Amsterdam, which was completed in 2019. In this twenty-storey building, the technical installations were projected for the fourth floor, so that they could be assembled during the assembly of the supporting structure.

Based on the optimised design structure matrix, it will also become clear whether it is possible to realise the assembly of each individual system in one continuous period and whether small specialised assemblies can be avoided. If it turns out that the assembly of a system is excessively fragmented and results in a significant decrease in productivity, it may be worth modifying the concept design. The goal is to be able to assemble each system without interruptions. However, it is also possible to view the assembly of a fragmented system as part of the assembly of a different system, thereby avoiding this loss of productivity. The latter approach was seen in the dwelling transformation case study (Chapter 5). The assembly of the interior systems was so fragmented that it was decided to have it carried out by multifunctional autonomous teams. This made the careful design of the assembly order less relevant.

\section{System-to-system connections}

After deciding on the assembly order, the system-to-system connections can be inventorised and the desired locations of the interfaces determined. Based on this inventory, the number of system-to-system connections can be optimised. The saying "less is more" usually applies. An example of a structure for which the number of system-to-system connections could be reduced by half is shown in Figure 8.10. The figure shows that both the lower and upper steel walkways are attached to the concrete structure. Based on design-for-assembly considerations, it would have been preferable to instead connect the lower landing to the upper landing. This would have replaced two system-to-system connections with two within-system connections. Within-system connections are generally far easier to realise than system-to-system connections.

In order to realise a system-to-system connection, the location of an interface must be chosen in such a way that the part to be added can be moved, with a crane if necessary, into the desired position based on the associated assembly process. The weight of the parts often makes it impossible to manually move them in a horizontal direction during the positioning process. The location of the interfaces must therefore be designed in such a way that the 


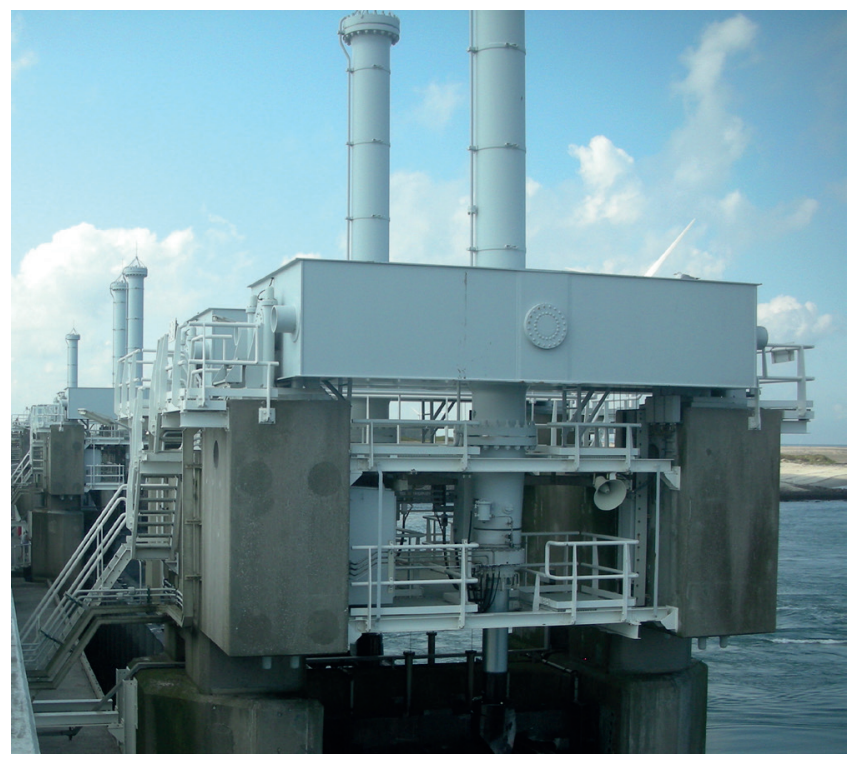

Figure 8.10: An excess of system-to-system connections.

horizontal movement of a heavy part is not necessary during positioning. This also facilitates the application of forced positioning. The desired functionality of the interfaces can be described in terms of the design. With this information, it is then possible to describe the quality of the assembly base to which this interface is attached in a qualitative manner.

\section{Feasibility of the assembly}

With the information that is now available at the system-to-systems level, the individual systems, including their limits in relation to the location of the connection of an interface or joining, can be represented in a qualitative manner. Following this, it can be assumed that the parts in question will be present at the assembly location and that they can be placed in the desired positions. With this representation, it is then possible to determine whether the chosen systems are also compatible with the specified system-to-system joinings. Systems are compatible if the key characteristics at the location of the system-to-system joinings can be achieved. This compatibility will be evident from confronting the system limits with the aesthetic requirements at the location of the joinings. The situation at the location of the system limits can be assessed based on the following information:

- The potential dimensional, directional and positional deviations present in the system to which a connection or joining must be made.

- The potential dimensional deviations of the system being connected or joined.

- The desired quality at the location of the connection or joining. 
The assessments are made using a simulation on paper of the object to be assembled. For this, the previously determined assembly order and the information from the templates can be used. During the simulation, it may become apparent that the positional and dimensional deviations at the location of a system limit are too great. In that case, it may be desirable to adjust the concept design or to carry out any necessary adjustments on site. This may involve the onsite fitting of components or the offsite production of parts based on measurements made on site. This issue proved highly relevant with the add-on façades described in the first case (Chapter 5). If all the add-on façades for an entire row of homes to be renovated are seen as a single system, "continuous joints" will be identified as a key characteristic. A consequence of this is that the frame joinings to the existing window frames were not realised through the assembly process but rather through carpentry. However, it would also have been possible to instead choose "window frame joinings" as the key characteristic, which would have resulted in non-continuous joints between the individual homes. The choice made also depends on the assembly processes, the robustness of the joinings and, of course, certain aesthetic considerations.

\section{Design result}

In addition to the concept design, the chosen product architecture and the framework conditions, the following components can be added to the building information model:

The design structure matrix.

Information about the sequence of the assemblies.

The construction system templates.

Information about the mass and preferred dimensions of the system components.

A quantitative description of the key characteristics of each system and of the system-to-system connections and joinings to be realised.

Principle details of those joinings that pertain to the tectonics.

For each system, the general position of the interfaces for realising the system-to-system connections.

The need to allow for some onsite, non-assembly activities for certain systems.

\section{Bringing in the supplier chain of contractors}

When gathering information for the construction templates, it will become clear whether sufficient information is available about a system to facilitate the design of the assembly. If this is not the case, it may be a reason to bring in a supplier chain or a supplier for the system design of the system in question. Suitable suppliers can also provide validated quantitative information about an assembly that is represented with a certain flow-down. A supplier that can only provide information about the manufacturing aspects of a system is not an appropriate choice when seeking information for a construction system template. Based on the finished system-to-systems design, suppliers, with or without the involvement of a system integrator, can work on the design and the realisation of the assembly. 


\subsubsection{Phase 5: Nominal design of the assembly}

The input for the nominal design phase consists of the framework conditions, the concept design, the construction system templates, the system-to-systems design and the design information about the dimensioning of the individual systems. The following principles apply in establishing the nominal design of the assembly:

The dimensional deviations of the parts are negligible.

The assembly processes are carried out in such a way that the construction parts are positioned and attached at the theoretically determined positions.

The nominal design of the assembly can therefore be realised in a value-oriented manner based on functional considerations. Up to, and including, the system-to-systems design, the key characteristics to be realised, including those of system-to-system connections and joinings, are only qualitatively described. In the nominal design, these must be quantified each system in the as-built situation based on functional considerations. The quality of the system-to-system joinings to be realised must also be specified.

Given the aforementioned principles, the influence of the parts' key characteristics in terms of their dimensional deviations, the assembly process's key characteristics and the key characteristics of the assembly base are all negligible in the nominal design. As was addressed in Section 4.6, the key characteristics of a product's interface can be chosen in such a way that they compensate for any dimensional deviations in the parts and any dimensional deviations that occur at the location of the assembly base as a result of the assembly process. In order to develop the nominal design in accordance with the system-of-systems approach, the nominal design can be done on an individual system basis. The ordering can be derived from the design structure matrix. The items and activities covered in the nominal design are shown in Figure 8.11 and then described in turn.

The nominal design of the assembly of a system starts with the quantitative description of the key characteristics that have to be realised at the system and the part levels, as well as those at the location of the system-to-system joinings. Next, the required position of these components in the as-built situation must be determined, along with the so-called critical points that can be used to position these components. Based on this information, and the dimensioning of the system parts, the nominal dimensions of all the parts can be determined.

In order to attach the parts using the interfaces, the locations of these interfaces are then determined. In order to determine the adjustment space of the interfaces, information about the assembly key characteristics at the location of the mounting of the interfaces is required. This information can generally be derived from the available construction system template. 


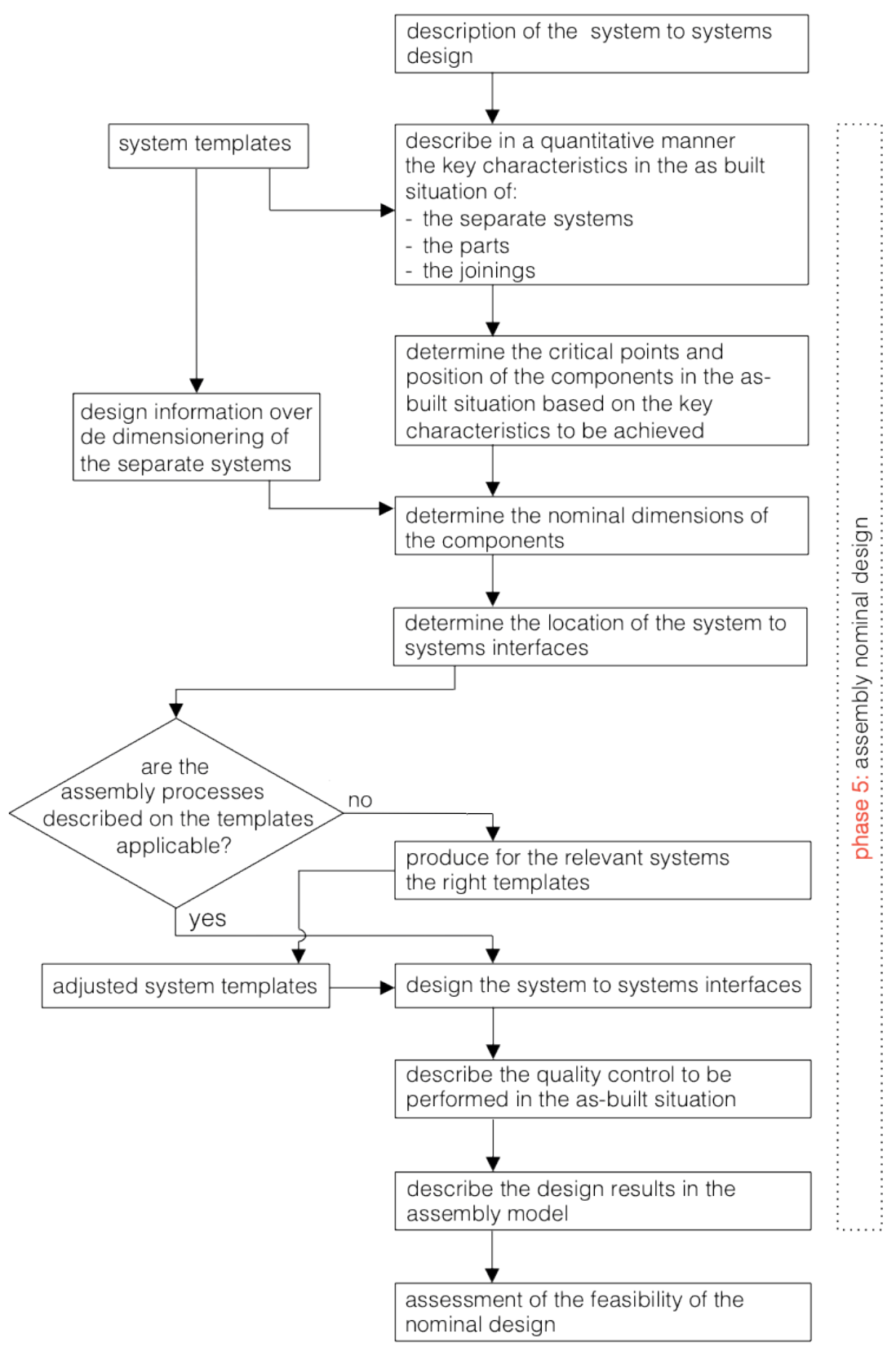

Figure 8.11: The nominal design of the assembly. 
Since it is possible that the design of a system is no longer fully in line with the template that was used previously, it is desirable to first determine whether the templates still match the design. If this is not the case, the templates in question need to be replaced with updated versions since it is not possible to design the assembly of a construction system without accurate templates. If these are available based on the desired process feasibility ( $\mathrm{Cpk}$ ) of the assembly processes, the assembly key characteristics in question can be estimated and the interface designs can be completed.

Since assembly is only possible when the systems to be assembled meet the specifications, it is necessary to verify the geometric quality of an assembled system. In other words, the realisation of the key characteristics must be verified. Since this is one of the aspects of a construction template, a method for doing so will be available.

\section{Design result}

With regard to the design of the assembly, the following information will be available for each system upon completion of the nominal design:

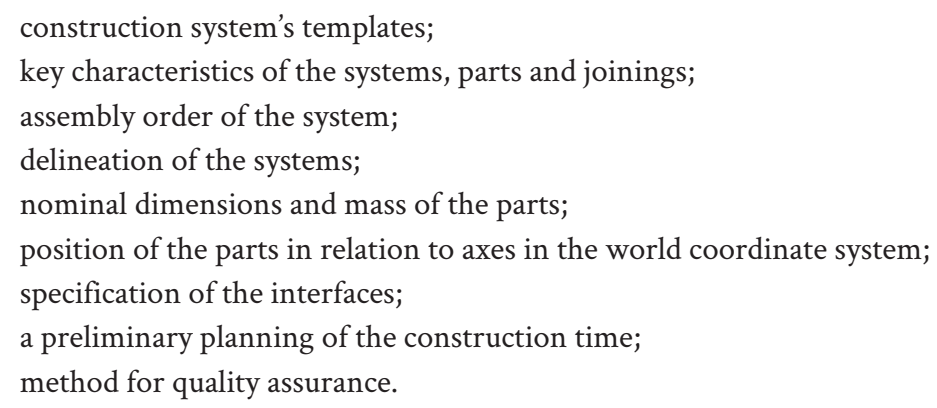

The nominal design can be represented using a three-dimensional representation of the building information model. The information that is relevant for the assembly, such as the construction system templates, can be linked to the parts as non-graphical information.

\subsubsection{Phase 6: Assessment of the feasibility}

Assessing the feasibility of the assembly's nominal design involves determining to what extent the key characteristics of the systems can be realised based on the nominal design. The deformations that occur over time and all sources of geometric variations that affect the object's key characteristics need to be taken into account. This means that information about the deformations that will occur must be available. 
To determine the deformations, the nominal dimensions can be used. The sources of geometric variation are:
Dimensional deviations in the parts.
Dimensional deviations in the assembled systems resulting from the assembly processes.

The ideal method for assessing the feasibility would be to conduct a test assembly of the object to be realised. However, this will rarely be possible. Alternatively, a pragmatic simulation of the assembly or parts thereof can be conducted. Given the spatial nature of the objects in the built environment, this validation should generally be conducted in three-dimensional space. The relevance of this approach became apparent during the utility building case study (Chapter 6).

Based on the nominal design, it is now clear which systems must be assembled, in what order these are to be realised and what assembly processes will be utilised to do so. In terms of the assembly processes, one needs to know which combination of the parts' key characteristics and the assembly process's key characteristics result in the system's key characteristics. The assembly process's key characteristics in particular should be based on a process feasibility ( $\mathrm{Cpk}$ ) of at least one. If this is not the case, the pragmatic simulation cannot be considered an appropriate assessment of the design. This also applies to the cycle times that are used to assess the realisation speeds of the systems.

In order to determine the geometric positioning of the assembled systems, a simulation is conducted in the time domain. To assess the feasibility of the assembly processes, possible obstacles such as hoisting facilities and the scaffolding that may be being used are taken into account. It is then possible to determine whether the proposed hoisting paths are available and whether there is enough space to manoeuvre the construction parts to the vicinity of their assembly location.

The simulation can be conducted in a pragmatic manner by combining the deformations of the structure over time with the positional deviations that occur as a result of the assembly process. During the pedestrian bridges case study (Chapter 7), it became clear that construction parts that are produced off site may be subjected to different forces during assembly than during the manufacturing process. As a result, the product dimensions during assembly may deviate from the specification. The simulation must provide information on the geometric effects of deformations and all sources of geometric variation at the locations of the attachments of the interfaces. In principle, the information used for this should be substantiated empirically. Unfortunately, this is not always possible. If this information is missing, then values may be derived from a flow-down. Such values may be derived from the tools used for the positioning and from the control measurements that are conducted after a part has been assembled. If the realisable key characteristics are derived entirely from 
a flow-down, the process for taking control measurements should be described as part of the assembly model.

During the simulation, the following aspects will be assessed in the time domain:

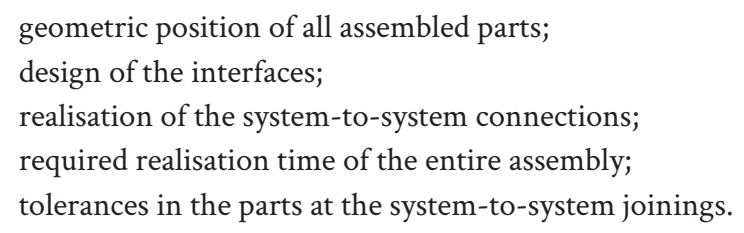

The assessment of the feasibility of the nominal assembly design is represented schematically in Figure 8.12 and the aforementioned five aspects are then covered in more detail.

\section{Assessment of the geometric position of all the assembled parts}

The geometric position is assessed based on the expected position of the systems and components once they are realised in the as-built situation. This shows whether the product and/or system key characteristics are realised. In principle, these were already formulated when designing the assembly. In practice, there will be surprises when it comes to realising these positions in the as-built situation. For example, the expected vertical deformation of structures over time is often not recognised as a key characteristic of the design, only for it to prove an issue when realising an assembly. It is also possible for the dimensional deviations of the supporting structure to be more critical than expected.

If it transpires that the geometric position of an assembly will not meet the key characteristics, and it is not possible to resolve the issue by monitoring the dimensional deviations that occur, it is advisable to modify the system design. Possible measures that could be taken are described in Section 4.7.

\section{Assessment of the design of the interfaces}

The simulated locations of the attachment points for the interfaces can be assessed by comparing them to the previously determined desired positions. If these are such that the room for adjustment of the interfaces is inadequate, one might decide to adjust the nominal design with regard to the interfaces or the design of one or more systems.

\section{Assessment of the realisation of the system-to-system connections}

If it is concluded that the adjustment space for a system's interfaces is adequate, the parts in question can generally be put in their desired position. It should then also be possible to realise the desired system-to-system connections, the so-called nodes. These nodes must be able to accommodate the dimensional deviations in the parts. Based on the position points, it will be clear where these deviations will occur. For each part, sufficient three-dimension- 


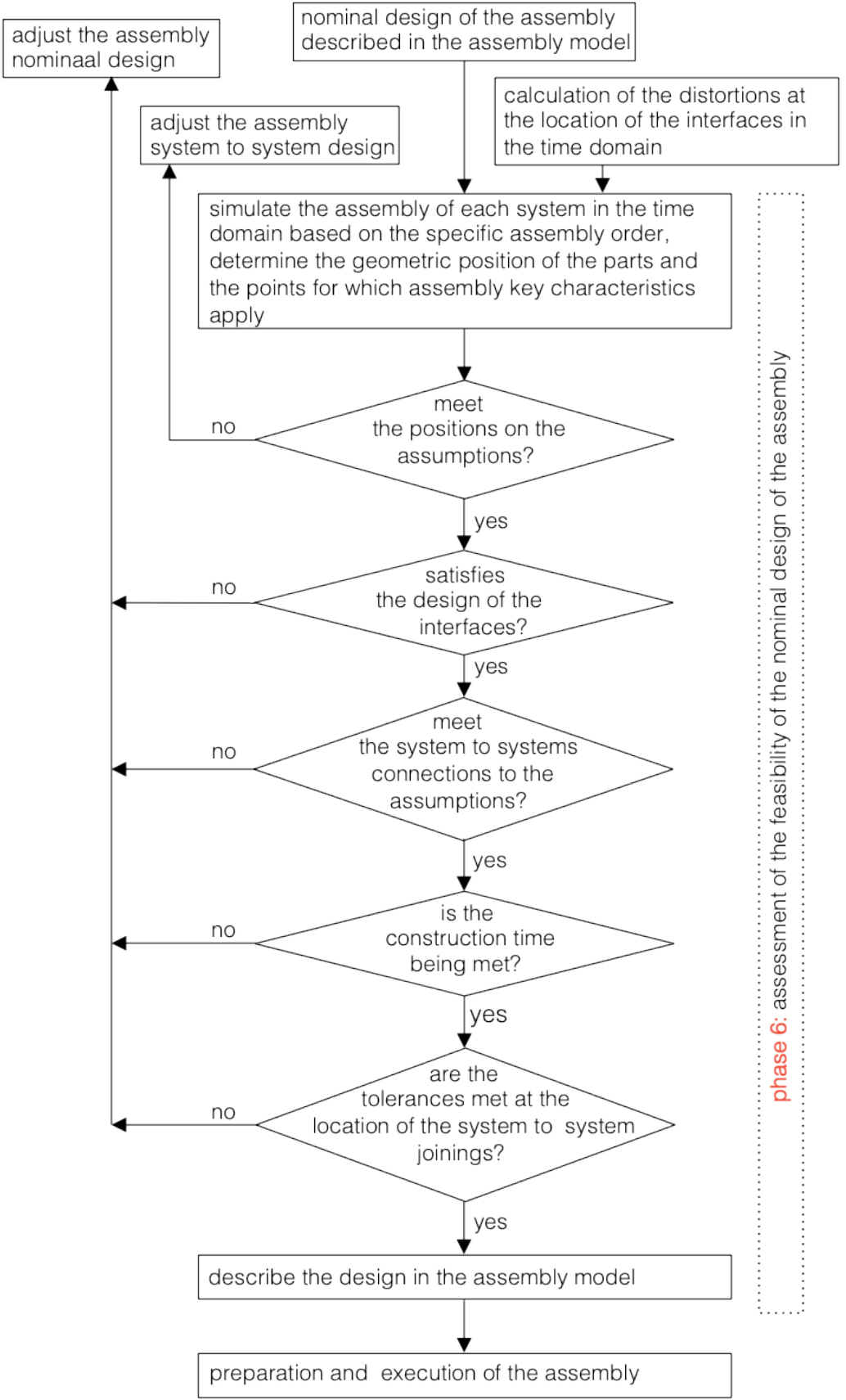

Figure 8.12: Assessment of the feasibility of the nominal design of the assembly. 
al space must be reserved to allow it to fit after accounting for the expected dimensional deviations. Given the nature of the assembly and manufacturing processes, it cannot simply be assumed that these will be evenly distributed. If the nodes appear inadequate, one should seriously consider modifying the nominal design.

\section{Assessment of the required realisation time of the entire assembly}

Based on the conducted simulation, it is also possible to predict to a certain extent the assembly times of the individual systems and of the entire assembly. The extent to which this is feasible is largely dependent on the robustness of the design with regard to the accommodation of deviations in the delivery times of parts and the cycle times of the assemblies.

\section{Assessment of the tolerances in the parts at the system-to-system joinings}

The final stage of the assessment addresses the allowable dimensional deviations of the parts at the location of those system-to-system joinings that have to meet certain aesthetic requirements. These must be greater than the tolerances of the relevant parts insofar as these manifest themselves at the location of these joinings. If such a connection is inadequate, it is again desirable to modify the nominal design.

\section{Design result}

Through assessing the feasibility of the nominal design, the possible risks involved in its realisation have been estimated. These can be derived from the additional operations that are expected to perform the assembly based on the used process capabilities. If it is decided to realise the actual assembly based on the assessed design, it means that these risks are accepted. The decision whether to accept the risks boils down to balancing the costs associated with reducing these risks against the possibility of reworking and waste management costs. However, there will always be ways to minimise the risks such as conducting trial assemblies or taking control measurements.

The assessment of the feasibility of the assembly nominal design, the expected deformations, the construction system templates that are used and the process feasibility to be realised can all be incorporated in the building information model. Provided the design is deemed feasible, the design of the assembly is complete. All the information acquired during the entire process, from the demand specification to the tested nominal design, then forms the assembly plan. The building information model can be used as a framework for this.

\section{Bringing in the supplier chain or contractor}

Based on the assessed nominal design, suppliers, maybe with the additional involvement of a system integrator, can continue to work on the preparation and realisation of the assemblies. 


\subsubsection{Phase 7: Preparation and execution of the assembly}

Section 4.9 provided an overview of the contents of an assembly plan for a construction system to be assembled. After the assessment of the design of the assembly, all the information required is now available in the building information model. During the series of case studies, it became clear that the following aspects deserve specific attention during the preparation and realisation of the assembly:

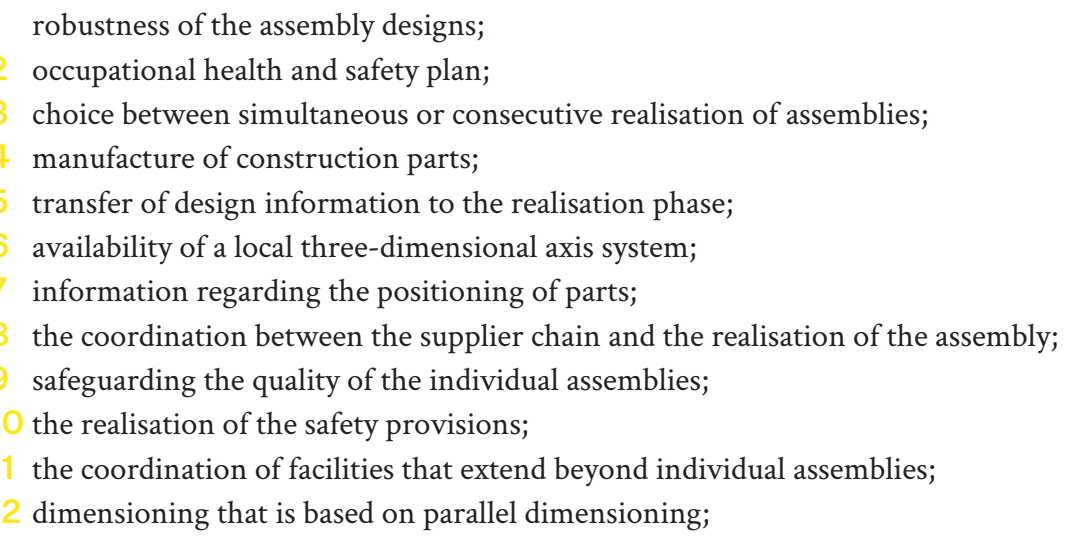

Each of these aspects is explained more in detail below.

\section{The robustness of the design of the assembly}

In the described method, the robustness of the design with regard to the quality to be realised is related to the sensitivity of the as-built object to geometric variations caused by dimensional deviations in the parts and the assembly processes. During the utility building case study, it became clear that the design was not sufficiently robust with regard to delivery times of initially unforeseen deliveries of construction parts. These were necessary because some construction parts became unusable during the assembly process and had to be remade. It is advisable to ensure that the assembly design has some robustness with regard to this aspect.

\section{The occupational health and safety plan}

During the utility building case study, the health and safety plan was not produced until after the assembly had already begun. With the proposed design method, it is possible to realise this plan during the system design stage. This then makes it possible to allocate responsibilities during the design phase with regard to later realising the assembly. This benefits the safety of the assembly. 


\section{The simultaneous or consecutive realisation of assemblies}

It is customary for multiple parties to work alongside each other when realising an object in the built environment. In an assembly process, this does not necessarily optimise the time required for its realisation. In the utility building case, it was decided to consecutively realise the assemblies. This allowed the parties involved to optimally prepare for and execute their activities. Furthermore, there were no waiting times resulting from the unavailability of the crane due to it being used by others.

\section{The manufacture of the construction parts}

The design-for-assembly approach is centred around an efficient assembly process that utilises construction parts that are produced off site. There is no specific focus on limiting the number of deviating construction parts. As a result, there may be marginal differences between notionally identical construction parts. It is often possible to replace a number of these with one version thereof.

In a sense, this utilises the platform approach. This will benefit the efficiency of preparing the assembly, the manufacture of the parts and the assembly itself.

To facilitate a smooth assembly process, it is desirable that construction parts in which no orientation is clearly visible to the assemblers are symmetrical. This prevents the construction parts being incorrectly positioned. If it is not possible to manufacture these parts in a symmetrical manner, there must be a simple way for the assemblers to determine the correct orientation of the parts. The tools used for this purpose are often clear to the designers, but not to the assemblers. The latter can be insufficiently equipped to recognise the identification methods for parts despite this being clear to the designers during the design phase. For example, grid lines are often indicated on drawings but not present in reality.

\section{The transfer of information between design and realisation}

As part of the design, the points through which a construction part is positioned are determined. These points are called positioning points and are derived from the critical points. If these are met, the key characteristics are realised. Further, this also determines which joinings have to accommodate the inevitable dimensional deviations in the construction parts. It is necessary to take this information into account when preparing the assembly instructions since, otherwise, it will not be clear where the dimensional deviations will appear. This can be achieved by only indicating the position of a construction part, in the relevant orientations, by a single measurement in relation to a geodetic datum. The use of two measurements leads to confusion and the assemblers may evenly position the part between the positioning lines.

\section{The availability of a local three-dimensional axis system}

It is common practice to install a local three-dimensional axis system at a construction site. However, during the execution of the assembly, it is often not immediately visible/ 
accessible. The consequence is that the assembling parties will install local systems without reference to this universal referencing system leading to incorrect positioning of construction parts and this needs to be avoided.

\section{Information regarding the positioning of parts}

The drawings that are used for the assembly generally feature an orientation. A representation of the object to be realised is positioned in relation to the existing environment. At the start of an assembly project, this is often not visible to the assemblers. As a result, parts may be assembled in the wrong position. Furthermore, the information used for positioning is also based on the availability of grid lines with corresponding numeric indicators. However, neither these lines nor their indicators are visible at the assembly site. Consequently, as the assemblers want to get their job done, construction parts are positioned in relation to previously positioned parts. This method is sometimes even facilitated by the necessary measurements being present on the provided drawings. Unless it is certain that this method will not compromise the manageability of the assembly in question, it should be avoided by producing unified information that the assemblers can rely on. This means that the position of construction parts should be clearly determined in relation to a geodetic datum that is present and accessible on the site.

\section{The coordination between the supplier chain and the realisation of the assembly}

The design of the assembly process is based on the time available for its realisation. The assembly times for the individual assemblies are then based on this. In order to realise these, the activities of the supplier chains must be tailored accordingly. If it is not possible for the delivered components to be assembled immediately, a facility for intermediate storage must be available. Given that storing construction parts at the assembly location often results in a loss of quality, this should not be the preferred solution. However, if such a storage option for such eventualities is not planned, construction parts that cannot yet be assembled for whatever reason will end up strewn about the construction site to their detriment.

\section{Safeguarding the quality of the individual assemblies}

In order to monitor the progress and quality of the overall assembly, it is desirable to safeguard the process at the system level. The quality realised should not be dependent on the competences of the assembler or supervisor. To ensure the progress of the assembly, one has to systematically safeguard the realised key characteristics. This approach to quality assurance can also be used when transferring the object to the client.

\section{The realisation of safety provisions}

Depending on the object to be assembled, specific safety provisions must be in place. These are often required for the assembly of a given system. These should be identified as part of the assembly design so that they can be immediately installed during the assembly process. In one of the case studies, the intended safety provisions were largely overlooked. 


\section{The coordination of facilities that extend beyond individual assemblies}

Even if the systems are assembled in a sequential manner, there will be facilities that are relevant to multiple individual assemblies. Examples include terrain hardening, site security and the installation of an adequate local three-dimensional axis system that can be used for positioning individual assemblies. The companies involved need to determine which facilities are generic and which can be seen as system-specific. An example of the latter is the disposal of packaging materials, whereas the development of a usable geodetic datum is an example of the former.

\section{Dimensioning based on parallel dimensioning}

In the construction sector, it is common to utilise so-called chain dimensioning. Additionally, the positions of some construction parts may also be derived from the position of other parts. Both approaches should be avoided. That means no chain dimensioning and, instead, construction parts should be clearly positioned based on the local three-dimensional axis system. Although the positions of construction parts are generally indicated on drawings in relation to grid and bay dimensions for the purposes of assembly, these tend not to be visible at the assembly location. To sum up, when developing the plans for the assembly of systems in the built environment, parallel dimensioning should be used based on the clearly visible geodetic datum that is already in place or can be installed. This will avoid the accumulation of geometrical deviations.

\subsubsection{Phase 8: Completion of the assembly}

This takes place based on the provision of reports on the realised key characteristics of the assembly. The structure of such reports should be specified as part of the construction system templates.

\subsection{The design-for-assembly method and its potential applications}

The described method can be used for the design, optimisation and realisation of an assembled object in the built environment and in both renovation and new construction projects. Its applicability is particularly suited to those parties who are regularly responsible for, or have a stake in, the efficient realisation of objects in the built environment that have a product architecture that is based on the assembly of construction parts that are produced off site. This could be relevant for the developer of business offices, of corporate housing, an architectural firm, a public sector principal or a provider of residential properties. Following this approach, these parties could develop a design-for-assembly for the objects they wish to realise. In doing so, they can identify the products' relevant key characteristics and develop 
feasible assembly key characteristics in close cooperation with the building contractors.

For companies that develop, manufacture and realise systems for use in the built environment, the method creates opportunities to develop their approach further and optimise it with regard to costs and quality. To do so, these parties need insight into the key characteristics that are relevant for their clients, as well as the processes through which these are realised. In the case studies, it became clear that such insights into the key characteristics are not always available, and that the manufacture and assembly processes are not always controlled in an integrated manner. Companies often do not know to what extent the geometric variations seen in the as-built systems are a consequence of the method of manufacture, the assembly process or a combination of both. Here, the design method provides guidelines to determine the sources of geometric variations in the as-built situation.

\subsection{A validation of the developed design-for-assembly method}

In order to determine the practical relevance and applicability of the proposed design method for construction assembly, three three-hour expert workshops were organised. In total 30 experts participated in these three workshops. Each workshop had a different focus. The focus of the first workshop was on assembly in the residential construction sector, the second workshop focused on assembly in the non-residential construction sector and the third discussed the assembly of infrastructural projects. The participants in the respective workshops are listed in the Appendix. During the workshops, the experts were first informed through an oral presentation that included practical examples about the substance and process steps of the developed design-for-assembly method. The presentation for each workshop was tailored to its specific focus. During and after the presentation, questions from the experts about the method were answered. The clarification and answering of questions was followed by an open discussion about the added value of the proposed design method. Finally, the experts were asked to complete a questionnaire to evaluate the developed design-for-assembly method. The experts were also asked to indicate if there were any aspects that required modification and/or further clarification. In addition to this written qualitative evaluation, the experts were also asked to provide a score based on two statements:

The assembly of the objects in question can be designed.

The developed design method can be used for the design of these objects.

In Sub-sections 8.7.1 to 8.7.3, the backgrounds of the 30 experts that attended one of the three workshops are provided, along with the results of the evaluations, the experts' proposals for modification or further clarification of the method, and an overall conclusion. 
Sub-section 8.7.4 concludes the chapter with a description of the development of context-based design methods for assemblies. The experts' remarks with regard to the modification or further clarification of the design method are also discussed.

\subsubsection{From building to assembling in residential construction}

\section{The participants in the workshop}

Ten experts from the residential construction sector took part in this workshop. Table 8.2 shows the background of the experts and the number of organizations concerned.

Table 8.2: Backgrounds and numbers of the experts of the workshop on residential construction.

\begin{tabular}{|lc|}
\hline organisations & number of participants \\
\hline contractor for the development and construction of homes & 3 \\
design office for architecture & 3 \\
consultancy company for constructions projects & 1 \\
supplier of insulated structural panels for walls and roofs & 1 \\
education and research & 2 \\
\hline
\end{tabular}

The results of the workshop on "From building to assembling in residential construction". Table 8.3 shows that most of the experts in this workshop were positive about the applicability of the developed construction assembly design method for the residential construction sector.

One participant, a supplier, has some reservations with regard to the use of the assembly method. This may have had something to do with that supplier's position in the supplier chain. As a producer of generally applicable building parts, this supplier has no direct stake in a stronger focus on a design-for-assembly approach.

Suggestions made for improving or clarifying the design method were:

- More depth is desirable with regard to the role of the project client and that of municipalities and their aesthetic committees in the process (contractor).

- I hear a lot about dimensional deviations and little about the standardisation of dimensions. This is necessary for an economically sufficient scale. More attention is needed to the way in which this method can be applied in the fragmented process involving forms of long-term cooperation (consultant). 
Table 8.3: Evaluation scores for the two overarching statements during the workshop on residential construction.

\begin{tabular}{|l||l|l|}
\hline evaluation criteria & $\begin{array}{l}\text { scores on the statement: } \\
\text { The assembly of houses } \\
\text { and residential buildings } \\
\text { can be designed. }\end{array}$ & $\begin{array}{l}\text { scores on the statement: } \\
\text { The design method can } \\
\text { be applied to the design } \\
\text { of the assembly of } \\
\text { houses and residential } \\
\text { buildings }\end{array}$ \\
\hline totally disagree & 0 & 1 \\
\hline mostly disagree & 1 & 0 \\
\hline neither agree nor disagree & 0 & 1 \\
\hline mostly agree & 3 & 4 \\
\hline totally agree & 4 & 2 \\
\hline
\end{tabular}

Freedom of choice for clients and customers: that must be clearly communicated to the client, end-user and architect. Modularity and circularity is nowadays an item that should certainly be taken into account. This can also influence the process (contractor).

The consequences of applying the method for the role of the client in the design of the assembly were questioned. Municipal aesthetic committees can influence the aesthetics of joinings between systems and this can lead to disruption. It may be worth seeing these committees as stakeholders. It was felt that the assumed desirability of standardisation had not been demonstrated. It was observed that the approach is based on the application of construction system templates and, once the parties involved have been chosen, all responsibilities have effectively been assigned. This comment does not lead to a modification of the method. The importance of giving customers choice was endorsed, and again this has no effect on the proposed method. It was commented that circularity could be incorporated in the method as a design aspect by including the relevant items in the construction template. This would make it possible to implement circularity at the system level. In addition to these comments, the participants drew attention to the need for context-related examples.

\subsubsection{From building to assembling in non-residential construction}

\section{The participants in the workshop}

Seven experts from the non-residential construction sector took part in this workshop. Table 8.4 shows the background of the experts and the number of organizations concerned.

\section{The results of the workshop on building to assembly in non-residential construction}

Table 8.5 shows that there were no reservations concerning the use of the assembly method in the non-residential construction sector and that the method is expected to make a positive contribution to the sector. 
Table 8.4: Backgrounds and numbers of the experts of the workshop on non-residential construction.

\begin{tabular}{|lc|}
\hline organisations & number of participants \\
design office for architecture & 2 \\
branch organisation of the concrete industry & 1 \\
branch organisation of the façade industry & 2 \\
education and research & 2 \\
\hline
\end{tabular}

Table 8.5: Evaluation scores for the two statements during the workshop on non-residential construction.

\begin{tabular}{|l||l||l|}
\hline evaluation criteria & $\begin{array}{l}\text { Scores on the statement: } \\
\text { The assembly of utility } \\
\text { buildings can be } \\
\text { designed }\end{array}$ & $\begin{array}{l}\text { scores on the statement: } \\
\text { The design method can } \\
\text { be applied to the design } \\
\text { of the assembly of utility } \\
\text { buildings }\end{array}$ \\
\hline totally disagree & 0 & 0 \\
\hline mostly disagree & 0 & 0 \\
\hline neither agree nor disagree & 2 & 3 \\
\hline mostly agree & 3 & 2 \\
\hline totally agree & 0 & 0 \\
\hline
\end{tabular}

Suggestions for the improvement or clarification of the design method made were:

- More steering of the indicated processes would lead to better performance and quality. Other aspects that also influence performance are procedures, people and culture. These aspects are currently not considered (branch organisation of the façade industry).

A more detailed description of how the various parties in the chain can introduce this approach in practice. Practical guidelines on how we can apply it will help in the stepby-step introduction (designer).

This first comment is relevant but does not relate to the method. The second comment concerns advice on implementation. Neither requires changes in the method. In addition to these comments, the participants drew attention to the need for context-related examples.

\subsubsection{From building to assembling for infrastructural projects}

\section{The participants in the workshop}

Thirteen experts from the field of infrastructural projects took part in this workshop. Table 8.6 shows the background of the experts and the number of organizations concerned. 
Table 8.6: Backgrounds and numbers of the experts of the workshop on infrastructure projects.

\begin{tabular}{|lc|}
\hline organisations & number of participants \\
\hline contractor for infrastructure & 2 \\
design office for architecture & 1 \\
producers of prefab concrete & 3 \\
clients & 2 \\
supplier of fiber-reinforced polymer bridge & 1 \\
engineering offices & 2 \\
education and research & 2 \\
\hline
\end{tabular}

The results of the workshop from building to assembling in infrastructural projects

Table 8.7 shows that a majority of the participants in this workshop had positive expectations regarding the applicability of the construction assembly design method for infrastructural projects.

Table 8.7 also shows that there were also some reservations with regard to the use of the assembly method for infrastructural projects. However, these reservations could not be linked to the suggestions made during the workshop.

Table 8.7: Evaluation scores for the two statements during the workshop on infrastructural projects.

\begin{tabular}{|l||c|c|}
\hline evaluation criteria & $\begin{array}{l}\text { scores on the statement: } \\
\text { The assembly of objects } \\
\text { in the infrastructure can } \\
\text { be designed }\end{array}$ & $\begin{array}{l}\text { Scores on the statement: } \\
\text { The design method can } \\
\text { be applied to the design } \\
\text { of objects in the } \\
\text { infrastructure }\end{array}$ \\
\hline totally disagree & 0 & 0 \\
\hline mostly disagree & 2 & 1 \\
\hline neither agree nor disagree & 0 & 2 \\
\hline mostly agree & 2 & 4 \\
\hline totally agree & 6 & 3 \\
\hline
\end{tabular}

The construction assembly design method versus the methods derived from it

In Section 3.1, the significance of the context with regard to the realisation of construction assemblies was described. This relates to the conditions under which these assemblies are to be realised and the deformations that occur. It should be emphasised that the design method is not object-specific and, therefore, during the three workshops, the same presentation could be used. For each workshop, the presentation was primarily changed by including specific examples of the product architecture in question. 
During the workshops, it became clear that the construction assembly design method came across as still somewhat abstract to a number of participants. This explains the request for detailed context-specific examples. Giving such examples results in a set of context-based design methods that are derivations of the construction assembly design method [Aken et al., 2016]. These design methods can be structured based on specific product architectures. A certain product architecture may result in an object-specific assembly design method.

\section{Modifications to the construction assembly design method}

During the workshops, comments were made which could potentially lead to modifications to the design-for-assembly method. These concern the possible influence of municipal building aesthetics committees with regard to the granting of permits for residential construction and improving the alignment of the design method with the as-built situation with infrastructural projects. These comments were made during different workshops and they do not concern the conditions under which the assemblies in the built environment are realised, as described in Section 3.1, or the deformations that occur during assembly. The two remarks can therefore be seen as context-specific and, as a result, they do not require a modification to the design-for-assembly method.

\subsubsection{The overall results of the validation exercise for the design-for- assembly method}

The overall scores of the evaluations with regard to the applicability of the construction assembly design method are shown in Table 8.8.

Table 8.8: The overall evaluation scores from the three workshops on the applicability of the construction assembly design method in practice.

\begin{tabular}{|l||c|c|}
\hline \multirow{2}{*}{ evaluation criteria } & $\begin{array}{l}\text { scores on the statement: } \\
\text { The design method can be applied to the design } \\
\text { of objects in the built environment }\end{array}$ \\
\cline { 2 - 3 } & in numbers $(\mathrm{n}=23)$ & in percentage \\
\hline totally disagree & 1 & $4 \%$ \\
\hline mostly disagree & 1 & $4 \%$ \\
\hline neither agree nor disagree & 3 & $47 \%$ \\
\hline mostly agree & 11 & $30 \%$ \\
\hline totally agree & 7 & \\
\hline
\end{tabular}

Based on the validation workshops that were conducted on the construction assembly design method, it is clear that a large majority of experts believe that the construction assembly design method can be applied in a meaningful manner in the construction process for residential, non-residential and infrastructure building projects. 


\subsection{Conclusion regarding the final version of the design-for-assembly method}

The question that was to be answered in this chapter is:

What adjustments are needed to the first version of the design-for-assembly method for construction and infrastructure projects to accommodate the findings from the series of case studies?

This question has been answered through the description of the final version of the Design-for-Assembly method.

Based on the findings of the series of case studies, the first draft of the design-for-assembly method as described in Chapter 4 has been modified. The result is the final version of this design-for-asssembly method that meets the specification described in Section 8.1. This final version was subsequently validated by organising three expert workshops. It has been found that a large majority of the experts (about 80\%) are convinced that the developed design-for-assembly method will have added value to be applied in construction and infrastructure projects. 



\section{Discussion of findings}

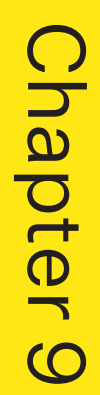

Contents

9.1 Introduction

9.2 Scientific contributions

9.3 Managerial implications

9.4 Recommendations for further research 


\subsection{Introduction}

Our built environment is no longer primarily realised through processing materials at construction sites, but mostly by putting together, on site, elements produced elsewhere. When designing an object whose realisation is to be based on the use of construction parts that are produced off site, it is important to also consider the design for the assembly of the construction parts at the building location. The design of this assembly and its connections with other construction parts that are to be similarly included have a major impact on the efficiency on the realisation process.

As explained in Chapter 1, insufficient attention is still paid in the design phase to the realisation of the designed objects. This gap between construction designs and their realisation inhibits the full potential of using assembly processes. This inattention manifests itself through issues such as dimensional deviations between the original design and the assembled system, disappointing aesthetic results and construction times that are far longer than necessary. As a consequence, the potential increase in efficiency is not fully realised. This failure to fully achieve the potential increased efficiency also means that the use of construction parts produced off site continues to have to compete with onsite production in the construction sector.

These considerations have led to the general conclusion that the design and realisation phases of construction processes are insufficiently aligned. The main goal of this study has therefore been to contribute to closing the gap between the design and realisation phases of objects in the built environment that are realised through an assembly process. This has been achieved by developing a design-for-assembly method for construction and infrastructure projects. To realise this development, this dissertation provides an answer to the following main research question:

How can construction and infrastructure objects be assembled using an evidence-based design-for-assembly method?

To answer this main research question, five sub-research questions have been addressed in this dissertation:

1 What can be learnt from the design of mechanical assemblies and which design rules, design methods and techniques can be derived that are also applicable in the construction and infrastructure sector?

An in-depth literature review into the design of mechanical assemblies revealed that designers of all types of assemblies are confronted with geometric variations as a result of production and assembly processes. Anticipating the likely geometric variations due to 
assembly processes and to production processes can be considered as the two fundamental requirements when designing assemblies. In order to reliably predict expected geometric variations, it is desirable to assess the possible geometric variations related to manufacturing and then assembly, and to interpret the influence of these geometric variations in the assembled state.

Mechanical parts are normally assembled at a specific location in a controlled environment that can be specifically designed for the assembly of a certain artefact of which, in general, more than one will be realised. In contrast, the assembly of an object in the built environment is generally realised outdoors, and a particular assembly is likely only to be realised once at that specific location. These fundamental differences influence the design methodology that is appropriate for the assembly. In other words, a specific design-for-assembly method for the construction sector is required. Nevertheless, the method used in designing a mechanical assembly can serve as a source of inspiration for the development of such a design method.

2 To what extent are the current design process and design techniques, as applied in the construction and infrastructure sector, geared towards designing assemblies?

A study of the widely applied Dutch NEN 2574 standard for construction design processes revealed that, with respect to assembly and manufacturing, there is a lack of explicit attention given to geometric variations. As a consequence, design activities are not initiated that would accommodate relevant geometric variations. This conclusion confirms and reinforces an earlier made recommendation by the Advisory Council for Technology Policy in the Construction Sector. In their advisory report [ARTB, 1998], the Advisory Council wrote that the increased level of prefabrication in the construction sector requires a feasibility assessment, in an early state of the design process, of the realisation of a building design.

Related to design techniques that are currently applied in the construction and infrastructure sector, namely Systems Engineering, Design for Buildability and Design for Manufacturing and Assembly, the conclusion is drawn that these design techniques are insufficiently geared to the design of assemblies in the sector. However, Building Information Modelling (BIM), as a design technique, was identified as a potential aid in creating an assembly design process.

3 What adaptations are necessary to the commonly used method for the design of objects in the built environment to make it suitable for objects that are constructed through an assembly process?

In this research, the Dutch NEN 2574 standard for construction design processes has been 
adapted to create a first draft of a design-for-assembly method. Important design aspects of this design-for assembly method are: the functional specification of the object to be realised; the specification of the geometric quality of the object; the expected geometric variations of the realised assembly; and the alignment of the specifications and the expected geometric variations. The first version of the design-for-assembly method consists of eight steps, which are detailed in Sections $4.3-4.10$ of this dissertation.

4 To what extent can the assembly process of dwelling transformations, utility buildings or infrastructure projects be improved by applying the proposed design-for-assembly method, and how can the proposed designfor-assembly method be further improved?

To answer this research sub-question, several in-depth case studies were conducted in three domains of the construction and infrastructure sector: four renovation projects in the residential sector; one office building project in the utility sector; and one bridge project in the civil engineering sector. The case studies clearly showed the added value of applying the proposed design-for-assembly method.

In the case study of the four renovation projects, the use of the design-for-assembly method led to the systematisation of artisanal construction activities, allowing them to be realised as assemblies. The case study of the four renovation projects also showed that the design-for-assembly method can help in identifying gaps between the parties involved in the design phase and in the execution of the assembly. A consistent application of the design-for-assembly method could therefore avoid gaps between the parties involved. The case study also showed that the application of the design-for-assembly method can facilitate the development of an assembly process for the system-to-system connections of add-on façades.

In the case study of the utility building project, the design-for-assembly method helped to achieve a structured transformation from the demand specification to the executed assembly. The use of the proposed design-for-assembly method made flow-downs generally available for the assembly processes. This prevented the need for onsite improvisation, thereby increasing the safety of employees. Applying the proposed design-for-assembly method helps to optimise the assembly order. The assembly of the entire object can be broken down into assembling various systems. The assembly order can then be optimised while interfaces ensure successful interactions between the systems. The specification of the interfaces is based on the geometric variations that result from variations in the production and assembly of the systems that have to be accommodated.

The case study of the infrastructure project demonstrated the efficient realisation of a bridge through the use of the product family concept. As in the other two case studies, the 
use of the design-for-assembly method results in efficiency improvements and increased employee safety.

The case studies were also used to evaluate the first draft of the design-for-assembly method in terms of further possible improvements. In each case study, the eight successive design steps were evaluated for possible improvements to the proposed design-for-assembly method. In Chapter 8, a complete overview of the recommended improvements to the first draft of the design-for-assembly method is provided in Table 8.1.

\section{What adjustments are needed to the first version of the design-for- assembly method for construction and infrastructure projects to accommodate the findings from the series of case studies?}

Based on the results of the case studies, the identified options to improve the first version of the proposed design-for-assembly method are explained in detail in Section 8.2. The identified options to improve the first version of the proposed design-for-assembly method have led to the development of a final version of the design-for-assembly method, consisting of eight phases:

1. Design of the typology.

2. Determining framework conditions.

3. Selection of the product architecture.

4. Design of the system-of-systems assembly.

5. Nominal design of the assembly.

6. Assessment of the feasibility of the assembly.

7. Preparation and execution of the assembly.

8. Completion of the assembly.

A detailed description of each of the distinguished phases is presented in Section 8.5 of Chapter 8 .

\subsection{Scientific contributions}

This $\mathrm{PhD}$ thesis, of which the main research findings are outlined above, makes several scientific contributions related to the field of construction and infrastructure management.

First, an in-depth literature review into the design of mechanical assemblies revealed that designers of all types of assemblies are confronted with geometric variations as a result of assembly and production processes. The existence of these geometric variations can be 
considered as the most fundamental field problem to be solved in the design and realisation of assemblies.

Second, a detailed analysis of the reviewed literature also revealed that this identified field problem can be represented by four design issues that need to be solved: the functional specification of the product to be realised; the specification of the geometric quality of the product; the expected geometric variations in the assembled condition; and the alignment of the specified geometric quality and the expected geometric variations.

Third, a study of the widely applied Dutch NEN 2574 standard for construction design processes revealed that, with respect to assembly and manufacturing, no explicit attention is given to geometric variations. This means that the most fundamental field problem to be solved in the design and realisation of assemblies is not addressed in this widely applied Dutch standard.

Fourth, a systematic literature review of existing design techniques in the field of construction and infrastructure revealed that none of them address the identified design issues related to geometric variations.

Fifth, and the most important scientific contribution of this $\mathrm{PhD}$ research, is the development, application and validation of a design-for-assembly method that can be applied in the process of designing and executing construction and infrastructure projects. This method takes into account the occurrence of geometric variations as a result of assembly and realisation processes in construction and infrastructure projects and identifies appropriate solutions for the four design issues. This design-for-assembly method can be considered as an essential complement to the existing literature on construction and infrastructure management. Finally, the developed design-for-assembly method can also be seen as an important contribution to the domain of modularity theory [Schilling, 2000; Voordijk et al., 2006; Veenstra et al., 2006; Hofman et al., 2009] since it facilitates the efficient assembly of off-site produced modular parts.

\subsection{Managerial implications}

The outcomes of this study also have three important managerial implications. Applying the developed design-for-assembly method could contribute to a more efficient assembly and production process, improved worker safety and a decrease in avoidable construction waste.

\section{A more efficient assembly and production process}

By applying the design-for-assembly method, on-site activities can be more often limited to 
assembling. This will reduce the labour-intensive on-site processing of building materials. In addition, application of the design-for-assembly method will stimulate the application of a product architecture that is based on the assembly of off-site produced modular construction parts. These two developments will lead to a more efficient production process and thereby increase labour productivity in the construction and infrastructure sector.

\section{Improved worker safety}

Recent research by the Royal Institute of British Architects [RIBA, 2013] has shown that off-site production, which the developed design-for-assembly method will promote, contributes to enhanced labour safety conditions. In addition, the availability of construction system templates, as advocated in the developed design-for-assembly method, will reduce the need for improvisation in realising assemblies and the consequent risk of accidents on the construction site.

\section{A reduction in avoidable construction waste}

A report from the Waste \& Resources Action Programme [WRAP, 2007] shows that a ninety percent reduction in waste could be achieved by increasing the use of off-site construction, which the method advocated in this $\mathrm{PhD}$ thesis would encourage. The controlled environment of off-site production not only protects against weather conditions, but also site theft. With off-site construction, excess materials from one project can be repurposed and used in other projects coming through the manufacturing plant, rather than being discarded at the end of an individual project, as is often the case on a conventional site.

\subsection{Recommendations for further research}

The development of the design-for-assembly method as described in this $\mathrm{PhD}$ thesis has raised various questions that would benefit from further research. Five topics that merit further study are summarised below.

In the course of this $\mathrm{PhD}$ research, several case studies have been conducted to evaluate the added value of the developed design-for-assembly method. So far, these evaluations have focused on renovation projects in the residential sector, on the design and realisation of an office building project and on a pedestrian bridge project in the civil engineering sector. These evaluations have contributed to improvements to the first version of the design-for-assembly method. Further improvements and extensions can be expected from additional case studies in the field of new-build residential dwellings, other types of utility buildings and other types of infrastructure projects such as viaducts and road bridges.

Further, no financial evaluations have been conducted to estimate the potential financial benefits of a complete shift towards off-site production of building parts and in particular of 
applying the developed design-for-assembly method in such projects. Financial evaluations could increase insight into opportunities for financial savings while still maintaining the desired quality.

In Chapter 2, the relevance of being able to manage the dimensional stability of an intended assembly was described. As part of this, it is necessary to determine, during the design, the position of the parts and to know which dimensional deviations should be taken into account and where they will manifest themselves. For these purposes, a geometric dimensioning and tolerancing (GD\&T) framework has been developed for use in mechanical engineering assemblies. As a follow up to this research, a study into the development of a geometric dimensioning and tolerancing framework that is suitable for construction in the civil engineering and infrastructure sector is proposed.

The scientific literature shows that the relevance of design for assembly and manufacturing in relation to design for buildability is also recognised beyond the Netherlands [e.g., StaubFrench et al., 20018; Yuan et al., 2018]. All the case studies reported here have been conducted in the Netherlands and conducting evaluation studies outside the Netherlands is recommended to investigate whether there are specific conditions that warrant extra attention or refinement for a successful and wider application of the developed design-for-assembly method. This would clarify and improve the generalizability of the proposed method.

In addition to conducting additional research to further improve and refine the developed design-for-assembly method, it is also recommended to initiate activities that will encourage the construction and infrastructure sector to adopt the developed design-for-assembly method. Here, organising seminars and compiling a practical manual for the application of the developed design-for-assembly method could help disseminate the knowledge and skills required to the use the method to improve the design of assemblies in the construction sector. 
References

Appendix

Acknowledgements

About the author 



\section{REFERENCES}

Adams, S. (1989) Practical buildability. Butterworths, London, Umited Kingdom.

Aken, J.E. van (2004) The Field-tested and grounded Technological rule as Product of Mode 2 Management Research, Working Paper 04.10, Department of Technology Management, Technische Universiteit Eindhoven, The Netherlands.

Aken, J.E. van (2005) Management Research as a Design Science: Articulating the Research Products of Mode 2 Knowledge Production in Management, British Journal of Management, Vol. 16, pp. 19-36.

Aken, J.E. van, Chandrasekaran, A., Halman, J. (2016) Conducting and publishing design science research - Inaugural essay of the design science department of the Journal of Operations Management, Journal of Operations Management 47-48, pp. 1-8.

AlGeddawy, T., Samy, S.N., \& ElMaraghy,H. (2017) Best design granularity to balance assembly complexity and product modularity, Journal of engineering design, Vol. 28, NOS. 7-9, pp. 457-479.

Alsem, D., Kamerman, J., van Leeuwen, C., van Ruijven, L., den Toom, T., \& Vos, M. (2013). Leidraad voor Systems Engineering binnen GWW-sector Utrecht, The Netherlands: Rijkswaterstaat. ARTB (1998) Bouwvisie 2015, Den Haag, The Netherlands.

Arts, J.P. \& Hoof, P. van (2011) Leren van deformaties, Cement no. 4, Den Bosch, The Netherlands.
Baldwin, C.Y., Clark, K.B. (2000) Design rules: The power of Modularity, Cambridge Massachusetts, United States. Ballard, G. (2000) The Last Planner System of Production Control. Doctoral thesis. School of Civil Engineering, Faculty of Engineering, The University of Birmingham, United Kingdom. Baxter, D., Gao, J., Case, K., Harding, J., Young, B., Sean, C. \& Dani, A. (2007) An Engineering Design Knowledge Reuse Methology Using Process Modelling, Research in Engineering Design, Volume 18, Number 1, pp. 37-48. BCA (2004) Code of Practice on Buildable Design. Building and Construction Authority, Singapore.

BCA (2016) BIM for DfMA (Design for Manufacturing and Assembly) essential guide. Singapore.

Boeijen, A.G.C. van, Daalhuizen, J.J., Zijlstra, J.J.M., Schoor, R.S.A. van der (2013) Delft Design Guide, Amsterdam, The Netherlands.

Boonen, T. (2018) Lead-time reduction through modularization and systems engineering in Dutch military basecamp design, Master thesis University of Twente, Department of Construction Management and Engineering, Enschede, The Netherlands 77 pp. Boothroyd, G. \& Dewhurst, P. (1983) Design for assembly handbook, Department of Mechanical Engineering University of Massachusetts, United States. Boothroyd, G., Dewhurst, P. \& Knight, W. (2010) Product Design and Manufacture for Assembly, Massachusetts, United States. 
Botter, C.H., (1993) Produktiemanagement, Kluwer Bedrijfswetenschappen Deventer, Nederland.

Brand, S. (1994) How Buildings Learn: What happens after they're built, New York, United States.

Breedveld, A. (2011) Producttekenen en documenteren, Boom uitgevers Amsterdam, Nederland.

Brugh, M. van de (2014) Een nieuwe jas voor het rijstjeshuis, NRC 27 \& 28 december, Amsterdam, The Netherlands, pp. W6 - W7.

Bunge, M. (1967) Scientic Research II: the Search for Truth, Berlin.

Chao-Duivis, M.A.B., Koning Z.Z.R. (2004) Aan het werk met bouwcontracten, Alphen aan den Rijn, The Netherlands.

Cools, B. \& Hoeckman W. (2017) Schip over het land, Bouwen met Staal no. 258, Zoetermeer, The Netherlands. Crone, J. (2007) Leren door demonstreren, Rotterdam, The Netherlands.

Demoly, F., Gomes, S., Eynard, B., Rivest, L. \& Sagot, J. C.(2009) Assembly-oriented product structure based on preliminary assembly process engineering, International conference on engineering design, ICED’09, Stanford, United States.

Eastman, C.M., Teicholz, P., Sacks, R. \& Liston, K. (2011) BIM Handbook: a guide to Building, Information Modelling, Hoboken: John Wiley \& Sons. Eekhout, M. (2015) Componentontwerpen en productontwikkelen, Amsterdam, The Netherlands.
Eppinger, D.S. \& Browning, T.R. (2012)

Design Structure Matrix Methods and Applications, The MIT Press Cambridge, Massachusetts, United States.

Fine, C.H. (1998) Clockspeed - Winning Industry Control in the Age of Temporary Advantage, Cambridge, United States.

Fine, C.H. (2000) Clockspeed-based strategiees for supply chain design, Production and Operations Management, Vol. 9 No. 3, pp. 213 - 221.

Ferguson, I. (1989). Buildability in Practice. Mitchell Publishing Company Limited, London, United Kingdom. Francis, V.E. and Sidwell, A.C. (1996) The development of constructability principles for the Australian construction industry. Research report, Construction Industry Institute, Adelaide, Australia.

Gao, S., Ruoyu Jin, R. \& Lu, W. (2019) Design for manufacture and assembly in construction: a review, Building Research \& Information, DOI:10.1080/0 9613218.2019.1660608.

Gelderman, C.J. \& Hart H.W.C. van der (2007) Business marketing, Groningen, The Netherlands.

Gemeente Rotterdam (2010) Strategisch document - Vervanging deelgemeentelijke langzaam-verkeersbruggen, projectcode LH9X010, Rotterdam, The Netherlands.

Gerritse, C. (1986) Integratie in de gevelzone, Delftse Universitaire Pers, Delft, The Netherlands.

Gibb, G.F. (2001) Standardization and pre-assembly - distinguishing myth 
from reality using case study research, Construction Management and Economics 19, pp. 307-315.

Graaf, R. de (2014) Basisboek systems engineering in de bouw, Nederland.

Gray, C. (1984) Buildability: the construction contribution, Ascot, United Kingdom.

Habraken, N.J. (1972; 1999) Supports: An Alternative to Mass Housing, Urban International Press, United Kingdom. Habraken, N.J. (2003) Open Building as a condition for industrial construction, Proceedings of the 20th ISARC conference, pp. 37-42, Eindhoven, the Netherlands. DOI: https://doi.org/10.22260/ ISARC2003/0004

Henket, H. (2013) Waar nieuw en oud raken, The Netherlands.

Heusinkveld, S., Reijers, H.A. (2009)

Reflections on a Reflective Cycle: Building Legitimacy in design Knowledge Development, Organisation Studies 30. Hofman, E., Halman, J.I.M. \& Ion, R. A. (2006) Variation in housing design: identifying customer preferences, Housing Studies, 21, pp. 929-944.

Hofman, E., Voordijk, H. \& Halman, J. (2009) Matching supply networks to a modular product architecture in the house-building industry, Building Research \& Information, 37(1), pp. 31 $-42$.

Hoof, P.A.J. van (2003) Maatregelen - Naar een betere maatbeheersing via moderne aanpak van maatvoering en maatcontrole, Rotterdam, The Netherlands.

Hurx, M. (2010) De particuliere bouwmarkt in de Nederlanden en de opkomst van de architect (1350 - 1530), $\mathrm{PhD}$ Thesis University of Delft, The Netherlands.

INCOSE (2020) Systems Engineering Handbook version 4.0.

Janse, H. (2012) Houten kappen in Nederland 1000-1940, Delft, The Netherlands.

Jørgensen, B., Emmitt, S. (2009) Investigating the integration of design and construction from a "lean" perspective, Construction Innovtion 9(2): pp. 225240.

Kals, H.J.J., Buiting-Csikós, Cs., Lutterveld, C.A. van, Moulijn, K.A., Ponsen, J.M. \& Streppel, A.H. (2009) Industriële productie - Het voorbrengen van mechanische producten, Sdu Uitgevers bv Den Haag, The Netherlands. Koolhaas, R. (2014) Elements of architecture 1 - 15, International Architecture Exhibition, la Biennale di Venezia, Italy. Kossiakoff, A., Sweet, N.W., Seymour, J.S. \& Biemer, M. (2011) Systems Engineering Principles and Practice, New Jersey, Verenigde Staten van America.

Lemmens, B. (2012) Maatbeheersing super hoogbouw, Cement no. 5, Den Bosch, Nederland.

Maas, G.J., Vissers, M.M.J., Poortman, E.R., Gassel, F.J.M. van, Hoof, P.A.J. van, Schaefer, W.F.M. \& Vastert, E.W. (1996) Uitvoeringstechniek 2, Eindhoven, The Netherlands. Malmgren, L., Jensen, P., Olofsson, T. (2010) Product Modelling of configur- 
able building systems - A case study, Electronic Journal of Information Technology in Construction 15: 354-368/.

Martinez, S., Jardo, A., Navarro, J.M. \& Gonzales, P. (2008) Building industrialization: robotized assembly of modular products, Assembly Automation, 28/2, pp.134 - 142.

- McKinsey Global Institute (2017) Reinventing Construction: A route to higher productivity.

Miyakawa, S., Ohashi, T. (1986) The

Hitachi Assemblability Evaluation

Method, Proceedings of the 1st International Conference on Product Design for Assembly, Newport, United States.

NEN 2574 (1993) Tekeningen in de bouw - Indeling van gegevens op tekeningen voor gebouwen, Nederlands normalisatie-Instituut, Delft, The Netherlands.

Net, A.J. van der (1998) Designing and Manufacturing Assemblies, PhD Thesis Technische Universiteit of Eindhoven, The Netherlands.

- Niimi, A., Matsudaira, Y. (1997) Development of a New Assembly Line at Toyota: Worker-Oriented, Autonomous, New Assembly System. In: Shimokawa K., Jürgens U., Fujimoto T. (eds) Transforming Automobile Assembly. Springer, Berlin, Heidelberg

- NCR (2009) report 'Advancing the Competitiveness and Efficiency of the U.S. Construction Industry', United States.

Olie, J. C. M. (1996) A Typology of Joints: Supporting sustainable development in building, $\mathrm{PhD}$ Thesis University of Eindhoven, The Netherlands.

Onderzoeksraad voor Veiligheid (2012) Het instorten van het dak van het FC Twentestadion, Den Haag, The Netherlands.

Onderzoeksraad Voor Veiligheid (2016) Hijsongeval Alphen aan den Rijn, Den Haag, The Netherlands.

Oostra, M., (2017) Democratising Large-Scale Retrofitting of Housing, UIA Seoul World Architects Congress, O-0859, pp. 1 - 9.

Petersen, K.J., Handfield, R. B. \& Ragatz, G. L. (2005) Supplier integration into new product development: coordinating product, process and supply chain design, Journal of Operations Management, Vol. 23 No. 3 - 4, pp. 371 - 388. Pheng, L. and Abeyegoonasekera, B. (2001) Integrating buildability in ISO 9000 quality management systems: case study of a condominium project. Building and Environment, V. 36, No. 3, pp 299-312.

Randen, Van A. (1990) Separation of support and infill: a chance for a quantum leap in productivity, Proceedings of the Open Industrialisation: A solution for Building Modernisation, Stuttgart, February 21-23, 1990.

Redford, A.H. (1994) Design for Assembly, New York, United States.

Research Rationalisatie Bouw (2007) Kwaliteit van tekenwerk in de bouw RRW 130, Zoetermeer, The Netherlands. RIBA (2013) Plan of work 2013 designing for manufacture and assembly, Royal Institute of British Architects, London, United Kingdom. 
Rijksvastgoedbedrijf (2014) Ambitiedocument gerechtsgebouw Amsterdam, The Netherlands.

Rijkswaterstaat, 2012. Aanbestedingsreglement, The Netherlands.

Salcedo Rahola, T.B. (2015) Integrated project delivery methods for energy renovation of social housing, $\mathrm{PhD}$ Thesis University of Delft, Rotterdam, The Netherlands.

Sanchez, R., \& Mahoney, J. T. (2012)

Modularity and Economic Organization: Concepts, Theory, Observations, and Predictions, University of Illinois, College of Business Working Papers, Nr. 12-0101 http://www.business.illinois.edu/Working_Papers/papers/12-0101.pdf.

Schilling, A.S. (2000) Toward a general modular systems theory and its application to interfirm product modularity, Academy of Management Review 2000, Vol. 25, No. 2, pp.312-334.

Simonsson, P. (2011) Buildability of concrete Structures: Processes, Methods and Material, $\mathrm{PhD}$ Thesis Luleå University of Technology, Luleå, Sweden. Spekking, D. (2010) Vooronderzoek systems engineering in de B\&U-sector, Delft, The Netherlands.

Staub-French, S., Poirier, E.A., Calderon, F., Chikhi, I., Zadeh, P., Chudasma, D., Huang S. (2018) Building Information Modelling (BIM) and Design for Manufacturing and Assembly (DfMA) for Mass Timber Construction, University of British Colombia, Canada. Stout, A. (2016) Application of the principles of mass customization: standaardisation and modularization, for an infrastructural object: a viaduct,
Master Thesis University of Twente, The Netherlands.

Stroomversnelling www.stroomversnelling.nl (visited on March 25th, 2019) Stuart, I., McCutcheon, D., Handfield, R., McLachlin, R. \& Samson, D. (2002) Effective case research in operations management: a process perspective, Journal of Operations Management, Vol 20 No. 5, pp. 419-33.

Sudarsan, R., Han, Y.H., Foufou, S., Feng, S.C., Roy, U., Wang, F., Sriram R.D. \& Lyons, K.W. (2006) A Model for Capturing Product Assembly Information, Journal of computing and Information Science in Engineering, Vol. 6, pp. $11-21$.

Sundin, E. \& Björkman, M. (2016)

Development of a Design for Manufacturing and Assembly (DFM/A) methodology concerning products and components made in composites of Carbon Fiber Reinforced Plastics (CFRP) used in the Aerospace Industry, Conference Paper Swedish Production Symposium (SPS) 2017.

Thornton, Anna C. (2004) Variation Risk Management: focusing quality improvements in product development and production, New Jersey, United States. Tol, P. \& Balvers, A. van den (2012) Cost-Effective Sustainability in Existing Housing in the Netherlands, Agentschap NL, Utrecht, The Netherlands.

Ulrich, K.T. (1992) The Role of Product Architecture in the Manufacturing Firm, Massachusetts Institute of Technologie, Massachusetts, United States.

Ulrich, K.T. \& Eppinger, S.D. (2008) 
Product Design and Development, New York, United States.

Vastert, E.W. (1995) Maatbeheersing: het afspreken van visueel toelaatbare maatafwijkingen, Eindhoven, The Netherlands.

Veenstra, V.S., Halman, J.I.M. \& Voordijk, J.T. (2006) A methodology for developing product platforms in the specific setting of the househuilding industry, Res Eng Design, 17, pp. 157173.

Verschuren, P. \& Doorewaard H. (2015) Het ontwerpen van een onderzoek, Amsterdam, The Netherlands. Voordijk, H., Meijboom, B. \& Haan J. De (2006) Modularity in supply chains: a multiple case study in the construction industry, International Journal of Operations \& Production Management, Vol. 26 No. 6, pp. 600-618.

Vrijhoef, R. (2011) Supply chain interaction in the building industrie, $\mathrm{PhD}$

Thesis University of Delft, Amsterdam, The Netherlands.

Wang, K. (2007) Applying data mining to manufacturing: the nature and implications, J Intell Manuf, 18, pp. 487 $-494$.

Werkgroep Leidraad Systems Engineering (2013) Leidraad voor Systems Engineering binnen de GWW-sector, Rotterdam, The Netherlands.

Whitney, D.E. (2004) Mechanical assemblies, Oxfort University Press, New York.

Whitney, D.E., Mantripragada, R., Adams, J. D. \& Rhee, S.J. (1999) Designing Assemblies, Research in Engineering Design, Volume 11, Issue 4, pp. 229 - 253.
Willemse, M.A. (1997) Interactive product design tools for automated assembly, PhD Thesis University of Delft, The Netherlands.

Womack, D. \& Jones, T. (2007) The machine that changed the world, United States.

Wong, F.W.H., Lam, P.T.I., Chan, E.H.W. and Wong, F.K.W. (2006)

Factors affecting buildability of building designs. Canadian Journal of Civil Engineering, V. 33, No. 7, pp 795-806.

WRAP (2007) Current Practices and Future Potential in Modern Methods of Construction, WAS003-001: Summary Final Report, Waste \& Resources Action Programme, United Kingdom.

Xu, 1.D., Wang, C., Bi, Z. \& Yu, J. (2014) Object-Oriented Templates for Automated Assembly Planning of Complex Products, IEEE Transactions on automation science and engineering, vol. 11, no. 2, pp. $492-503$.

Yang, K. (2003) Design for Six Sigma: a roadmap for product development, McGraw Hill, New York, United States. Yuan, Z., Sun. C., Wang, Y. (2018) Design for Manufacture and Assembly-oriented parametric design of prefabricated buildings, Automation in Construction 88, pp. 13-22.

Zha, X.F., Du, H.J. \& Qiu, J.H. (2001) Knowlegde-based approach and system for assembly oriented design, Part I: the approach, Engineering Applications of Artificial Intelligence, Volume 14, Issue 1, pp. $61-75$. 


\title{
APPENDIX
}

Participants in the expert workshops

Workshop: From building to assembling in residential construction

\author{
Participants Organisation \\ Janno van Dijke VolkerWessels \\ Arjan van Driel BAM Wonen bv \\ Margret Drok SACON Architecten \\ Prof. Joop Halman Universiteit Twente - Construction Management \& Engineering \\ Niels Hoeve Inbo \\ Hans Kerkhof BAM Wonen bv \\ Andreas Rindt $\quad$ NXT Architectuur en Bouwkunde \\ Henry Steenbakkers Kingspan Unidek B.V. \\ Jan Straatman Balance \& Result \\ Hans Voordijk Universiteit Twente - Construction Management \& Engineering
}

Workshop: From building to assembling in non-residential construction

$\begin{array}{ll}\text { Participants } & \text { Organisation } \\ \text { Prof. Joop Halman } & \text { Universiteit Twente - Construction Management \& Engineering } \\ \text { Tom Huizer } & \text { ABT | Ingrnieurs in bouwtechniek } \\ \text { Robert Platje } & \text { Mei Architecs and Planners } \\ \text { Cindy Vissering } & \text { Betonhuis } \\ \text { Hans Voordijk } & \text { Universiteit Twente - Construction Management \& Engineering } \\ \text { Henk Zoontjes } & \text { VMRG } \\ \text { Hans Zwaanenburg } & \text { VMRG }\end{array}$




\section{Workshop: From building to assembling for infrastructural projects}

$\begin{array}{ll}\text { Participants } & \text { Organisation } \\ \text { Jeroen Eulderink } & \text { Arcadis Architecs } \\ \text { Prof. Joop Halman } & \text { Universiteit Twente - Construction Management \& Engineering } \\ \text { Bert Hesselink } & \text { Movares } \\ \text { Jörgen Hermsen } & \text { Romein Beton B.V. } \\ \text { Pascal Lakerveld } & \text { FiberCore Europe } \\ \text { Rob Leenders } & \text { BAM Infra } \\ \text { Benny Nieswaag } & \text { Ministry of Transport, Public Works \& Water Management } \\ \text { Kees Quartel } & \text { Spanbeton B.V. } \\ \text { Pieter Schraven } & \text { De Hamer Beton B.V. } \\ \text { Frank van der Vaart } & \text { Stadsingenieurs Gemeente Utrecht } \\ \text { Thijs Verburg } & \text { Verburg Hoogendijk Architecten } \\ \text { Hans Voordijk } & \text { Universiteit Twente - Construction Management \& Engineering } \\ \text { Paul Waarts } & \text { Provincie Noord Holland }\end{array}$




\section{ACKNOWLEDGEMENTS}

In March 2014, I had an initial meeting with Professor Joop Halman and Dr Hans Voordijk. The subject of this meeting was my ambition to conduct research that would result in a $\mathrm{PhD}$ thesis. Ideally, this research would address an innovation-related topic for the built environment. Besides a scientific contribution, my aim from the beginning was for the outcome of my study to also have practical value and be usable by practitioners in the field of construction and infrastructure management. During this meeting, we agreed that my first step would be to identify an important and still unresolved problem in the field of construction and infrastructure management. The topic selected, which has mistakenly received little attention in the literature, concerns design for assembly in construction and infrastructure projects. I therefore decided to take this as the main topic for my $\mathrm{PhD}$ thesis. Here, I would like to sincerely thank my supervisors Professor Joop Halman and Dr Hans Voordijk for their trust in me in making this initial decision and their academic and dedicated guidance which has made this $\mathrm{PhD}$ thesis possible.

Given the limited attention in the construction management literature to designing assemblies, the realization of this research project would only ever have been possible with the cooperation of practice. The many organizations that I approached during my research project were all willing to cooperate. Here, I would like to thank the following for their support: Ballast Nedam, BAM, Bohemen, Bouwborg, Breman, CEPEZED, DuraVermeer, Emergo, Municipality of Rotterdam, OMA, Oostingh Staalbouw, Renovative, Schouten Techniek, Stam + Landman, Steinfort, Stichting Hoogbouw, Ursum, Van Noordenne, VBI, VolkerWessels and Wagemaker. Valuable contributions were made by the professionals who I interviewed during the project's case studies and the experts who participated in the validation workshops. In terms of individuals, my special appreciation goes to Ab Niezen, Alec van der Voort, Alex de Jong, Bart Schuring, Bertus Schalij, Coen Domhof, Dirk van der Plas, Erik van Himst, Ferry Molenaar, Ger van de Zanden, Gjalt Roo, Goos van der Kamp, Hans Bonekamp, Hans Kerkhof, Hendrik Sleurink, Herman Boerma, Hubert-Jan Henket, Janno van Dijke, Johan de Groot, Joost Heijnis, Kambiz Elmi Anaraki, Koen van Tienen, Koos Wessels, Lodewijk Van Kappelle, Marcel van Tichem, Margret Drok, Michiel Cohen, Mozafar Saïd, Niels Blauwiekel, Pieter Huijbregts, Peter Fraanje, Peter van Hoof, Ruud Geerligs, Thijs Hajee, Tom Jongen, Stan Roestenberg and Ton van der Net.

Over the past few years, many of my private conversations have of course also been about my research. The opinions to be countered and the questions to be answered have taught me, among other things, to exchange my thoughts in ordinary language, both when addressing their relevance and the content itself. These exchanges have undoubtedly also contributed to me acquiring a better understanding of the topic. For this I would particularly like to thank my industrial heritage friends, the card club players, my steel table mates and rowers. Moreover, I would like to thank Daan van de Vlist and my daughter Olga for 
assisting me as my paranymphs. And finally, I would like to thank Elisabeth for her good company during my foreign discoveries of assembly activities and for her interest and curiosity about my project.

Rotterdam, 2 april 2021. 


\section{ABOUT THE AUTHOR}

Word blindness, now better known as dyslexia, took me to the Lower Technical School (LTS) in IJsselstein in 1969. My education there lasted three years and it was not a bad start. I learned useful things and it was good for my self-confidence. While there, I decided I would follow the so-called theoretical direction, but in combination with carpentry. There appeared to be more to it. I was then able to go to the Secondary Technical School (MTS) and, two years later, to the Higher Technical School (HTS), both in Utrecht. In 1980, I entered the labour market with a HTS diploma in Road and Hydraulic Engineering and a HTS diploma in Construction Engineering. At that time, the Rotterdam Dry Dock Company (RDM) was looking for an employee with just such diplomas. In those days, RDM was still part of the Rijn-Schelde-Verolme group and the reason for this vacancy was the commission to build two submarines for Taiwan. As an employee, I helped maintain, renew and expand the non-movable equipment at the shipyard. At RDM, there was a lot of work that required specialised knowledge of structures and building physics. To be able to do this work, I successively followed classes at the Higher Technical Institute in Amsterdam to become a concrete constructor, and then at the Technological Institute of the Royal Flemish Engineering Association (TI-K.VIV) in "higher acoustics".

After RDM went bankrupt in 1983, I was briefly employed at Gist Brocades, now part of DSM, in Delft. In early 1984, I was appointed as a constructor and building physicist in the Construction Department of the Civil Engineering Design Group of Hoogovens B.V. (currently Tata Steel) in IJmuiden. At that time, Hoogovens was investing in the design and building of completely new factories for the continuous casting of steel and the galvanizing and coating of thin steel plates. For me, this was fun and challenging work. So challenging, that I also followed the TI-K.VIV training on "Thermal insulation and moisture problems in buildings". At that time there were a number of people who encouraged me to further develop myself at the TU Delft. I subsequently quit my job at Hoogovens and started in September 1986 on a master programme at TU Delft's Faculty of Civil Engineering. After successfully passing the exams, specializing in "Mechanics \& Constructions", and the completion of my graduation project concerning the development of a reinforcement corrosion diagnosis expert system at IBBC-TNO, I became a fully-fledged civil engineer in October 1990.

My first job as a civil engineer was as an employee researching building structures at the Building and Housing Supervision Department of the Municipality of Rotterdam. It was striking that the safety assessments carried out with good intentions by the consultancies of the Municipality involved were rarely appreciated. As far as the people involved in the projects was concerned, it was only about approving the drawings. In mid-1991, I started working at the Project Analysis Bureau, an organization funded by the European steel industry. The aim was to increase the market share of steel structures in multistorey 
buildings. At the time, steel was hardly used, and this gave me the opportunity to work with others to give shape and content to steel education, to position steel as a sustainable building material and to influence market parties in such a way that they would choose steel. I was also encouraged to follow the master programme in Business Marketing at Eindhoven University of Technology, during which I gained many valuable insights.

In part because of the uncertain financing of the Project Analysis Bureau by the steel industry, I started my own company in 1999: Consultancy for Construction Marketing. Since then, I have initiated and executed projects for architectural and consultancy firms, construction sector organizations, knowledge institutions, the Municipality of Rotterdam, Rijkswaterstaat and Arcelor Mittal. The assignments have primarily focused on marketing-related aspects, on design issues related to objects in the built environment and often also on research and development projects. Since mid-2014, I have combined this consultancy work with the research presented in this thesis. 


\section{Stellingen}

\section{BEHOREND TOT HET PROEFSCHRIFT THE DEVELOPMENT OF A DESIGN-FOR- ASSEMBLY METHOD FOR CONSTRUCTION AND INFRASTRUCTURE PROJECTS}

Willem Hendrik Verburg

30 juni 2021

1 De vereiste vaardigheid in het ontwerpen van assemblages kan de bouwen infrastructuur sector leren van andere sectoren.

2 Zonder het toepassen van de ontwikkelde ontwerpmethode voor assemblages kan het tekort aan betaalbare woningen in Nederland niet binnen afzienbare tijd worden opgelost.

3 Het bouwtechnisch ontwerpen is als vakgebied een conditio sine qua non bij het opleiden van system engineers voor de bouw- en infrastructuur sector.

$4 \quad$ Het ontbreken van design rules in de bouw- en infrastructuur sector leidt tot onbeheerste transactiekosten.

5 De toekomst wordt altijd op basis van een bepaalde interpretatie van de geschiedenis ingericht.

6 Opvoeden is ook een zaak van vaders.

$7 \quad$ Stapelaars van opleidingen die promoveren leveren een bijdrage aan de diversiteit van het wetenschappelijk onderzoek.

8 De bij cartografie gekozen weergave van de nulmeridiaan beïnvloedt het wereldbeeld van de waarnemer.

$9 \quad$ Elektrisch aangedreven voertuigen dienen zich aan te passen aan het gedrag van voetgangers en fietsers.

10 Schieten op dieren dient als een laffe daad beschouwd te worden. 